\title{
MOTHERS ON MOTHERS
}

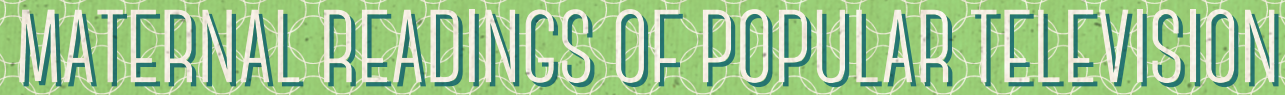

\section{REBECCA FEASEY}

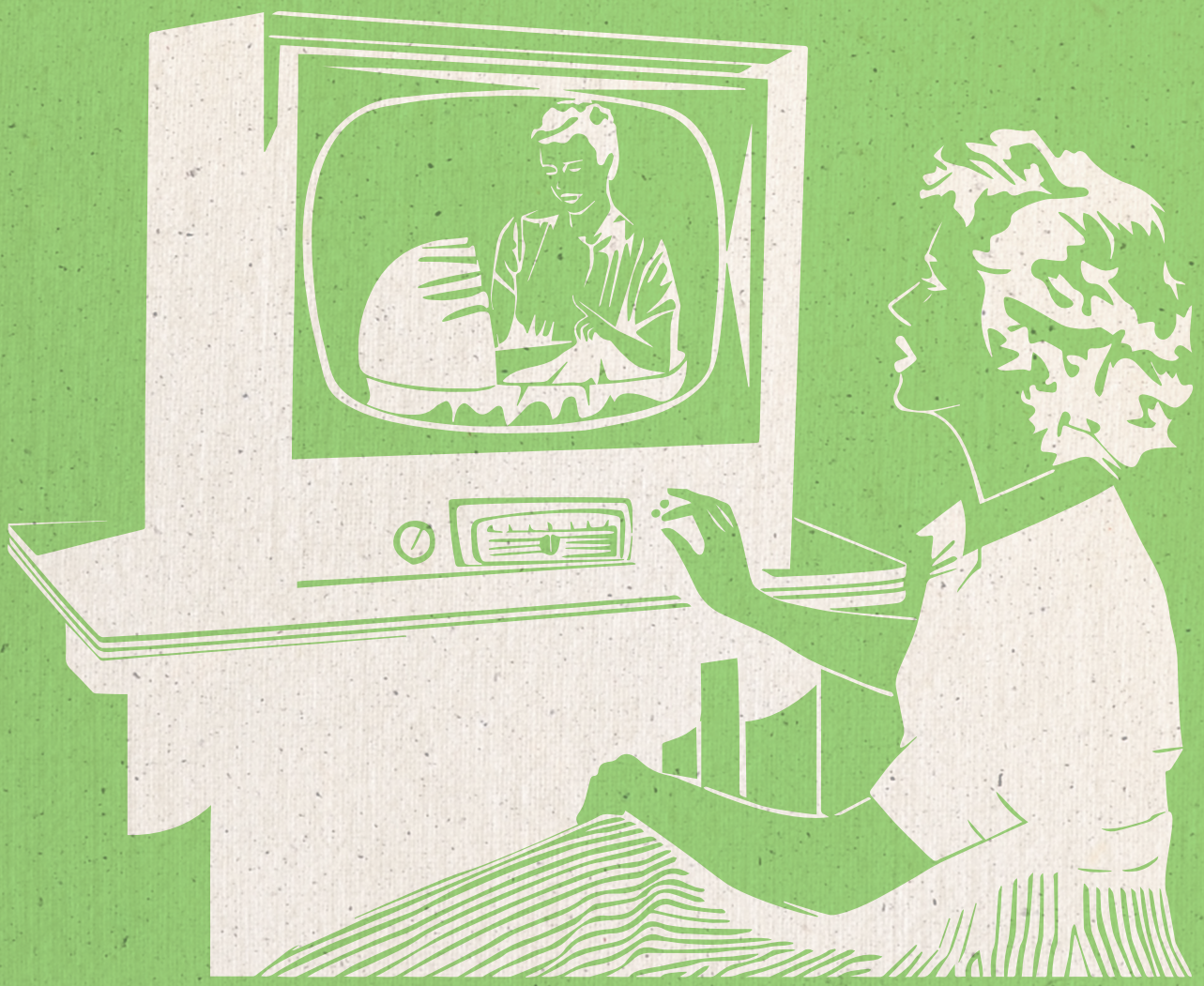


From Supernanny to Gilmure Girls, from Katie Price to Holly Willoughby, a widerange of examples of mothers and motherhood appear on television today. Drawing on questionnaires completed by motheris across the UK, this book sheds new light on the varied and diverse ways in which expectant, new and existing mothers make sense of popilar representations of motherhood on television. The volume examines the ways in which these women find pleasure: empowerment, escapist fantassy, displeasure and frustration in popular depictions of motherhood. The research seeks to present the voice of the maternal audience and. as such, it takes as its starting. point thosée maternal depictions and motherwork representations that are highlighted by this demographic. including fiğures such as Tess Daly and Katie Hopkins and programmes like TeenMom and Kirstie Allsopp's oecuré

Rebecca Feasey is Senior Lecturer in Film and Media Communications at Bath Spa University. She has published a range of work on the representation of gender in popular media culture, including book-length studies on masculinity and popular television and motherhood on the small screen. 
MOTHERS ON MOTHERS 



\section{MOTHERS ON MOTHERS}

\section{MATERNAL READINGS OF POPULAR TELEVISION}

REBECCA FEASEY

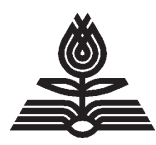

PETER LANG

Oxford • Bern • Berlin • Bruxelles • Frankfurt am Main • New York • Wien 
Bibliographic Information published by the Deutsche Nationalbibliothek The Deutsche Nationalbibliothek lists this publication in the Deutsche Nationalbibliografie; detailed bibliographic data is available in the internet at http://dnb.d-nb.de.

\section{A catalogue record for this book is available from the British Library. Library of Congress Control Number: 2015955236}

An electronic version of this book is freely available, thanks to the support of libraries working with Knowledge Unlatched. $\mathrm{KU}$ is a collaborative initiative designed to make high quality books Open Access for the public good.

More information about the initiative and links to the Open Access version can be found at www.knowledgeunlatched.org

\section{RIJ}

Cover image: @ RetroClipArt - fotolia.com
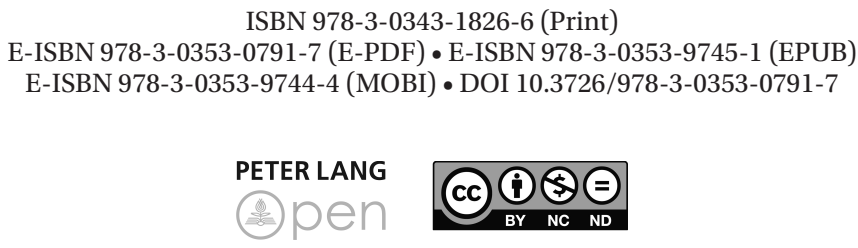

Open Access: This work is licensed under a Creative Commons Attribution NonCommercial NoDerivatives 4.0 unported license. To view a copy of this license, visit https://creativecommons.org/licenses/by-nc-nd/4.0/

This publication has been peer reviewed.

(c) Rebecca Feasey, 2016

Peter Lang AG.

International Academic Publishers

Bern

www.peterlang.com 
For Barnaby 



\section{Contents}

Acknowledgements

Introduction

CHAPTER I

Media methods research: Finding audiences

and giving a voice to mothers

CHAPTER 2

Maternal preferences: From ordinary celebrity

to the sitcom star

CHAPTER 3

Emulation, not identification: Sartorial styles, domestic skills and maternal discipline

CHAPTER 4

Bad mothers and poor role models: Maternal inadequacy

and the problem of perfection

Conclusion: A call for maternal diversity

Bibliography

Index 



\section{Acknowledgements}

I would like to say thank you to all of the mothers who took the time and effort to complete my questionnaire, as I am fully aware that you all had far more pressing demands on your time. Your words have been enlightening and entertaining in equal measure. I hope to have presented your views and opinions as you see them on the representation of motherhood on British and American television; the pleasures and frustrations that you have spoken of are the cornerstone of this research and my hope is that your candid views will go some way to informing future planning and productions. Thank you not only for your answers to my set questions, but also for your broader comments regarding your own mothering practices and family dynamics, and helpful suggestions and recommendations regarding this research endeavour within and beyond the scope of the form. For all of your emotional honesty and candour, once again, I say thank you. I was and continue to be incredibly grateful for your time and efforts, and although it was never my intention, there was the suggestion in a small number of comments that I may have instigated a sense of frustration or disappointment not fully realised until now in relation to those images of motherhood and motherwork that you tend to watch on the small screen. And for that I am both delighted and apologetic. 



\section{Introduction}

The lived reality of motherhood has changed in recent generations, and, likewise, depictions of motherhood in the media have been seen to fluctuate and shift. Although research exists to account for the hypothetical or academic reading of such changing maternal depictions, little research exists to account for the ways in which maternal audiences respond to representations of motherhood in the media.

The social, political, self-help and entertainment marketplace present a rather unified and monolithic image of 'good' mothering, with the ideology of intensive motherhood being singled out as the only acceptable form of motherwork and maternal investment for expectant, new and more experienced mothers in the contemporary period. The ideology of intensive mothering, or what I shall refer to as the 'good' mother, demands that mothers are responsible for the social, cultural, creative, educational, emotional, physical, nutritional and cognitive development of their children. The figure in question is asked to uphold impeccable domestic standards while maintaining a slim appearance and serene demeanour. These stay at home caregivers should, according to the demands of intensive mothering, not only dedicate their entire waking hours to their children, but should find fulfilment and satisfaction in this nurturing role (Maushart 1999; Green 2004; Borisoff 2005; Douglas and Michaels 2005; Warner 2007).

Although the 'good' mother is presented as an ideal maternal figure, the reality is that very few women are able to, or would want to, devote their entire being to their children. Women who work outside of their domestic role are deemed inappropriate mothers due to their time away from their children (Borisoff 2005), and the reality of the stay at home mother is often at odds with the serene and satisfied 'good' mother due to the physical labour, emotional intensity and financial implications associated with this ideal (Held 1983). Andrea O'Reilly makes the point that the ideology of intensive mothering 'has become the official and only meaning 
of motherhood, marginalizing and rendering illegitimate alternative practices of mothering. In so doing, this normative discourse of mothering polices all women's mothering and results in the pathologizing of those women who do not or can not practice intensive mothering' (O'Reilly 2004, italics in original). And the fact that many mothers are unable to mother within the appropriate ideology of intensive motherhood does not seem to lessen the power of this maternal model, rather, as I have suggested elsewhere, it simply means that many expecting, new and existing mothers struggle to uphold, yet continue to speak about, the value associated with this maternal ideal (Feasey 20I2a).

A wide array of popular media texts are said to construct, circulate, conform to and thus confirm the appropriateness of the ideology of intensive mothering, with parenting manuals, mainstream film, news reports, advice columns, women's magazines, celebrity-led publications, and advertising being said to act as 'the major dispenser' of the ideals and norms surrounding motherhood (Douglas and Michaels 2005). And although it can be argued that television plays a part in upholding the 'good' mother myth, it has also been seen to present mothers as inept, ineffectual and fragile. Indeed, television appears committed to the depiction of single, sexual and scared mothers who are variously struggling with authority and finding little in the way of maternal satisfaction, which might go some way towards exposing the romanticised maternal ideal as precisely that, an ideal.

With this in mind, this book will draw on an online questionnaire in order to shed light and offer critical insight into the varied and diverse ways in which expectant, new and existing mothers of different ages, from different class and maternal backgrounds, make sense of popular representations of motherhood on television. The volume will examine the ways in which these women find pleasure, empowerment, escapist fantasy, displeasure and frustration within popular depictions of motherhood, considering the ways in which such responses inform their own maternal thoughts and practices. This research seeks to present the maternal voice of the audience and, as such, will take as its starting point those maternal depictions and motherwork representations that are highlighted by this demographic. Where appropriate, I have drawn attention to a range of secondary media texts such as news articles, reviews, interviews and the wider blogosphere 
that both underpin and elaborate on such readings and consider the ways in which maternal responses can be understood in light of extant literature from within the fields of feminist motherhood studies, media theory and television criticism.

Each chapter will present a clear and comprehensive account of the ways in which maternal audiences respond to existing representations of motherhood and the maternal role in a number of television programmes, series and genres, with specific case studies being positioned in relation to a wider consideration of motherhood both on and off screen. In terms of structure, Chapter I explains why it is important to give voice to the maternal audience before introducing the reader to a range of media methods, each of which has its own stages of development, strengths and limitations, ethical considerations and specific demands on researcher and participants alike. The section foregrounds existing ethnographic work in the fields of feminist mothering, film, television and media studies in relation to harlequin romances, celebrity gossip magazines, female film stardom and soap opera before outlining the nature and scope of this research, paying particular attention to the role of the online questionnaire in gathering views, opinions and comments from mothers in the television audience.

Chapter 2 goes on to outline the maternal figures, tropes and archetypes that have proved popular with mothers in the audience, and yet despite being asked to consider a limitless range of programmes, genres, channels and schedules, audiences spoke favourably about a very small number of televisual presenters, performers and characters, demonstrating something of a maternal consensus, dependent on generation, in their routine viewing pleasures. Audiences have historically been said to invest and identify with particular characters based on a sense of community, commonality and shared experience and, as such, Chapter 3 introduces the reader to maternal comments regarding notions of identification and the ability to relate to representations of motherhood on the small screen, be it in terms of motherwork, domestic practices, lifestyle or sartorial choices. Again, a diverse maternal audience seemed to unite in their, this time, frustrated commentary as they tell us that they barely recognise the maternal roles that are played out in the television landscape, acknowledging the entertainment and escapist fantasies on offer in the medium while 
simultaneously deriding the lack of believable, relatable figures. Chapter 4 draws attention to those representations of motherhood that audiences deem to be flawed, negative and problematic, considering why mothers choose to watch or avoid such 'bad' maternal figures. Although a number of women made the point that they would never judge another mother, the extremes of perfect motherhood and selfish parenting were simultaneously judged and found wanting by the majority of maternal viewers. In short, the research seeks to understand the ways in which certain depictions of motherhood are reviled while others revered, and the ways in which these distinctions can be seen to pick up on broader debates concerning the socially acceptable 'good' mother or the culturally inappropriate 'bad' mother. The conclusion draws attention to what is seen as a lack of maternal diversity on television. Respondents routinely and repeatedly commented on what they viewed to be predictable stock characters and limited maternal stereotypes, with minority maternal groups being said to be overlooked, and, on the rare occasion when they are given screen time, exploited. The maternal audience united to voice their concerns over the medium's continued commitment to maternal extremes, with an overwhelming outcry for a wider scope and breadth of mothering depictions.

The women who responded to my questionnaire have been open, honest and indeed candid about their viewing pleasures, frustrations and criticisms in relation to representations of motherhood on television and their views have offered the first real insight into this topic within the fields of television, media and gender studies. However, their voices have not only added significant original thought to the academic community, but must be seen to open up a dialogue with the wider entertainment arena. Although many women spoke of favourite maternal characters, preferred presenters and mothers on the small screen that they were invested in, they appeared to speak in agreement when they stated that they did not feel fairly or appropriately depicted on television. Women felt that there were very few characters that they could relate to and that those women who were regularly and routinely seen on screen played to narrow and divisive extremes of parenting.

There is clearly a burgeoning interest in feminist research on the institution of motherhood, ethnographic work that engages with maternal voices, 
media research on representations of motherhood in popular culture and social and economic projects committed to the reality of motherwork practices, and I hope that this research can be seen to contribute in some small way to each of these fields of study and perhaps initiate a drive for more maternal diversity on and beyond the small screen, be it for public service purposes or commercial profit. 



\section{Media methods research: Finding audiences and giving a voice to mothers}

Film, media and television studies have, since their emergence, relied on a diverse range of research theories, methods, practices and approaches in order to examine what is deemed important, significant and of interest to both the academic community and the wider society. Textual, discourse and content analysis, focus groups, interviews and questionnaires are but a few of the qualitative and quantitative techniques used to explore the popular media environment. Each method has its own unique structures and stages of research, its own strengths and limitations, and the use of a particular approach depends on the aims and objectives of specific research projects. While some projects demand breadth and scale, others are committed to the minutia of a particular area; while some seek to offer informed debate as part of a theoretically rigorous desk-bound study, others prefer to position audience voices at the forefront of their research.

In order to understand and give voice to women about their responses to representations of motherhood on television, it is important that we understand the ways in which questionnaires, interviews, oral histories, netnographies and focus groups have been and should be employed by the researcher. It is not my intention to look in detail at the pros and cons of each available media method - indeed, there are a myriad of successful volumes dedicated to that particular topic (Priest 2010; Berger 2013) rather, this chapter will give a brief overview of existing ethnographic studies that present women's responses to gendered media genres, namely, harlequin romances, celebrity gossip magazines, female film stardom and soap opera, before outlining the ways in which I looked to find suitable participants, listen to their voices and present their views as they relate to maternal depictions on the small screen. 
I have previously examined representations of motherhood on popular television and considered the ways in which such depictions inform the 'good' mother myth in an age of intensive mothering and the professionalism of motherwork, paying particular attention to the ways in which maternal images might be seen and understood by the mother in the audience (Feasey 20II, 20I2a, 2013). Although this work was crucial in presenting the relationship between media and motherhood studies and in foregrounding historic and more contemporary representations of motherhood in the entertainment area in relation to the changing social, sexual and political context, what was missing here of course was the voice of the audience. My research within the field of feminist television studies was not unique in this regard; indeed, much seminal work points to a hypothetical viewer and an imagined spectator rather than giving voice to those in the audience (Dow 1996; Haralovich 1999; Brunsdon 2000; Brunsdon and Spigel 2007; Lotz 2014). This textual research is crucial within and beyond the field as it allows us to understand and reflect upon those gendered images that both saturate the media environment and inform our common sense notions of appropriate, inappropriate, credible and devalued sex and gender roles within the contemporary period. One might hope that such literature plays a role in the ways in which future representations of gender inform the entertainment marketplace within and beyond the public service remit and speak to the importance of such roles and representations for a range of social and identity programmes.

Acknowledging and unmasking existing, new and forthcoming representations of gender is crucial within academia, and yet, the near universalism of textual analysis has resulted in theorists overlooking the role of the audience and the significance of their voice as it either chimes with or challenges extant literature within and beyond feminist media and motherhood studies. 


\section{Audience and reception studies}

That said, there is a small number of theorists who have, since the emergence of feminist media studies sought to redress the balance, and put audiences front and centre of their research, drawing on a range of questionnaires, interviews, focus groups and surveys. This work has to be applauded for its contribution to the fields of gender, media, sociology and motherhood studies because, "critical readings of "texts" mean nothing without at least some attempt at ethnography - how people actually watch TV, for example' (Wolff I993).

Janice Radway's seminal Reading the Romance: Women, Patriarchy and Popular Literature (1984/1991) was groundbreaking for its ethnographic study of a group of longstanding female romance novel readers in a Midwestern American city. At a time when much feminist theory derided popular romances for their patriarchal narratives of male domination and female submission, Radway looked to challenge such research by considering the ways in which readers made sense of and found pleasure within these seemingly ephemeral volumes. Radway combined reader-response criticism with anthropology and feminist psychology, in order to discover why romance readers remained loyal to their chosen genre texts. She asked readers to explore their own reading practices rather than to make assumptions on their behalf. Radway discovered that these women devoted endless time to their families, yet received little attention in return. From this perspective then, these women looked to romance fiction as an escape from their mundane domestic routines, focusing on a caring and tender hero who provided the much-needed attention that they felt was missing from their lived reality. By speaking to the readers themselves, Radway discovered that romance readers were not, as previously assumed, passive recipients of fairy-tale narratives, but rather, frustrated wives and mothers who admired strong, resilient and intelligent heroines, heroines who defied the expected stereotype of the genre. Through focus group debate and continued discussion with these women, Radway came to understand how these readers turned to these ostensibly patriarchal texts at times of 
resentment at their own limited life choices. Radway spoke throughout this work about the need to shift our attentions away from text-based analysis whereby the scholar offers theories concerning general reading practices, to what she referred to as 'the complex social event of reading', looking beyond the text itself to a greater understanding of the complex relationship between text, culture and reader (Radway 1984/199I).

A decade after the publication of Radway's important volume, Joke Hermes looked to examine the ways in which magazine readers made sense of gendered publications by conducting extensive interviews with readers. In Reading Women's Magazines: An Analysis of Everyday Media Use (1995) Hermes employed reception analysis in order to explore the ways in which women used such ephemeral texts in their daily routines. While extant literature on the women's magazine sector tended to show concern for passive female readers in opposition to the privileged feminist author, Hermes was keen to show that readers were not as earlier research had suggested, cultural dupes or silly housewives. Hermes took respect for these women as her starting point, emphasising their agency rather than dependency on gendered magazines. And although one might suggest that the reader response findings appeared banal, this was precisely the point of the research. Hermes was not seeking to reclaim these magazines or to theorise readership responses, but rather, to understand the role of these texts in the lives of the reader. This research suggested that women's magazines were a valuable and unique genre due in part to the fact that they allowed women to forge imagined communities with one another and, rather controversially, to 'inoculate' readers against lived events that they might encounter in their own lives.

However, beyond this, Hermes found that readers had little interest or investment in the content of these texts, but rather, that they valued them for their ability to fill small gaps of time in their daily routines. Although women's magazines do on occasion and for a fleeting period afford women a symbolic space within which to imagine their 'perfect selves' this was not why they continued to look at these texts. Indeed, it was clear that very few women were able to recall a single article, feature or theme from their recent reading encounters. Hermes was not defensive about her decision to base her research exclusively on readers' perceptions of women's magazines, 
nor did she feel the need to reintroduce the voice of the 'exceptionally knowledgeable' reader. Rather, when she discovered the limited meaning that these texts had in the lives of the reader, she continued to remind us of the importance of reader responses over textual approaches, irrespective of, or precisely because of, the ostensibly trivial commentary unearthed in her research. After all, text-based research perpetuates the 'fallacy of meaningfulness' as this approach gives voice to academic interpretations, interpretative repertoires and theoretical considerations in a way that has little in common with the average, mundane, normal or 'ordinary' reader (Hermes 1995).

On the back of existing literature concerning the ways in which female readers responded to a range of romance narratives and the gendered magazine sector, Peter Jackson, Nick Stevenson and Kate Brooks combined interviews with editors and key production staff, content analysis and focus group discussions in order to locate the appeal of men's lifestyle magazines. The volume, Making Sense of Men's Magazines (2001), hoped to examine the ways in which these texts played a role in the social construction of contemporary masculinity for young readers. However, what was significant about this volume was not simply the findings offered by the group discussions in relation to notions of capitalism, consumption, masculinity and gender politics, but also, and perhaps, more importantly, their candid assessment as to the reality of doing ethnographic research. These authors sought to speak to readers in line with Radway and Hermes before them, trying to discover the pleasures and frustrations on offer in texts such as FHM and Loaded against notions of irony and retro-sexism that underpinned textual considerations of such work, but they struggled to locate willing participants.

These researchers looked to secure focus group discussions in Sheffield and London, seeking to recruit readers and non-readers from a wide range of age, employment and educational backgrounds. The book tells us that after distributing 200 flyers in their chosen locations, II individuals suggested that they would be available for a focus group. However, two of these were clearly 'joke' submissions, with only one person arriving for the discussion. The notion of a focus group soon turned into an interview situation, at which point the tape-recorder microphone stopped working, leaving no 
meaningful or lasting record of any audience research having taken place. Jackson, Stevenson and Brooks did eventually find relevant participants after using the snowball technique whereby researchers looked to friends, family and their wider social and professional networks to secure respondents for their project. The authors proposed that the men's lifestyle magazine market should be understood as a cultural response to social change, rather than as a backlash to feminism or escapist fun, and yet, irrespective of the fascinating findings of the research, this work was valuable for its candid presentation of the problems of reception studies in terms of finding willing and relevant participants and then getting them to commit time and energy in the shape of focus group sessions. The authors were frank about the difficulty of finding the appropriate facilitator for this gendered project, and the challenge of encouraging and maintaining group interaction across social and economic demographics (Jackson et al. 200I).

The return to the reader, or reception studies, was also evident beyond those interested in print media. After all, at a time when Radway was interviewing romance readers in order to better understand their reading habits, Ien Ang was looking to examine the ways in which Dutch viewers responded to the American prime time television soap opera, Dallas (1978-9I). The findings of this research informed the slight but significant volume, Het Geval Dallas (1982), or, as it is known in English translation, Watching Dallas: Soap Opera and the Melodramatic Imagination (1985). Like Radway before her, Ang was not focused on academic readings or a theoretical analysis of the American production, but rather, the research for the volume was based on replies to her advertisement in a women's magazine, Viva, where she posted a request asking viewers to let her know why they liked or disliked the show in question.

Rather than view audiences as passive recipients of the powerful cultural industries, Ang sought to discover the ways in which international audiences made sense of and found (dis)pleasure in the long-running programme. The research focused on notions of realism, fiction, melodrama and feminism as they were highlighted in the letters written, embracing the complexity of readers' responses to the show in question. Reponses came from loyal fans of the show, those who claimed that the programme was trash (even as they admitted to watching), and those again who mentioned 
that they barely watched television (even though their commentaries suggested otherwise). However, irrespective of how these audiences positioned themselves in relation to television in general and Dallas in particular, Ang was interested in trying to understand what pleasures were on offer in the popular text.

While some respondents disliked the show for its low-brow soap status, for exploiting the most base common denominators of taste and distinction, others resisted or negotiated the ideology of mass culture by way of an 'ironic' mode of viewing; others sought to defend themselves from the ideology of the text while others again appeared unaware of any ideological structures present. The letters revealed a variety of responses to the ideology of mass culture that informed the programme; so too, they revealed differences in terms of debates over realism and identification. Respondents suggested that the pleasure of watching Dallas came from recognition, from being able to identify with and relate to the characters, locations and scenarios; however, there was no single agreed or monolithic definition of what was 'realistic' in these accounts. While many did not perceive Dallas as realistic on a simple denotative level, some acknowledged that the family structure, importance of home and broader relationships could be read as entirely recognisable, if not realistic (Ang 1985).

In Women Watching Television: Gender, Class and Generation in the American Television Experience (1991), Andrea Press looked at the history of women on television, considering a myriad of representational roles in relation to notions of class, generation and gender, distinguishing between pre-feminist, feminist and postfeminist images on primetime. Press made the point that postfeminist programming continued to present the traditional nuclear family unit as the ideal for contemporary women to aspire to. Press outlined this textual history and an overview of extant television representations before presenting the findings of her own empirical investigation, based on extensive interviews with working and middle class women. This research emerged out of Press' concern that the media in general, and television in particular, influenced women's identities in their wider cultural environment. We were told that 'it becomes more and more pressing to ask how women in our time use the images and ideas our culture makes available to them as they construct their own identities in 
the world and as they form their own ideas about what is normal and real outside of themselves' (Press 199I). In short, how had women's lives and thoughts been influenced by those depictions of feminism, femininity and the woman's role as it was presented on the small screen.

Press conducted open-ended interviews with working and middle-class female viewers in the San Francisco Bay area in order to examine the ways in which women identified with the gendered images seen on television, paying particular attention to notions of reality and the question of what viewers accepted as realistic in relation to their wider social experiences. We were told that working class viewers are more committed to realism while their middle class counterparts presented a distanced, even ironic, stance when speaking about their television viewing practices and preferences. Press suggested that although middle class viewers were less interested in television than the working class cohort, they ultimately identified more strongly with television characters than the working class audience. Press accounts for this class-based reading by foregrounding the historic middle class bias of much television programming. In short, middle class audiences were said to be able to identify with privileged characters on screen while working class audiences were found to feel alienated by such middle class realism. Press' overarching contribution here was to note that while working class viewers watch television through the lens of class, the middle classes view through a more gendered lens, contributing therefore to debates within the fields of gender, media and the broader social sciences.

Later that decade, Mary Strom Larson was interested in examining the ways in which adolescent soap opera viewers perceived single motherhood in comparison to those who do not watch such daytime television fare. She began by telling us that television 'is a major source of information about behaviours appropriate to gender' and noted that televisual representations have the power and scope to influence a viewer's perception of social reality. She went on to introduce what she referred to as the 'serious and costly' consequences of single parenthood, pointing out that, at the time of writing, ' $45 \%$ of all female-headed households live in poverty ... and children in single parent households are six times as likely to be poor as those in two parent families.' She continued to cite details concerning emotional and 
crime problems, life-long learning disabilities and behavioural problems associated with single parenting (Larson 1996).

On the back of a detailed content analysis of several popular American soap operas it was found that the single mothers depicted in the genre were well educated, in professional, rewarding careers, lived in beautifully furnished homes, wore designer clothing and faced few challenges concerning childcare. Indeed, these women were seen to carry out successful careers, dress impeccably, take time for themselves and still maintain a supporting maternal role. No maternal sacrifices were seen having to be made for children. We are told that the representation of single motherhood in the American daytime soap opera was at odds with the reality of that role, and that it was this disharmony that was of interest to the researcher. Larson wanted to discover if watching these unrealistic depictions of unmarried motherhood on screen influenced understandings about the reality of single parenting in society.

Her findings, based on questionnaires completed by i 6 - to I 8 -year-old students, made it clear that those who watched daytime soap operas were ill-informed about the reality of single parenthood, basing their opinions about this parenting status on what were overwhelmingly positive experiences for this family unit in the domestic genre. The young soap opera viewers assumed that single mothers were educated, with good employment prospects and few financial concerns. The optimistic assumptions continued when they noted that they would have healthy babies, an active social life, a beautiful home, designer attire and male friends who helped with childcare. The concern here was that the lived reality of and young people's perceptions of single parenting were at odds. Depictions of single mothers in the popular genre encouraged young women to think that such parenting had desirable consequences while telling young men that fatherhood comes with few responsibilities, which is problematic if one considers the high rates of unexpected teen pregnancy on both sides of the Atlantic. Larson viewed the media as a powerful force in shaping cultural norms and mores, with televisual representations being said to exert a significant influence on how audiences understood their wider social environment (Larson 1996). Jackie Stacey (1994) echoed the sentiments of the aforementioned theorists as she spoke of the importance of female spectators to the field of 
feminist film theory. Since the mid-1970s, feminist film criticism had been committed to the production and reproduction of textual approaches, focusing on both the 'images of women' and the 'woman as image' debate. The former was concerned with stereotypical images of women in Hollywood and the ways in which these restricted definitions of femininity informed a patriarchal culture (Haskell 1974), while the latter looked to discover how the cinematic language of mainstream cinema constructed female stars in a 'to-be-looked-at-ness' role via the mechanism of psychoanalytic theory (Mulvey 1975, 1989). Indeed, due to the near-universalism of the psychoanalytic approach, debates concerning unconscious mechanisms and the male gaze, voyeuristic intent, fetishistic scopophilia and narcissistic ideals continue to dominate this particular field. Although these two modes of study differ in many respects, what they had in common was that they overlooked the ways in which women in the audience made sense of representations of women on screen.

Stacey was a lone voice heard asking how academic understandings of female spectatorship might be transformed by accounts from women in the cinema audience. In the groundbreaking Star Gazing: Hollywood Cinema and Female Spectatorship (1994), Stacey informed us that she sought to put 'female spectators back into theories of spectatorship' by combining feminist film theory with a rich body of ethnographic research, a rich body indeed. Stacey's research was informed by letters and questionnaires from regular cinemagoers from the wartime and post-war period, examining the different ways in which women looked at images of femininity on the big screen. Stacey investigated the importance of female stars such as Ginger Rogers, Deborah Kerr and Joan Crawford in women's memories of wartime and post-war Britain, with an emphasis on escapism, identification and consumption, taking the women's voice, as Radway had done a decade earlier, as the cornerstone of the research. When a respondent wrote to Stacey to inform her that: 'I loved the cool charms of stars such as Deborah Kerr ... my childhood dream was to become like her and I used to spend hours shop window gazing and selecting what she would wear' (Stacey 1994), it made it clear that glamorous images of fashionable film stars offered a unique dialogue between the female image and the female spectator in line with an active female gaze, at the time unaccounted for 
in the field, an active gaze later explored by Rachel Moseley (2003) in her thought-provoking audience research concerning generational readings of Audrey Hepburn.

More recently, Beverley Skeggs, Janet Thumin and Helen Wood (2008) employed a range of audience approaches in order to examine the ways in which women could be seen to make sense of reality parenting texts such as Supernanny (2004-I2). This research used the recently developed textin-action approach which involved the researchers watching a particular title with participants and detailing their responses at the time of viewing, or what might perhaps be understood as the Gogglebox (2013-) technique on the back of the success of the Bafta-winning reality show that watches members of the public watching television. The researchers were flexible in terms of their chosen methodologies and agile from the point of view of gathering the most meaningful data from their participants. Indeed, much of the write-up outlined the ways in which the researchers looked to find the most suitable fit between participant and approach. Their multi-layered methodology 'allowed the production of different types of knowledge relating to forty research participants and their relationship to "reality" television' (2008), beginning with textual and intertextual analysis in order to select the programme sample, and later, interviews, text-in-action and focus group discussions in order to compare (or otherwise) individual readings of shows such as Supernanny with public statements about the genre.

Much like the work of Jackson, Stevenson and Brooks (200I) before it, this research offered a significant contribution to the fields of media studies and the broader social sciences due to its honest, or what Oakley (1979/198I) might refer to as 'unsanitised' account of their research process. Skeggs, Thumin and Wood discovered that middle class women were entirely comfortable in their position as interviewee, clearly at ease being questioned by academic researchers in relation to their preferred viewing practices and their consumption of reality texts. These women spoke as equals to the interviewer, they had a shared professional status and were able to talk at length and reflect on their attitudes towards reality programming with a critical distance as is encouraged by academic research.

However, this sense of ease and comfort was not shared by respondents across the differing demographic groups in the sample. Many working class 
women offered shorter, blunt answers when questioned about programme choices, with little elaboration or reflection. Even though the working class women watched reality television far more than their middle class counterparts, they were either less willing or less able to express their readings of such shows beyond a text being 'funny' for example. There was no commentary as to gender or class depictions, which was clearly a surprise to the researchers in relation to texts such as Wife Swap (2004-). After all, even a cursory glance at such shows tell us that taste formations, cultural distinctions and notions of class are paramount to the narrative of these texts. While the middle class participants were able to express and reflect on notions of class and gender in reality television, the working class subjects spoke more stiltedly about immediate pleasures and viewing gratifications with little in the way of contemplation. This unease between subject and interviewer was at its most extreme when the researchers spoke to new migrants. One Pakistani woman with limited knowledge of the English language assumed that the researchers were representatives of the state, going on to offer 'her bank statement as if to prove her legitimacy' before trying to provide the 'correct' answers about her life in the UK. The data gathered from the middle and working class women were not comparable, and rather than let this compromise the findings of the research, the 'text-in-action' approach was used in order to help overcome the uneasy interview situation. In short, the use of these varying methods enabled the researchers to 'see how class was being performed differently through the three stages of [the] empirical research: interviews, text-in-actions and focus groups' (Skeggs et al. 2008). The point here then was that audience research did not generate natural or neutral responses to set questions or group discussions, but rather, that the method chosen went some way to defining the responses given, ranging from discussions of class capital to specific examples of maternal authority. Skeggs, Thumin and Wood offered a candid account of their research process, foregrounding the importance of specific methods and approaches to particular demographic groups, even before they embarked on the analysis of the data itself.

With this in mind, it is worth noting that film, television and media studies more broadly have witnessed a resurgence in audience and reception 
theory in recent years, with research putting a myriad of readers, viewers and spectators at the forefront of their work. Indeed, entire journals have developed on the back of this newfound approach to media research (Barker et al. 2014).

\section{Mothers and motherhood in audience and reception studies}

The maternal voice has been encouraged in contemporary research on pregnancy, motherwork and the maternal role, with women relaying pregnancy experiences, child-birthing practices and their inability to find a harmonious balance between their public work and their mothering role. By drawing on a range of questionnaires, semi-structured interviews and focus group discussions we are able to acknowledge women's lived experiences, foregrounding a much-needed voice in the fields of motherhood studies, gender theory and feminist criticism.

Ann Oakley might be understood to have inaugurated this strand of motherhood research in her seminal volume Becoming a Mother (1979/1981), which emerged out of an earlier project on women's experiences of housework (1974/1985). Oakley was interested in women's experiences of childbirth and, as such, she conducted detailed interviews with women during and after pregnancy, and in some cases, during the labour itself. Although the news media was showing an interest in rising induction rates and women's experiences of antenatal care during the time of her writing, little work in the social sciences appeared relating to how the treatment of women in childbirth was experienced by the women themselves. Oakley's work drew much needed attention to maternity care and her research was seen to inform academic debate, feminist scholarship, social commentary and childbirth policies. Indeed, Oakley was keen to stress that her role as a social scientist was to energise academic debate while offering an accountable impact in the wider social context, in order to improve the day-to-day lives of individuals (Oakley 2013). 
Oakley conducted four, two-hour interviews with each of her participants, starting in pregnancy and concluding five months after the birth of their first child, and she was candid about the interview techniques employed here. Oakley was granted access to the medical records of these women, and spent many hours in their company, but the volume made no mention of research ethic committees or processes. Rather, Oakley herself has acknowledged that the research proposal did not go through such approval stages because these were not stipulated in line with more recent research practices. She has, more recently (with a team of researchers at the Social Science Research Unit), returned to this research and made contact with many of the original participants, where more formal channels of approval had to be established in terms of contacting individuals and requesting consent for interviews.

What was interesting here was Oakley's commentary on the differences between formal interview techniques as they pertain to the field of media and social science research and how she herself conducted her original data gathering. Oakley informed us that she struggled to maintain the mechanical techniques and critical distance routinely demanded from the interview method. The author was open about how she actually ran the interviews rather than a more 'sanitised' version that could have been presented in her book. Indeed, Oakley devoted a chapter in Becoming a Mother to the approach undertaken here.

Oakley discovered that women's expectations of pregnancy, labour and motherhood were at odds with the reality of those experiences, causing new mothers to feel scared, ashamed and guilty about their maternal feelings and motherwork practices. Oakley's participants made it clear that they struggled to maintain the appearance of the 'good' mother while feeling emotionally overwhelmed and physically exhausted by the reality of that role. Oakley's work gave respect to mothers and their maternal voices and took the time to present their thoughts, feelings and motherwork practices in a clear and considered volume. Oakley offered crucial insights into the ways in which women experienced childbirth and early parenting, helping us to better understand the ways in which these accounts are (mis)understood in relation to antenatal classes and medical advice, while also making 
a valuable contribution to debates concerning the role and responsibilities of the researcher within and beyond the social sciences.

Two decades after the publication of Oakley's seminal research, Christine Everingham contributed to work in women's studies and the sociology of the family in Motherhood and Modernity (1994). The theorist studied the links between modernity, rationality and individuation in relation to a debate about motherhood, by drawing on research informed by an 'ethnographic study of maternal-infant interaction in suburban, kinship and alternative playgroup settings'. Previous studies of such relations tended to be located either within the home environment or in laboratory settings, with little understanding of the role of the social-cultural milieu to infant-mother interactions. Everingham engaged in conversation with mothers and went as far as joining in the play activities of the children prior to observing the interaction in these groups so as to blend in and avoid being seen as the 'detached outsider'. On the back of these observations, Everingham went on to conduct more formal, semi-structured interviews with women from each playgroup in relation to the question of parentchild interaction.

Mothers (and on occasion, fathers) were asked about their parenting ideals and expectations before being questioned about the ways in which they learned to look after their children. They were then asked about the reality of that role, who they looked to for help and support, and the role of different social environments on their interactions with their children. Everingham drew attention to feminist theory, notions of morality and the self, maternal attitudes and maternal-infant conflict before concluding that women, across differing group settings, modified their preferred maternal practices and child-rearing ideals during the early child-rearing period, with the assertiveness of the child overriding and overruling the autonomy or agency of the mother. She discovered that friendships and social ties formed through the playgroup and other maternal settings provided an overwhelmingly positive sense of connectedness for mothers, while on occasion being seen as a negative space of judgement and stress for those women who felt responsible for a child's problematic behaviour. In some cases, the latter was seen to lead to a loss of self-esteem for mothers as they 
compared the reality of their parenting practices to what they considered to be ideal maternal standards. These findings were relevant, Everingham told us, in relation to broader debates concerning the separating of private and public spheres, the role of mother as the primary care-giver and notions of agency and autonomy for women with children (Everingham 1994).

Like Everingham before her, Sharon Hays employed in-depth interviews, but rather than focusing on the playgroup setting, she looked to understand the ways in which working women adhered to social expectations of motherhood. In The Cultural Contradictions of Motherhood (1998), Hays demonstrated that motherhood, or rather, that acceptable notions of motherhood are prone to shift and flux, charting the development and prevalence of what is now understood as the ideology of intensive mothering. Hays offered a brief content analysis of popular child-rearing manuals before talking to working mothers about their personal and professional experiences. Hays conducted detailed interviews with mothers of two-, three- and four-year-old children from a broad class spectrum and a variety of working positions, asking them about their own upbringing, their routine maternal practices, sources of discipline and avenues of support, feelings about childcare provision and their own position as working mothers.

Through these lengthy interviews she discovered that working women, specifically middle class professional women, were caught in a double bind whereby they were trying to maintain a rational, competitive and ambitious stance in the world of work while holding themselves up to nurturing and selfless childrearing ideals outside of office hours. Although one might look to talk about the balance between work and home life or family-friendly employment practices, the simple example of a mother wanting to spend time at hospital to comfort her sick child when her boss is requesting her presence in the workplace speaks volumes about how women have internalised the ideology of perfect motherhood and the delicate, difficult, balancing of appropriate maternal care and acceptable working practices.

Hays suggested that at a time when greater and growing numbers of women with small children were entering the workplace, society should have been making the practice of mothering a more simple and efficient task, and yet, the ideology of intensive mothering had made this dual role even harder to maintain, exacerbating tensions between the competing 
private and public arena for many of these women. In short, 'the cultural model of a rationalized market society coexists in tension with the cultural model of intensive motherhood' (Hays 1998). However, the importance of intensive mothering and the difficulties of living up to the 'good' mother myth is not limited to middle class professionals. Hays' findings echoed those of Everingham before her when she told us that a diverse range of mothers shared 'a set of fundamental assumptions about the importance of putting their children's needs first and dedicating themselves to providing what is best for their kids, as they understand it'. Mothers from different class, education, financial and religious backgrounds may well have demonstrated their own agency in terms of the childrearing advice that they chose to embrace or ignore, and yet they each sought to uphold the ideology of intensive mothering and hold their own maternal practices up against that unrealisable ideal (ibid.).

Naomi Wolf picks up on these motherhood anxieties and practices in Misconceptions: Truth, Lies and the Unexpected on the Journey to Motherhood (2002) in a book that interweaved medical fact, personal biography and women's own stories of labour and early motherhood. Wolf was damning of the medicalised version of childbirth that dominated American hospitals in relation to caesarean and episiotomy rates, routine foetal monitoring and labouring positions. Indeed, she made the point that American hospitals encouraged medical intervention in order to create profit for hospitals, telling us that private obstetricians practicing in America currently 'earn far more for performing Caesareans than for attending vaginal births, and hospitals bring in more income that way as well'. She went on to announce that if only s per cent of women, those who genuinely needed a caesarean section, had this operation, American hospitals would lose \$I.I billion revenue annually. The boom in this procedure meant shorter hours at increased pay for obstetricians, and as such it was clear that the professional success of a private medical practice was at odds with the physical and psychological health of the pregnant woman.

On the back of revealing interviews and in many cases traumatic conversations with primigravidas on their experiences of medicalised childbirth, Wolf stated that irrespective of time spent with medical staff, pregnancy manuals and birth classes, American women remained ill-informed about 
the reality of labour. Moreover, she discovered that the lack of awareness led to feelings of shock, shame, anger and disillusionment when a woman's birth experience bore little relation to her birth plan. Wolf compared her own 'traumatic' birth experience with those of other women to find that what she assumed to be her own rare 'bad' birth experience was actually rather commonplace, coining the term 'ordinary bad birth' to point to the frequency of what she originally thought to be an isolated trauma. Wolf showed great respect for the women that she spoke to and appeared moved by their stories of humiliation, shame, loss and fear, and as such, I would suggest that Wolf, like Oakley before her, struggled with the formal notion of interviewing or mechanical data collection. Wolf started the book by informing the reader that the most common phrase used by her participants was 'I wish someone had told me' followed by the notion that they felt that they were being kept in the dark, not being given all the information, about the experience of childbirth. Wolf agreed that 'quite a lot of important information is too often concealed from pregnant women' and it was this shroud of secrecy that she sought to address in this polemical volume (Wolf 2002).

Writing at a similar time, Tina Miller's enlightening and accessible volume Making Sense of Motherhood: A Narrative Approach (2005) gave voice to women's experiences of first-time motherhood, paying particular attention to the ways in which maternal narratives could be seen to develop and shift as mothers adapted to their new-found maternal role. Miller's research was generated by following women for a full year through pregnancy, childbirth and motherhood. This detailed research process involved women being interviewed on three separate occasions, alongside telephone discussions and a questionnaire. She discovered that new mothers struggled with the transition to motherhood, questioned their maternal abilities and felt suffocated by motherwork practices, and yet were afraid to speak out about these difficult early experiences. Like Oakley, Everingham and Wolf before her, Miller discovered that a disjuncture existed between the idea of motherhood and the reality of that role, and made the point that this disharmony between expectation and experience was damaging for the physical and physiological wellbeing of these women. 
On the back of her semi-structured longitudinal interviews, Miller noted that the socially acceptable birth plan (seeking a natural birth with minimal intervention with immediate bonding with the newborn) rarely matched up with what was later recounted as a 'bad' or what Wolf refers to as an 'ordinary bad birth' experience, and yet, rather than give voice to this contradiction or draw attention to the disjuncture, many of the women admitted that they perpetuated the unrealistic 'good' birth narrative by silencing themselves or rewriting their stories for fear of judgement from other women and mothers. And this self-silencing continued throughout new motherhood as these women were seen to struggle with 'overwhelming feelings of love, guilt, exhaustion, joy and fear'. Routine maternal practices and recognisable emotions were misunderstood as different or deviant responses to early mothering, and the lack of open dialogue saw these women self-censure what they dare and dare not say about their experiences, which in turn continued to perpetuate the mask of 'good' motherhood and upheld an unrealistic mothering ideal (Miller 2005).

Miller, like many within and beyond the field of motherhood research considered the role of the middle class mother at the expense of her less privileged socio-economic counterparts. In order to counter this gap in the field, Val Gillies presented two separate but related research studies in order to explore working class experiences of parenting in her volume Marginalised Mothers (2006). The first was based on single intensive interviews with five working class mothers who mother outside of the nuclear family unit, who lived in high deprivation areas with limited financial resources; the second study was concerned with parenting resources and support as understood through an extensive National Opinion Poll and 25 follow-up interviews. While extant literature from the fields of motherhood, media and social policy tended to focus on the lived experience of motherhood and the revelation of maternal thoughts and practices as they related to middle class mothers, little work accounted for the experiences of those working class mothers who lived outside of the nuclear family unit and who were frequently the focus of public concern and intervention.

The working class mothers in her research sample were seen to suffer from social marginalisation, vulnerability and powerlessness and, as such, these women were forced to make decisions about family life based on their 
strained circumstances, so that in many cases, the notion of choice actually precludes genuine choice or option. These women were seen to make the best choices for their children based on available resources. While middle class mothers were seen struggling to uphold the ideology of intensive mothering, these working class women were more concerned with 'obtaining sufficient money and securing decent housing' with disadvantage leading to poorer health and fewer life chances for their children.

The analysis presented here, based on the accounts of lone mothers who were in receipt of welfare benefits highlighted both the financial difficulties faced by these women and the emotional responsibilities that they faced with limited support. These mothers did not choose single motherhood, but rather, had it foist upon them when faced with an absent father, or made the decision to leave a violent relationship for the sake of the children. Gillies made the point that these women could have had a more secure future had they themselves chosen to leave their children, but that in each case, these women faced long-term hardship as they struggled with the single parenting role. We find that these women routinely fed, clothed, housed and educated children on an income that would barely sustain an individual, while 'actively compensating for the day-to-day experience of disadvantage through love, protection ... humour and affirmation'. Gillies informed us that motherhood was central to contemporary debates about class, with working class mothers being 'depicted as ignorant, promiscuous, uncaring, irresponsible and most significantly, undeserving. However, this work examined notions of class and race in order to challenge those longstanding negative images of working class motherhood that dominated the media agenda and policy initiatives, and highlighted the fact that professional discourses around appropriate parenting were grounded in middle class advantage for women who were in a position to make genuine choices for themselves and their families removed from economic and social constraints (Gillies 2006).

Pamela Stone returned to an examination of privileged middle class motherwork, taking the idea of the 'opt-out' revolution as the basis for her original research in Opting Out: Why Women Really Quit Careers and Head Home (2008). Stone interviewed high-achieving professional married mothers from the fields of medicine, law and finance in order to discover 
their reasons for leaving the workplace. We were routinely shown statistics concerning working and stay at home mothers, and these were often used as the basis for social policy family initiatives, but little research had given these women a voice to explain or explore their decisions. Stone commented that our limited understanding of these women was based on popular media stories that followed a predictable set of tropes starting with the professional women who had devoted many years to her public success (making sure to mention the supportive employer who happily accommodated family and work responsibilities) and concluding with the notion that motherhood was the most important and most rewarding job in the world. Along this journey we were reminded that children were a blessing and that the once high-powered woman now wanted to spend more quality time with her offspring. Stone questioned this recurring narrative, and asked herself, if the company was so supportive of family friendly policies, why then were these women leaving rather than reducing hours, considering job shares, working to flexible contracts or working from a home base.

The new and recent mothers that she spoke to made it clear that although they wanted a personal and professional life balance, the reality of the work environment and social support systems made such a balance improbable. These women were not leaving to save face for being dismissed from the workplace, nor were they leaving to embrace the 'new traditionalist' role. Rather, Stone made the point that these women were less choosing to leave the world of work and more being pushed towards the domestic context by an inflexible corporate structure, ineffectual social policies and unhealthy cultural expectations. While these women may have spoken about their decision to leave the world of work to take up a full-time maternal role in terms of choice and privilege, the 'stories they tell reveal not the expression of choice, but rather the existence of a choice gap, a gap that is a function of a double bind created primarily by the conditions of work in the gilded cages of elite professions.'These women were unsuccessful in seeking flexibility and found themselves marginalised in what was understood as their 'full-time plus' working role. On leaving then, these women went on to face a crisis of confidence and loss of direction, however rewarding their maternal lives (Stone 2008). 
While Stone pointed to a lack of gender equality or parental flexibility in the professional workplace, Rebecca Asher has more recently conducted detailed interviews in order to examine notions of equality in the family. On the back of these accounts, she suggested that women may well outperform men at school and university, seek professional careers on the back of their educational successes, and demand equality from their chosen partners, but went on to say that any semblance of equality was destroyed when the wife or girlfriend became a mother. In Shattered: Modern Motherhood and the Illusion of Equality (2012), Asher echoed existing work as she discovered that women continued to be held responsible for childcare, at the expense of their social, sexual and professional lives, with little resistance to the traditional nurturing role that underpinned accepted notions of family.

Asher drew on accounts of parenting in and beyond the UK and uncovered the ways in which antenatal care, maternity leave, parenting manuals, work practices, relationship dynamics and childcare costs each contributed to the unequal status of mothers and fathers in society. Like many writers before her, Asher's interest in this subject and her ability to speak to men and women about their parenting roles and responsibilities stemmed from her own biography. Asher spoke of her own personal and professional experiences, and highlighted her shock and anger to find that what she assumed to be a position of equality in her domestic arrangements was in fact a thin veneer, revealed as such after pregnancy. One might suggest that Asher's research was an attempt to discover whether her private experiences of traditional domestic roles and the unexpected return to a conservative family agenda was confined to her own experiences, or if it commented on a wider inequality. The age-old feminist adage that the 'personal is political' underpinned much of the work outlined here, with motherhood studies being dominated by not only women and feminist writers, but also mothers and professional childcare experts. While theorists such as Wolf (2002) and Asher (2012) were candid about the ways in which their own maternal experiences had impacted upon their professional research practices, Gina Ford used her decade-long experiences as a maternity nurse to advise parents about the importance of order and routine for their babies and toddlers. 
Ford played an important role in the cultural construction of appropriate motherhood, penning volumes such as The Contented Little Baby Book of Weaning (2006), The Complete Sleep Guide for Contented Babies and Toddlers (2006), The Contented Baby's First Year (2007) and From Crying Baby to Contented Baby (2010) to name but a few of her titles. However, Ford has more recently contributed to the field of motherhood studies by speaking to hundreds of women both in person and via her popular website, ContentedBaby.Com during her research for Good Mother Bad Mother (2013). There was little written here in terms of feminist approaches or media studies methodologies, after all Ford was writing as a leading baby and childcare expert rather than someone grounded in the conventions of the social sciences. And yet, in line with extant literature from the field of motherhood studies, her research spoke to each of these fields as the author gave voice to existing mothers throughout the volume, interweaved with stories from her own childhood.

Ford pointed to changes in motherhood and motherwork over the last four decades, discovering that for those women who choose motherhood, their decision 'to sacrifice freedom, time and money in order to become a parent has made the desire to get it right more acute than ever' (Ford 20I4). The author acknowledged the challenges faced by contemporary mothering and suggested that despite the wealth of often well-meaning parenting information, many women continued to feel overwhelmed by the responsibility of making childcare decisions in the face of conflicting advice regarding feeding, weaning, routines and work. These women revealed that they felt isolated as mothers for fear of a maternal judgement that saw Everingham, Miller and Wolf's participants' self-censure. Ford relayed the candid views expressed by a diverse range of mothers who had given up careers, those forced back into the workplace, those struggling alone with new babies and those enjoying their newfound maternal role, with stories sharing tales of friendship and intimacy, rejection and bitterness.

Ford made the point that there was no such thing as a 'good' or 'bad' mother, simply differing maternal styles and motherwork practices. Ford asked mothers to accept and respect maternal differences and focus their attention not on judging other women, but in lobbying the media, employers and government to improve the lives of women and children. Ford is 
a controversial voice within and beyond the field of self-help literature, parental networking sites and motherhood studies and yet, like many of the authors introduced here, she was reflexive about her own childhood and her professional experiences in her work on the maternal. This brings us full circle to the founder of motherhood studies, Ann Oakley, as she commented on her own work and the wider research agenda in and beyond the field of motherhood studies. She informed us that, 'in the vast majority of cases, the choice of research topic amongst social scientists reflects a mixture of the personal and the professional' (Oakley 2013).

Tamara Mose Brown and Erynn Masi de Casanova went one stage further than those researchers who choose to study motherhood on the back of their newfound maternal status. Their research was dedicated to examining and potentially exploiting the maternal status of the social scientist in ethnographic studies involving women as mothers. For those researchers who are mothers, we are told that 'engaging in ethnographic fieldwork with women provides a unique opportunity to analyse the effects of motherhood in the research process and relations with participants. They went on to suggest that the 'lens' of motherhood could be utilised to enrich ethnographic accounts by reflecting on the multiple role of the maternal researcher and by building a rapport between participants and researchers.

Feminist scholars have long put forward the idea that female researchers studying female participants, lend themselves to a more open dialogue, allowing for a deeper understanding of social issues, and yet, Brown and de Casanova more recently suggested that motherhood 'humanizes the researcher in ways that are not always disclosed in academic writing, even in ethnographies that reflexively analyse the researcher's class/racial/gender identity. Their article was a reflexive analysis by two ethnographers whose status as mothers became an important component of studies of working women in Guayaquil, Ecuador, and Brooklyn, New York who found that motherhood provided a 'different type of access to participants' and affected the way that people in the field reacted to a researcher and her work.

The researchers/mothers commented that 'the language of motherhood coloured many conversations and interactions' and spoke of the times when their maternal status left them feeling 'like a participant' rather than the professional ethnographer. On occasion the line between mother and 
ethnographer became blurred, for example when one author admitted that she was putting on a maternal performance in light of what she believed was expected from her participants and for 'fear of being inappropriate in their eyes and having them lose respect for [her] as a mother'. Social scientists are trained to write in an impartial, objective and scientific voice, but these researchers sought to debunk the fiction of objective social science research by striving towards transparency and 'an integration of the authoras-researcher with the author-as-mother' (Brown and de Casanova 2009).

If we are to look to motherhood studies beyond the framework of film, television or media studies research it is clear that a number of feminist and social science researchers are keen to speak to mothers about their maternal experiences through a range of qualitative techniques, including those interviews, questionnaires and focus group discussions employed within media studies and its surrounding disciplines. Such research offers useful and significant insights into the lived reality of pregnancy, new motherhood and the reality of combining paid professional work with maternal commitments. However, research to date says little about the ways in which women respond to representations of motherhood, motherwork and the maternal role in the media environment, or about the ways in which these maternal depictions inform or challenge their own maternal choices and motherwork practices. In this way this book hopes to uncover some of the ways in which women think about their own maternal thoughts and feelings in relation to those popular televisual representations that dominate the media landscape.

\section{What, who and how to ask: Qualitative questioning}

Research already exists to account for the myriad of maternal depictions that exist on the small screen and beyond, and although this research is a crucial starting point for an understanding of the ways in which society might come to make sense of motherhood, it tells us little about the ways in which mothers in the audience read and respond to these maternal representations. 
Theorists such as Radway, Stacey, Oakley and Gillies made it clear that academic interpretations and 'knowledgeable' readings can be, and often are, at odds with more populist responses, and as such I was keen to discover the ways in which mothers in the television audience experienced pleasure, identification, frustration and disappointment as they watched their maternal counterparts in a range of fictional and factual programming.

Extant literature draws on an impressive range of data collection methods and approaches including questionnaires, semi-structured interviews, participant observations, focus group discussions and the text-in-action approach, and it is clear that each author has spent substantial time and energy considering the implications of each approach in relation to their chosen research proposal. So too, I have had to carefully consider the ways in which I looked to speak to women in the audience about their social and maternal status, viewing preferences and responses to representations of mothers on screen.

As research in the field of qualitative data gathering and audience studies recommends, I considered the use of face-to-face interviews, telephone surveys, focus group discussions and text-in-action observations, paying attention to the ways in which social media and network sites such as Twitter might be useful in relation to debates over participation, convergence and interactivity. Although I do not want to spend the entirety of this volume outlining the stages, strengths and limitations of individual and differently combined methods and approaches, I will give a very brief outline for readers uninitiated in research methods and point to further resources should they be inclined to discover the historical and theoretical specificity of qualitative data techniques.

\section{Questionnaires and surveys}

The questionnaire, as used by Larson and Stacey, is a popular and longstanding media research method that can, in its various guises, standardise the collection and processing of information so that set questions can 
be asked to a large number of people from the relevant demographic. In this way, the questionnaire is understood as a useful method for finding out about individual opinions attitudes and behaviour. However, there are a number of ways in which one might employ this particular method, ranging from closed questioning if one requires factual information and more open-ended questions if one is keen to engage respondents' opinions at length. Questionnaires then are flexible and can be used effectively for both the large-scale social survey and more qualitative methods of research. The self-completion questionnaire has become popular of late, in part due to the emergence of sites such as Google Forms and Survey Monkey. One might consider this method as the forms are relatively simple to compile, cost effective and can be used to garner information from a large population sample. And yet, even though self-completion questionnaires, be it on paper or online, are easy to post physically and electronically, respondents might seek help, advice or contextual information which is not to hand, and as such, completion rates tend to be low. With this in mind, researchers might look towards either telephone surveys or face-to-face questioning in order to increase completion rates from their chosen population.

Telephone surveys are rarely used in contemporary media research even though they have some obvious advantages in terms of ease of administration and cost-effectiveness. However, due to the very real possibility of phoning at inopportune times, it is advised that researchers looking to use this technique write to the respondents in advance, possibly weeks in advance, in order to introduce themselves and perhaps arrange a mutually convenient time to ask their set questions. That said, this can only be considered for those surveys where contact details can be chosen in advance and with parties interested enough to respond to the written request. Moreover, existing literature highlights some of the limitations of this method when it comments on the lack of personal contact and the ways in which potential respondents might be dubious about both the research and the researcher in an age of telemarketing and cold-calling (Hansen et al. 1998). With this in mind, it is important to understand the opportunities that arise from the face-to-face interview method. 


\section{Interviews and focus group discussions}

The interview is a useful technique for gathering detailed opinions as they relate to the mass media, and theorists such as Oakley and Press have utilised this particular approach in their work. Interviews are a flexible method as the researcher has control over the structure of the interaction and because it allows them to change the direction of the dialogue in response to comments presented on the back of a tentatively worded set of questions outlined in the interview guide (Priest 2010). Oral history interviews follow a similar pattern to the traditional interview, with participants often being referred to as the narrator rather than participant or interviewee because this technique encourages individuals to talk about their lives. While the traditional interview sees the interviewer in control of the process, however adaptable and flexible that process might be, the oral history interview shifts this dynamic in order to 'allow the narrator to take the interview in the direction he or she wants to go' (Brennen 2012). This process demands time and emotional commitment from both interviewer and narrator, because unlike the interview technique, the relationship between these parties is crucial and depends on a rapport being allowed to develop prior to the first recorded oral history. Although some have questioned the reliability and credibility of such in-depth interviews, the goal here is less about uncovering truth or fact, but rather about trying to understand emotion, meaning and feelings. That said, there are of course limitations with both the traditional interview and the oral history approach. On a practical note they demand, like the telephone survey before them, scheduling at a time of mutual convenience and in the case of the oral history, the arrangement of several sessions over any given period. The strength of these techniques over the telephone survey method is that it allows for face-to-face contact which goes some way towards negotiating any tensions regarding authority and authenticity that might exist in the previous method.

If one is looking to speak to participants directly then researchers usually have to make a choice between single person dialogue or group 
interaction. The focus group technique is credited with presenting the most 'natural' setting for the participant, based on the idea that the ways in which we understand the media and make sense of our relationship with it usually takes the form of a discussion in a social setting, which the focus group seeks to emulate. That said, there are clear difficulties in acquiring shared group permissions and a schedule to suit numerous participants. Moreover, one must consider the necessary preparations regarding the dynamics of each group and the formulation of a menu of topics that will engage all participants in discussion. Furthermore, the role of the researcher becomes that of the moderator in this more social setting.

Although the focus group might be commended for its group dynamics, it is these self-same dynamics that are seen as the possible limitation of the method. If one uses the interview technique it avoids the predictable consensus associated with group discussions whereby a single voice or opinion comes to dominate an initially divergent group due to individual members speaking vocally, eloquently, at length or all of the above. If one is interested in group dynamics but fears the very real possibility of these group interactions morphing into the enthusiastic reasoning of one or two members of that group, then it might be worth using self-selecting groups, small numbers of individuals who are related, work together or attend the same social groups for example so that they are comfortable and thus conversant in the company of one another, helping to alleviate the differing dynamics of more random group sampling. Indeed, these 'naturalistic' discussions can draw out complexities, nuances and contradictions, or promote what is referred to as a 'memory synergy' among participants whereby the social nature of the setting can encourage efforts to bring forth the 'collective memory' of a particular group (Kamberelis and Dimitriadis 2013). Furthermore, depending on the project in question, one might look to combine the self-selecting nature of the focus group with the comfort and convenience of a domestic setting, so as to further encourage the 'naturalness' of the group discussion as routine in more ethnographic approaches. 


\section{Observation, ethnographies and netnographies}

Ethnographies demand that researchers observe, talk to and interact with people in their natural environments, be it where they work, socialise or their domestic space in order to 'learn about the explicit and tacit realms of their experiences, routines and practices' (Brennen 2012). For those projects where a form of participant observation is crucial, this seems a useful addition to the methodological choices currently on offer within the fields of media and motherhood studies. The technique has clear time and timing implications for both researcher and participant but it is without question the most natural setting for the person or group being studied.

Researchers have recently started to look to new media technologies in order to conduct ethnographic studies online, or what have become known as netnographies, with self-selecting groups and professional networks. We know that 'people with similar interests, values and beliefs create virtual communities in an effort to identify and bring together like-minded people to hang out, discuss issues and topics, and coordinate activities' (ibid.), and these online spaces can be examined in order to gather audience reviews, commentaries and communications. Theorists in media and gender studies have looked to the blogosphere as a way to understand media audiences and relationships between audiences and texts beyond predictable fan sites or pedestrian celebrity authored pages, with fascinating work existing on the growing number of memorial (Ibrahim 2010; Christensen 2010) and infertility weblogs (Striff 2005) that have appeared in recent years. Such netnographies share similar characteristics with simple observations in that the researcher takes a 'fly on the wall' approach to their subject and participants, participants who remain unaware of the researcher's activities (Deacon et al. 1999).

Online criticism, commentary and conversation can be easily and inconspicuously observed, and as such, it can be seen as a contemporary extension of earlier observational methods. For example, existing work seeks to explore the potential of social network sites such as Twitter as locations 
for audience research in relation to examples of those who both engage with and in some cases create the news and television commentary (Deller 2011). Twitter has become a commonplace communication forum since its emergence in 2006, with those who utilise this network communicating via 'tweets' or messages of $\mathrm{I} 4 \mathrm{O}$ characters or less. This micro-blogging website can be understood as part of an academic debate concerning interactivity and participatory cultures that has emerged in recent years (Jenkins 2009; Couldry, Livingstone and Markham 2009). The 'style and content of tweets varies from simple link sharing or retweeting with little to no commentary, to one-to-one conversation, to talk between a small number of users engaging in direct address', with the most popular tweets taking the form of one to many conversation (Deller 20II). With this in mind, Twitter alone offers researchers a wealth of opportunities for making sense of audiences, consumers and prosumers, and the links between them in the contemporary media marketplace. Research drawing on such social networking sites could choose to monitor hashtags or keywords, it might look at the changing and in flux 'trending topics' in relation to a broader social, sexual, political or entertainment arena; alternatively, it might look to a more detailed examination of interactions between specific users, or the relationship between a celebrity (be it a person, programme or paper) and their followers. Using Twitter in audience research can help us locate zeitgeist media moments and understand public responses to real-world events and news stories as they happen (ibid.).

The anxiety here is that much of what appears on Twitter is about performance, by way of usernames, avatars, twibbons and humour, and researchers may want to look beyond such deliberate role-playing to examine attitudes, beliefs, opinions and behaviours that may be exaggerated or overlooked in such real-time social networking sites. However, as Ruth Deller rightly argues, 'Twitter marks a potentially significant development ... for anyone interested in studying the media, studying the way "audiences" and celebrities, producers and media professionals now interact [after all] it provides instant access to people who are often happy to communicate their thoughts and feelings in an articulate and succinct way' (ibid.). 


\section{Choosing media methods and finding maternal audiences}

The aim of my research was to gather information from mothers about if and how they watch depictions of motherhood on television and, where possible, if they would talk to me about their pleasures and frustrations, role models or negative responses to particular maternal figures. On the back of the work outlined here, I am aware of the importance of choosing the most appropriate research method, not simply in terms of general pragmatic, practical concerns relating to time resources, economic factors or research ethics involving human participants, but in relation to the appropriateness of the method for garnering meaningful information from a broad demographic of mothers in the television-watching audience.

Interviews were ruled out due to the class-based concerns encountered by Skeggs, Thumin and Wood and telephone surveys for this same reason. Focus group discussions were discounted next due to the bias of voices heard in a group setting as discovered in Jackson, Stevenson and Brooks' research. The text-in-action approach provides an important and as yet, little seen way of unmasking audience readings and responses to specific entertainment texts, and yet, as it is not my intention to set the television reference points for this research, such observation is not without problem here. Moreover, what all of these options had in common was the logistical difficulty and organisational challenge of women who were busy with childcare and in many cases other personal and professional responsibilities, trying to find a time and place to meet with either myself or myself and others. Although I could meet these women at a pre-arranged work or social setting, plans change due to the changing demands of employers and dependents. And although technologies such as Skype and GoogleHangOut allow a little more spontaneity for interviews and groups discussions, time constraints still existed on both sides. Indeed, when I first proposed face to face (or their online equivalent) meetings with mothers in the initial stages of the research plan, the overwhelming response was that these women would simply not have the time to take part in discussions, and, to a person, they 
commented that they were 'too busy' or could not specify a scheduled meeting slot in advance, irrespective of their interest in the project.

With this in mind I decided to pursue the questionnaire as the most credible mode of study for my research. This is not to say that the questionnaire is not without its limitations; indeed, all of the methods and approaches pointed to here have strengths and weaknesses irrespective of the ways in which they are utilised within any given research project. Rather, on consideration of all available audience research options, the questionnaire appeared to be the most appropriate for my purposes. Although questionnaires have historically been conducted in person, with the researcher talking participants through each question and answer option, as a sole researcher seeking to make contact with significant numbers of mothers across a range of social, sexual, class and geographical locations, it became clear that due to the logistics of the proposal, the questionnaire would have to take an online form. This enabled those women who were 'too busy' or those without a predictable schedule to complete the form at their convenience without having to plan or prepare, travel or juggle responsibilities. This is not to suggest that the online questionnaire was the only or best way to conduct my research, but in terms of the time, cost and sampling implications, it became the most desirable method available. I am being candid about my choice of approach here, because although it is possible to present a narrative that suggests that the online questionnaire is the only suitable option for gathering the required data for my research, such partial reporting ignores the fact that 'compromises are an essential feature' of any research project (Hansen et al. 1998).

Online questionnaires are a popular way to explore opinions and interrogate contemporary behavioural patterns, but without the face-to-face contact with potential respondents, it was crucial that the number, ordering and wording of questions was considered carefully. The first attempt included too many questions, the second attempted to offer too few, but within each of these there were then sub-questions, and both were, on reflection, trying too hard to gather every detail concerning viewing habits, character and programme preferences and then a breakdown of maternal readings through genre categories. The form relied too heavily on closed 
questions and drop-down lists in order to garner what I hoped to be useful data from respondents, without encouraging more detailed responses or providing greater space for more considered observations. Media method textbooks routinely remind us that questionnaires must be fairly short with a limited number of questions so as to prevent interested respondents giving up part way through a lengthy and arduous set of enquiries (ibid.), and therefore, after several further attempts at adding, excluding, re-ordering and re-wording individual entries, I ended up with some questions that I felt I had to include, many I wanted to include and several that I felt that I ought to include, with space given to incorporate basic socio-demographic data.

\section{About you}

The 'About You' section of the form asked participants to provide details of their living, marital, employment and job status, age, ethnic group and number of children, and yet, even though this section of the questionnaire did not seem particularly demanding to produce or time consuming to complete, it remained a significant and yet difficult section for many reasons.

It was crucially important that when looking at the comments and responses of completed questionnaires I was able to draw conclusions on the back of age, socio-economic, ethnic or marital differences if relevant or appropriate to the findings. If teen mothers respond differently than their more mature counterparts or if single mothers speak of alternative pleasures and frustrations than married or co-habiting mothers then this makes for relevant data to be explored and presented. Differences and similarities, contradictions or a consensus between biological, foster, adoptive and other mothers is also crucial to this discussion, and it would have been to the detriment of the project to not seek out this information. However, I am fully aware that what seems like basic demographic details are fraught with potential upset and anxieties for the individual. Being asked to identify themself as a teen or more mature mother may be asking more than to simply tick a box, but could lead to introspection about their marginalised maternal status. So too, asking about marital status may be difficult for anyone who has been recently divorced, widowed or considering leaving the 
family unit. Moreover, asking someone to reveal their status as a biological or alternative mother may lead to feelings of regret, failure or inadequacy for those who have chosen not to, or who are unable to conceive, or who have aborted, miscarried or lost a baby. By asking women to differentiate themselves as natural or other maternal figures, I could be seen to be adding to the unconscious weight of a society that upholds biological mothering as the appropriate and ideal form of maternal care. Indeed, providing an answer to the question of maternal status might in itself be problematic for some recent mothers who have looked to assisted reproductive technologies, where donor eggs and a gestational surrogate is used.

It was certainly not my intention in gathering this data to cause upset or offence to any mothers, but after much moral, ethical and practical considerations, I felt that it was important data that could be invaluable to this and future research. However, the participants were not obliged to complete this section of the form, and were able to skip such maternal and marital questions and still send their responses without such personal details being revealed. It is worth noting of course that all of the responses are anonymous - neither myself nor anyone looking at the book will be able to tell who these women are, and their responses will only be recognisable to themselves should they wish to read the work and compare it with their original contribution to the questionnaire. And such anonymity is made clear to the participants in the polite request for their time and in the questionnaire itself.

In terms of questions regarding age, ethnicity, employment and job status I looked to relevant professional bodies for clarification of classification. For example, in terms of age, I looked to a range of standardised survey classifications for their breakdown of age groups (Gerstmann 2014); for employment details, I looked to the Office for National Statistics and the ways in which they categorise different unit groups based on similarity of qualifications, training, skills and experience commonly associated with the competent performance of work tasks, ranging from Managers and Directors to what they refer to as Elementary Occupations (ONS 20I4a). And likewise, I used the ethnic classifications set out by the Office for National Statistics as they 'recommended when a show card is used in a face-to-face interview or self-completion survey' (ONS $2014 \mathrm{~b}$ ). Although 
completing this section may not appear problematic, there are of course still concerns here relating to people's social and class perceptions perhaps not mapping onto extant employment categories, creating friction or frustration at the end of the questionnaire. However, it was important that I not only included them here, but used recognisable and credible classifications for such data to add rigor to the research gathered and to avoid any oversights or unintended bias to the classifications included.

\section{Questions}

The phrasing of each question might seem a modest task, but in reality, trying to word each question in a way that was accessible to all potential audiences was difficult, not because I was using impenetrable theories or committed to dense academic conventions, but simply because I struggled to phrase the questions in an open, engaging and impartial manner. Giving participants enough detail in the question so that they could fill in the form in a way that provided relevant and meaningful information was difficult without actually pointing them to particular characters, programmes or case studies. Although it was of course tempting to ask them about specific texts, on-screen personnel or pre-selected family structures, this seemed problematic. The point of this research was to find out how the maternal audience responds to images of motherhood, images that they define, outline and comment on. For me to provide characters and case studies here was inappropriate considering the aims of the research, and as such I looked to gather feedback on the questionnaire. My aim here was to present the voice of the audience, not to limit, frame or curtail discussion from the outset.

I piloted the form amongst colleagues and a broader set of co-workers, friends and acquaintances outside of the academic environment in order to assess the use, ease and appropriateness for a diverse audience. Indeed, it is commonplace to 'administer several rounds of questionnaire testing [in order to] identify ambiguous questions or those respondents find hard to answer' (Priest 20IO). On the back of constructive feedback, I included 
guidance and helpful commentary under each question in order to assist the participant in answering, not in a way that leads their answer or prompts a particular response, but rather, to offer a frame of reference and supporting context for each question posed.

Rather than just post a questionnaire in isolation, it was important that in the absence of personal contact with respondents, the questionnaire be situated in a broader website that introduced my professional role and responsibilities, details of past research within the fields of gender and popular media culture and information relating to the motherhood research that I was embarking on. What I hoped to have achieved here was an accessible and informative site for those who were considering completing my questionnaire, demonstrating the authenticity of my professional role, the relevance of the research, the importance of their voice to the debate, a broader set of references and resources for any parties interested in pursuing their own reading, and my contact details for those individuals or organisations who would be interested in follow-up discussions and continued dialogue. The final website, entitled 'Mothers on Mothers: Maternal Readings of Popular Television' offered a welcome, details about myself as the researcher, an overview of the project, information for participants, the questionnaire itself and further follow-up resources (Feasey 20I4b).

I am not claiming to have obtained a representative sample of the population; rather, my research is based on a self-selecting sample of mothers who took the time and effort to familiarise themselves with my work, read the questionnaire and respond (in most cases, at length) to the questions posed. I am aware that many mothers will be excluded from expressing their thoughts in this context due in part to the very real digital divide in this country whereby 17 per cent of households do not have access to the internet (ONS 2013a), and beyond that, there are issues relating to time pressures and competing demands on those women whom I might want to contact. But I have been rigorous in my question selection, reflective throughout several pilot stages of the questionnaire and careful to speak to those organisations that were in a position to help me to reach the relevant maternal population.

In order to gather rigorous and relevant data it was important to reach as many mothers as possible and as such I compiled a list of useful 
contacts ranging from friends and extended family to charities, social media groups and governmental organisations. In the first instance I contacted all Bath Spa staff and students and requested that the mothers in that group consider completing the form, then relying on the snowball technique whereby these women then contacted their extended friends and family networks in person, online and through social media such as Facebook. I then requested that colleagues present this request at a number of other institutions across the UK, including Manchester, Winchester, Leicester, Chester, East Anglia and Bournemouth. After exhausting my personal and professional contacts I spoke to a broad range of organisations which were responsive to my request to post details asking for mothers in their audience to familiarise themselves with the research project and then complete the short questionnaire. I made it clear here and throughout this stage of my research that the work was non-commercial and that all responses would be anonymous and treated in confidence in order to further encourage participation and engagement with the questionnaire presented.

Details of my research and a request for respondents appeared on a range of local motherhood themed social media groups such as Bath Mums (Feasey 20I4c). Bath Mums is one of many local online maternal support groups that have been set up by volunteers and sustained by local advertising revenue. Bath Mums is a free, open and candid social media hub full of information about schools and nurseries, activities to do with children ranging from the baby years to teenagers and parental recommendations in the South West region. Sites such as these are seen to offer emotional and more practical support from parents to parents with no pre-existing political, religious or other agenda. Such online communities are freely available to those with computer access and inclusive of all mothers and grandmothers in terms of class, age, race, sexual preference and lifestyle choices. These maternal sites stood out as useful spaces in which to advertise my research request. Likewise, Netmums (Feasey $2014 \mathrm{~d}$ ), the central resource for a number of different local online support groups kindly agreed to my request, so too, did Mumsnet (Feasey 2014e). Mumsnet was one of the first, and is now the most far-reaching and visible support network for parents. Since its emergence in 2000 , the site has sought to make 'parents' lives easier by pooling knowledge, advice and support' with limited 
moderation or censure (mumsnet 2014a). The site now generates over 60 million page views and over Io million visits per month, and for a small fee I was able to speak to this maternal audience through their dedicated media request page. Due to the high traffic on these local, regional and national sites, it is naïve to assume that I would be speaking directly to or receive responses from the whole population of users, but even a miniscule percentage of those women who look to these pages for advice, support or company would provide invaluable data for this research project.

I then spoke to a local nursery chain covering the Bath and Wiltshire area who posted details of my research project on their award-winning website, their monthly magazine and gave out flyers to interested mothers as they came in and out of their nurseries over a period of several weeks. Although one might talk about the limited reach of this avenue in comparison with online maternal networking sites, the enthusiastic and personable introduction to the research project by known and trusted nursery staff made this a valuable and perhaps indeed, the most productive way of capturing interested mothers. The request foregrounded not only my academic status and affiliation but also my personal interest in the project as a way to connect to those mothers who showed an interest in participating in person or via my website.

I also publicised the research project and my request for participants on Media Parents, a website and organisation which seeks to situate all of the short-term, job share and part-time media employment in one place to 'help freelance working parents or anyone who wants to work flexibly to balance the demands of media and other commitments, and to make it easier for employers to find this highly skilled and experienced part of the media workforce' (MediaParents 20I4a). The site tells us that 5,000 women left the television sector alone over the last three years, and it is clear that there is a link between these numbers and the amount of women becoming mothers in this environment, a sector well known for its unsociable hours and lack of routine family-friendly policies (Dent 2013; O'Brien 2014). The website puts over 700 employers, freelancers and networkers in contact with one another, and many creative employees are women seeking flexible contracts that enable them to spend quality time at home while maintaining a professional career. Indeed, the testimonials currently published on 
the website make it clear that not only is work in the creative industry at odds with the domestic routine of parenting but that this discord is actually preventing people from starting families for fear of what they see as an impossible work-life balance:

I just want to say what a fantastic job you've done setting up this much needed site!! I'm not a parent yet, as I've been putting it off and putting it off, because I was worried about finding flexible work hours and still making an ok living. (Media Parents 2014b)

Worried, with reason, as another commentator on the site tells us of the perceived reaction to motherhood in the creative sector and the working routines associated with television production. We are told that it has 'been tough getting back into TV since having my son 9 months ago as I can no longer accept jobs that require you to be working very unsociable hours' (ibid.). Other voices echo her very real concerns here:

Being pregnant was a difficult enough adjustment, so not having felt confident enough to apply for broadcast roles, anticipating a negative reaction to 'the bump' even when it was a very small one - hasn't made me feel especially bright about the future. (ibid.)

I worked bloody hard to carve myself a career as a drama script editor, so hard in fact that by the time I got my first script-editing job I was reaching prime baby making age. Once my first child came along there was no way I could fit the expected long hours around child rearing, and so I've had to say goodbye to both my income and my career hopes and dreams. It seems so short sighted of companies to lose talented women (and men) in this way. Within drama production, especially long running series, there's a culture of working long long hours - you get to prove yourself by staying up all night working on scripts and taking them home at weekends. Surely it's common sense that employees will give better quality work if they are happier and can balance work with other parts of life. Why burn people out and send them away exhausted and half crazy when you could respect employees' needs, get them trained up to do the job just right, and keep hold of them for years? (ibid.)

One member refers to her children as her 'dirty little secret' (ibid.) and wonders at what point in networking opportunities does she bring up the fact that she has children in order to both explain gaps in her professional career and to foreground her need for flexible working. Although several 
members go on to thank the professional networking site for its role in finding them flexible employment, the problem of finding harmony between the public and private realm remains for this and other sectors.

After discussions with the site editor, I was asked to write a short 's minutes with ...' about my interest in representations of gender and my current project on maternal audiences, with the intention of drawing further attention to my research request for participants. I noted my desire to introduce undergraduate students to the media theory behind and the wider socio-political context that informs our understandings of contemporary gender roles before explaining my research narrative through masculinity studies to motherhood in the media, drawing attention to my personal and professional profile as it relates to my interest in motherhood and motherwork in the media. I made the point that although I have spent my entire professional life researching the representation of gender in a range of media genres, texts and mediums including the representation of male friendship in the situation comedy, fatherhood in the crime drama, the role of sisterhood in teen television, the importance of gossip and star styles in celebrity gossip magazines and the notion of female ageing in relationship to contemporary Hollywood performers, I had shown no academic or pedagogical interest in representations of or responses towards motherhood in the media ... and the next part is of course incredibly predictable. I went on to note that '... I became a mother, and soon after I came to the realisation that although my research to date had been interesting, relevant, or (on the rare occasion) both, it was crucial for me to rethink what was important about gender and the media' (Media Parents 2014c).

In order to reach a different employment market I contacted the Environment Agency in their position as a large government quango with a reputation for family-friendly policies and flexible working patterns for employees. The Employers Network for Equality and Inclusion talks about the Environment Agency's Women's Network, and its attempts to 'encourage, enable and equip women to achieve their full potential in the workplace' (ENEI 20I4). On the back of this initiative the network has created a job share register, whereby the CEO and Directors have agreed that all roles within the agency are eligible for a job share, with Director-level approval needed if someone believes a role is not suitable. Details about 
my research was posted on the Environment Agency Women's Networking 'Community' which reaches 1,300 members and friends of the group, and what is worth noting here is that the publication of my request was positioned above a piece from the Diversity Confidence Programme entitled 'Taking a "Yes if" Approach to Flexible Working', which gave details of flexible working roadshows being held around the country in that week to help make such working patterns successful for staff and managers alike.

Details about my research and a request for mothers to complete my questionnaire was later posted in a National Childbirth Trust newsletter, with a potential reach of 100,000 members over 300 branches (NCT $2014 \mathrm{a}, 2014 \mathrm{~b}$ ). The NCT is a UK-based charity offering information and support in pregnancy, childbirth and early parenthood, and although there have been many changes to the charity since its emergence in the 1960 , it remains committed to ensuring all parents-to-be and new parents feel supported, informed and confident' (NCT 2014c). And again, although I cannot demand or assume that all members will be interested in or have the time or technology available to complete my questionnaire, having the potential audience of several thousand mothers must be seen as a rigorous and relevant point of contact for my research.

I have spoken elsewhere about the middle class bias of mumsnet, and even a cursory glance at the threads, news and reviews makes it clear that those women who look at and contribute to this site come from a position of privilege (Feasey 2012a), in many cases reflecting the ideology of intensive mothering and the appropriate face of the 'good' mother, or seeking advice in order to help them situate themselves in line with this romanticised figure. With this in mind one might assume that those mothers who completed the questionnaire after seeing the details posted on the Media Hub on this website are positioned in the middle classes. So too, those respondents who have found my questionnaire by way of the Ofsted Outstanding nursery chain, Media Parents or the Environment Agency might also be assumed to reside within the comfortable classes. While an Ofsted Outstanding nursery chain does not exclude working class families, the cost of such childcare outside of those hours subsidised by the government for three- and four-year-olds does prohibit those on lower incomes. Media Parents and The Environment Agency, although 
interested in different skills and competences in their employers, are both interested in trained professionals, again suggesting a level of formal education or industry experience that hint at another middle class bias. So too, the National Childbirth Trust comes with perceived and real middle class connotations in terms of membership. Indeed, one NCT member tells us, only half jokingly that 'Everyone knows [joining the NCT] is a way to pay a reasonable amount of money to meet other nice middle-class parents' (Yee 2013). Although it is easy to mock economically advantaged parents who, in no particular order, buy a Bugaboo, join Mumsnet, order the Boden maternity range and sign up for NCT classes, the more serious issue here is that 'a two-tier antenatal system is emerging, where less well-off women have little access to the advice and support so crucial for first-time mothers' (Rock 20II). After all, 'new figures show that there has been a boom in the number of women paying around $\$ 200$ to attend a course of private NCT sessions - a jump from 25,000 in 2005/6 to 40,000 in $2010 / \mathrm{II}$ - while the provision of free NHS classes in austerity Britain is increasingly patchy' (ibid.).

There is unquestionably a middle class bias to many of the organisations that I have spoken to about the project, and yet I have tried to counter this by spending time talking to a more diverse range of mothers at Children's Centres and informal play meetings around the South West region. These were not formal interviews and no set questionnaire or schedule was followed; indeed, I was attending these sessions as a mother with young children during a period of maternity leave, weaving my research interests into numerous conversations about motherhood more generally. It was not my aim to observe these mothers nor to note their parenting strengths or strategies, but rather, to talk to them in a comfortable environment about the mothers who they watch on television, their reasons for watching these figures and any demonstrable links between those images and what they see as their own childcare practices. I was entirely open about my research project and was upfront about my interest in talking to them about the topic of motherhood and the media; my aim in visiting these organised play sessions was simply to speak to a myriad of mothers in a conversational way in a natural and comfortable setting so as to elicit their responses beyond the questionnaire. One might suggest that this informal technique should 
take the form of the dominant methodological approach for this research due to the personable nature of the questioning, but balancing the maternal role with relevant questioning proved more difficult than expected. In order to appear as a maternal ally rather than what Everingham refers to as a 'detached outsider' (1994) it was important to attend these groups as a mother with young children, but the reality of attending a playgroup with those who actually want to play means that you cannot fully focus on adult conversations, let alone academic questioning. In this same way, women's responses, although generous, were not given serious thought or consideration as their attentions were divided here. In my experiences then, talking to mothers in an informal play setting was an incredibly valuable exercise that provided meaningful responses, but, as Everingham and others who not only observe play activities, but who actually go as far as joining in with such activities tell us, it is not always possible for either researcher or respondent to commit fully to the conversation (1994). Although this may be less of a problem for some studies, I was interested in getting these mothers to think about their television viewing in a way that they have perhaps not done so previously, and as such, an ability to fully focus on the conversation would have proved fruitful here. Therefore, while Everingham followed up her playgroup observations with more formal semi-structured interviews, I looked to the questionnaire in order to secure relevant and meaningful data for this research.

That said, although I was initially concerned about the middle class bias to this research in terms of where I presented my questionnaire and how I sought to gather information from respondents, the responses that I have received demonstrate a reasonably balanced demographic in terms of age, ethnicity, employment and family structure.

In terms of presenting the words, thoughts and voices of the mothers who generously took the time to read and respond to my questions, in many cases, at length and in great detail, to make it clear where their words are being presented, these sections will be in italics throughout the volume, with comments from blogs, reviews, and other social media networking sites appearing without this change to type. In terms of expression, I will change typos and small grammatical errors merely for the sake of clarity and coherence for the reader, with no intention of changing the sense of 
engagement or argument. Where text speak, or mumsnet abbreviations are used, I have again made small amendments to these responses. I am aware that mumsnet offers a useful overview of routine and recurring acronyms for uninitiated readers ranging from AFAIK (as far as I know) to YABOS (you are being over sensitive) with talk of DS (Darling/Dear Son) and DDs (Darling/Dear Daughter) being commonly used within each thread (mumsnet 20I4b), I would not expect readers to have to decode the reader responses with a mumsnet manual, rather, I am aiming for clarity and coherence for all readers. And it is to these responses that I now turn. 



\section{Maternal preferences: From ordinary celebrity to the sitcom star}

There are a myriad of maternal figures represented on the small screen, spanning reality to fiction, comedy to serious drama, presenters, pundits, commentators and personalities. In this same way, there are a myriad of ways of mothering in line with age, class, geographic and lifestyle preferences. With this in mind, it is enlightening to see which mothers, maternal figures, tropes and archetypes have proved popular with mothers in the audience. Responses in this chapter relate to a question that I posed early on in the questionnaire, namely, 'who are your favourite mothers on television, what is it that you find entertaining or appealing about these women?' The added help text provided a prompt if necessary, asking 'do you like to watch maternal characters on soap opera, sitcoms, police, hospital, teen drama or television adverts? Alternatively, do you like to watch "real" mothers in reality television, celebrity programming, gossip and chat shows, make-over fashion, cookery, gardening or home improvement programmes? Do you like where they live, how they behave, how they relate to their family or their working role?

\section{Televisual and vocational personalities: More than a mother}

It is interesting to see that in commentaries about preferred and favourite mothers on television, many respondents were, knowingly or otherwise, in dialogue with extant research on television stardom, or what theorists such as James Bennett refer to as the 'television personality' (Bennett 
2010). Theorists from within the fields of film stardom and celebrity culture refer to the 'impossibility' of television stardom because the on screen/off screen duality of performance demanded by the film star cannot be emulated by presenters, pundits, hosts or newscasters (Langer 198I). From this perspective then, they have used the phrase 'personality' to refer to those presenters whose televisual 'image enters into subsidiary circulation' such as appearances in magazines, newspapers, chat shows and advertisements with such promotion and publicity then feeding back into their later small screen appearances (Bennett 2008). The fame of the televisual personality 'rests on their work in such a way that there is very little sense of a private life and the emphasis is on the seamlessness of the public persona' (Geraghty 2000). In this way the televisual personality is distinct from that of the television actor because while the actor takes on parts akin to the film star, the personality merely plays themselves, with authenticity, credibility and ordinariness said to be key to success, with limited juxtaposition between their television role and their private persona.

In terms of popular television presenters, there is a distinction made between the televisually and vocationally skilled. The former are professional presenters while the latter are on screen due to a previous skillset in terms of cookery or nutrition, gardening or house renovation for example. That said, since the emergence and development of lifestyle programming in the 1990 s, beginning with the popular and long-running Changing Rooms (1996-2004), the lines between the televisually skilled and vocationally talented performer has blurred somewhat, so that vocationally skilled performers become the sole presenter of a show and the televisually skilled performer tries to develop a talent or skill beyond their original presenting role. Indeed, the boom in factual entertainment on British television from the late 1990 os onwards has led to the vocationally skilled presenter no longer simply divulging their specialised knowledge, but producing or maintaining an image similar to the televisually skilled performer. This is notable in lifestyle programming's increased reliance on the ability of one of its vocational performers to present the programme, rather than using a presenter (who is solely televisually skilled) acting as an 
intermediary between expert and ordinary contestant/viewer. However, irrespective of their skillset, these performers must exemplify a sense of everyday 'ordinariness' so as to appeal to the television audience, so much so in fact that many skilled and socially connected presenters play down their personal networks and professional accreditations in order to maintain popularity. Indeed, Jamie Oliver seems to have spent his entire television career encouraging us to forget his training as a sous chef at the Michelin star restaurant, The River Café. Moreover, the more Ant McPartlin and Dec Donnelly seem to be like they appear on television, the more commercially and critically successful they become. And yet, however popular or professional Jamie, Ant or Dec might appear to a viewing public, these figures say little about the ways in which mothers in the audience read and respond to depictions of motherhood on the small screen. Rather, women in the audience who responded to my questionnaire commented on a small number of favourite maternal personalities, with the ability to balance professional and domestic responsibilities playing a key role in their popularity with viewers.

\section{Approval for working Mothers: Daly, Willoughby and Berry}

In terms of televisually skilled performers, two names appeared frequently in response to the questionnaire, namely, Tess Daly and Holly Willoughby; and although they were never named individually, the presenting team on Loose Women (1999- ) were seen to be popular with the audience. What is interesting here of course is the fact that many respondents looked to women such as Daly and Willoughby who are rarely, if ever, seen on screen with their children. Rather, we see their pregnancies develop week by week in their role as professional presenters, and then follow the birth stories and motherhood narratives in the wider media marketplace in general and the gossip and women's magazine sector in particular. 
I like Tess Daly, she appears to have a great family life, exciting job and amazing figure. ... seem real and striving to 'do well' at motherhood whilst retaining their own careers and identity.

Tess Daly, she looks amazing, is great at her job and has a beautiful family. She does really well to balance work and motherhood.

I like the working mothers that manage to have children and work but that are honest about the struggles... so usually $T V$ presenters.

Tess Daly is just another working mum taking on the weekend night shift, it is just that hers is more glamorous and pays much better than the rest of us.

... down to earth, opinionated, glam/career yet with a sense of self-depreciation and humour about the real world, acknowledging difficulties and shortcomings.

I do like to watch glamorous mums such as Tess Daly and Holly Willoughby hosting programmes as I like the professionalism and maternalism that they portray.

Tess Daly, I found her baby book to be really honest and helpful, it was nice to find out that someone as famous and glamorous as she is can still struggle with motherhood at times.

Tess Daly is such a natural, normal mum even though she has such a high-profile presenting job. She seems to be just like the rest of us, the only difference is she gets to be dressed up for her job!

Tess Daly, I read her baby book and it made me really warm to her as a mother and a presenter. She comes across as totally normal, just like the rest of us working mothers, but she just gets to wear better clothes.

Tess Daly is amazing, she is beautiful, stylish and normal. She seems like a normal mum that you could talk to in the playground. You can tell that she looks after her children and doesn't use loads of nannies and paid staff to help with the family.

Tess Daly, I feel that she is totally normal, and really loves being a mum and spending time with her children. She is lucky that she actually gets to be with them a lot because she does not have a normal $9-5$ to work around for childcare. 
I think that many of the women primetime presenters are a good role model to show you can have a career and children, like Tess Daly taking maternity leave during Strictly Come Dancing, and talking about sharing childcare with their partners.

Tess Daly is the forty-something model and television presenter, best known for her co-presenting role on the long-running and popular celebrity programme, Strictly Come Dancing (2004- ). She has been married to Vernon Kay since 2003 and they have two daughters. Much commentary from respondents and the wider media marketplace refers to Daly's 'ordinariness' in terms of her idyllic childhood in the Peak District, her down-to-earth nature and her marriage, irrespective of the fact that the duo are considered a celebrity power couple with all the financial and material accoutrements that come with that title.

In this way, Daly must be understood as the ideal television personality because she manages to combine a critically and commercially successful modelling and television career with an air of 'normalcy' that viewers feel that they can relate to. And Daly's role as a wife and mother is crucial in this regard. Audiences feel that they can relate to Daly as a mother, in part due to her baby book (Daly 2010) and her more recent family-inspired blog (Daly 2013). Daly currently models Florence and Fred designs for the high street supermarket Tesco, and each Daly performance within and beyond the television landscape goes further to reaffirm her very ordinariness and authenticity. It is not uncommon for interviewers to comment that the 'abnormal thing about Tess Daly is her normality ... She is so ... unpretentious' (MacDonald 2008). And when Daly reveals details about her private, domestic life, she does so as a working mother struggling to maintain the ideology of intensive mothering. In short, she presents herself as a struggling yet satisfied, hence appropriate mother figure:

My life is no longer recognisable to the life I had before kids. I wouldn't change it for the world obviously. Now my whole life revolves around my girls - the school run, doing ponytails and plaits and making them porridge with chocolate sauce faces on top to encourage them to eat it. That's just how it is and I love it. To me it's just a role that I was born for, it's the most important role of your life. (Mumazine 2013) 
And in terms of her working role, she presents her recent blog for Yahoo as if it were simply an ordinary diary that may be familiar to other contemporary mothers keen to document the trials and tribulations of their motherwork efforts, rather than anything demanding real time, energy, effort or labour. We are told that it is 'a weekly diary of what we are up to whether it be making ice cream sundaes or our plans for Halloween, and it's so much fun because I could talk about parenting all day long' (ibid.). Rather than see Daly as a working mother spending less time with her children, or having to seek support for the daily school run and extra-curricular playground activities, it comes across as something that is done for the family, rather than for a financial incentive.

Daly is successful in making her glamorous career seem everyday and her celebrity marriage appear anything but, and it is her ability to appear ordinary while maintaining an extraordinary lifestyle that endears her to mothers in the audience. The star reminds us that, like most working mothers, her life is a constant struggle between work and family. Daly sighs, 'ah the pressure of being The Perfect Mother - who NEVER forgets a thing! Deep down we all aspire to and (hopefully) manage to pull it off sometimes' (Daly 2013). Elsewhere she informs us that 'I'm lucky to do a job I LOVE but those special moments with my family are the ones I value most', reminding readers that after her interview, she is on her way to a reception class picnic, as one example of those school events that she prioritises and cherishes over her well-paid working commitments (Ison 20I3).

The celebrity mother profile that dominates the media environment offers an incredibly narrow, and to some, unrealistic narrative of pregnancy, birth and new motherhood. Since the late i970s a myriad of recognisable women have spoken at length about their serene pregnancies, exhilarating natural childbirths and joyous maternal experiences, with little acknowledgement of emotional, physical or financial pain. Depression, sleep deprivation and maternal anxieties are seldom seen in these high-profile celebrity interviews; rather, the celebrity confessionals and accompanying interviews routinely and regularly present a serene, selfless and satisfied image of both mother and child (Douglas and Michaels 2005). And although Daly is not entirely debunking this profile, she presents herself, and by association, her readership and audience as 'good enough' mothers. In reminding us 
of the importance of motherhood above all else, Daly is not straying too far from acceptable notions of good parenting, but by acknowledging that the maternal role can be a struggle, especially with more than one child, she offers a more candid and approachable take on motherhood, albeit celebrity motherhood:

If there's one thing that puts us all on a level playing field it's becoming a mum for the first time, everything else - work, sleep, sanity - goes out of the window. When I was handed our first daughter, Phoebe, I was terrified. This tiny bundle seemed so small and helpless and it was down to me and Vernon to take care of her every need when between us we couldn't change a nappy. This book is the story of my journey into motherhood. From the shock and excitement of the positive pregnancy test to trying to look 'stylish' when I couldn't even see my feet, the overwhelming emotion of having our beautiful baby and the horror to come of not sleeping properly for over three years. And then deciding to do it all over again! I do hope that by sharing my story you will have a better idea of what to expect, pick up a few tips and gain a little reassurance that even if the journey is rocky at times (as ours was!) we all become brilliant mums ... eventually. (Daly 2010)

Daly is not alone here; there are a growing number of female celebrities who have put pen to paper and shared their well-meaning, but not perfect, maternal experiences with an interested readership. Books such as From Here to Maternity: One Mother of a Journey by Mel Giedroyc (2005), Minus Nine to One: The Diary of an Honest Mum by Jools Oliver (2006), My Bump and Me by Myleene Klass (2009) and Bumpalicious: How to Relax and Enjoy Your Pregnancy by Denise Van Outen (2011) are all presented as honest, revealing yet entertaining narratives about pregnancy and new motherhood. In all cases, these books play to a shared experience with the reader, a commonality of experience, foregrounding a camaraderie that can only really exist because the notions of celebrity and the trapping of wealth and luxury are played down, or told with humble humour in these offerings.

According to these titles, difficulties in finding stylish maternity wear is less about the cost of clothing or the accessibility of luxury stores, and makes little mention of the fact that many of the aforementioned women have spent time modelling due to their 'thin ideal' physiques, but rather, about the difficulty of dressing for the later stages of pregnancy due to a changing body shape. Likewise, sleep deprivation and nappy changing are 
presented as a social leveller for working mothers, irrespective of the fact that the celebrity can afford specialist nursery and childcare staff. These books, like celebrity reality television, are popular when they make celebrities appear ordinary, with motherhood being presented as the common point for entry for celebrity mothers and maternal audiences alike. These texts all talk about intimate experiences, they share candid photographs of the stars in question and offer what they deem to be helpful hints, tips and advice to new and expecting mothers. What is most revealing here in terms of building a relationship with their reader is their promise not to pass judgement, but rather, to applaud all motherwork efforts, which would of course seem appealing to new mothers who are struggling to maintain a serene, selfless profile. Although the anecdotes differ depending on the star in question, these volumes can be understood as predictable in their narratives, carefully balancing routine symptoms and emotions with a life more glamorous than the average reader, with the overriding agenda that motherhood is more important than any celebrity lifestyle or television role. And the popularity of these titles suggests that they are a welcome addition to those pregnancy and baby manuals that are currently available. The role of the celebrity is key here, and the delicate balance between ordinary mother and extraordinary working role is key to their success. And it is these maternal narratives that go some way to informing their screen appearances, even though their maternal role is not 'seen' on screen, audiences are able to read these women as mothers due to their ancillary maternal materials.

Daly reminds us of the balance when she comments that her children have grown up with her Strictly Come Dancing commitments, making it clear that they are involved with her work, not separate from it: 'I was pregnant with both of them on Strictly so the show's been there from day one for them ... They watch it every week and come to the studio to see me when they can. Phoebe wanted a Strictly dress for her ninth birthday so I had one made. She has a purple organza ball gown that she wears to watch the show' (Della-Ragione 2013). And it is this maternal commitment combined with professional success that remains key to Daly's career longevity. Daly speaks of the glamorous hair, couture clothing and flawless make-up demanded by the show as escapism, as a fun part of the job that 
is at odds with her own day-to-day sartorial choices, because 'ball gowns aren't great for the school run' (ibid.). Televisually skilled personalities present a unified image, and each time we see or hear from them, it must accord with the on-screen image. One might suggest therefore that Daly's Strictly Come Dancing performances are at odds with the more natural, maternal role that she speaks about in the wider media marketplace, creating a sense of discord between on-screen personality and the broader celebrity profile; however, the fact that she draws attention to the seeming disparity between these roles, continues to remind us about her maternal priorities and finds a way to bring her family and working life together goes towards cementing her maternal star image for those women who have an interest in the performer outside of her professional presenting role. Indeed, the fact that Daly has been pregnant, twice, throughout the show's history makes it difficult to overlook her maternal status, irrespective of interest in ancillary materials. And the same seems to be true of Daly's younger counterpart, Holly Willoughby.

Thirty-something Willoughby is married to her television producer husband Dan Baldwin and has three young children, and her career, like Daly before her, stemmed from modelling, with Willoughby presenting another celebrity dance format, Dancing on Ice (2006-I4), before presenting This Morning (1988- ) four mornings a week, alongside a myriad of other presenting projects. Maternal audiences heap praise on the personality, for her natural charm, humility and maternal instincts:

I like people like Holly Willoughby who can relate to those mothers that she is interviewing.

Holly Willoughby ... I like to see working mothers on television, as that's the reality for most people now.

Holly Willoughby would be a great mum friend; she seems nice, approachable and dedicated to her children.

Holly Willoughby seems so nice, you can just tell that she is a normal mother when at home with the children.

Holly Willoughby from This Morning is beautiful and down to earth; I bet she even does normal PTA things like bake sales and fund-raising. 
Holly Willoughby always looks stunning on This Morning, she seems like a really nice person and she sounds like she is a really doting wife and mother.

Holly Willoughby should be applauded, I know her job looks glamorous and effortless but she must be working really hard to present, write, design and spend quality time with her children, she stands as a role model for young women contemplating motherhood.

Holly Willoughby is beautiful and successful but she isn't pretentious, in fact she seems really down to earth when she is on This Morning and blogging about her children, I always find it fascinating to listen to her talk about her family, it makes me think we're not that different after all.

I like watching Holly Willoughby on This Morning and try to imagine her hectic morning at home with the kids before going in to hair and make-up ready for work. I convince myself that her life is like mine, although I realise that she has help to achieve her home and work balance.

Holly Willoughby ... it is interesting and inspirational to see working mums on television. I am one myself, who is juggling quite a hectic career whilst caring for my little boy, so it is good to see mums who are doing just that on TV. I think sometimes, nowadays it is much more fashionable and socially desirable to be at home with your children, and that women who do both are frowned upon.

Like Daly, Willoughby is applauded both for her flawless appearances on the small screen, and for speaking candidly about her more pedestrian domestic commitments and fashion choices. In the same way that Daly made light of the juxtaposition between her glamorous work and more comfortable domestic attire, so too, Willoughby tells us that she is not camera ready when off air, reminding us that 'I work a lot so when I don't its down time, I don't put on make-up, I don't blow-dry my hair' (Bale 20II). Moreover, even though she is an established clothes designer with a successful range for the online boutique, Very, she tells us that 'I literally grab anything I can shove on. On a practical front, if I'm taking Harry to the park and putting him on a slide I can't wear something that, when I bend over, I'm going to flash my pants. Most things have leggings underneath nowadays' (ibid.). Again, like Daly, Willoughby has spoken about the ways in which she negotiates her maternal and professional roles by taking her children to her place of work, an option unavailable to most women outside of the 
entertainment area. Indeed, some might say an option unavailable to many women within it. Veteran newsreader Jon Snow recently announced that:

... many female colleagues had sacrificed careers when they had children while others
lost out on children because of their jobs ... Television has an undue quantity of
women who don't have children ... They are less likely to advance someone with
children ... It's beyond imagination to think that an employer would say, 'You're
going to have a third child? My dear, it doesn't matter at all'. Men don't have to face
that - ever. (Prynne 20I4)

However, after announcing her third pregnancy, Willoughby made it clear that she has neither seen nor faced such sexism in the industry. She has rejected claims that sexism in television made it impossible to be a mother or to hold down a presenting job and gives an example of former Spice Girl, Emma Bunton as another mother who is successfully balancing the two (Foster 20I4). Indeed, she speaks approvingly of her profession for its flexibility and family-friendly practices. Willoughby was heard speaking as part of a panel including Rebecca Hopkins founder of beauty brand Balance $\mathrm{Me}$, Bec Clarke of jewellery brand Astley Clarke and Marie Claire editorin-chief, Trish Halpin on the importance of work-life balance, telling her audience that she has got the work-life balance 'nailed' (Kendrick 20I2). Willoughby tells us that her success here is down to a heroic amount of planning and organisation.

Willoughby speaks at length about her ability to combine maternal and presenting work, referring to her commitments as part time and to her volume of work as comparable to that of the teaching profession (Bradford 2012). She tells us that she works Monday to Thursday with Fridays, the weekend and summer as family time, describing her typical working day on This Morning ending at I pm, with a variety of different work projects filling her afternoons. Willoughby states that 'I also get a massive chunk of time off in the summer and I ring fence that and protect it with my life. Any job offers during that time are a complete no' (ibid.). The presenter is adamant that she finishes at $5 \mathrm{pm}$ 'so that I'm home for dinner and bath with the kids in the evenings' (Styles 2013). Willoughby states that 'I consider my work to be part-time. Most weeks I do four mornings, and whenever things start heading into the territory of being full-time I start reining it in' 
with family taking priority over the entertainment arena (Kendrick 20I2). However, one might pick up a hint of defensiveness when she tells us that she only works during term time, and says that her schedule always looks far busier than it actually is (Bradford 2012, italics in original) in response to questions about her professional commitments, perhaps aware of the importance of maintaining the mask of 'good' motherhood which demands prioritising the maternal role.

Willoughby offers an interesting example of contemporary working motherhood that can be seen to, at least ostensibly, negotiate notions of intensive mothering. After all, she appears entirely comfortable with her work-life balance, something that many mothers appear anxious about. She is clearly aware of the pressures and judgements aimed at working mothers, but she suggests that she has found personal and professional harmony. She is clear that what she sees as a balance may not be suitable for others, but rather, that it works for her and her family:

There are a lot of working mums on TV now. You've just got to work out a balance ... Everybody's balance levels are very different. I've got mine figured, but that doesn't mean it works for anybody else. I can't judge anyone else on how they run their life and I wouldn't want anyone to judge the way I live mine. (Foster 2014)

Willoughby tells us that she 'loved returning to work' after each of her children, without apology for her desire to combine motherwork with her professional role. However, it might be worth revisiting the notion of celebrity motherwork here. After all, Willoughby has 'fessed up to a magazine that her ability to master the perfect work/life balance is down to her "brilliant" nanny' (Bradford 20I2). 'Fessed up' indeed. While television audiences are not naive as to the importance of childcare and other domestic professionals to performers such as Willoughby, indeed, the fact that Willoughby refers to $5 \mathrm{pm}$ as the end of her working day, when the school gates close at 3.20 makes it clear that she has help with her childcare routines. The reason why Willoughby is seen to have 'fessed up' is because many families in the entertainment arena play down their reliance on childcare providers beyond the family unit. It is rare for these women to talk openly about the role and responsibilities of such assistants, therefore 
when Willoughby tells us that 'I do have a nanny, who's here when I'm at work. She's brilliant. I couldn't do anything without her' (ibid.) we may feel envy that she can afford such provision but perhaps also grateful that she acknowledges the need for and value in such childcare. As respondents were happy to point out:

Juggling work and motherhood is not easy, but it is a little easier if you have family to help or the finances to pay for good childcare. Knowing your children are safe and happy makes it much easier for a mother to go back to work and enjoy her job without worrying about the children.

I find working mothers have always got to have a certain level of admiration as it is hard juggling motherhood and work together, however a celebrity mum, in my opinion has it a little easier than most, as they have a much more flexible approach to work or simply pay a nanny, something most mothers could not afford to do.

Celebrities who can afford the best childcare make combining motherhood and work look easy because they are not worrying about the school run, sick days or what to make for dinner that evening. I know they say that money can't buy you happiness, but I am pretty sure it can make life easier for working mothers.

Willoughby's popularity is evidenced by the fact that she received no public outcry or furore when she returned to work on The Xtra Factor (2004-) just five weeks after giving birth to her son, Harry, when other women within and beyond the entertainment arena have received hostile criticism for taking such short periods of maternity leave. Indeed, perhaps this is why Willoughby went out of her way to remind audiences that not only was she able to take her new baby to work with her and continue breastfeeding, but that she also had her own mother with her during these periods of work, so that she wasn't seen to stray too far from the ideology of the 'good' mother. A recent entry on Parentdish Celebrity entitled 'Celebrity Mums and their Micro Maternity Leaves' points out the relatively short periods of leave taken by several women in the entertainment sector, stating that although most new mothers 'enjoy every moment of our maternity leave with our new baby and away from work it's not quite the same for celebrity mums' such as Karren Brady (three days), Myleene Klass (ten days), Denise Van Outen, Amanda Holden, Vera Farmiga and Kim Raver 
(two weeks), Nicole Kidman (three weeks), Una Healey (four weeks) and Gisele Bundchen (six weeks), with Victoria Beckham jokingly asking what maternity leave actually was (Stansfield 2014).

Although Willoughby appears entirely comfortable with her domestic and professional work practices, one might question her prompt return to work, especially after her first child, before she had established herself as a household name with This Morning. After all, one might suggest that the harsh reality of motherhood in the fickle entertainment industry is to blame for the micro-maternity periods outlined here. Willoughby makes the point that 'you can't just take three years off, because people move on quickly and you're forgotten about ... I'm freelance, so I've got to keep my finger in the pie' before quickly adding 'But I only do what feels right' (Kendrick 20I2) so as not to betray the mask of appropriate motherhood. Therefore, although Willoughby's short period of maternity might appear surprising, or problematic to mothers outside of the entertainment sector, there is a sense that it is relatively routine within her field of work. After all, performers such as Klass take only days, and occasionally weeks off after childbirth because they do not want to be overlooked or ignored by the viewing public. We are told that there are many who criticise Klass for being overexposed or for not taking what is deemed appropriate periods of maternity leave. After all, the mother of two is a television presenter and a classical musician; she has a radio show and a children's line for Mothercare; she is a model for the high street shop Marks \& Spencer and the catalogue store Littlewoods and hosts a film show on CNN. However, although she is aware of the negative commentary she:

has no intention of stopping. Having won and lost fame twice before - she broke records as a member of reality TV pop group Hear'Say before they split, and then signed a five-album deal with Universal Classics and Jazz, only to be dropped after one record - she's not prepared to take time off. (Lampert 20II)

In her own words, Klass is 'petrified' showbusiness will leave her behind (Stansfield 20I4). And although Klass goes to great lengths to remind us of her appropriate maternal role, making it clear that she takes her daughters to work, one might question her exclusion from the 'favourite' mothers list 
and commentaries precisely because she is seen too frequently in the media environment, drawing attention to time spent away from her children, which in turn leaves women in the audience questioning her priorities.

Both Daly and Willoughby are beautiful models turned popular presenters who have combined motherhood with high-profile television presenting work; both have presented during pregnancy, taken brief periods of maternity leave and returned to their professional roles. They each speak of the importance of balancing motherhood with professional careers, suggesting that the entertainment arena offers flexible and family-friendly working practices, and point to the fact that they are in a position to employ childcare provision beyond the routine nursery and school hours. Willoughby hints at the reality of the fickle entertainment marketplace, and one is therefore left wondering if her return to work and presence on screen is less about finding a harmonious work and life balance, and more about understanding that if she took an extended period of maternity, she would not be in a position to return to her televisual role, especially given Snow's recent comments and work by Dent on the number of women who leave the creative industries each year (Dent 2013).

\section{Applauding the 'mumsy' principle}

While the beauty, approachability and admirable work-life balance endeared Daly and Willoughby to contemporary mothers, a more mature image of motherhood appealed to a broad demographic of women in the audience, both mothers and grandmothers alike mentioned their fondness of the vocationally skilled personality, Mary Berry. Berry is an English food writer who has studied catering, published more than 70 cookery books and hosted several food shows. Although Berry's name has been synonymous with traditional cooking for decades, her recent claim to celebrity is through her role as a judge on the popular and long-running The Great British Bake Off (2010- ). Berry and her antique bookseller husband, Paul Hunnings had three children, and later, three grandchildren. Berry has suffered from polio, has been diagnosed with a bicornuate uterus, has experienced repeated miscarriages, and years later, the death of her teenage 
son. And although television audiences may not know the intimate details of such diagnosis and tragedies, Berry has spoken openly on screen and in her writing of such events. Therefore, when one sees Berry on screen, she stands as both a fragile-looking domestic judge and an incredibly resilient maternal figure depending on how much attention one gives to ancillary materials outside of the television frame:

I like Mary Berry for her domestic goddess prowess.

Mary Berry is stylish, kind and witty, it is difficult not to warm to her when she shows such compassion for the people baking around her.

Mary Berry is a stylish and elegant mother and grandmother, I don't like to think of her as a celebrity cook because she just seems to be herself.

I like Mary Berry who I know is a mother but not specifically for this reason, because she is a good cook ... I've personally met her and she was lovely!

Mary Berry is a British institution, she should be treasured. She is kind and supportive to those around her, and I think this is her genuine nature.

She is proud to be a domestic cook, and that endears her to women at home. She makes food that we all love and that we might (on a good day) try and copy, nothing too fancy or elaborate.

Mary Berry is a great role model for older women everywhere, she is not afraid to age gracefully in the public eye which is refreshing when you look at most other women resorting to surgery and enhancement.

Mary Berry is a lady with manners and compassion, unlike many other reality television judges who seem to thrive on humiliating their contestants. She seems to really want people to bake well, rather than relishing their disasters.

It is worth noting that Berry took only five weeks off from work after giving birth on each occasion, and although this seems consistent with the aforementioned film stars, television personalities and models, it was incredibly rare during the 1960 s and 1970 s. After all, it was assumed that Berry, like all married women who became mothers during the pre-feminist era, would leave the workplace in favour of full-time motherhood. Despite the gradual 
decline of the 'marriage bar' between the 1940s and late 1960s, married women in the UK were still facing discrimination in the workplace. Indeed many women were routinely sacked for becoming pregnant up until the late I970s during the height of the second-wave feminist movement. Victoria Beckham may well jokingly ask 'what is maternity leave' as she continues to take on designing duties, but mothers have only recently been granted extended periods of paid leave (Jarvis 2010). It may surprise contemporary mothers to know the recent history of maternity policies, namely that:

The UK introduced its first maternity leave legislation through the Employment Protection Act 1975, which was extended through further legislation, such as The Employment Act 1980. However, for the first is years, only about half of working women were eligible for it because of long qualifying periods of employment. In 1993, coverage was extended to all working women, in order to bring Britain into compliance with a European Commission Directive on this issue. (Striking Women 2014)

When Berry talks about periods away from work she acknowledges that her desire to return to her professional roles after childbirth was uncommon and that her time spent away from her catering duties was not part of any formal or financed maternity leave. Berry goes on to commend her husband for his participation 'with things like the school run' (Foster 20II), which was rare for men of the time to embrace or even engage in, and to some extent continues to be so today (McVeigh 20I2).

Some might suggest that Berry's desire to work and the acknowledgment of her husband's role in the domestic context appears in keeping with gender role equality, said to be rare even in contemporary family unions. And although Berry is adamant that she is not a feminist and goes as far as to suggest that 'feminism is a dirty word' because she doesn't 'want women's rights and all that sort of thing' she continues to speak of the importance of both her private and professional role, a stance in keeping with the early feminist agenda (Glennie 2013). Indeed, Holly Willoughby has herself referred to Berry as 'her inspiration for sticking with the day job after becoming a parent' (Styles 2013).

Berry speaks of her need to return to her professional position mere weeks after giving birth for fear of being replaced, making the point that 'if you didn't come back to your job soon, someone else would jump into 
your shoes. By then, I was cooking editor of a magazine and there was lots of competition' (Foster 20II). And later, 'I was too afraid to ask for more time off ... I would have liked to have stayed with the children, but I didn't have enough confidence to say, Okay, I'll take two years off' (Thomas 2012). Her words echo those of Willoughby and Klass nearly four decades later. Although all three women speak of their love of their professional life and their desire to combine motherwork with their public role, there is the suggestion that these women are easily replaced rather than respected as professionals. These women have all felt the need to explain or justify their maternal and professional choices to the woman in the audience, taking the time to point to their flexible and child-friendly workplaces and the role of fathers and grandparents and their early guilt at balancing both roles in order to alleviate any threats to the performance of appropriate motherhood. Indeed, decades later, in an interview for Hello! Magazine, Berry tells us that her decision to be a working mother in the late 1960 s and early I970s is one that still fills her with guilt:

I really didn't think I was the most brilliant mother ... I was very keen on giving the children the right food, but I didn't play as long as I could have ... My husband always did the reading every night with the children because I was always trying to do two things at once. I didn't do enough homework with them. (Thomas 2012)

Berry is a seventy-something baking phenomenon, and there is the suggestion that her popularity, like other long-standing and successful television personalities is down to the seamlessness of her public and private persona. In short, the quietly spoken, encouraging, supportive and maternal Berry of The Great British Bake Off fame is the authentic, 'real' persona off screen. And although Berry has balanced her maternal and professional commitments for several decades, there is a sense that she exists in a world without feminism. She incited feminist outrage when she spoke about her daughter's love of cooking, telling a magazine that the young woman in question was 'lucky' because as a wife and mother she was going to be doing it her whole life so she, and other young wives and mothers 'might as well enjoy it' (Glennie 2012). The suggestion here is either that young wives and mothers will not return to the workplace or that they will combine professional 
employment with the 'double shift' of domestic duties. Either way, the role of maternity leave is crucial as it gives women time to consider their personal and professional options while spending time with their newborns.

Women in the UK are now entitled to more paid maternity leave than previous generations, with the promise of their old job available on their return, and yet although one might assume that this situation would please Berry on the back of her own experiences of unpaid maternity leave and precarious employment prospects on returning to the workplace after a short time away, this is not the case. Berry has spoken openly, albeit quietly, about the problems of contemporary maternity policies and practices, condemning rather than championing those women who take the full leave period to stay home with their children. She states that:

I had about five weeks off and now I think, gosh, they haven't half cottoned on to it!... You have a year off, and you don't have to tell [your employer] whether you're coming back or not. It makes it terribly difficult for the small employer to employ young women, young married women or [women] with children. You've got three in the department and they all go to have children and you've got to leave the job open. (Hall 2013)

Mother and Vogue editor, Alexandra Shulman goes as far as to suggest that maternal rights are making women unemployable:

... while a slew of government policies are aimed at helping working women achieve a more satisfactory existence, are they not losing sight of the real workplace picture? And are they ignoring the evidence, not documented but heard in the beat of the tom-toms if you listen hard enough, that some of this legislation might even be harming women's chances of employment? Nowadays, the majority of pregnant women I know take close to a year off, during which they are entitled to statutory maternity pay for up to 39 weeks. They return with the expectation and right to have their old job back after 52 weeks. Except that, when they do return, many of them don't want exactly their old job back. They want the same role but moulded into a time frame that suits family life better. They want to investigate four-day weeks, flexitime, job shares, and they often then have another baby and are entitled to take another year off. But is this realistic? (Shulman 2009)

Likewise, successful fashion entrepreneur Anya Hindmarch makes the point that: 
If we are not careful (and I speak as a mother and an employer), maternity leave and benefits will become too biased towards the mother and not considerate enough for the employer. In which case, it can start to work against women as it becomes too complicated and expensive to employ them. To me, it shouts of shooting ourselves in the foot. (Hindmarch, cited in Shulman 2009)

Another, this time anonymous, female employer agrees:

You're not allowed to say it, but the reality is that the maternity situation is a nightmare. Of course what happens is that the younger ones in the office step up to fill the gap and they're cheaper. At the end of a year, how much do I really need that person back? (Anon., cited in Shulman 2009)

Shulman suggests hthat maternity practices are increasingly encouraging small businesses, individuals, or employers in small rural communities who simply can't work around an employee's year off and who don't have a pool of freelance cover, to look instead for women who won't have more children - or indeed men' making it clear that while employers certainly should have a duty of care for their employees, employees should in turn have a certain duty of responsibility to their employer, and that working nine months out of three years then demanding flexi-time when resources are already stretched during a recession is anything but respectful or responsible (Shulman 2009). The fashion editor, like Berry, is not against maternity benefits for mothers in the workplace; indeed, they both work in a feminine, majority female sector, concerned that the next generation of female workers might be seen as 'too inconvenient and awkward to employ' the fear here then is that women might well find themselves 'legislated back into the home' (ibid.).

However, while Berry and Shulman worry that generous maternity packages and family-friendly contracts will become an obstacle for future mothers, Rosalind Bragg, director of the national charity Maternity Action has challenged such ideas and spoken of her 'disappointment' at hearing Berry's recent comments. Maternity Action would like to see 'greater support for women balancing work and caring responsibilities, not ill-informed complaints about women who exercise maternity rights' (Hall 2013): 
Maternity rights are fundamental to women's ability to maintain employment during their child-bearing years. If we backtrack on maternity rights, we will force women out of the workforce, losing valuable skills from the market, and leaving more families in poverty and reliant on benefit. (Bragg, cited in Hall 2013)

The 'Everyday Sexism Project' is peppered with stories of mothers who have been unable to return to work after their period of maternity leave has come to an end (Bates 20I4), perhaps unsurprisingly as recent research has found that 14 per cent:

... of the 340,000 women who take maternity leave are unable to return to the job that they had left because of discrimination by employers, with many finding their positions under threat when they try to return to them. They are denied the right to work part-time, or flexible hours, to enable them to factor in childcare pickups and drop-offs. Others are shoehorned into more junior posts, or return to virtually no job description at all, while others still are effectively constructively dismissed. Pay rises and promotions are also harder to come by for those that do go back. (Joseph 2013)

These figures do not tell us 'how many mothers had the option to go back to work, but faced with the choice of not seeing their children much, or lack of childcare provision, or rigid working hours, decided that they couldn't or wouldn't return' and yet, they remain a cause for concern (ibid.). With such statistics in mind, many new and existing mothers have lambasted what they see as Berry's 'antediluvian views' on maternity leave (White 2013), but in so doing, they appear to have ignited the 'mommy wars' by critiquing those women who do not take extended periods of maternity. Writing in response to Berry's claims, several mothers have suggested that 'leaving small babies as early as five weeks is tantamount to neglect. At that point the little ones are feeding every four hours and need round the clock, drop-of-a-hat care from mum' (ibid.). While Berry and Shulman suggest that new mothers are exploiting generous maternity packages and showing little respect for loyal employers, there is evidence not of a glass ceiling at the upper echelons of a profession, but a 'cliff' at the middle which women are said to fall off when they have children (Rowley 2013). As such, it is crucial that maternal charities, politicians and policy makers continue to discuss maternity leave in the hope of giving new mothers genuine choices 
about their personal and professional roles, and without judging or ranking those choices in line with romanticised notions of maternal care.

Berry has made her comments about feminism and maternity leave clear in the Sunday broadsheets and it sparked commentary in the women's magazine sector and maternal networking sites, and yet none of the respondents to my questionnaire made reference to her views; rather, they spoke approvingly of her televisual performances, with the suggestion that she was a kind and gentle judge with a nurturing and compassionate personality that existed within and beyond the screen space. Maternal audiences did not comment on Berry's opinions concerning feminism and maternity leave; her views were seemingly unknown or of little importance to audiences interested in the vocationally talented presenter in question.

While Daly and Willoughby remind us of their maternal status in terms of their on screen pregnancies, references to their maternal role and images of their children in the wider entertainment arena, Berry's status as an older mother and grandmother is notable in its absence. The Berry persona seems generally warm, welcoming and maternal, almost irrespective of her actual mothering status. Indeed, one might suggest that she stands as a generic maternal figure in her role as food critic. Most respondents speak about Berry in her televisual role or through her multitude of cookbooks, rather than via any attributed celebrity status that demands revealing intimacies and sharing candid domestic images. In short, the extra textual interviews and confidences appear to be of less interest to Berry audiences than those invested in the maternal presence of Daly and Willoughby. After all, as a vocationally rather than televisually skilled performer, Berry's credibility with audiences is based on her culinary skills and expertise, which are evident in her screen appearances.

Berry is appreciated and applauded as a working mother with expertise in the culinary tradition; so too, mother-of-two, Kirstie Allsopp was spoken about in a similar way, as a warm, nurturing maternal figure, but this time, with a skillset in the property sector. Before appearing on our screens with Phil Spencer in Location Location Location (2000- ), she worked for her mother's business, Hindlip \& Prentice Interiors, studied at Christie's and set up her own Home Search company, Kirmir, focusing 
on top end purchases in Central and West London. Either because of or in spite of Allsopp's professional career, mothers in the audience spoke with admiration and interest in the television presenter:

... very family focused - lovely lifestyle.

There is something very likeable about Kirstie Allsopp.

Kirstie Allsopp ... I appreciate her honesty regarding childcare arrangements when working.

I really like Kirstie Allsopp as a working, crafty mum ... I prefer a more simplistic, crafty lifestyle that she represents.

Kirstie Allsopp seems warm and funny, she comes across as a stay at home mother by heart, even though she is obviously doing presenting.

Kirstie Allsopp. My admiration has come more from what I have read about her rather than from watching her. The life choices that she has made, and her family values.

Kirstie Allsopp does seem to know a lot about the property market, she is not just another pretty face on television, she seems genuine, you want to think that she really is that person.

Kirstie Allsopp is a positive role model of motherhood and womanhood, she seems kind, considerate, affectionate and fun. She stands out against the more predictable thin, blonde, attractive presenters on television.

I might not make the things that Allsopp makes, but there is something welcoming about her presence on screen. She comes across as 'mumsy' in a good way, someone that you would like to spend time with at the school gates.

I find it relaxing to watch Allsopp in her 'at home' programmes, you get the sense that she is quite traditional, which is rather endearing. You can imagine her making packed lunches and organising football kits before the school run.

I know Allsopp has 2 sons and stepchildren, and from the way she appears on television, I imagine her to be a doting wife and mother. She looks and sounds very conservative, not boring, just traditional, a mother who puts her children first, and I think this is why I watch her with fondness. 
I have always liked Allsopp on the Location shows, and because of that I have taken to watching her Handmade programmes. I imagine her home to look like something Cath Kidston and Gisela Graham would put together, warm, welcoming and feminine. I think she has 2 boys so it might be wasted on them, but I always picture her wearing Laura Ashley against a floral backdrop, but then that might say more about me than Allsopp!

Respondents seem to be in agreement when they stated their opinions of and attitudes towards Allsopp. The presenter is deemed, in different commentaries traditional, conservative, stay at home and 'mumsy', with a penchant for those most middle class and romantically feminine of shops, namely Cath Kidston and Laura Ashley. What is interesting here is that the mothers who completed the questionnaire said nothing of Allsopp's recent media interviews on the topic of fertility education, which have caused controversy in the wider blogosphere and social networking sites. In an interview with The Telegraph she tells Bryony Gordon that:

Women are being let down by the system. We should speak honestly and frankly about fertility and the fact it falls off a cliff when you're 35 . We should talk openly about university and whether going when you're young, when we live so much longer, is really the way forward ... At the moment, women have is years to go to university, get their career on track, try and buy a home and have a baby. That is a hell of a lot to ask someone. As a passionate feminist, I feel we have not been honest enough with women about this issue ... I don't say it from a position of smugness. I only whistled in there by a miracle when it came to children. This isn't something I've just decided in an arbitrary way. [Fertility] is the one thing we can't change. Some of the greatest pain that I have seen among friends is the struggle to have a child. It wasn't all people who couldn't start early enough because they hadn't met the right person ... But there is a huge inequality, which is that women have this time pressure that men don't have. And I think if you're a man of 25 and you're with a woman of 25 , and you really love her, then you have a responsibility to say ... men need to know, men need to be taught in school that there is a responsibility, that if you love someone, decide if you want to have a child with that person or not. I don't have a girl, but if I did I'd be saying 'Darling, do you know what? Don't go to university. Start work straight after school, stay at home, save up your deposit - I'll help you, let's get you into a flat. And then we can find you a nice boyfriend and you can have a baby by the time you're 27 ... that might sound wholly unrealistic. But we have all this time at the end. You can do your career afterwards. We have to readjust. And men can have fun after they have kids. If everyone started having children when they were 20 , they'd be free as a bird by the time they were 45 . But how many 45 -year-olds do you know 
who are bogged down ... I don't want the next generation of women to go through the heartache that my generation has. At the moment we are changing the natural order of things, with grandparents being much older and everyone squeezed in the middle. Don't think 'my youth should be longer'. Don't go to university because it's an 'experience'. No, it's where you're supposed to learn something! Do it when you're 50! (Gordon 2014)

There are three different yet related issues being presented here: firstly, in relation to notions of age-related infertility; secondly, in terms of educating young women about the condition; and thirdly, about the role of higher education. Infertility is a common experience among women within and beyond the UK, and this experience 'is not usually discussed publicly' (Striff 2005). And yet, although a woman's infertility story is generally only witnessed by the medical profession, there has been a recent trend in the women's, tabloid and gossip sector whereby celebrities share their infertility stories with a willing public. The problem here, however, is that celebrities tend only to announce their infertility struggles once they are holding their healthy newborn, which in itself sends out a rather misleading finale to the infertility narrative (Feasey 2014a).

And although an exhaustive number of contributions to newspaper blogs and postings congratulate these women for speaking publicly about their infertility (Yuppy Mom 2010; BustedKate 2013; Wertman 2013; Gorenstein 2014), what these maternal narratives overlook is the cost of IVF, the role of egg donation and the limited success rates of such treatment. The success of IVF depends on the age of the woman undergoing treatment, with 32.2 per cent success rate for women under 35, a 27.7 per cent success rate for women aged 35-37, a 20.8 per cent success rate for women aged 38-39, a 13.6 per cent success rate for women ages $40-42$, a 5 per cent success rate for women aged $43-44$ and a 1.9 per cent success rate for women over 44 (NHS 2014b), and yet these statistics have no place in the successful celebrity infertility narrative. The average age of a first time mother in the UK is growing (ONS $2013 \mathrm{~b}$ ); more women than ever before are having children in their late 30 s and early $40 s$ and beyond (ONS $2013 \mathrm{~b}$ ); assisted reproductive technologies are advancing; the number of women taking advantage of such techniques is increasing and more celebrities than ever before are presenting their infertility stories in 
the women's tabloid and gossip sector. Although one might suggest that the celebrity infertility confessional can offer hope through identification with the celebrity revelation, by defying the privacy of infertility treatment, the partial account on offer here could perhaps lead to reproductive complacency, false hope or go further to reinforce the sense of stigma and failure that many infertile women are said to experience (Woollett 1994), none of which can be understood as helpful to individuals or beneficial to society. I agree with Allsopp that age-related infertility is rarely commented on in a way that is meaningful to the next generation. Indeed, a 'survey of educated young professional women found that $90 \%$ thought that they could wait until age 45 to start having their own biological children, even though next to none over 44 are able to, despite advanced technology' (Bonifazi 2003). If female readers are looking to the celebrity sector as a source of good, responsible and aspirational motherhood, and these stories about more mature mothers overlook problems with conception and fertility and ignore the use of assisted reproduction then no wonder readers are confused and ill-informed about the reality of the experience.

However, it is harder to agree with Allsopp's statement that, if she had a daughter she would be telling her not to attend University. Indeed, many commentators, both conservative and liberal were heard challenging Allsopp for her suggestion that University is neither important nor necessary to young women, making it clear that the daughter of Charles Henry Allsopp, 6th Baron Hindlip, may well not need the formal qualification, but that a university degree is the pathway to social mobility and financial security for many women, irrespective of decisions over marriage and motherhood. Allsopp was critiqued for what many saw as a disservice to feminism and mothers alike with her views by giving maternal advice to a hypothetical daughter rather than parenting advice to her own sons here (Freeman 2014; Gyngell 2014; Mumsnet 2014c).

While respondents made no comment concerning Berry's statements on maternity leave, likewise, the women who completed my questionnaires said nothing of Allsopp's views on infertility or education, even though such comments have been debated at length in the popular press, on popular social networking sites and maternal forums. Again, these respondents were either unaware of the debates, uninterested in such commentary or simply 
see such views as in-keeping with the Allsopp persona that they speak of liking and warming to, which go further to confirm her status as a skilled television personality. On screen, Allsopp is routinely talking to families about their property needs and asking pertinent (or inappropriate) questions about their current or future children in order to secure them the most suitable home. So too, in her Homemade Home (2009-II), Handmade Britain (20II) and Handmade Treasures (2013) programmes she speaks of making artefacts for the home, drawing attention to the needs of children's bedrooms and playrooms and suggesting how children can in fact help on some of what she calls the easier 'Child's Play' projects (Allsopp 20I5).

Respondents referred to Allsop's traditional and feminine status in terms of her dress code, creativity and maternal status, but no one made reference to her father's peerage, her relation to designer Cath Kidston or her long-term partnership with millionaire property developer Ben Andersen. In short, her privileged status was of no importance to the mothers in the audience, she was neither liked nor disliked due to her socio-economic background, but rather, applauded for her warmth and humour, said to be evidenced throughout her televisual career. In terms of her on-screen performances, Allsopp gives away little of herself or her domestic, family or maternal behaviours; rather she presents herself as a welcoming friend, which is often read by many in the audience as 'mumsy'.

\section{When the professional is not personal}

While the majority of respondents favoured presenters such as Daly and Willoughby and vocationally skilled performers such as Berry and Allsopp, a small number of women spoke of an admiration for women such as Mariella Frostrup, Kirsty Young, Fiona Bruce, Kirsty Wark and Julia Bradbury. These women were chosen despite their maternal status not because of it. Indeed, one might suggest that news bulletins, documentaries, consumer affairs and arts programmes such as Antiques Roadshow (1979- ), 
Watchdog (1980-), Newsnight (1980-) Crime Watch (1984-), Countryflle (1988-) and The Book Show (2007-13) are not reliant on the personability of the presenter or the performing presence of the reporter in the same manner as escapist fare or more deliberately domestic offerings. The women who present these programmes are professional, capable, admirable women, leaving little place for a maternal presence or an acknowledgement of any domestic or family context.

For those women who spoke fondly of figures such as Bruce and Wark, they made the point that they didn't look to them as mothers, irrespective of their off-screen maternal role, because, in doing so it would somehow lessen their credibility or mark them out as one-dimensional. One respondent went as far as to tell us that she was 'not particularly drawn to mothers on television' while another states that she 'doesn't really see these women in relation to their role as mother'. Indeed, we are told that 'real mothers actually give away very little of their private lives ... as if this may diminish them as performers'. And although for popular entertainment presenters such as Tess Daly and Holly Willoughby, their maternal status plays a key role in their public visibility and audience investment, for more arts, culture and news presenters, the notion of motherhood is viewed as a distraction, rather than an accompaniment to the professional role:

I like many of the presenters on the news channel ... we never really get to know what they are really like.

I'm interested in women who are also mothers, rather than stock mother figures.

I regard Fiona Bruce as a person of integrity who appears to have a successful career.

I tend to see female characters as just that rather than mums, it is just an aside that they have children and can't really say that I think about them any differently than male characters that may be dads.

Kirsty Wark, but I don't think of her as a mother - just an amazing woman who has had children - and I admire that about her (no one ever thinks about Jeremy Paxman as a dad) and also that she has forged a career as an individual. 
When women in the audience spoke of newsreaders, arts and cultural commentators, they often made a point of saying that they did not actually know if these women were married or mothers, which goes further to remind us of the difference between these figures and the appeal of the aforementioned television personality. We are told that 'I like Joan Bakewell, Angela Rippon, Sally Maggneson, Jenny Murray and Susanna Reaid. I don't know if they have children' and although this information does not inform their television persona, it may be worth noting that Joan Bakewell and Jenny Murray have two children, Susanna Reaid has three, Sally Maggneson has five children, while Angela Rippon is not a mother. The general point here then is simply that these women are liked as credible, intelligent and charismatic women on television, not as mothers on the box, and Angela Rippon's status as a newsreader and non-mother is testament to that fact.

Although female presenters and newsreaders are deemed popular with contemporary mothers in the audience, these figures were historically frowned upon (Holland 1987; Holland 1998). Female newsreaders were barely tolerated while pregnant performers were routinely shunned. Although Janet Ellis has commented that she left her much coveted Blue Peter (1958-) presenting role voluntarily in the late 1980 of after she became pregnant, as an unmarried mother, $\mathrm{BBC}$ management at the time felt that it would set a bad example to the children who watched the show and the presenter has since been 'written out of Blue Peter history' (Dowell 2013). If one thinks that this is understandable given the age group of the audience, it might come as a surprise to find that during the same period, Good Morning Britain (1983-92) anchor, Anne Diamond was lambasted for continuing to work throughout pregnancy. Reports of the pregnancy were front-page news, and although Diamond was initially inundated with flowers, cards and hand-knitted bootees from every corner of Britain' public and professional opinion changed as she continued in her role (Diamond 20roa). Her pregnancy was even the subject of a leader article in the Guardian, along the lines of 'what is the world coming to when a pregnant woman expects to continue with her high-profile job as though nothing has changed?' (Diamond 2010a). Diamond was surprised to find that she had been the first television presenter in Britain to be pregnant and to continue working, and talks about her experiences of that time: 
Obviously pregnant women had appeared from time to time on TV, in the occasional drama or on a baby programme. But never in a daily job, live and in front of millions ... what truly shocked me was the attitude, which continued through my four later pregnancies, to the pregnancy itself. In the words of one young producer, shocked that I was continuing my job to the very end, it was 'a bit icky'. A wardrobe mistress, a genius at choosing my daily outfits, became flustered at my growing girth. She simply couldn't handle my changing shape. She backed off, as though I had become something slightly distasteful. In response to viewer demand, I - just once - showed off my ultrasound pictures. I was hurt then, that when I went on Gloria Hunniford's afternoon show as a guest, she put it to me that I 'was flaunting my pregnancy'. She even asked me why I didn't take the next few months off screen, and not return until the baby was born - 'like actresses do'. I don't think for a second she meant to be unkind, but her attitude floored me. Actresses retire from the spotlight when they are pregnant because it doesn't suit their profession, unless they're playing a pregnant woman. I was appearing on TV to do a job, presenting and interviewing, which was entirely unaffected by the size of my stomach. As for myself, I feel proud that I paved the way for generations of female TV presenters to go on doing their jobs as real human beings, not bimbos. Every time I saw the likes of Lorraine Kelly or Kate Garraway on breakfast TV, happily patting their baby bumps to the chuckles of a delighted studio, I felt I'd done my bit for pregnancy liberation. (Diamond 20roa)

\section{When the professional is entirely personal}

Mothers in the audience announced that 'it's good just to see pregnant women on the television' and again that 'it's good to see Sarah Beeny and Kirstie Allsopp presenting programmes whilst heavily pregnant'. However, the proud moment must be reasonably short lived as a number of models, film and television actresses, judges and presenters have come in for criticism for 'flaunting' (Cox 2014) their pregnancies and in several cases, dismissed during pregnancy, with Denise Van Outen as a very public case in point. Van Outen was told that she would not be returning to Andrew Lloyd Webber's latest BBC TV series because she was expecting. A senior member of production is said to have told her that 'you're pregnant, so of course there's no way you can do the show', which was then repeated to 
her by other producers (Plunkett 2010). Van Outen went on to say that being pregnant at work is part of a wider problem for women, saying that 'it should be up to the woman to decide if they feel well enough to carry on working' (Nathan and McConnell 20ıо). A wider problem indeed. Outside of the entertainment arena, women are suffering escalating levels of illegal discrimination at work when they get pregnant, and are often made redundant while they are on maternity leave:

... one in seven of the women surveyed had lost their job while on maternity leave; $40 \%$ said their jobs had changed by the time they returned, with half reporting a cut in hours or demotion. More than a tenth had been replaced in their jobs by the person who had covered their maternity leave. (McVeigh 2013)

There is clear discrimination in the workplace for celebrity and ordinary mothers alike, and although 'only a very small percentage of women take any action against an employer who has broken the law' one might hope that the public furore caused by more visible pregnancy discrimination will help encourage others to seek legal advice (ibid.). Anne Diamond famously used her media profile to raise awareness of Sudden Infant Death Syndrome (SIDS) after the death of her son back in 1991. She fronted the 'Back to Sleep', campaign, telling parents to ensure that babies slept on their backs. Since then, there has been a significant fall in incidents of SIDS in the United Kingdom, from more than 2,000 per year to around 300, which has been attributed to the campaign. Diamond was awarded the Gold Medal from the Royal College of Paediatrics and Child Health, the only time it has ever been awarded to a non-medic (Diamond 2orob) for her efforts. With such media interest and public change in mind, one might hope that if recognisable women speak out over maternity discrimination, they might change individual circumstances and wider social practices.

Mothers on television, can be seen to embrace or underplay their offscreen motherwork depending on their professional roles, responsibilities and wider media contracts, with Cherry Healey standing out here as a young woman who actively exploits her maternal status for her work. Healey is a British television presenter, frequently featuring in self-titled light-hearted lifestyle documentaries on topics such as childbirth and parenting. Younger, 
new mothers made reference to Healey as a woman that they could relate to precisely because of her documentary productions:

I liked ... the Cherry Healey documentaries about breastfeeding and children's eating.

... hear about the day-to-day struggles like getting a child dressed in the morning. It makes a celebrity more real.

I like to watch Cherry Healy documentaries about motherhood type subjects in the past. I like her because she is honest.

I like to watch Cherry Healey - she seems like someone I can relate to, very down to earth seems intelligent as well as a sense of fun.

Cherry Healey seems like a normal mum, dazed, confused and well meaning. It is refreshing to see a celebrity ask the same parenting questions as the rest of us.

I love that Cherry Healey admits that she struggles with motherhood, she lets us know it is ok to cherish our children but struggle with the day-to-day reality of looking after them.

... natural, honest women who talk openly about motherhood, their work life balance, how they cope with various situations. I am interested in those that share their experiences.

Cherry Healey asks useful questions but never preaches about motherhood, she seems a sensible young woman who is not afraid to reveal a little (or a lot) about her own parenting, and doesn't pretend that she has all the answers to the day-to-day struggles with eating, sleeping and sharing.

Healey frequently relates documentaries to her own life both during the programmes and on her blog, with follow-up publications in titles such as You Me Baby magazine. For example, in relation to the documentary Cherry's Parenting Dilemmas (2011), the official synopsis tells us that:

Cherry Healey may be a proud new mum, but she is facing a battle of wills with her daughter Coco. In this personal documentary, Cherry goes to meet other mums with very different parenting styles. From a pro-smacking strict parent to a super-liberal single mum, and from a mum who works all hours to buy her kids everything they want to a mother in crisis with her teenage daughter, Cherry finds out what being a mother is all about. (BBC 20IIa) 
Healey goes on to write a candid confession that led her to make the programme, pointing to her own trials and tribulations with motherhood, telling us, in the mode of a confession that:

Before I had a kid, I thought parenting was ...
a) a doddle
b) boring
c) totally instinctual

What I have experienced is that ...
a) it can be pretty complicated
b) it is far from boring
c) I need help

I used to walk past playgrounds on my way to the pub/club/shops and think to myself 'wow those parents look bored'. I realise now that they aren't bored because being with your child is both surprisingly fun and challenging (okay, so sometimes playing peek-a-boo for the hundredth time is a touch boring). One of the things I'm often told is 'oh, don't fret about it, trust your instincts'. Well, I have found that my instincts can sometimes be pretty unhelpful. For example, my daughter does not like sitting in her high-chair ... oh no she does not. My instincts told me that it wasn't a big deal and it was more important that mealtimes were relaxed. In reality, this has meant I have spent the past year chasing her around with a spoon or leaving bowls of food on the floor in the hope she will eat something. Eating in restaurants or having a simple cuppa in a cafe is a no-go. I have since tried and tested a few new tactics, spoken to dozens of mums, been on a dozen websites, read a few books and come up with ... a solution: no chair, no food. I won't bore you with the details of why or how this works, but, for some reason, it just does. But there is no way on earth my instincts would have given me this information at the start. What I have learnt from experiences like this, and from making Cherry's Parenting Dilemmas, is that being a good parent doesn't just happen overnight. Like most things, it is a skill that you learn and that you can become better at. (BBC 20Irb)

It is precisely this candid address to audiences and readers alike that respondents welcomed here, not because she is saying anything particularly controversial or original in terms of childbirth or new motherhood, but because she is revealing her maternal vulnerabilities and giving credibility to those women who are themselves unable or unwilling to present themselves in line with the serene, satisfied 'good' mother. In this way Healey performs 
in line with many fictional mothers who present themselves as well meaning but struggling figures, mothers who are available for us to laugh at, cry with or find encouragement or amusement in.

\section{The appeal of the sitcom mother: Marge, Lois, Sue and Claire}

Indeed, although many women found 'real' mothers such as Daly, Berry, Allsopp and Healey to be their favourite, most trusted or treasured maternal figures on television, other women pointed to fictional representations of motherhood and motherwork as their preferred small screen counterparts, with a small number of sitcom characters being routinely and repeatedly mentioned by those women who responded to my questionnaire, namely Marge Simpson/Julie Kanver (The Simpsons 1989- ), Lois Wilkerson/ Jane Kaczmarek (Malcolm in the Middle 2000-06), Sue Brockman/Claire Skinner (Outnumbered 2007-14) and Claire Dunphy/Julie Bowen (Modern Family 2009-). Although I invited participants to comment on maternal figures from any factual, fictional category, genre or hybrid format, with no set period for programmes being screened, it was interesting and rather surprising to see the homogeneity of the figures and genre pointed to here. That said, the findings remain consistent with a number of annual 'Best Television Mother' and 'Favourite Television Mothers of all Time' polls that appear annually around Mothers day and in line with many comments made on a recent mumsnet thread on television mothers (Mumsnet 2013).

Situation comedy has, since its emergence on commercial radio in I930s America, been committed to the family unit. Since that time, the genre has presented dramatic changes to family life, in response to wider social, sexual and political periods, ranging from the happy suburban middle class housewife to urban and ethnic representations, divorced, widowed and single mother formats to irresponsible and unsentimental images of working-class families. The situation comedy has presented a diverse set of family representations, and has historically spoken of the importance 
of motherhood and motherwork within its comedy conventions (Feasey 2012a).

For the majority of women who spoke of fictional programming, they made mention of popular situation comedy texts from the past decade, and spoke warmly about the representation of mothers from within a limited number of titles, titles seemingly dedicated to the depiction of harried and hurried mothers outnumbered by their children. What was said to be endearing about these maternal figures was their valiant parental efforts under strained circumstances, be they emotional, logistical or financial. Although there are some differences in terms of the characters being presented in relation to class, country and cartoons, there are numerous similarities between these mothers and, in many cases, participants commented on more than one character, to the point that they seemed somewhat interchangeable in their maternal practices. Marge, Lois, Sue and Claire are seen to be strong, hard-working women who are committed to their families and work tirelessly to support them, irrespective of mistakes and misdemeanours. They are loving and compassionate, strict and demanding in equal measure, and want nothing more than to see their children happy and content. Although they are authoritarian figures in the domestic environment, they do not always find satisfaction or fulfilment in this space, and on occasion yearn to experience love, life and laughter outside of the confines of their maternal role.

Marge Simpson is the stay at home mother of three with blue hair from The Simpsons, the popular and long-running animation best known for its social, sexual, religious and political commentary on education, corporate capitalism, the health-care system, modern child-rearing, globalisation, commercialism, consumerism, racism, religious intolerance, alcoholism, drug abuse, environmentalism, immigration, violence, media effects, sexism, homophobia and changing gender roles. It has been suggested that the situation comedy has 'offered oppositional ideas, depicted oppression and struggle, and reflected a critical consciousness that stops just short of political mobilization' (Hamamoto I99I), and that it is able to do this because of its recognisable characters and conventional settings, as they go some way to neutralise the potential threat or discomfort with such 
commentary. It was surprising to see just how many mothers in the audience favoured, felt affection for and recognition with a cartoon creation:

I love Marge Simpson

Marge in The Simpsons seems close to reality!

Marge Simpson ... running around doing everything!

Marge Simpson ... She's patient, funny and tries her best!

I nearly forgot Marge, how could I forget Marge - Best mum ever!

Marge Simpson is great because she tries her best but is a flawed character.

Marge Simpson is also a great mother role model. Calm and caring and always there for her kids.

Marge Simpson ... being kind, gentle accepting and supportive of her children - these are great mothering qualities.

I like Marge Simpson as she is responsible, hard working and so much brighter than her husband. I think it reflects real life!

Marge Simpson is one of my favourites. She seems like a very real mother to me, despite being yellow with unusual blue hair.

Marge Simpson ... does seem to be a remarkably calm, mature and nurturing mother on the whole. I would like to have these qualities.

I like Marge Simpson as they portray her as a mother who is trying her best but isn't perfect and you can see the sheer frustration she feels at her husband and children.

Marge is a maternal legend, she is not just a long-suffering wife and mother but a compassionate and passionate individual who has her own needs and desires. She might not always (if ever) be able to act on them, but it is clear that, given the opportunity, she is more than her domestic role, and I find this both endearing and refreshing, and dare I say believable. 
I have been watching Marge my whole life, at times I thought I would like her as my mum, and now I would value her as a friend. Watching her domestic triumphs as well as her well-meaning mistakes is far more potent that any Supernanny episode because you are invested in her life and value her efforts.

I have spent a while thinking about this and the mother that I warm towards is a cartoon, Marge Simpson stands out as a loveable and believable mother. I like her because I am her, her struggles with routine, discipline, tantrums and misdemeanours are my struggles. She makes motherhood look like work, which it is.

Marge Simpson. She is surprisingly three-dimensional for a two-dimensional character. I love that we see her wanting to do more (almost having an affair, becoming a cop, starting a pretzel stand, getting into trouble with her gang of lady thief girls) all the while trying to toe the morality line that she is trying (without success at times) to instil in her kids. It's touching when she has breakthrough moments and gets the point. And you always feel mad on her behalf when she's mistreated!

Marge Simpson from the cartoon The Simpsons. She's totally devoted to her family and wants the best for them. She isn't perfect, but tries her best. She also finds it hard to reconcile the fact that her family expect her to do everything around the house for them and doesn't have much of a life, if any, outside of this so she sometimes goes off and does her own thing and leaves the older ones to look after themselves more (whilst still making dinner quite often). In relation to this, she also gets quite upset in the episode(s) where she discovers that her family don't think she could hack being in the 'real world' with a real job, instead of being a stay at home mum.

The Simpsons family in general, and Marge in particular, have been on our screens for over two decades, and since that time the character has developed as a fully rounded, credible and relatable figure for women in the audience. Looking past the colourful images and slapstick humour of the programme that appeals to the child in the audience, the programme has presented a complicated, contradictory maternal figure who is both committed to her domestic environment, yet on occasion stifled by that self-same domesticity, and it is this challenging maternal figure rather than a narrow domestic stereotype that has proved popular with mothers in the contemporary audience, who have quite literally in many cases grown up with this maternal figure. 
While The Simpsons is well known and much loved for its animated version of working-class family life, Malcolm in the Middle has proved popular for what many have suggested is the live action version of its animated predecessor, with Lois stepping into the role of Marge. And although Malcolm in the Middle finished nearly a decade ago, this programme continues to prove popular with audiences, either due to its impact on maternal audiences when it first aired in 2000 or due to its continued presence on our screens through a range of terrestrial and satellite channels. This American sitcom is set in a working class suburban neighbourhood, focusing on the educational, social and domestic tribulations of Malcolm/Frankie Muniz, his three, and then later four brothers, and their parents, Lois, who works full time at a drugstore and $\mathrm{Hal} / \mathrm{Brian} \mathrm{Cranston}$. The title character of the series, Malcolm, is a genius with an IQ of 165 and a photographic memory, and as such he is placed in a class for gifted students, which simply compounds existing adolescent feelings of alienation and otherness experienced by the average teen (Feasey 2008a). Irrespective of his educational abilities and gifted status, he and his brothers are given strict rules and responsibilities by their mother, which are repeatedly and routinely ignored. As the series progresses, storylines focus on the other family members, but it is the character of Malcolm who breaks the fourth wall by talking directly to the viewer in a mockumentary style of commentary.

With five wilful boys (and possibly a sixth in the final episode of the show), a full-time job and a hapless husband, Lois takes on the responsibility of the family in terms of organisation and discipline. Her maternal style is akin to that of a drill sergeant. She demands respect from and for her family and she always follows through with her threats. The actress who plays the role tells us that:

Those kids are naughty, but what I love on that show is that they just never got away with anything, as naughty as those children were. And I think that's part of the reason that show was so funny was that if you let your kids get away with stuff it's not funny to watch. If you know that Lois is like a hawk watching those kids, they have to really be clever on what they're trying to get away with. And that's where the humor was. (Graham 2008) 
Lois has high aspirations for all of her children, but none higher than Malcolm. When, in the last episode, he is offered an impressive professional role with a six-figure salary she turns it down on his behalf, telling him:

... it's not the life you're supposed to have! The life you're supposed to have is you go to Harvard, and you earn every fellowship and internship they have. You graduate first in your class, and you start working in public service, either district attorney or running some foundation, and then you become governor of a mid-sized state, and then you become president ... of the United States ... you're gonna do it ... you'll be the only person in that position who will ever give a crap about people like us. We've been getting the short end of the stick for thousands of years, and I, for one, am sick of it. Now, you are going to be president, mister, and that's the end of it ... you know what it's like to be poor, and you know what it's like to work hard. Now you're going to learn what it's like to sweep floors and bust your ass and accomplish twice as much as all the kids around you. And it won't mean anything because they will still look down on you. And you will want so much for them to like you, and they just won't. And it'll break your heart. And that'll make your heart bigger and open your eyes and finally you will realize that there's more to life than proving you're the smartest person in the world. I'm sorry, Malcolm, but you don't get the easy path. You don't get to just have fun and be rich and live the life of luxury ... you look me in the eye and you tell me you can't do it. (S7:E22)

Lois is a strong and demanding mother who works tirelessly for her family, and although there is little reward or recognition for her efforts, it is clear that her husband and children care deeply for her and for one another, in spite of, or perhaps because of, her authoritarian demands. Lois' maternal sacrifices are paid off in the final episode of the show when Malcolm speaks of the importance of family in his valedictorian speech, quoting Paul McCartney as his mother had asked him to do. It is only a few words and a small gesture, but in the context of the programme's long history it speaks volumes about her maternal influence over her family, and offers a reward for all of her emotional, physical and financial commitments to her children.

Lois stands as a proud working-class matriarch, and although we are asked to view her class battles throughout the series, her commentary on their lower socio-economic status is most clearly felt in this final episode. The character appears a firm favourite with mothers in the audience because 


\section{of her commitment to her family, her efforts to support them and her need to speak out against injustice:}

Lois is queen of them all... I love her big speech in the very last episode.

I am always drawn to those strong, dominant mothers who demand respect (rather than a friendship) from their children (and husband) ... classic example of this type of maternal role model.

If ind mothers appealing who have their own personalities and who are in relationships with their children that demand effort and energy. Blissful babies that conveniently run in at the end of conversations just for hugs make me feel a bit ill.

Lois is controlling and demanding of her children but it clearly comes from a place of love and frustration, because she wants her children to have a more comfortable life than she herself has experienced, and surely that is a sentiment most mothers can relate to.

When Lois gave that speech about her son becoming President one day, the hard way, from his working class roots it was genuinely moving, I know sitcom is meant to be funny, but Lois actually makes me think about politics and parenting while I am laughing.

Strong, smart, capable and compassionate in equal measure. She is an incredibly dedicated mother who doesn't always find satisfaction in her maternal role, but she does not apologise for these feelings. She is a good mother, not an impossible ideal of how mothers should be.

Lois is the best mother on television, she really cares about her family but not in a sugar-coated way, she sees their flaws, loves and accepts them and tries to support them through mistake after mistake. She makes motherhood look hard, relentless, unforgiving and unappreciated ... she is the nearest thing to a real mother I have seen on television.

Lois is the queen of sitcom mums, she is a strict disciplinarian who would give Supernanny a run for her money, but then Supernanny never had those smart, scheming boys to contend with. She is a wilful woman and a caring mother, and she always did her very best to care and provide for her children, which was admirable under strained circumstances.

Lois is by far the most developed 'mother' character - she is complete in her frustrations and successes with family and work and in the midst of trying really really hard to make sure her kids have a better life, she occasionally finds humour and time to enjoy herself with them. You can feel the palpable relief when she can actually let go and enjoy her time 
off ... you empathise with her stress and frustration and her desire to keep vigilant in a tough world ... hilarious but believable relationships with her husband ... and children.

While The Simpsons and Malcolm in the Middle are popular for their representations of strong, working-class mothers, their middle-class counterparts have more recently returned to our television screens, and although the size and location of the home and the quality of furniture and home furnishings may differ, maternal practices remain reasonably consistent, the fathers appear hapless, the mothers harried and the children outnumber their parents.

Outnumbered is the south London-based middle class suburban sitcom centred around the Brockman family, focusing on the exploits of parents Sue and Pete/Hugh Dennis and their three children. While Sue works part time as a personal assistant, Pete works full time as a history teacher in an inner city London school. The show has received critical acclaim for its semi-improvised scripting and realistic portrayal of children and family life, due in part to the fact that although the adult actors rehearse their comedy scripts, the children are given last-minute instructions by the writers:

The words those children speak are of their own, on-the-spot devising. In probably any other family sitcom you can name, the child characters talk not like children but tiny adults, all slick wisecracks and old-before-their-time wisdom. The ones in Outnumbered, though, display the stumbling speech patterns of real-life children and their adult-confounding logic. (Deacon 2010)

However, although critical commentators praise the improvised nature of the show for its ability to capture realistic communications between parents and children, writer Andy Hamilton echoes the maternal audience when he says that the show's success with parents is based on debunking the 'good' mother, for one that is well meaning and just 'good enough'. We are told that Outnumbered was 'conceived in small part as a counterblast to the great torrent of books about to years ago advising people on parenting, as if it was a perfectible art' going on to tell us, that 'all those books do is make people feel inadequate and miserable' (ibid.). Therefore, while parenting advice manuals were encouraging women to adhere to the ideology of intensive mothering and present themselves as selfless and satisfied caregivers, the 
sitcom in question was keen to 'celebrate the incompetence of parenthood' because 'when you talk to ... parents and get them to be honest about some of the abysmal parenting they might have done, you realise that most parents ... muddle through at best. That's just the way nature plans it' (ibid.). This notion that the programme can be seen to reflect and respond to the reality of contemporary family life is echoed throughout much cultural comment on the show in question, so we find that:

The magic ... is that it's close enough to real family life to strike a chord with parents and children alike. Watching the Brockmans' wonderfully frazzled Mum, Sue ... and put-upon Dad, Pete ... desperately trying to work out how best to enforce decent moral codes in their middle-class madhouse of a family home, must be recognisable to any parent watching from the sofa, nodding along in despair. (Stock and Smith 2014)

Mothers in the audience echo these sentiments as they comment on the ordinary, mundane and everyday nature of the scenes and sequences that make up the programme, with participants routinely commentating that they have observed, understand or experienced much of the parental behaviours being presented in the show. They are clear to point out both the poor parenting practices and the well-intentioned decisions behind such practices, and it is this combination of mother love in concert with wellmeaning yet ineffectual maternal practice that speaks to mothers in the audience:

The mum in Outnumbered I found easy to relate to.

No one other than Sue Brockman in Outnumbered

I like Outnumbered, it is a clever and funny series about parenthood.

I love the fictional but realistic mums - the mum on Outnumbered is great - it looks like real family life!

I like Sue in Outnumbered ... something of the 'ordinary' about their lives ... even though they are fictional!

The mum in Outnumbered who is constantly juggling - it reflects my life. Also, the children are not perfect or outrageous. 
If find the series Outnumbered has more of a realistic view on motherhood, that being said, the narrative is written for comedic effect.

I loved the programme Outnumbered as that seemed to show it how it is and was very well and realistically observed - and very funny.

I do like the mum out of Outnumbered as she is, in a funny way, a real mum muddling by with everyday challenges of raising kids.

One that I can think of is the one on BBC's Outnumbered. They have a normal family house and a realistic family life ... even if it is a comedy.

I like Outnumbered, the parents literally outnumbered by their three children ... the kids are challenging, the father loving ... the mother trying to keep the peace.

I'm just doing my best balancing the needs of all members of my family including myself ... If I had to pick a character it would be the mother in Outnumbered!

The show Outnumbered - that's amazing, the mum is spot on, frazzled trying to do everything for everyone and somehow always getting it wrong, however well intentioned.

The mother on Outnumbered. This to me is the most realistic portrayal of parenthood; messy, unplanned, feeling your way through life rather than having the answers to every problem.

The mum on Outnumbered! I guess because she's most closely portrayed to real life! (And she's probably the only mum in a show which I watch which is actually about being a mum really).

I generally find the portrayal of mothers traditionalist and unrealistic, stay at home mums or super-mums, not in between ... the mother in Outnumbered is the only one that is a believable mother.

I do ... love the way that family life is portrayed in Outnumbered. I know many fellow parents who find it so close to the truth that they find it painful to watch! I find it hilarious, and somehow comforting!

Outnumbered. It's not a million miles from reality. We watch it as a family and poke each other when the frequent observant remarks are made. The attitude to the children is probably similar to mine. And their lives seem real. 
This notion of realism, or at least recognition is key to the appeal of another long-running sitcom on the other side of the Atlantic, Modern Family. Modern Family is an American sitcom based on an extended family unit over three generations. The programme is based on the exploits of Jay Pritchet/Ed O'Neill, his second wife, his stepson, and their infant son; and his two adult children and their families in suburban Los Angeles. Although Malcolm in the Middle broke with traditional sitcom conventions by employing a mockumentary mode of address for the eponymous Malcolm, Modern Family asks all characters to talk to camera, in a confessional, break-the-fourth-wall style. Although there are a number of mothers seen in this programme, it was Claire Dunphy, the stay at home mother of three married to real-estate agent Phil/Ty Burrell who received acclaim from audiences. Moreover, it is the Dunphy unit that draws repeated comparison to the Brockmans of Outnumbered, with commentators asking 'middle-class parents, unruly kids, mishaps involving dad shooting people by accident with a toy gun, the middle son getting his head stuck in the bannisters. Remind you of anything yet?' (Frost 2009).

Irrespective of whether audiences noted the comparison, they found Claire, like Sue, to be a believable maternal figure struggling with the changing daily difficulties of contemporary parenting. The character biography tells us:

If her teenage daughter, Haley, never wakes up on a beach in Florida half-naked, then Claire Dunphy feels she's done her job as mom. See, it's not easy to keep everyone in line when you're raising three very different kids (four, if you include hubby Phil). As exasperated as she sometimes seems to be, we get the sense that Claire wouldn't change a thing when it comes to her family. Claire will always fight for what's right. An ignored request for a stop sign at a dangerous intersection led to a run for town council against smarmy Duane Bailey. Things didn't go well at the debate as evidenced by the autotuned 'Sex Freak Candidate' video that went viral afterwards. Election day didn't go much better as Claire not only lost the race, but she also lost a fake tooth incurred during her 'Fire and Nice' ice skating days with brother Mitchell. Nevertheless, Claire Dunphy will always be a winner at home and the persistent one who keeps this Modern Family going. (abc 20I4) 
This biography is echoed by cultural commentators when they tell us that:

Claire is a control freak, and as the series has gone on, she has become more so. Tasked with overseeing the smooth running of her household, she can be shrill and bossy, finger-pointing and cutting ... It is understood by all the Dunphy's, Claire included, that she is what makes their family run and also that she is no fun ... Despite all of this, I still really like Claire and I'm not the only one ... She plays, on paper, Modern Family's most unlikable character and she does so with no caviling or pulled punches, just spiky, committed energy and a knack for pratfalls. As sitcoms get older they often end up being about, inadvertently, people's inability to change. Characters stay more or less the same, because the traits and quirks and jokes they have and make stay more or less the same. Claire knows that she is high-strung and lacerating, and that she can't stop herself. She is constitutionally fated to be the grown-up. (Paskin 2012)

On the spectrum of mommy sainthood ... Claire Dunphy ... lands somewhere on the higher end of the scale but falls far short of perfection ... a mom who believes she knows best - but much to her chagrin (and the audience's delight) very often doesn't. Women especially respond to Bowen's character because she makes so many laugh-inducing mistakes. They love her because she mirrors just about every wellmeaning if fallible mother out there. (Kennedy 20II)

Mothers in the television audience can be seen to form a consensus with the shows creatives and cultural commentators when they state:

Claire from Modern Family... I enjoy any programme where there is a real sense of family.

Modern Family - Claire Dunphy. It might be satirical but many of the situations could be my life!

Claire is a believable character, not just a mother, and that is why I find her enjoyable to watch.

I like watching comedy series with my son ... Modern Family is very funny and also often awkwardly close to reality!

Claire is a believable mum of three struggling to get her husband and children to behave like civilised and responsible individuals.

I like narrative settings where the mothers seem 'buman' - that means not one-dimensional, with admirable and flawed aspects. 
Claire is a brilliant 'bad cop' in the show because she has to show her children the importance of rules and responsibility when their 'cool dad' is behaving like another child.

Claire is rigid and uptight, but I still find her endearing, she takes on a difficult maternal role and is doing her best to maintain order and teach her children about responsibility.

I like the fact that Claire is not a one-dimensional housewife who adores every maternal moment and household chore, I think her frustrations make her more realistic for mothers to watch.

Claire may not be laugh out loud funny, but she is certainly a character that I find entertaining to watch, mostly because she reaffirms my own parental practices, well meaning but not always well considered.

Modern Family is wonderful, I know that there are a host of endearing and comedic figures, but I feel that I can relate to Claire, three children and a buffoon of a husband, she is the only one trying to bring order to the chaos.

I like ... Clare Dunphy from Modern Family and Marge Simpson. I think they both have a happy family life and are both secure in their decisions and situations. They are both stay at home mums which I can relate to and have happy families who look to the mother as the core of the family. They are both strong, caring and loving mothers.

Claire in Modern Family!!! It's hilarious. The house is of a similar type to ours. We have our ups and downs with our teenage children. Then there are the grandparents ... ours have dementia and grumpiness. We have the mad aunt and demanding nieces and nephews. The family squabbles and fantastic holidays together. Yep it's a melting pot but I wouldn't have it any other way.

Claire is liked and even admired by mothers in the television audience due to the fact that she is both a warm and generous maternal figure but not restricted to this role. This character is both a stay at home housewife and sexy, smart and sarcastic woman in her own right. She is a full-time mother but refuses to be reduced to a domestic title, and it is this multi-dimensionality that is appealing in an era seemingly dominated by the notion of intensive mothering. Claire may ostensibly stand as a 'good' mother due to the fact that she is a stay at home caregiver in a middle class nuclear unit, committed to nurturing the emotional, cultural, social and educational development of her three children, but her inability to find serenity and 
satisfaction in this role and her demands for social and sexual fulfilment outside of the domestic environment position the character as something more recognisable and relatable to the women in the audience, a mother who is 'good enough'. After all, even though caring for children might at times be pleasurable, fulfilling and emotionally rewarding, the show, like Outnumbered before it, makes it clear that 'the burden of caring for children can become routine drudgery or emotional torment when it is done constantly, repeatedly, because of one's obligations, and when it consumes nearly all of one's energies and time' (Held 1983).

What is interesting here is the way in which the maternal traits of the character and actor accord. After all, while Claire Dunphy is admired and applauded for her 'good enough' mothering outside of the ideology of intensive mothering, so too is actress Julie Bowen. Indeed, we are told that it is easy to find similarities between role and star because both are the harried mother of three children, both are quick-witted, funny, fiercely protective of their families and blunt about motherhood. Bowen, like Dunphy strayed from the romanticised image of ideal motherhood when, in a moment of candour, confessed that raising babies was 'pretty awful' at times, stating that she 'did not always enjoy' her children's younger years (Neithercott 2014).

Moreover, Bowen admits to needing childcare help during the week and finding a return to the working week a welcome relief from the maternal role, telling interested parties that 'I really resent the militants who insist things must be one way or another. Do what works for you, and cut yourself some slack with the comparisons' (Kennedy 20II). While she admits that time spent with her first child was in line with professional motherhood practices, her twins demanded a change of parenting style, meaning 'fewer Mommy \& Me classes ... and an ability to stop sweating the minutiae of her children's lives' (ibid.). Bowen announced:

I like the episodes where Claire has to have a glass of wine and collapse, and they all know it and no one really judges it ... I didn't know, maybe lots of people in the world didn't realize, that there were other parents out there who were kind of just holding it together with tissue paper and twine some days of the week. Claire is doing a great job, but still there's times that she's like 'Mommy's gotta lie down now, and I find that very comforting. (Shewfelt 2013) 
Bowen has been vocal about the pressures of contemporary mothering and the ways in which women set themselves impossible maternal goals, to the point where she has been applauded by psychotherapist Debra Gilbert Rosenberg for her candid views on parenting. Rosenberg tells us:

\begin{abstract}
The pressures of modern-day motherhood can feel overwhelming ... Women buckle under it. They simply can't be in three places at once ... yet they try to be. With so many women working full-time jobs while attempting full-time motherhood, there are many false expectations. And this combination of factors pushes toward ever higher, often unattainable standards of what it means to be a good mother. (Rosenberg, cited in Kennedy 20II)
\end{abstract}

Rosenberg has referred to Bowen's more relaxed approach to motherhood as 'healthy' for both mother and family unit; that said, even though Bowen suggests that there is too much pressure on contemporary women to become ideal mothers, her comments can be read in line with the ideology of 'good' motherhood. After all, Bowen makes it clear that her work on the set of Modern Family 'happens to dovetail nicely if you have a family ... There's a lot of kid time, and there's a lot of work time. It works' (ibid.). She goes on to comment that while her co-stars in the sitcom work on other projects when the show is on hiatus, she makes a conscious decision to stay at home:

The boys are finally at an age where I find them so luscious and fantastic that I don't want to be away if I don't have to be, she says. It's such a gift not to feel the pressure to go hunting down a job right now. I'm just lucky as hell. (Neithercott 20I4)

And in case readers and audiences remain uncertain as to Bowen's parenting credentials, she informs us that 'I'm constantly shocked that I am successfully taking care of this family and that I'm capable of putting their needs in front of mine' (MacIntyre 20II). And interviewers are happy to anchor this appropriate maternal image by telling us that 'Bowen's changing diapers. And building towers out of Legos ... they're content to just spend time with their mom. And Bowen is, first and foremost, Mom' (Neithercott 2014). Under the title 'Motherhood is Well Worth a Few Sacrifices', the Modern Family actress informs us: 
Once the kids were born, 'me time' went away. But I have years and years of me time ahead of me. I didn't really do anything that valuable with it. I did not cure cancer, I did not write the great American novel in blood on a stone. I volunteered, I took up different forms of exercise, I traveled. But ultimately, not having that same me time and giving those extra minutes to my kids is, right now, much more rewarding. (Horten 2014)

Bowen plays a 'good enough' mother on screen and although her earlier comments about her own maternal role positioned her in this self-same struggling position, her more recent remarks are in line with a more idealised figure who finds motherhood the priority and motherwork fulfilling. There is little mention of the demands of the working mother outside of the fact that she refuses to have professional help at the weekends (Leon 2011). The change of tone here might be to do with her growing sons, her work routine or the desire to promote a more acceptable face of contemporary motherhood, and yet, irrespective of the reason behind this shift, audiences were keen to comment on the maternal character rather than the mothering practices of the actress behind that role.

\section{When the professional is political}

I have already stated that a small number of women spoke fondly of newsreaders and culture reporters because they were smart, intelligent women who were not defined by motherhood; so too, a minority audience made this same point regarding fictional television characters. A small number of women commented that they liked strong, complex professional characters who also happened to be mothers, women who are defined by their working role rather than their domestic commitments. These mothers were not favourites for the majority of women, but are deserving of notable mention due to the fact that they speak of a very different portrayal of motherhood, namely Abbey Bartlet/Stockard Channing (West Wing, 1999-2006), Dr Lisa Cuddy/Lisa Edelstein (House, 2004-I2), Skyler White/Anna Gunn 
(Breaking Bad, 2008-13), Alicia Florrick/Julianna Marguiles (The Good Wife, 2009- ), Lori Grimes/Sarah Anne Wayne Callies (The Walking Dead, $2010-$ ) Birgitte Nyborg/Sidse Babett Knudsen (Borgen, 2010-13), Rachel Matheson/Elizabeth Mitchell (Revolution, 20I2-I4), Freya Hoynes/Emily Watson (The Politician's Husband, 2013) and Ellie Miller/Olivia Colman (Broadchurch, 2013-). This audience highlighted the astute, expert or skilled status of these women before making mention of their maternal role or motherwork practices:

I like Alicia Florrick for her strength and career focus whilst also being a caring mother.

I tend to watch drama, I like to see strong articulate women ... I think I prefer motherhood to be almost incidental to the character.

Birgitte Nyborg, she is a powerful and resourceful woman. I enjoyed watching her juggle her career and mothering responsibilities.

Dr Lisa Cuddy is an interesting portrayal of wanting to have children and facing the challenges that it brings... She is smart, capable and seeks a balance between work and bome life.

I find characters such as Rachel Matheson in the show Revolution interesting - she is intelligent, able and willing to fight for her kids, but isn't portrayed as the typical 'soppy'mother.

I tend to watch box sets of US dramas where motherhood is part of life, not a topic, brunt, joke or stereotype. A good portrayal of mothers on television is Abbey Bartlet. She is intelligent, has a great career yet prioritises her family in an appropriate way.

Emily Watson's role in The Politician's Husband was brilliant as it showed a power struggle in a honest way, and the balance which mothers and wives have to make, and it made you question the status quo, i.e. the media-ready impression of politicians' relationships.

I... like to watch interesting women who happen to have children, rather than characters defined as mothers. For example Skyler White on Breaking Bad is a very interesting, complex, rounded character and her role as a mother provides just one element of this 
complexity. Similarly, Ellie Miller on Broadchurch brings motherhood as an important element of her outlook and worldview but is not defined by it.

I like characters in which a woman is a mother as well as her other roles. I particularly like Alicia Florrick in The Good Wife, as a mother who has returned to work as a successful lawyer as well as a caring mother. I love how successful, gorgeous and threedimensional she is ... I also love Birgitte Nyborg, who really demonstrates the challenges of combining a high flying career with motherhood, and does it with such charm. She loves her family, but also makes compromises.

These women are all seen struggling to maintain a working balance between their personal and professional lives, but they rarely apologise for their work commitments and make little attempt to hide their interest in their professional role; this does not mean that they are not being judged or ranked for their personal or professional endeavours, but that they continue to maintain, and in many cases, prioritise their hard-won professional positions. Indeed, there was only one mention of a mother in a professional role who was immune to playing out the difficulties of balancing the personal and professional arena, and that was in the shape of Dr Beverly Crusher/Cheryl Gates McFadden from the Star Trek: The Next Generation (1987-94) universe:

Dr Beverly Crusher. She works, raises an independent kid, and maintains a love life without jokes or story lines about mommy guilt. Not only does she behave like a whole person who also has a child, but she is treated as a whole person by her peers. No one constantly questions her choices.

The fact that the only maternal character to be removed from debates concerning 'good' or 'good enough' mothering belongs to a fictional future in the world of science-fiction and telefantasy, is perhaps unsurprising given the predominance of such debates to the contemporary landscape. I am not suggesting that factual or fictional programmes are held up as a mirror to reality, but rather, that they can be seen to be in dialogue with existing social, sexual and political debates, in short, they are located in, if not entirely committed to, the reality of a given period. 


\section{Conclusion}

Mothers in the audience pointed to a wide range of maternal favourites on the small screen, spanning presenters, personalities and fictional characters. The majority of the women who commented on these maternal images, be they 'real' women or televisual constructions suggested that they liked them precisely because they were associated with the maternal role and a wider domestic context. That said, while the majority of audiences responded to presenters such as Tess Daly and Holly Willoughby by way of their maternal status, others foregrounded newsreaders who, although mothers, were not performing in line with a maternal role. Likewise, although the majority of participants spoke with fondness about situation comedy characters such as Marge, Lois, Sue and Claire because they were read as mothers first and foremost, this was not to suggest that they were only mothers, nor solely defined by their maternal practices, but that for the most part, they were seen in and understood in relation to their maternal role. Maternal favourites and likeable mothers are intertwined with notions of recognition and identification; it is as if many women respond to or invest in those characters whose domestic patterns or family deportment reflects, on some level, their own family unit, choices and behaviours, and the majority of the women responding to the questionnaire appear to acknowledge and look sympathetically upon the harried wife and mother struggling to find satisfaction in the domestic role.

What is interesting here is the generational differences between responses, whereby mothers with younger children appear committed to both the fictional depictions of motherhood and to those television personalities whose fame rests in part on their maternal presence. Alternatively, those mothers with older children look for escapism, entertainment and information via mothers removed from their motherwork role. The former finds favourites because of a woman's maternal role, the latter, in spite of it. I asked mothers in the audience to talk to me about their 'favourite' mothers on television, asking them to consider the plethora of factual, fictional, long standing and more recent representations and these women 
seemed to share a consensus in terms of those women mentioned in their commentaries. The number of fictional characters praised by these women was small in number and so too, those maternal performers who appealed to this demographic can be counted on one hand. Although one might suggest that the small number of case studies being spoken about might tell us something about terrestrial viewing, the role of domestic and imported programming or perhaps about the rise of Netflix, where many of the aforementioned texts and characters can be found; what I take from these comments is that, irrespective of the multi-channel, 24-hour television environment, very few characters and personalities on screen appeal to mothers in the audience, and irrespective of where, how or when these figures can be accessed, it speaks of a dearth of appropriate or appealing mothers on the small screen. 



\section{Emulation, not identification: Sartorial styles, domestic skills and maternal discipline}

Terrestrial television gives us access to numerous television channels, and the list of television stations in the United Kingdom available on satellite and cable systems offers more variety again, with many scheduling 24 -hour programming. And in this steady stream of television coverage one might expect mothers in the audience to come across or seek out familiar, recognisable and relatable maternal figures. From this estimation then, it is crucial that we listen to these women as they describe the ways in which they relate to mothers on the small screen and listen carefully when they explain, in detail in many cases, why they do not and cannot identify with the fictional characters and factual personalities that are presented in the schedules. Responses in this chapter relate to a question that I posed in the middle of the questionnaire, namely 'Are there any mothers on television that you can relate to?' with the additional help text enquiring 'Do you feel that you are like these women or can think of experiences that you have seen reflected in the mothers that you see on television? Are you able to identify with their domestic space, relationships, friendships, mothering skills or working environment?'

\section{No, not really and not at all: Struggling to relate to maternal depictions}

A number of women blurred the lines between their favourite fictional mothers and their ability to relate to these women, with recognition being a key part of their investment in one character amidst the many and ostensibly 
varied maternal protagonists seen on screen in the contemporary period. However, it was surprising to find that when asked more directly about any sense of recognition or identification, the majority of women in the audience said that they could not see their maternal choices and motherwork practices depicted on screen, and answered 'no' or a variation of that word when asked.

Many made it clear that they were unable to relate to televisual mothers because they saw these women as predictable stock characters and one-dimensional stereotypes who lived at either end of the maternal spectrum. Indeed, many respondents made the point that motherhood is rarely predictable, straightforward or constant, and that parental thoughts and practices have to adapt daily to changing sibling, family, educational, social, financial and physical dynamics, which were not, they suggested, being shown on contemporary popular programming. The overwhelming majority of women who completed this questionnaire made the point that there were no mothers on screen who could be said to reflect their experiences of motherhood. This is not to say that they did not watch maternal protagonists or that they were unable to take pleasure in viewing fictional mothers and television personalities, but rather, that their enjoyment was removed from any sense of personal identification or more meaningful investment. This question was answered by all women and in the majority of cases these women went on to describe, in some detail, the reasons why they were unable to, or felt discouraged from trying to relate to, mothers on television.

No.

None.

No, never.

Not really.

Not usually.

Not particularly. 
It would seem not!

No, haven't found any.

Not that I can think of.

No one at the moment.

No, I can't think of any.

No, they're not realistic.

No, many are not achievable.

No, I think we're all flawed in some way.

Not particularly - realise they are manufactured!

No. No one person could ever get everything right.

No. There is not one mother that stands out to me.

I cannot think of any on screen mothers that I relate to.

No. Not really. That might be because I'm just a bit weird.

I haven't thought about this before. No one comes to mind.

No. Most of the time they are unachievable or unrealistic to me.

Mothers in TV shows are either portrayed as negligent or perfect.

None that I've seen but my viewing habits are perhaps a little narrow.

I can't think of any, which probably says a great deal about the topic.

Ifeel they bear no relation to my life so I am not interested in watching.

Nope, I usually find those kind of aspirational role models quite annoying...

Most mothers ... are either too mumsy or trying too hard to look like teenagers. 
American sitcom mothers are harassed, frazzled and normally play minor roles.

Not really, I think it depends on your own experience of having and being a mum.

I find most representations of mothers on television to be reductive or unrealistic.

Not on telly. I rather concentrate on real life mothers as I find telly mothers fictional.

I actually can't think of a fictional portrayal of motherhood that I identify with on television.

I can't instantly think of anyone; it may be that I relate more to a blend of different people.

I'm struggling to think of a mum on television that I actually like. They are all so unrealistic.

Women on television seem to lose their own sense of identity when they become a mother.

Many of the situations mothers are depicted in feel clichéd - going out covered in baby sick etc...

Not off the top of my head, I can't really say that there is one person or character I can relate to.

No. I really don't feel there are any characters on television who reflect real modern motherhood on my terms.

I really don't like watching celebrity mums on $T V$ as they can give an unrealistic view of what motherhood is like.

When shows undermine women and make it funny, it pisses me off. It reinforces negative stereotypes and agendas.

I generally feel like mothers on television are either stuck in a relationship, undermined, or left to clean up the messes.

No, I can't think of any such figures in the programmes that I watch. Perhaps because they would not be amusing characters.

None - not found anyone I can relate to. I can't think of any parents on television with a family similar to mine at present. 
None. I believe we all plough our own furrows in life, and do not seek to compare my circumstances with those in the public eye.

Negative images of motherhood are everywhere on television, it somehow seems normal to watch women who are terrible caregivers.

... serves to fuel maternal guilt with the stereotype that women will always choose a family over her career ... as you can't have both.

No, not really. They either have cleaners, nannies, and lots of available money, or are portrayed as victims/stereotypical 'dippy' women.

No. I think my life is pretty common - two kids, I work part time while my partner works full time, but I don't see 'me' represented on television.

Most mothers on television are portrayed negatively, they are not showing the reality of what it is to have to care for young children, if at all.

... benefit families at one end then people like the Kardashians at the other. I don't remember seeing much about people I can relate to.

Most don't seem to be shown in a balanced light and are either far too 'good' and therefore hard to live up to or too 'bad' and therefore unrealistic.

Depends on my mood. Reminds me how these woman are set apart due to their enormous wealth. I don't think their lives relate to most women at all.

No. So little of the representations of mothers is about them being a mum - it's usually about being a household manager. They are two very different things.

Women are usually portrayed as home makers or domineering characters even if they also have a job. Either that or they are tough, unkind, business women.

... too unreal. Story lines have to be very exciting to keep viewers watching and do not reflect the average family at home. Things are always over exaggerated.

I have never thought about this before, but now that I do, I realise that most of the programmes that I watch tend to focus on women who are terrible mothers.

I think mothers are represented as extremes, either the extreme hippy, the extreme hands off mother. I don't feel that there is a true and honest representation on television. 
I generally find portrayals of mothers traditionalist and unrealistic, stay at home mums or super-mums, not in between, there is nothing to relate to in such tired stereotypes.

... patronising and make inappropriate assumptions about how our roles are split and how we relate to our husbands. Many are also ridiculous with their attention to stereotypical concerns.

No, I take everything I watch with a pinch of salt and don't aspire to be like fictional/ unreal expectations. I have always done what I think is right for darling son and I, not what I think others expect of me.

No-one jumps to mind sadly. There are people such as MPs who are seen on $T V$, who are rare examples of people who combine a good career, intelligence and motherhood... but no characters or presenters that I can think of.

You do see more parenting of teenagers on TV, and storylines of bullying ... but family life and motherhood has all sorts of other issues from birth until they fly the nest (including those that don't seem to want to leave home!) that are not reflected in fictional television.

No, I think that most people in the celebrity world either promote their ideal life in magazines etc. that in reality aren't actually like that or their lifestyle isn't achievable for me (I don't have the money/childcare to go on expensive breaks, do fitness classes/ have beauty treatments).

At no time do we see families playing board games with the television off, having a Sunday roast dinner at the table, or making salt dough for the children, going for walks or visiting their grandparents. I wish there could be more love instead of cheating or fighting.

No, It can be misleading to look up to the idealistic view of the television mum as it is exactly that, television, and it is made with a view or target audience and with a narrative that is being told, I believe looking at family and friends will give you a better aspirational ideal.

No one comes to mind. I admire most mothers from all walks of life, those that have more challenging situations than most, the part time mum, the, stay at home mum, to the full-time working mum. I am more inspired by mothers I know rather than mothers I don't know on $T V$.

They are often unrealistically glamourised (e.g.played by actresses not actually old enough to be the mother of their character's children) and restricted to stereotyped clichés of 'the 
working mother' or the 'stay at home mom'. If they get any storyline at all it's generally restricted to the old standard of the affair or almost affair.

Not really. Don't identify with their lives. Having teenagers, I feel they invariably get it wrong when it comes to mothers of teens in sitcoms, for example. They overdo the laughs. Every mother - whichever age group her children is in, has her own moments that, when I hear about them and experience them, make me laugh much more than those presented on television.

No. Where are the $T V$ shows that show the reality of when your child screams their way round Tesco, or hits another child with a brick at the stay and play? Or even better, those lovely times in the woods or out and about when they do something so amazing you just have to stop and stare at their brilliantness? There's none of the highs and lows - just a whole load of bland.

With working mums in particular I feel television does carry on the very dangerous stereotype that the price for having it all (i.e. children and a job) is to do it all ourselves. That a man's working day ends when he gets home, but a woman's must be 24 hours a day. And even when the women are 'allowed' to do stuff outside of the home on television, you never actually see them outside of the four walls of the home.

Generally, no. These fictional television mothers generally never have to think about childcare or babysitters, their partner/husband will be back in time so they can go to whatever appointment they need to get to. You rarely see a fictional character trying to do the weekly food shop with two small children, trying to juggle work around home-life (and vice versa), struggling with car seats, coping with sickness bugs etc ...

No. I see very little on television that I identify with, or that reflects my experiences of motherhood. I work four days a week and my husband works five. We split the housebold and children tasks equally - it suits us temperamentally and practically. The only representations I see of working mothers are the harassed, overworked mum who works all day, and then comes home and does all the housework too while the husband hangs about being a bit useless. The implication being that she has an extra child to look after, manage and get under her feet, rather than a partner that she runs her life and home with.

Not really. Although perhaps this is because I tend to be watching Peppa Pig these days ... and no I do not identify with mummy pig. It winds me up that Miss Rabbit (the only character without childcare responsibilities) does EVERY single job available. And you never see daddy pig cooking. Am I off topic here? 
For those readers unaware of the 200-plus episodes that make up the Peppa Pig (2004-) phenomenon, Miss Rabbit does indeed do every conceivable job in the cartoon swine world, including school bus driver, ice cream seller, supermarket checkout operator, museum worker, ticket seller at windy castle, shoe shop worker, operator of car crusher at the local recycling centre, dental nurse, train driver, firefighter, librarian, helicopter pilot, and no the respondent is not off topic here. Peppa Pig and its surrounding merchandising bring joy to toddlers and infants alike, but it is clear that traditional sitcom characters remain in play in this animated universe. The female character without dependents is the one who routinely contributes to the public sphere, and although both mummy and daddy pig are both seen working, it remains mummy pig who routinely takes control in the domestic arena.

Mothers in the audience appeared to speak in agreement when they commented that their day-to-day lives were not reflected in the shows on screen, be they children's programming, family texts or post-watershed titles; irrespective of genre, schedule or format. Women critiqued existing maternal representations in part because they refused to show the lived experience of early motherhood, and in part because they often removed children, and by default, the mothering role from popular programmes:

... mothers seem to have optional children, e.g. in dramas where the children are only present when relevant to plot but absent without explanation for the rest of the time.

I find it interesting how people in the public eye seem to be here there and everywhere without their kids. I find this difficult as a stay at home mum. There seems to be a lot of famous people who rely on a nanny. How our lives differ!!

I find that family life is not portrayed realistically in television at all. It might be to do with the complication of getting children to act, but children are not featured much ... characters often become mothers and still find time for the lives that they were living before ... who bears no relation to real mothers.

Characters are always unrealistic - the baby/child will be in the storyline at certain times but at other times, often for extended periods of time, the baby/child will be nowhere to be seen and not even referred to! Whereas all parents I know never have this luxury 
- their baby/child is there or on their mind in terms of who is looking after them and when they need to pick them up etc. ALL the time!

... actor children just don't behave like the real thing as they are usually incidental to the story while for a real mother, her children are central to her story.

\section{A number of women sought to make sense of the limited depictions, noting that their lives were not reflected because the subject matter was deemed too dull, repetitive or lacking in drama, glamour or escapism:}

Real mothers' lives are not glamorous or interesting.

I am a married, full-time working mother with two children under five and each morning feels like a challenge in itself. I am constantly feeling guilty that I am a disappointment to my colleagues, children and husband. I rarely see mothers in this situation on television, or at least I have not come across any that I readily identify with. To be honest, even if I did see my own situation and stresses replayed on screen, I wonder if I would either recognise the similarity or relate to it. Perhaps I would find it unappealing to watch if it was too close to my own situation.

I could semi-relate to Miranda from Sex and the City even though her domestic and financial situation was far removed from my own, I empathised with the guilt and frustration that she expressed at having to compromise on what she saw as both her career and domestic duties. I have no housekeeper or nanny so my sympathies only went so far, and my sympathies morphed into frustration during the film of the same title when Miranda asks Charlotte 'How do mothers without help cope'. How indeed! I guess that a slightly more 'realistic' version of the career/domestic juggling act would be a little less glamorous and a little less of interest to a mainstream audience without the fabulous clothes, dwellings, lifestyle and social events.

I don't think that people really want to see the true face of motherhood, the two hours a night sleep, clothes that if you are lucky fit you let alone clean and roots that come down to your ears where you are deprived of money and time, something the portrayal of mums on television do not show.

Storylines may not be seen as interesting if focussing on the tasks a new mum has to carry out day-to-day ... Examples of this can be seen in Friends and How I Met your Mother. 
These viewers experience frustration and disappointment because their lives are not being depicted on screen, and yet, they also acknowledge that their families' trials may not be deemed appropriate material for mainstream audiences. Some respondents went as far as to suggest that 'realistic' depictions of motherhood and motherwork might actually be off-putting for a mother experiencing her own chaotic domestic environment. The assumption here is that the minutia of domestic routines and maternal responsibilities is both unwelcome and unpalatable, which is surprising given the content of much critically and commercially successful programming that takes domestic concerns as their focus within a myriad of popular and niche genres and formats. One might go as far as to suggest that these women are devaluing their everyday skills and maternal competencies and overlooking the emotional narratives and continuous dramas that are played out in their seemingly mundane mothering practices. Indeed, commercial broadcasters might want to take note of all those maternal voices who are unable to find a mother on screen that they can relate to; after all, to offer these women an authentic rather than a one-dimensional stereotype could prove popular, and those women who seem convinced that they would neither recognise nor particularly enjoy watching more realistic maternal depictions might find themselves surprised by the fascination, interest and investment in the details of women's stories in contrast to those dramas on offer in extant family and domestic programming.

Moreover, while the paucity of recognisable maternal images might prove financially viable for commercial television, it is crucial that these women are fully represented on public service programming. The BBC, for example, tells audiences that they can expect their productions to 'reflect the many communities that exist in the UK' - be they based on faith, language, geography or shared interest (BBC 2014). Although the definition given in their example of 'shared interest' is sport, so too motherhood might be understood as a defined community with a particular focus, one which is currently not being appropriately or responsibly depicted according to numerous women in the popular audience. And although representing diverse communities to the broader nation is not considered the most important priority for licence fee payers according to the BBC Trust's recent research, it is said to remain a crucial part of their public purpose, 
and as such, the corporation might do well to look again at its current representations of motherhood throughout their schedules.

Seminal research produced by the professional lobbying group and gay rights charity, Stonewall, highlighted problematic representations of homosexuality on the BBC. By conducting a detailed content analysis and subsequent focus group research, Stonewall discovered that there was a disturbingly small number of gay lifestyles or life experiences depicted on screen, and that those few representations that did exist relied on negative assertions and homophobic commentary, albeit presented under the guise of humour (Cowan and Valentine 2006). The suggestion here was that homosexuality was being ignored or negatively portrayed in public service programming, and one might suggest that many mothers who responded to my questionnaire felt similarly overlooked or misrepresented within and beyond the public service remit. It is both surprising and disconcerting to find that although motherhood remains the most common shared experience amongst women, the majority of these women found nothing and no one to identify with on the schedules. I am aware that as I write the words women, mothers, motherhood and motherwork there is the suggestion that I am referring to a single, monolithic and stable maternal figure that crosses all age, ethnic, class and geographic boundaries. I am not, of course, trying to suggest motherhood is a unifying experience or that there is not a myriad of maternal thoughts, behaviours and practices, but what is clear here is that women from a range of different age, economic and domestic backgrounds deem themselves invisible on screen.

Women made the point that the representations of motherhood on television were pitched at the extremes, with maternal figures being routinely written, and written off, as one-dimensional figures with little scope for growth and little room for complex characterisation. At one end we have the figure of the professional working women remaining just that, with storylines revolving around her working life with the occasional nod to the struggles of juggling the personal and professional arena. At the other end we have the well-meaning stay at home wife and mother who struggles to discipline her children and hapless husband with the occasional failed foray into the world of work. There is very little sense that these women might be, have been, or look to be both the stay at home and 
the professional woman, with storylines exploring more seriously (with or without comedic relief) the difficulty of balancing a myriad of personal and public responsibilities. The television schedules do present varying levels of economic viability and family stability, showcasing differences in lifestyle, dress codes and parental conduct depending on the programme in question, with several shows foregrounding generational differences between grandmother, mother and daughter, but within the confines of the character biography for each show, there is often little in the way of complex character development for the mother. Storylines are introduced, characters move from a state of equilibrium to disequilibrium and back again as demanded in a linear narrative, but mothers rarely develop within or beyond their defined maternal role.

It is not uncommon for reality programming, situation comedy, lifestyle shows, dramedy or more traditional dramatic genres and formats to remain on our screens for several years at a time, and this is where television must embrace its distinctiveness as a mainstream entertainment medium. Writers have the luxury of time, time to develop fully rounded, multidimensional and multi-tasking women who are, at varying times, able to present their maternal instincts, motherwork efforts and broader professional ambitions or skills. Soap opera remains one of the few television genres that is routinely championed for looking beyond stock characters and predictable maternal stereotypes for the simple reason that popular characters are seen too frequently and for such an extended period of time that it actually makes it difficult to script within the confines of a strict and unchanging biography (Hobson 2003).

Although many respondents found recent maternal storylines on the soap opera to be too depressing, harrowing, troubled and traumatic to be understood as recognisable or even favourable due to the genre's recent attempt to attract a broader audience demographic, the genre's ability to write characters who are difficult to classify or categorise might be considered a useful starting point for programme makers keen to embrace more rounded maternal figures. Moreover, one might chose to look to what Amanda Lotz has recently referred to as the 'male-centred serial' for examples of character development and complexity. Representations of masculinity have historically dominated fictional entertainment, and 
television is no exception; yet Lotz is not using the term 'male-centred' to simply foreground a set of shows that have a male protagonist or a slew of male characters at the forefront of the narrative, rather, she coins this term to refer to those contemporary cable productions that tell stories about men in both their personal and professional roles, in order to examine 'the entirety of men's lives' as they are presented in the text (Lotz 2014). Recent titles such as The Sopranos (1999-2007), Scrubs (2001-10), The Shield (2002○8), Nip/Tuck (2003-I0), Rescue Me (2004-II), Boston Legal (2004-08), Entourage (2004-II), Dexter (2006-13), Psyche (2006-14), Californication (2007-14), Sons of Anarchy (2008-14), Breaking Bad (2008-13), Hung (2009-II), Men of a Certain Age (2009-II) and The League (2009-) are all said to focus on the changing and conflicted depictions of masculinity and indeed, in many cases, fatherhood, something currently said to be lacking in female defined texts. The fact that I struggle to write the phrase 'female-centred' drama is telling and may be an issue bound up with the lack of real, meaningful, difficult and complex representations of women as mothers, and of women as more than mothers in the contemporary television landscape.

I am not suggesting that women do not find pleasure, escapism or comfort in existing representations of motherhood on the small screen; indeed, the comments supplied by hundreds of women to my questionnaire and a cursory glance at the commentaries and reviews provided by mothers and audiences to television forums on maternal networking sites makes it clear that there is much to admire and amuse on screen, but there remains a proportion of the maternal population who remain unconvinced by, and cold towards such depictions. One might suggest that the lack of convincing, believable or realistic representations of motherhood might be consistent with a patriarchal set of creatives behind the scenes, and although this might seem a simplistic leap, it is worth noting that in American television women comprise only 27 per cent of all 'individuals working as creators, directors, writers, producers, executive producers, editors and directors of photography' with only one in four women taking on a writing position in prime time American television in the 2013-14 season (Lauzen 2014). Women comprise the majority of television audiences on both sides of the Atlantic (Ryan, cited in Ryan 20I I), and as such, it is surprising to find that 
men continue to outnumber women as writers. One might tend to think it an advantage to have equal numbers of men and women working on developing new and existing programmes in order to present a depth of personal and professional experience. And yet in reality the industry is anything but an equal opportunities employer:

Between 2006 and 2009, some 5,000 women (compared to 750 men) left the TV industry. This suggests that the demands of family life are convincing some women that their TV careers cannot continue. This is clearly unfortunate for those mums who want to carry on working in an industry they love, but it is equally concerning for the industry itself. The audience is not accurately represented, and it is also losing a considerable amount of valuable talent and experience. (Smith 20I5)

And likewise,

... writers talk about how in tough economic times and with their business model up in the air, networks go for the familiar, which means more dudes. And some showrunners think having one woman writer is enough, though that's not easy on the sole woman in the room. One writer said she had worked on a show that fired the only woman on staff every few months, and compared her own experience to 'walking around with a target on your back'. (Carmon 20II)

When asked to comment on the reality of the gender bias in the industry, writers 'offered various interpretations, ranging from economic pressures to old-fashioned sexism. Taken together, their observations paint a nuanced picture of a professional environment that's as stubbornly resistant to change as any in America' (Ryan 20II). It has been suggested that job opportunities for writing staff have been decreasing since the writers' strike and the recession, and that 'when jobs are harder to come by, it's minorities, including women, who are disproportionately impacted' (ibid.). It is difficult not to make connections between the lack of female creatives and the lack of what some audiences see as convincing and relatable maternal figures on screen. However, this creative inequality is not restricted to the American networks; indeed, it is Britain where the gender disparity is more noticeable. Exhaustive research has looked at 'every scripted show that aired six or more episodes in America in the last three years on any broadcast network' and concluded that out of the I54 American television shows looked at, only 
one employed no female writers, 0.6 per cent of programming' (Glymore 2013). The equivalent research on British television, namely, looking at each 'scripted show that aired six or more episodes in Britain in the last three years on ... BBC One, BBC Two, BBC Three, BBC Four, ITV, and ITV2' concluded that 'of the 34 non-auteur British television shows ... looked at, 7 employed no female writers at all' equivalent to 20.6 per cent (ibid.). And although American shows may produce more episodes in which to hire male or female writing staff, of the 154 American titles looked at 'only in took more than 6 episodes to get to their first female writing credit. In Britain, I3 shows took more than 6 episodes to get to their first female credit-and that's not counting the 5 shows that had more than 6 episodes but no female writing credits at all' (ibid.). What has caused genuine outrage amongst feminist television scholars in recent months is the fact that Doctor Who (1963-) show-runner, Steven Moffat has not hired a single female writer in his three-year, 42-episode tenure (ibid.; Baker-Whitelaw 2014).

I am not making any bold assertions that women are better writers or are more suited to writing about pregnancy or motherhood than men, but one might look to make links between the two. The fact is that women are greatly underrepresented in the television industry, and many women in the audience feel that their lived experiences of motherhood are not being realistically presented on screen. Indeed, popular and long-running screenwriter and television producer Shawn Ryan makes the point that in order to appeal to the female demographic, 'it would be an advantage to have greater numbers of women on staff' (Ryan, cited in Ryan 2011). This is not to say that motherhood is being ignored or that relevant themes or meaningful storylines are not being presented; rather, the maternal characters are not relatable or recognisable in and of themselves.

Women in the audience suggested, repeatedly, that they recognised maternal scenes, could relate to mothering conflicts and identified with specific motherwork situations as they were presented on television, but made it clear that they were unable to make sense of the character or wider narrative context. In short, they could identify with the representation of toddler tantrums and sleep deprivation for example, or the notion of 'having it all' as women struggle to combine professional success with maternal responsibilities, but it was the small-scale experience being presented, or 
what one mother referred to as 'bits and pieces of programmes' rather than any character or characters that they could relate to here:

No, not the characters, but some of the situations ... responsibilities, the frustrations and concerns.

I can't think of one mother in particular whom I can relate to but there are instances when watching a programme I feel a connection.

I can't say that I've ever especially related to any mother in any $T V$ show, but there are small parts of many programmes that resonate.

It is less a relation to any character or programme, and more a relation to particular traits that I can acknowledge. Also if they have gone through a certain issue, i.e. sleepless nights, then you can see the similarities in how you deal with it and how they do.

\section{Recognisable behaviours: Toddler tantrums}

Mothers commented on their ability to recognise and on occasion relate to particular scenes, sequences, and storylines as they dealt with the theme of toddler tantrums and misbehaving children, with the suggestion that viewing children's (scripted or otherwise) antics made them feel comforted in terms of their own parental struggles with wilful children acting out the rite of passage commonly referred to as the 'terrible twos' (Sullivan 2014).

Although many parents and much parenting advice speak of the 'terrible twos' as a social and emotional developmental stage, there is said to be little evidence to support the notion of the 'terrible twos' per se. Tantrums and mayhem can begin at any age, and they do not end as a toddler reaches their third birthday, rather, experts tell us that 'most toddlers begin testing limits shortly after their first birthday and continue until about age four' (Onderko 2014). With this in mind, some parents experience years of toddler tantrums, and depending on the number of siblings, some mothers 
might find themselves living with wilful children for over a decade as one child grows out of this phase and another, younger sibling, enters into it. In order to guide parents through these brief or drawn-out tantrum periods, well meaning manuals and online resources take the time to remind us of the joy that young children bring into our lives while offering helpful hints on how to put an end to problematic behaviour:

Toddlers get much bad press, with talk of tantrums, whining and the terrible twos. The truth is, most of the time they're terrific and kind. Here's how to cope with the bad times and make the most of the good. To help you get through the more difficult times, and to put things in perspective, think about all the wonderful aspects of toddlerdom. You could even write a list to refer to when tantrums and tears get you down ... Most toddlers cry a lot less than when they were babies. You should be getting a better night's rest as sleep patterns are established - although some sleep problems can persist during this time. You may have more time for yourself than you had when she was a baby. With your toddler around, you have an endless supply of cuddles and affection. Her zest and enthusiasm for new discoveries can be infectious. Watch her play with a puzzle and enjoy her delight as she manages to make a piece fit. Her perseverance, trying things over and over again, and her sheer determination to master new skills can be thrilling. Your toddler's love of silliness and laughter often allows you to be a child again. Her funny little sayings and expressions can be an endless source of delight. (BBC Parenting, cited in babycentre 2012)

Toddlers and young children are prone to tantrums as part of their development. After all, they are finding their independence and forming their own opinions while struggling to express themselves, which leads to frustrations for both parent and child. Although many parents might value and indeed seek out advice from childcare experts, experienced parents, friends and family, with the thread of mumsnet as just one example paying testament to that fact, other women, such as those who responded to my questionnaire take comfort in seeing children play out their toddler tantrums on screen, be they fabricated or part of a more realistic narrative. For mothers in the audience who have long ago experienced toddler tantrums, viewing such behaviours on television appears almost nostalgic, with women reminiscing about their own experiences of that parenting stage. For women who are currently experiencing this stage of toddler development, they appear to take comfort in what they see as real, authentic and believable tantrums 
when they themselves are struggling with a stubborn child. Although many parents are keen to share stories of irritabilities at play-dates and tantrums in supermarkets, sometimes mothers can feel that they alone are experiencing difficult toddler behaviour, especially when no other children are causing a disturbance at the checkout. Therefore we can understand why these women are interested in seeing storylines that focus on this stage of toddler development. In response to the BBC's well-meaning advice that sees 'zest and enthusiasm' in place of flared tempers and tantrums:

BBC Parenting - they're kidding, right? .... This is not the truth for us at the moment!!! I've had mummiiiiiiiii mummiiiiii all day getting annoyed because he can't get things right. Frustrated because I don't always understand him, upset because he wees and poos in his pull up by accident and wants me but then doesn't ARGHHHHHHHHHHHHH

And another:

He cried his way through his first hair cut which is understandable but that tired him out so when I had to nip to Sainsbury's and get flowers he had the biggest strop ever. He wanted to hold the basket. Fine. But he didn't want to go the right way. He wanted to hold the flowers. Fine. But he wanted to carry them by the stems and drag the heads on the floor behind him. Then he actually punched, hit and stomped on the flowers, threw them at me and screamed as if I'd just slapped him. This was all in the queue. I was obviously pretty embarrassed but I think held it together pretty well, I just ignored him while holding his hand so he couldn't bugger off. I let him drag the battered flowers back to the car then he threw himself in the middle of the carpark road twice. So he got shoved over my shoulder and practically thrown in the car. Then he cried so much he went blue. So I went for the best option of cranking the music up and leaving him to it, he stopped straight away lol, then cheered up as soon as we got home to daddy. Grrr.

\section{The thread continues:}

My son ... is a tantrum thrower and screams and cries at everything. He used to be a fantastic sleeper, $\mathrm{I} 2+$ hours solid from 3 months old, now getting him in to bed is the first struggle and now he gets up in the night too for some reason. More time to myself ? Er no, he gets up earlier, doesn't nap and needs constant stimulation. Puzzles usually end up with him throwing it all on the floor in a huff because he can't do it. I would just love a nice kiss and cuddle but this kid doesn't sit still for a second and 
would NEVER just sit there and cuddle. Yeah, so it's a load of tosh in this house as far as we're concerned!!

\section{And continues:}

... with my daughter doing anything involves 'mummy do it, mummy help little bit' when mummy really is trying to submit a vat return and a no is met with more fake tears than a TOWIE girl and a swoon on the floor followed by a delicate chin knock as she cannot commit to a full head bang bless her.

One blogger even went to the effort to correct the BBC parenting advice in line with her own maternal experiences:

Most toddlers cry and moan a lot more than when they were babies. You should be getting a better night's rest as sleep patterns are established - although you are probably not. You will have less time for yourself than you had when she was a baby. With your toddler around, you have an endless supply of tantrums, snot, tears, slaps in the face and the occasional cuddle or kiss if you ask them enough times for one. Her zest and enthusiasm for new discoveries can be irritating when you just want to go for a wee. Watch her play with a puzzle and enjoy the five minutes of quiet and her delight as she manages to make a piece fit after repeatedly shoving it in the wrong place then throwing it in temper. Her perseverance, trying things over and over again, and her sheer determination to master new skills can be thrilling. Your toddler's love of silliness and laughter often allows you to be a child again. Her funny little sayings and expressions can be an endless source of delight and embarrassment. (Babycentre November 2009 birth club 2012 , italics in original)

Such comments are reminiscent of the delight, relief and camaraderie experienced by those mothers who completed my questionnaire, as they demonstrated an interest in viewing toddler tantrums and difficult behaviours on the small screen:

I do take an interest when seeing a mother dealing with a tantrum or kid behaviour problem.

Storylines that show a tantrum being set off by the tiniest thing are the ones that I can always relate to. 
Desperate Housewives has shown some utterly convincing toddler tantrums, it's always the small thing that triggers them.

It is difficult for any child to act out a convincing tantrum, when you see them on those reality programmes you know that they are real upsets.

Outnumbered has shown some classic examples of children behaving badly over a range of ages, each one looks believable and something I can relate to over the years.

Seeing a full on tantrum is really reassuring, I know we all have our own horror stories, but seeing it played out on television makes me realise it is totally normal and nothing to be concerned about.

Some of the toddler tantrums on the 'nanny' programmes are staggering, watching them week by week is a guilty pleasure. I feel cruel finding pleasure in another mothers' difficulties but it makes me feel a little better when my own children decide to take a tantrum turn.

Toddler tantrums are played out in minute detail on parenting reality shows ... there is something entertaining in watchingyoung children break into fits over the tiniest thing... it reminds you of all those times that you accidentally used the wrong beaker or gave your toddler a different lolly to his sister... all those things that caused tantrums in our house.

I sometimes feel like a terrible parent when my children are having multiple tantrums, without warning, in civilised public places. I am sure that most mums have been there but I never seem to see it happen to them. Watching toddler tantrums on television is like someone giving you reassurance that it is not just me, it is not anything I am doing wrong.

Whether mothers in the audience enjoy a sense of maternal superiority over other mothers whose children are acting up or take comfort in viewing those challenging behaviours that they too are experiencing, the notion of making such behaviour public is popular with many parents in the contemporary period. While the picture perfect family portrait clearly remains popular with many parents, albeit in an ostensibly 'candid' moment favoured by many studio photographers in recent years (Bartlett 2014), child shaming is a growing phenomena on and beyond the small screen. While fictional programmes script toddler tantrums and reality television films them as they happen, thousands of parents are posting photographs of their children mid upset for the attention of an interested public. Greg Pembroke's 
multi-award-winning blog, 'Reasons My Son is Crying' has received over I4 million hits, the content of which is, quite simply, photos of his sons having tempter tantrums and a short caption explaining the reason why. In relation to this recent representation of toddler tantrums we find that:

Greg provides relief by cheerfully cataloguing his failures, his bafflement at the illogical responses to ordinary situations of his children, Charlie, four, and William, two, and the myriad ways in which he has disappointed and distressed them ... Parents everywhere have grasped with joy the pictorial evidence that reveals, despite cultural differences, that the despotic nature of toddlers is universal. (Maxted 2013)

Pembroke posts a new toddler image and accompanying caption every day taken from the thousands now sent to him, and his desire to debunk the perfect family photo for something more real or relatable has proved popular with national and international audiences alike. The blog might be seen to echo the sentiment spoken of here in terms of finding more realistic and less romanticised depictions of early childhood for the mother in the audience experiencing the reality of those early developmental stages.

\section{Recognising behaviours: Sleep deprivation}

Like the representation of toddler tantrums, the theme of sleep deprivation came up repeatedly in the commentaries, with a number of women foregrounding Sex and the City (1998-2004), Desperate Housewives (2004-12) and How I Met Your Mother (2005-14). What is interesting here is the fact that mothers in the audience relate to the theme of sleep deprivation rather than relating to the particularities or peculiarities of a specific character in these popular texts:

Lily on How I Met Your Mother accurately reflects how tired new mums can be!

How I Met Your Mother doesn't know what to do with the character of Lily now that she is a mother, her maternal role looks forced and awkward, not the acting, but the script 
and story. The only bit that seems remotely believable is how her and her husband are handling life with a newborn, or rather the lack of a normal social life and their lack of sleep.

Alison Hannigan's character in How I Met Your Mother. I like the more realistic and amusing representation of elements in her life as a mother, such as the tiredness, arguing about whose turn it is to get up, weaning, trying to get the baby to sleep. But it does seem unrealistic how often she is able to meet her friends at the bar, especially compared to my experience!

I loved the mums in Cold Feet; this was before I was a mother myself but they all seemed really true to life and I often think of Karen bursting into David's office with her kids demanding a nanny when my two are stressing me out!

Desperate Housewives - for example dealing with sleep deprivation

... one of my favourite lines is when Lynette finds out she is due to have twins not cancer and asks them to check again!

I like watching programmes that don't show Stepford Wife types and show women struggling with real world issues - even Miranda in Sex and City wasn't able to wash her hair for days and fell asleep in her law books!

It's not new, but I remember watching Miranda on Sex and the City struggle with sleep deprivation ... it made a lasting impact on me, the fact that it was in such a 'fabulous' show made me feel less weak when it came to my turn to experience that particular pain. I made a point of re-watching those far too brief scenes in the early days of motherhood. I was nothing like the character of Miranda, and had no real understanding of her privileged life, but I could relate to her lack of sleep.

What is clear here is that although audiences are able to loosely relate to the theme of sleep deprivation as it is presented by characters such as Lily (How I Met your Mother), Lynette (Desperate Housewives) and Miranda (Sex and the City), there is little else about these figures that they find relatable or realistic, either within or beyond their domestic role:

In reality most mothers - especially those who work outside the home-are permanently frazzled.

Sleep deprivation is genuinely traumatic and I am glad to see it acknowledged on television. 
Not specifics, but I empathise with mothers who are having to work to provide for their children on so little sleep and even less family support. Even when it is played for laughs I still think of it as a serious scene.

I am always slightly relieved to see programmes acknowledge the reality of sleep deprivation for parents of new and young children, I don't care what genre, channel or time of day, just to see others, even fictional others, address this as a genuine problem makes me feel like I am not the only one suffering in my sleep deprived fug.

I know its not a soap or series, but I felt real empathy with Michael McIntyre during one of his stand-up routines when he was talking about his experiences of havingyoung boys, he made the point that while childless couples wish one another goodnight, couples with small children wish each other good luck. I laughed to the point of tears. The fact that I can still remember it speaks volumes about its impact on me watching as a new mother.

Sleep deprivation generally, and sleep deprivation for working mothers in particular is understood to be a serious condition with harmful consequences, so much so that countless blogs, advice manuals and self-help guides exist to document this phenomena. Indeed, recent research tells us that 'the majority of mums in the UK today suffer from chronic sleep deprivation which affects every area of their lives' (Zur, cited in BBC 2002). Although most adults need between six and nine hours of sleep every night (NHS 20I4c), new mothers get an average of four hours sleep and a mother of a toddler gets on average five hours. Unsurprising then that many women are struggling to cope, with consequences at home and work. The statistics tell us that:

... 56\% of working mothers said weariness left them in a 'state of despair' ... $82 \%$ admitted a lack of sleep affected their performance at work ... $88 \%$ felt fed up, exhausted and pulled in too many directions ... $70 \%$ said their tiredness was so debilitating they felt unable to function properly ... 55\% said lack of sleep made them irritated with their baby ... Eight out of Io mothers with a baby aged up to two said a lack of sleep put their partnership under immense strain and caused rows ... Nine out of Io said their relationship had been badly affected, $70 \%$ said they had gone off sex and $92 \%$ admitted 'feeling wrecked' at work. (Zur, cited in BBC 2002)

The notion of 'feeling wrecked' at work is interesting here as it chimes with the final theme addressed by mothers in the audience, themes that 
they find they are able to identify with beyond a single character or title. Although a small number of women responded to representations of stay at home mothers, with Debra Barone/Patricia Heaton from Everybody Loves Raymond (1996-2005) being singled out for her believable depiction of the 'bardworking housewife', mothers spoke much more frequently about depictions of working motherhood. Whether this was because representations of working mothers outnumber their stay at home counterparts on screen or simply because the women who responded to my questionnaire were in the main speaking from their experiences of the double shift. Extant research routinely talks about the guilt felt by the working mother, both at home and in the workplace, and many women speak of the difficulty in combining these personal and professional spheres. And although we currently live in a society dominated by romanticised and idealised notions of the 'good' mother, it is important to consider the notion of the 'good enough' mother whereby women attempt to strike a balance between motherhood and other sexual, social and working commitments without guilt or self-judgement. Indeed, Debra Gilbert Rosenberg suggests that rather than trying to be 'all things to all people, all of the time' mothers should:

... strike a balance that works for you on all levels - financially and emotionally. Listen only to your needs and the needs of your family, to establish this balance, whatever it may be ... Banish the guilt ... If finances dictate that you work a full schedule, or if you need to work to maintain a healthy sense of personal identity, then good: Work. If this is what's best for your family, accept it. Then find nurturing child care and let the guilt go ... Be a 'good enough' mother ... Your job as a parent is to provide your children with healthy food, safe shelter, good education, love, respect, and nurturing. But no one ever said it all has to come solely from you. (Kennedy 201 , italics in original)

Like sleep deprivation before it, representations of working mothers are on occasion spoken about in relation to a particular character, but there tends to be little else about the character that resonates with the viewer, and on other occasions the comments are spoken about in more general terms, removed from any single or defining television text. In terms of general respect and recognition about the working mother:

... just aspects of them, like if they are able to manage work life balance well etc. 
... those who have a family but still a strong identity as a woman not just a mother.

I always like to watch programmes where mothers are trying to hold down a job and their home life and showing that even with strict organisation and planning it is a hard daily task with little in the way of thanks.

You see mums working hard to provide for their families and then coming home and taking on the domestic responsibilities, and even though I don't like it, I can see the realism here. It is good that it is seen but I wonder how many people other than working mothers even notice.

It is nice to see that some characters and real mothers mention that they actually want to return to work, I know this is true for some mothers but it is usually concealed in talk of financial necessity rather than an actual choice. I am able to identify with some of these stories.

Watching mothers balancing home and work and acknowledging that it can be at times difficult always strikes a chord with me and I am glad to see that it is acknowledged in the programmes I watch. It isn't exactly part of a major storyline or important to the plot, but it is there, and Inotice it.

Mothers who work always fascinate me, and I semi-relate to some of their struggles and plights. The fact that the professional mothers can usually rely on private childcare is not something that I can relate to exactly, but the feelings of guilt about going to work is recognisable whatever the work and whoever the childcare professional.

\section{Other women in the audience spoke of an acknowledgement of and respect for television presenters and fictional characters who attempted to combine their maternal role with professional endeavours:}

I look up to the likes of Karren Brady - I find her management of her life in general inspirational and as a mum - she really has a fantastic balance.

Lynette on Desperate Housewives who tries to juggle everything and do her best ... not always successfully.

Lynette from Desperate Housewives reminds me a lot of me ... trying to juggle work and family and assuming the grass is always greener and then finding out that you were wrong... That's me! 
Alicia Florrick, for going back and being a success. A career after children is possible, our brains are not eaten by our babies, or if they are, they grow back!

Alicia from The Goodwife and Skyler from Breaking Bad, I can relate to in part despite the differences in my life and theirs! They all want the best for their children even though it is sometimes a struggle.

The Good Wife, Raising Amy, The Cosby Show show strong working mothers that have a lot to deal with! They are trying their best at work and at home and don't always get either right but they love their children.

... I do admire Sarah Beany, Kirstie Allsopp, Lisa Faulkner, I admire how they juggle work and family life.

I admire women like Sarah Beeney who seem to maintain a balance between their professional on screen role with their maternal responsibilities. Not that you see this on screen, far from it. When Sarah Beeney is on screen in a range of home and property shows the only hint of her maternal situation are the visible pregnancies. It is only on reading about her in other arenas such as the Sainsbury's parenting club magazine that she acknowledges the reality of her motherwork and the strength of her maternal feelings for her four young boys. I rather admire her ability to be both a professional woman and a dedicated mother, without having to blur the lines between the two. That said, in her most recent renovation programme (her own property being the make-over home in question) there is a sense for the first time that these two worlds are not as distinct as previously thought.

While mothers in the audience could, on varying levels, relate to and take some comfort in scenes of toddler tantrums, sleep deprivation and the struggles of the working mother it is worth noting that notions of identification were not always spoken of in relation to the lived experience of mothers in the audience. While many women approved of storylines because they resembled their own maternal behaviours or encouraged them to look nostalgically back at earlier maternal practices, other women spoke in more hypothetical terms about notions of identification, drawing on wish fulfilment in their responses. Although many women struggled to relate to or identify with fictional characters, presenters or personalities on the small screen, it is clear that they continue to watch a range of television texts, 
finding feelings of pleasure and fulfilment within contemporary popular schedules. With this in mind it is crucial to consider alternative pleasures as they are foregrounded by the women in the audience, namely notions of maternal fantasy and domestic escapism.

\section{Mothers, daughters, friends: Maternal fantasy and escapism}

Some women watched heritage titles (Downton Abbey 2010- ) and fantasised about having 'housekeepers and nannies' while others spent time viewing quality American dramas (Brothers and Sisters 2006-II) and imagined a life 'in a pristine mansion in California with a lovely big kitchen'. Some women wrote at length of an illusory mother who they see themselves becoming, particularly in relation to the changing dynamics associated with parenting different age groups. Mothers of toddlers and young children spoke on occasion about their future maternal selves while others again spoke about a family fantasy far removed from their own parental status, specifically in relation to the mother-daughter bond depicted in the popular and long-running Gilmore Girls (2000-07):

Lorelai makes single teenage motherhood look like the preferred maternal option, her relationship with her daughter is nothing short of a fantasy.

Love love love Lorelai and Rory ... and I daydream that I will be a cool mum that my daughter actually likes and wants to spend time with ... it is a daydream.

Lorelai Gilmore. Only her relationship with mother and daughter. She's an intelligent, educated (albeit late educated) woman. Nothing else about her life is the same for me, though it is attractive.

There is absolutely no reason behind this and it makes no sense in terms of my family status but I pretend to myself that I am like Lorelai and that my relationship with my daughter will be like that of Lorelai and Rory ... I am happily married! 
This is anonymous so here goes ... I want to be Lorelai Gilmore, and I fantasise about me and my young daughter one day having the relationship that she has with Rory. But I couldn't be any less like Lorelai and I realise that having a husband and giving birth to my daughter 2 decades after Lorelai did means that the 'best friends' relationship isn't entirely plausible.

I totally relate to the mother on Gilmore Girls. Even though my daughter is 2o-monthsold, I hope that we can be very close when she's older. I would do anything for her, and I hope that she can feel comfortable to confide in me like Rory does to Lorelai. I can identify with the mother's relationships particularly with her own mother, which has been rocky. I've had a rocky relationship with my mother at times.

I wouldn't say that I've really found any television mothers realistic ... but ... I absolutely love the depiction of the Lorelai-Rory mother-daughter relationship in this show, which seems to depict the kind of love I have for my own daughters (and of course the LorelaiEmily relationship mirrors frustration with my own mother!). The intensity of Lorelai's love for her daughter is shown so beautifully - something that I don't remember ever seeing in another show. This is a show about women's lives, so perhaps this is why it works so well - the women/mothers are not incidental to the story.

This response to the critically and commercially successful show is nothing new; indeed, a number of blog posts and feature articles are based entirely on the premise of a self-confessed happily married woman having fantasies about becoming a single mother so as to forge a closer bond between mother and daughter and experience maternal freedom and independence as depicted in the show in question. Cara Wall talks of her own Gilmoreesque fantasy when she comments that:

The reason Gilmore Girls is so appealing isn't the sunshine and lollipops veneer - it's the irresistible fantasy just beneath the surface ... there is a decadent fantasy being spun here ... a debauched, irresistible dream. I wasn't aware of it until my daughter was born, but now I can't contain my lust. I am beside myself. I desperately want to be Lorelai ... Lorelai is witty. Lorelai has long legs, good hair and fantastic clothes. Lorelai has an appealing job at which she is the boss, can set her own hours, and works with her best friend. Lorelai had her one child at 16 ... Lorelai's child is pretty, modestly dressed, motivated, has wholesome friends, and, though she has her license, doesn't pester her mother for a car ... 
Let's compare: I am not witty; I am exhausted. I have bags under my eyes and straggly ponytail hair. I gave birth at 33 ... I have a job at which I am definitely not the boss, and my best friend lives halfway around the world. My child is, of course, even more beautiful than Rory, but she cries a lot, demands to get her own way and, if her single-minded pursuit of play strollers at the playground is any indication, will most definitely pester me for her own car. I have a stack of preschool applications on my desk, a minefield of toys on my living room floor, and I 3 unanswered messages on my answering machine. I also have a pair of parents, a husband, and a mother-in-law. In contrast, Lorelai is free to date ... It's seductive: this vision of mother as sexual being, mother as romantic, mother as beautiful, with the rest of her life ahead of her. It's seductive: this world where mother and daughter are best friends, where the child is grown while the mother is still young ... but the fantasy really gets interesting when I pause at the fact that Lorelai got to raise her child alone.

This, like all porn, is politically incorrect and totally naive. Of course single, teenage motherhood is impossibly hard. Of course we should not glorify it; of course we should not long for it. But here is the deep, dark, shameful secret I, over-privileged, Gilmore Girls-watching, future suburban mom, keep: Sometimes I wish I could raise my child alone. I wish I didn't have to argue about the best sleep-training method or which school to send my daughter to. I wish I didn't have to have long discussions about what kind of toys she should play with and how to keep her from becoming spoiled. I wish I hadn't had to compromise on the nursery color or defend my decision to wean early. I wish I didn't have to pack my household up four times a year to visit relatives, when it is patently obvious that it would be so much easier for them to come here ... Maybe I'm the only one ... But I don't think so. Lorelai, for all her surface gloss and patter, is a powerful talisman, as powerful as the lights on a slot machine. Despite our desire to revel in the show's wholesomeness, we mothers can't quite ignore the dark feelings she ignites within us. She is the anti-Donna Reed, not the mother who's perfect in the way others want her to be, but the mother living the life all mothers secretly want to lead. And it makes Gilmore Girls an explicit turn-on: an hour in which happily married women can drool over the life of a good-looking, well-dressed, engagingly funny, totally independent, daughter's-best-friend, happily unmarried one. (Wall 2005)

The Gilmore Girls is an interesting case study and it is perhaps unsurprising that it has been mentioned by mothers in the audience, after all, even though the programme was initially conceived for a teen demographic by 
the Family Friendly Programming Forum (a consortium that was set up by a number of mainstream advertising companies to fund programmes that offered multiple generation appeal, or, to put it more simply, an organisation that offers financial incentives to American networks to produce shows that parents can watch with, and enjoy alongside, their children) it proved, like much adolescent programming, to be popular with the thirtysomething woman in the audience (Feasey 2006a).

Lorelai/Lauren Graham and Rory/Alexis Bledel not only eat fast food at an alarming rate, they also stock up on sweets, crisps, peanut butter and marshmallows, with little negative effect on their skin, weight or physical health. And although one should not and would not recommend the Gilmore diet or domestic routine to anyone outside of a fictional television series, the fascination with this young single mother from the perspective of a more mature and happily coupled female speaks volumes about the possibility of investing in or fantasising about an escapist maternal figure, a figure so diametrically opposed to the viewer's own motherwork routine that she becomes a fantasy figure, irrespective of the perceived realism or authenticity of the show or character in question.

The character of Lorelai offers a tantalising image of single teen motherhood, and many respondents who fantasised about morphing into this particular maternal image routinely acknowledged their maternal and marital distance from this particular family unit. That said, the escapist entertainment offered by the show, within and beyond the narrative structure of the series demonstrates both the power afforded by specific maternal texts and the pleasures afforded by such televisual escapism. Although not all women pointed to the Gilmore Girls as a potent domestic text, many respondents made it clear that they found pleasure in watching a diverse range of family units, particularly those removed from or outside of their own domestic experiences. 


\section{Maternal learning through sexual, social and cultural diversity}

A growing number of programmes seek to depict the lived experience of gay couples as they try to conceive, give birth, foster, adopt and then parent, perhaps unsurprisingly. After all, the number of gay and lesbian couples bringing up children has risen, and continues to rise in recent years. Statistics reveal that there were 4,000 same-sex couples raising children in the UK in 2010 , compared to 8,000 in 2011 and 12,000 in 2013 (Sof 2014; ONS 2012). Richard Lane of Stonewall said 'the shift could be down to the effect of the Government's move to introduce same-sex marriage' (Lane, cited in Malnick 2013). After all, legislation to allow same-sex marriage in England and Wales was passed by the Parliament of the United Kingdom in July 2013 and came into force on 13 March 2014. And likewise, legislation to allow same-sex marriage in Scotland was passed by the Scottish Parliament in February 2014 and received Royal Assent on 12 March 2014.

While same-sex couples are now able to marry in England, Wales and Scotland, so too, they are able to make choices pertaining to parenting. Indeed the 'options available to potential gay and lesbian parents are wider now than ever before' (NHS 2014d). Stonewall informs us that:

In the UK it is legal for lesbian, gay and bisexual people to both adopt and foster children. According to the British Association for Adoption \& Fostering, growing numbers of gay men and lesbians have been entering into joint adoption proceedings since adoption for same-sex couples became legal in 2005 (lesbian, gay and bisexual people have always been able to adopt as individuals). The Human Fertilisation and Embryology Act 2008 and the Civil Partnership Act 2004 have made it easier for lesbian couples to secure parental rights for any children they conceive through artificial insemination. (Stonewall 2014)

The number of gay and lesbian couples adopting children in England has doubled in the past four years, rising from 3 per cent in 2009 to 6 per cent in 2013 (McAleenan 2014). Moreover, in recent years Barnardos, the British Association of Adoption and Fostering (BAAF) and First 4 Adoption have all been proactively encouraging adoption by lesbian, gay and bisexual 
people. Indeed, in both Britain and America, 'we are witnessing the early stages of a "gaby" boom, a situation wherein lesbian women and gay men are opting into parenthood in increasing numbers' (Dunne 2000). A small number of mothers in the audience noted their interest in and desire to learn from the representation of gay and lesbian families:

I like ... different types of family setups e.g.gay parents ... because it helps to expand my understanding of contemporary parenting... something I have no understanding of myself.

I like watching programmes about gay parents and I hope to be one myself someday. It is refreshing to see how many gay couples are adopting and having their own 'biological' children ... it seems to be a pretty new situation.

There seem to be a number of programmes on at the moment about gay and lesbian parents. I don't know any gay parents and I am always a little curious to see how such family dynamics work in reality' in terms of divisions of work and parental labour without the predictable sex and gender roles informing day-to-day decisions about childcare. I am usually rather surprised to realise how 'traditional' these couples appear to be in terms of their parenting roles and responsibilities, bar their shared sex.

While some mothers in the audience commented on their desire to watch and learn more about gay parents and parenting, others spoke of an interest in viewing maternal practices from a diverse range of countries and continents, ranging from the wealthiest to less socio-politically privileged locales, from the strictest to the less disciplinarian. Women spoke with reverence rather than judgement, making the point that different parental techniques were simply that, 'different', not better or worse. And even then, some mentioned the surprising similarities in what were, ostensibly, alternative family dynamics. A number of mothers in the audience made the point that they used these viewing opportunities as a chance to question their own maternal practices and to see if there were any useful techniques that they might want to emulate in some way, or an approach that they might want to consider implementing within their family. Others watched such maternal difference played out on screen with a sense of maternal empathy and compassion. In short, these women were respectful of and open to alternative and unknown maternal practices: 
I don't see other mothers as 'different' really.

Yes, it can be interesting to get a different perspective.

I think it's interesting to watch mothers who are different to me.

Yes, it's really interesting and it can actually challenge my views.

Yes, it can give you ideas on other things to try, or alternatively things you would never try!

I like to watch mothers from different cultures and how they bring their children up within that culture.

I am always interested in differing family set ups and learning how I might do some things better.

I do like watching mothers who are different to me because perhaps I can learn something from them.

Sometimes it's refreshing and interesting to see a different context ... puts things in perspective.

Sometimes it is nice to challenge assumptions. I enjoy World's Strictest Parents and Wife Swap for that reason.

I suppose I like to see how I could do things differently, is there a secret way to juggle kids, work, housework and some 'me' time?

It makes me realise there are more similarities than differences ... we all try our best and look out for our kids and try to be a good mum.

Yes, it's interesting to see different approaches, and to be reassured that everyone has their own way and we are all trying our best, there are very few wrongs or rights.

I am often surprised at how few differences I see on these programmes because ... the same basic sentiments are there but the circumstances and situations are more extreme.

I find it fascinating to watch things about family units in other countries like World's Strictest Parents ... the parenting styles are so different to mine ... I find it slightly voyeuristic viewing but it is fascinating to see the alternatives. 
Watching other mothers in America, Africa, and Asia, my heart goes out to those who struggle to make ends meet. Their lives revolve around their elders and their children and seem to have a hard time. I wish I could make a difference to them.

I am fascinated by people's different approaches to motherhood, what works and doesn't work for them, what they have to deal with in different scenarios and how they cope. I am interested in different ways of doing things, being challenged to think of things in a different way.

Watching people with different experiences is more exciting than watching those who are the same. Seeing how a character will react under challenging circumstances is always interesting. It's also a way to 'experience' things that you'd never see normally.

I love to see mothers in other countries. I feel I am very fortunate, having had a wonderful childhood in a loving family home. I have been married twice ... I have three children of my own and two step children ... all married with good jobs, and ten grandchildren who I see very regularly.

It was not only sexual preference, location and disciplinary regimes that were offered as alternative maternal practices, notions of generational difference and distinction came to the fore in a number of audience commentaries:

I like to see how younger mothers cope with bringing up children and having to juggle a working life as well. Very different from my day.

Watching programmes about mothers today makes me realise just how much has changed since I was a mother of small children many decades ago now ... motherhood is hard but it seems even more difficult when you have to work to help provide for your family.

I was a stay at home wife and mother and although I found the role challenging at times, I wasn't having to work outside the home so I never had to worry about childcare in as much as I had the children's routines as my own, without any conflict or other demands on my time. I see now that this was a luxury when compared to some of these young mothers that I watch on television who have to navigate a logistical maze before and after taking the children to school and nursery. I see my daughter's life reflected in some of these shows and I cannot believe how many demands she and women like her have on their time and energies.

As noted at the outset of this chapter, many women in the audience were critical of the lack of recognisable mothers on screen, and as if in response 
to this frustration, a number of women deliberately sought out images of maternal difference for reasons ranging from fantasy and escapism to curiosity and information. Depictions of gay parents, the portrayal of mothers from other countries and generational changes to the maternal role are said to offer both entertainment and educational value. That said, while several mothers enjoyed watching maternal diversity played out on the small screen, a small number of these women were frustrated by what they saw as 'patronising' and 'condescending' representations of third world family life. For these women, the promise of maternal differences were appealing, but ultimately the programmes in question were critiqued as ill-informed, misguided or problematic.

Those mothers who are watching alternative depictions of motherhood played out on screen clearly enjoy and find pleasure in alternative, maternal representations, however, they are unable to fully invest in these portrayals. After all, mothers and grandmothers made the point that they were more inclined to invest in a programme if they could identify with the character and that they were most likely to identify with a character when they were able to find similarities and familiarities between themselves, their own motherwork endeavours and those of the mothers on screen. The fact that many of the women in the audience were unable to find their own situation played out on television meant that many women were left disappointed with the programme options available.

\section{Copying mother: Disciplinary techniques and domestic emulation}

A number of women in the television audience found pleasure in viewing a diverse range of maternal techniques and practices, with some going as far as to suggest that they considered watching a myriad of mothers on television an eye opening and on occasion, educational experience. From this perspective then it is worth thinking about the ways in which 
motherhood in the media might be seen to offer advice and instruction in line with the more obvious pleasures of entertainment and escapism. I went on to ask the question 'Do you try to emulate the domestic skills or maternal practices of any of these women on the small screen' and continued to try and clarify by prompting 'Do you try and copy the domestic efforts, disciplinary techniques or family activities of any of these women that you see on television?'

In a media and entertainment environment saturated with pregnancy and parenting guidebooks, self-help leaflets and online forums dedicated to providing emotional support and more practical guidance to new mothers, it was worth asking what role, if any, television played in supporting or assisting women in the audience with their motherwork efforts, be it in the overt manner of shows such as Supernanny as they give details about specific disciplinary rules and techniques, or more scripted programming as they might be seen to offer codes of family conduct for parents trying to find the upper hand in a battle of wills with their children.

That said, what was surprising here was how few mothers looked to television as a source of maternal etiquette, support or assistance with their own parental roles and responsibilities. Extant research makes the point that shows such as Supernanny (2004-I2) are watched in part because of the programme's ability to communicate with its audience about tried and tested disciplinarian techniques, and even a cursory glance at the programme makes it clear that it can be watched with this position in mind (Feasey 20II). Supernanny is said to serve as an educational device 'for parents, who may indeed be at a loss for how to deal with bad behavior [and] in this view, Jo Frost becomes a kind of national spokesperson for audiences who need a kind of civic education in parenting' (Tally 2008). Indeed, a relatively small number of women confirmed that this was a reason to watch such 'nanny' texts, either taking on board particular techniques directly or using them as a more general guide to be reconfigured in line with their own family circumstances:

I do use some of Jo Frost's techniques e.g.praising.

Supernanny's I23 naughty step discipline works on my toddler. 
Supernanny ... the programme has some good tips for how to manage my little monkeys.

In the past I have tried using a couple of 'disciplinary techniques' that were shown in Supernanny

Occasionally I see either parenting techniques or ideas for activities to do with the kids on television and use them.

... I know that Supernanny has inspired some of my friends struggling with toddlers or problematic behaviour. That programme is slightly skewed for dramatic effect but the principles it aims towards and the general approach is sensible and practical.

Although audiences are well aware that reality parenting programmes are heavily edited and that fictional genres such as soap opera and situation comedy are scripted, acted, directed and again edited, several women still considered fictional characters to be able to offer parental guidance:

Lois from Malcolm in the Middle ... she always had a good answer and an interesting threat ... if needs must I will rehearse some of those scenes on my own family.

I do see Debra from Everybody Loves Raymond as a role model because she struggles with discipline with her children. What she learns that works, I will remember.

I always like watching Outnumbered, I remember some of the arguments and the ways in which the parents outwitted their children, and if I am honest I have borrowed from their script on more than one occasion!

Some mothers spoke in general terms about trying different techniques and taking meaningful advice, from any respected avenue, with television playing a part in a parenting style that is about creating and supporting a harmonious family unit:

Sometimes you see something that works and you think, I'll try that. It's the same with every other endeavour in my life, I'm always looking for ways to do what I do better.

If something looks like it works I will probably try it out on my children, especially if it creates a more pleasurable and less chaotic environment ... television, magazines, friends and family... if there are relevant experts I would be mad not to at least listen to their advice. 
One mother pointed out that she borrowed particular phrases from popular American children's programmes such as 'Sesame Street and Daniel Tiger's Neighborhood' in order to provide what she saw to be the 'bealthiest and most considerate way to communicate' with her young children. There were no strict techniques being presented here and no rules to be followed; rather, the mother in the audience responded to a compassionate and carefully considered voice that she deemed appropriate and accessible for her and her family unit.

For those mothers who acknowledged that they did on occasion look to and borrow phrases and techniques from adult and children's programming alike, television might be understood as both an entertaining and informative medium; however, those women who emulated what they considered to be sensible, useful and helpful ideas and terminology were in the minority of those who responded to my questionnaire. Many mothers skipped over this question, answered in the negative or commented that they did seek helpful advice and practical support, but that this was to be found in friends and family members whose parenting styles they approved of and respected first hand. Others again suggested that they followed their own instincts or made their own decisions when it came to their maternal practices, questioning the appropriateness of those who emulate techniques demonstrated on shows such as Supernanny:

Sometimes I have taken some advice from Supernanny in the past ... I now have quite strong opinions on my own domestic life.

I tried some of the Supernanny techniques when my first son was small, but soon realised I needed to go with my own flow and that what works best for me and my family.

I am capable offollowing my own instincts and ideas about mothering ... which is not to say I don't seek advice from friends or share problems, and learn from their experience.

I just try to keep juggling... whatever gets the family through the day ... I tend to think of Supernanny routines as brilliant in theory but hopeless in practice ... the reality is that you need to be able to be more flexible than she allows for.

I may not be an 'expert' in the traditional sense of the word but I am a mother... I want the best for my children... I think I am the one who knows how best to care for them. 
I will listen to well meaning advice but at the end of the day I will do what works best for me and my family rather than look to the parenting fads or fashions that seem to be spoken about.

Programmes like Supernanny ... has lead to people setting themselves up as a professional nanny for help with certain child rearing issues and putting forward some quite outlandish advice. An example that comes to mind is one of my cousins and her husband getting a 'sleep consultant' in and telling them not to go to the toddler child at all during the night if she can't go to sleep/makes a noise or wakes up during the night.

Supernanny Jo Frost is committed to a rather traditional view of childcare that centres on routines and respect. Indeed, members of the Conservative party have praised Frost's organised methods in a parliamentary debate on anti-social behaviour (Macaulay 2010). And yet, there was little suggestion here that mothers in the audience were watching for practical advice. That said, away from the perhaps emotive or sensitive matter of motherhood and the questionable effectiveness of one parenting technique over another, mothers in the audience made it clear that they were happy to, and often did, follow a range of recipes, home styles and occasional fashion choices as they were presented on television. Although one commentator suggested that she didn't 'bave a Nigella complex' it was soon evident that figures such as Kirstie Allsopp, Sarah Beeny and Mary Berry were applauded and emulated for their homeware, homebaking and haberdashery efforts:

I quite fancy being as crafty as Martha Stewart.

I may get ideas for crafting, cooking activities from $T V$.

I like ... home-made things, the rural lifestyle of Kirstie Allsopp and Sarah Beeny.

I aspire to have a home 'style' like Sarah Beeny or Kirstie Allsopp - shabby chic 'Country Living'style.

I did try to find the bowls Paul Hollywood was using on his bread show. Oh and I did spring clean my kitchen after seeing Lorraine Pascale minimalistic kitchen!

Can't help but start baking after The Great British Bake Off. I won't pretend to copy those showstoppers, but it is always fun to try a signature dish with the full recipe details. 
I tend to watch cooking and gardening shows which don't focus on maternal figures as such but I do take note when they say what works for their children, e.g. chef Monica Galetti.

I love the sort of programmes that Kirstie Allsopp presents, all those cute projects and homely nic nacs that look a million miles away from the IKEA dream that has swept the country.

Those home programmes are really fun to watch, I confess that I have actually tried to copy a few things from them, not the complicated stuff, but the easy projects ... you can even get the whole family involved.

The Great British Sewing Bee got me really interested in 'trying' to make a few simple pieces for the family... I confess it is more for fun than function or necessity, but what a nice way to relax in the evening.

I have tried to make a few things, knit the odd item and try my hand at cross-stich when Kirstie Allsopp did it. I never really think that I am copying from television, but I have always tried them after watching something, so yes, I must be.

The handmade and homemade programmes that Kirstie Allsopp does ... it makes you realise how much you could save if you tried to make your own things... and that there is a real market for such items... I used to buy them and now I have a go at making them.

The Great British Bake Off always gets me making muffins ... it's a bit like Wimbledon, you never think to play tennis all year but feel the need to get the racket out for two weeks over summer. I don't attempt to make any of the really tricky stuff, but it gets me baking a few bits and bobs for the family, and I always then wonder why I haven't done it for so long ... Until next year.

I do love watching all those home and property shows, not the ones where you buy and sell houses, but the ones about turning a house into a home, I actually made one of those beautiful fabric pin boards rather than purchase the one that had been hanging around in my Amazon basket for several weeks. I wouldn't copy everything that was shown but now and then it is quite relaxing and ever so slightly productive.

Since her television career started with property shows such as Location Location Location (2000- ), Kirstie Allsopp has made a career out of not only buying houses for those in need of professional support, but out of home making. In shows such as Kirstie's Hand Made Britain (2011), Kirstie's Vintage Home (2012), Kirstie's Handmade Treasures (2013) and Kirstie 
Allsopp's Home Style (2013), Allsopp learns the skills, and by association, teaches audiences some of the techniques used in fashion and furniture upcycling. Episode guides give a sense of Allsopp's homemade etiquette for her own projects and those for existing couples and families:

Kirstie demonstrates how to create a stunning handmade invitation, then shows how you can make a delightful cupcake bouquet to show off these on-trend treats. She then tries her hand at ice sculpting with a chainsaw, before rounding things off with a playful pudding. (4OD $2013 \mathrm{a})$

Victoria Cranfield, who has won gold medals for her jams and jellies, leads Kirstie through the torturous task of removing every stone by hand as Kirstie learns how to make damson jam. (4 $\left.{ }_{4} \mathrm{OD} 2013 \mathrm{~b}\right)$

Kirstie pulls out all the stops for Cheshire couple Iman and Heather, who have a brand new home and a baby on the way. They'd like a vintage nursery and a I920s inspired sitting room, but Heather's due date is in just five weeks and Iman doesn't like buying vintage goods ... The good news is that because it's a new house Kirstie has a perfect blank canvas on which to work her magic, and she finds inspiration in the art-deco decadence and travel influences of the 20 s. Kirstie comes up with crafts and bargain hunting to help Iman overcome his aversion to second hand, and he even discovers a craft he really enjoys. From finding rare pieces to making personalised toys and gilding picture frames, with Kirstie's help Iman and Heather are able to create the home they dreamed of. (4 $\left.\mathrm{OD}_{2012}\right)$

Although Allsopp was not the only name mentioned, her move from selling houses to creating homes speaks of a broader domesticisation that seems to have emerged during the recent recession, with this link being most blatant in the latest Kirstie's Fill Your House for Free (2013) production. With the rise of sites such as Freecycle, Freegle, Gumtree and the resurgence in knitting, crochet and sewing in recent years, Allsopp might be seen to act as the face of, or her name become the short-hand for such homemade endeavours. The programmes are popular with the viewing public, and there is evidence provided by mothers in the audience that they do actually attempt some of the less demanding projects being presented here. And yet, turning to television as an educational and informative medium is nothing new, British broadcasting has always had a strong impulse to improve its audience, with a strong 'hobbyist' or 'enthusiast' strand appearing popular 
throughout television history. We are told that evening broadcasts in the igsos catered to:

... minorities who are enthusiastically devoted to some form of self-expression... the jazz fancier or the pigeon fancier, the man or woman who wants to learn, say, Spanish from scratch, the fisherman or cyclist or collector of LP records ... the bridge player or the naturalist, the more sophisticated filmgoer, the ardent motorist or the enthusiast for amateur dramatics. (Radio Times, cited in Brunsdon 2003)

This 'hobbyist' strand of programming was overtaken by 'lifestyle' programming in the early 1990 s with a number of fashion, gardening, cookery, home buying and Do It Yourself productions proving popular with audiences in general, and with the female audience in particular. The key differences between the 'hobbyist' text and the more recent 'lifestyle' production was that the former sought to instil a skill while the latter was committed to entertainment and commodification. An increase in home ownership, the growing number of women in employment and the postponement of childbirth among the middle classes at the end of the last century saw an increase in those programmes that offered immediate home and garden transformation through the purchase of specialist skills, trades, equipment, plants and furnishings. The instantaneous display of transformation took priority over education, with the 'reveal' as the dramatic finale of the piece. And yet, due in part to the recession and growing numbers of female unemployment, we have seen the resurgence of the 'hobbyist' strand whereby, like its I950s predecessor 'the narrative of transformation is generally one of skill acquisition' (Brunsdon 2003). Charlotte Brunsdon looks at the $\mathrm{BBC}$ archives and discovers that:

In the 1967 BBC series, Clothes that Count ... each ... programme focused on the making of one garment, interspersing very close camera work on hands and sewing machine with more fashion-show like segments in which the garment is modelled, made up in a range of fabrics. ... The whole process of making, for example, a piped buttonhole in a coat, was shown in real time with framing that mainly excluded the dressmaker's face ... Similarly, in the earliest surviving Gardener's World ... we are shown appropriate spring pruning, how to divide herbaceous perennials and the planting-out of hardened seedlings during 20 minutes of continuous address by Percy Thrower ... the close-up is on the operation being demonstrated. The programmes 
are didactic - they show you how to do or make things - and, historically, they deal with the difficulty of doing this in the 'now' of television through the device that has become a catch-phrase in Britain, 'Here's one I made earlier' - or else they simply use real time. The hobby genre, like the short-lived broadcasts on Network Three in 1957, addressed the amateur enthusiast. By the end of the programme, the listener would know how to do something. (Brunsdon 2003)

Figures tell us that middle-aged women have been hit hardest by the recession (McVeigh and Helm 2012), and there is the suggestion that it is these women who are watching, and on occasion, making the handicrafts as displayed in the Allsopp oeuvre. Whether it is for the purposes of relaxation, budgeting, for environmental interest or commercial profit, mothers in the audience have spent time making and baking in line with their television counterparts. This is not to say that they actually relate to or find themselves invested in a particular performer, but rather, they speak of an interest in their homes, meeting the needs and wants of their family and a sense of entertainment and enjoyment in attempting modest and grander scale projects in line with the 'hobbyist' as the figure has returned to our television screens in recent years. Indeed, one could consider the irony of taking advice on frugality from the daughter of a baron or the disingenuousness of free homeware that demands time and financial investment to be upcycled for purposeful use, but it is the sense of home, hearth and domestication that audiences within and beyond my questionnaire have commented on here, with Allsopp appearing as a figure head for this particular trend. A cursory glance at the shopping phenomenon 'Not on the High Street' is another clear indicator, beyond the television screen, of the popularity of the crafts and creativities that Allsopp champions:

We're passionate about hand-picking the best creative small businesses to sell on our marketplace, making it simple for you to find inspired, personalised, stylish or unique things ... We choose sellers who offer great design and the best quality products, many of which can be customised to suit you. It's easy to find (or create) the look or style that works for you ... See how ordinary doesn't get a look-in ... We won't show you just anything - we want to inspire you. Or even surprise you. Think concrete wallpaper, balloon lights or a wall print featuring the entire text of a literary classic. Just like you, we're not interested in being the same as everyone else ... And if you're shopping for someone else, we can make you look 
good too. Whether you're looking for a present for your mum, saying thank you to someone or need gifts for everyone in your business, find products that show how well you know the people you're buying for ... Everything you buy from our site comes directly from one of the artists, designers and curators who make up our collection of sellers. By shopping with us you're doing business with diverse, talented independent sellers who care about quality, innovation and style as much as you do, as well as supporting the future and growth of creative talent. (Not on the High Street 2014)

The vast majority of mothers made no mention of their interest in copying parental techniques, telling us that 'my lifestyle is different to those I have seen on television and I've yet to find a mum I wish to emulate' and yet many of these same women spoke of their investment in and emulation of the 'making and baking' that they see on screen. One might consider the sensitivity of the subject at hand here, whereby it is deemed socially acceptable and indeed socially desirable to admit to copying a creative art or food speciality, but it seems less appropriate to admit to seeking advice or help in your maternal role, for fear perhaps of failing to live up to the romanticised 'good' mother myth that continues to pervade the entertainment marketplace, with Allsopp, as other comments indicate, playing a part in this continuing façade. While it is deemed acceptable to emulate the homewares and craft projects as displayed on the small screen, it is worth considering the ways in which such copying or imitation extends beyond the home to maternal style, fashions and dress codes.

Extant theoretical work on fashion, marketing, advertising and celebrity culture speaks of the importance of celebrity endorsements, testimonials, advertising and sponsorship to the fashion and beauty sector (Desser and Joweth 2000) and I have written elsewhere about fashion, transformation and the interest in following the styles and trends as worn by film stars and the wider circuit of female celebrities (Feasey 2006b). Popular and long-running magazines such as Now and Heat, alongside more glossy titles such as Grazia, regularly present a range of features on star style and celebrity fashions - be it designer casual wear, vintage clothing or glamorous red-carpet gowns. In this way, one might suggest that the reader can look to these publications as a quick, easy and 
entertaining way to browse contemporary styles and fashion trends on a seemingly endless array of beautiful stars. However, rather than dedicate its star style pages to the exclusive, vintage, or couture of celebrity clothing and expect the fashion-conscious reader to live somewhat vicariously through such exquisite yet often unattainable items, it is worth noting that these magazine encourage the female reader to both try on and buy such feminine fashions in features such as 'Steal Her Style' which point to the different garments being worn (not modelled) by the personality and the details whereby you can buy that item or a similar one on the high street as part of the wider domestic and spendthrift economy. Such features can be seen as an arbiter of fashion tastes, dictating which star styles to try on and which celebrity fashions to avoid, and readers appear happy to discuss their interest in and use of these articles when making sartorial choices.

My point here is simply that there is a long history of film stars and more recently, celebrity figures being positioned as fashion models or as unofficial style icons for women in the audience (Stacey 1994; Fox 1995; Moseley 2003), and that evidence exists to suggest that magazine readers appear happy to talk about their famous fashion inspirations (Feasey $2008 \mathrm{~b}$ ). From this perspective, one might consider the role of women on television, and more specifically, mothers on television, as fashion inspiration for mothers in the audience. If one considers the changing pregnant body and the sartorial demands of the new mother, it might seem obvious that women would look to fashion role models, perhaps coming as no surprise to see mothers emulating the style and trends of one celebrity mother over another.

With this in mind, I asked the question 'Do you copy the surface appearance, hair or fashions of any mothers that you see on television' with the supporting text asking 'Do you look to these women for fashion inspirational or stylistic expertise?. Although some women commended particular figures for their sartorial efforts, only a very small number of mothers suggested that they did look to mothers on television for fashion help and inspiration, and found pleasure in doing so, particularly during pregnancy: 
I do like seeing how pregnant women dress on television but not really mothers.

I like many of the pregnant presenters on the news channel and chat shows ... they always look good and have lovely clothes.

Holly Willoughby has a great sense of style when pregnant and I watched her deal with her increasing bump with interest.

I do like seeing what pregnant $T V$ presenters wear e.g. newsreaders, weather presenters how they stay smart with a bump.

Yes, definitely ... you need help when you have not had to dress during pregnancy before. You get more confident the second time around, but I remember being so self-conscious, especially at work, I would look to see what women on television were pregnant and what they were wearing to look respectable.

It is so difficult to find something flattering and cool (as in warm weather rather than the other sense of the word) to wear when you are heavily pregnant during the summer months, so I did keep an eye on what pregnant women on television were wearing, it was the era of Rachel being pregnant in Friends and I distinctly remember trying to form a similar look.

I don't want to fall into the 'mumsy' trap where everything is comfortable and ready for the school run so I look to mothers such as Holly Willoughby and Tess Daly to see the styles that they are wearing when they are pregnant. Not that I will be going out to buy expensive formal wear, but just to get a sense of the more sensible and everyday clothes that they are seen wearing.

When I was pregnant and struggling to find something comfortable and stylish I did occasionally look to pregnant celebrities for sartorial inspiration. It was not my intention to copy an exact garment, but rather to replicate a particular 'look' in terms of bohemian long summer dresses or smart-casual flared jeans with a slouchy nautical top and striped blazer. It gave me the confidence to choose pregnancy clothes from the masses of available options. This is not something that I had done before or since, but I wonder if it was because I was lacking the comfort of my usual style during my pregnancy.

You read the books that tell you about your changing pregnant body, you buy the same stretchy comfortable jeans and wrap around tops in classic styles that are available in every single high street maternity range and then after wearing the same outfits for a couple of months you start to feel incredibly bored and boring ... so it is nice to see what other pregnant women are wearing, it is nice if you can find and can afford something 
suitable or similar just to give you a change... I know nine months isn't long in the grand scheme of things, but wearing the same sensible comfortable outfit for that length of time is tiresome. Sorry, rambling ... yes I have copied the styles of pregnant mothers on screen and I will continue to watch what new mothers are wearing to give me a bit of confidence when I am tired of my own predictable wardrobe rut.

For some women then, looking to recognisable women on the small screen gave them the confidence to try and perhaps purchase everyday, casual clothing and work ensembles that they would otherwise have been unsure about. It is clear that these women were not looking to emulate the high-end fashions or glamorous outfits often seen on the Saturday evening schedules, but rather, to look to more moderate and manageable offerings as they were seen on particular personalities, characters or shows. In this way, these audiences appear to support extant research, which talks of the value of the celebrity in terms of beauty and fashion sales. And yet, these women were in the minority as most mothers made it clear that they were not particularly interested in and had never actually considered looking to mothers on television in this way. For a number of different reasons, including available time and limited finances, the majority of women spoke negatively about the television screen as a shop window for mothers, with a small number commenting on what they felt was the 'liberating' period of new motherhood whereby a woman did not have 'the time to doll yourself up as much as you used to'. For many mothers, however it was most crucially a matter of foregrounding their own styles and tastes:

No. I know my own identity.

No, I have my own standards and style which I adhere to.

No, I wear what suits me and what is practical for what I'm doing.

No I would rather be my own person, I've never followed fashion.

No, and I wouldn't want to ... I am better suited to choosing my own style.

No, I want to look like me with my own style not a pretend or false version replicated from television. 
Why would I? These women are being dressed by others, they don't even have their own style so I certainly wouldn't let them create mine.

No, I try and present myself in my own way, I am not interested in what is fashionable but rather hone what suits me, even when pregnant.

I like to try and dress like the individual that I am, not to say that I don't buy fashionable clothes, but I would never try and copy a whole look that someone else was sporting.

For others it was a negative response due to what they saw as the stereotypical maternal images and identikit fashions of mothers and indeed women on the small screen:

No, Definitely not. I am me, not a carbon copy of someone else.

No, I think that it's false and I need to be the person and the parent that I am.

No. They don't look like me. In fact they all look the same really, a certain style of clothes, hair, makeup and build. There's no diversity at all - either in terms of surface looks or ethnicity.

Not really. Television has a standard 'mom wear' category of hair and clothing which isn't my style. I try to dress as I did before children or at least maintain a current look ... driven by comfort in a traditional style.

God no, they all tend to look the same ... the middle class mums all have blonde highlights, skinny jeans and brown leather boots while the working class versions are dressed in tracksuits and denim skirts. I kid you not, this is all I seem to see mums wearing...

Mothers on television who deviate from the 'mom' look, do so to highlight their role. Sexy mom, corporate mom, lazy mom. But they're all done in contrast and in reference to the tradition garb. I don't want my style to be mom centred even if it is an oppositional form.

Mums tend to just look frumpy on television ... either budget BHS or the more expensive Laura Ashley version ... it is still all about cardigans, flat pumps and chinos. Even when the actress is beautiful and you have seen them looking stunning at an awards bash or in the glossy magazines, they are still dressed in a frumpy mum wardrobe, so no, I would not look to emulate these fashions. 
Others again mention that they were prevented by time and financial constraints:

No, I don't have the time!

No. I don't have the time/energy!

No! No time to even look in mirror, let alone have style!

No ... I don't have the disposable income to do so if I wished.

Not a chance, I have to be out ready for the school run in three different directions.

Chance would be a fine thing, I barely have time to get dressed let alone think about fashion and outfits.

I don't have the income to have a work wardrobe, a going out wardrobe, and a mom wardrobe, so I don't buy those clothes.

No, but then I'm not spending much time or effort thinking about my appearance at the moment as it's just about being functional for dealing with small children all day.

A number of mothers in the audience highlighted the façade or maternal mask of mothers on screen, this time in relation to the sartorial appearance and surface apparel rather than the character, roles or responsibilities of the televisual mother:

No, a lot of these women are dressed in glamorous 'going out' clothes which I currently have no use for ... if they would wear more everyday clothing then I might consider it, finances permitting.

No, most Mums on screen who look good have a hair and make up artist and wardrobe expert to assist them, plus this is all done while they are being paid for their time. Totally unrealistic for me.

No not really, I'm just happy not to have Weetabix in my hair when I do the school run! Mums on television are so immaculate and for me unattainable figures that there is no point trying to copy, e.g. Holly of This Morning. 
No, some of these women are dressed in a very particular style that ordinary mums like me just couldn't pull off at the school drop off and certainly not at work. I like that they show different styles and fashions, but I would not look to copy any of them ... and to be honest they change so frequently that I would run out of time, energy or money if I was interested in looking like them.

You know that these women have been 'dressed' by a stylist and that they probably wear or want to wear the same comfortable outfits that the rest of us can get away with at work or the school gates... they wear what is needed by the programme rather than what is needed in their maternal role... I would be more interested in seeing what they change back into when returning home ... and who knows, maybe I would be interested in copying that look!

Others shifted the focus of the question and commented on the physical appearance, surface attractiveness and the post-pregnancy bodies of the women on screen, in relation to what they saw as successful yet hard-won physiques. As I have noted elsewhere, the popularity of make-over fashion programming in general, and the plastic surgery makeover show in particular provides evidence of the ways in which the celebrity mother myth and the wider 'yummy mummy' profile are impacting on a generation of new mothers (Feasey 20I2a). There has long been a focus on age prevention and maintaining a youthful visage for women in society, indeed, cosmetic advertising from the 1920 s was trying to collapse the physical age distinctions between generations as they asked women to 'Stay Young with Your daughter!' (Addison 2009). However, since that time, mothers have been asked to not only stay young with their daughters, but to rehabilitate 'themselves as sexualized subjects post-childbirth' (Gailey 2007). Elizabeth Gailey makes the point that makeover television renders 'motherhood itself pathological because women are being asked to be sexually viable well into their late 30 and 40 (Gailey 2007, italics in original). Gailey tells us that 'reclaiming the "blown-out" body parts sacrificed to childbirth is a routine aspect of responsible women's self-management and care' and reminds us of the ways in which the plastic surgery profession views pregnancy as a pollutant on the female body (Gailey 2007).

Extant research on maternal responses to the post-pregnancy body suggests that many new mothers compare their own physiques to those 
of new mothers in the television arena and wider media marketplace only to 'self-blame and internalize a sense of private bodily failure' (Dworkin and Wachs 2004) as they are unable to return to their pre-pregnant size, shape and fitness levels immediately after birth as is viewed as the norm in the mass media. And yet, the women who commented here on the postpregnancy health, fitness and physiques spoke not only of their differences from these women, but of the immense time, effort and energy that must have gone into such transformations, which in itself must be seen to go some way towards lessoning the effect of these figures as role models for new mothers.

Therefore, while some women said that they deliberately avoided those magazine style programmes that 'put unfair pressure on women to feel that they should be able to do everything perfectly and look great all the time' others watch from a critical distance, aware of the role of stylists, dieticians, personal chefs, trainers and childcare providers who help to make such a physical transformation possible:

Most celebrity mothers have a lot of help, which ordinary working mothers can't afford.

I don't have a stylist, personal hairdresser, personal make-up artist or personal trainer!

Davina McCall looks great after three children and at least she's honest about having to work hard at it.

I may admire their weight loss post pregnancy but I assume they had access to more support than me with it.

Many mums on television look great after giving birth ... but ... they live a much more cash rich lifestyle than I can afford.

I sometimes wish I was like celebrities as I'd like to have their personal trainer, personal chef etc. and be able to afford a nanny. That's not realistic for most mothers.

I am aware that their lives are very different to mine and the things that I admire such as the fact that they are very glamorous, have great jobs, have several kids which they seem to effortlessly look after whilst maintaining a glittering career come from having more money and help etc. (who wouldn't love the glamorous life and to seemingly effortlessly pop out children whilst maintaining this perfectly - however this is unrealistic for most). 
While extant scholarship from a diverse range of academic fields has pointed to the role and importance of Hollywood and the women's magazine sector as inspirations for feminine fashions, there is some evidence here to suggest that mothers might look to the television screen for sartorial inspiration, but in the main, these audiences are more cautious of speaking about mothers on screen as fashion role models. For a number of diverse reasons mothers on screen are not considered relevant or worthy fashion models for mothers, with comments being made about these characters and personalities being both too frumpy and too glamorous, too pedestrian yet also too outlandish; it is clear that fashion and style is a matter of personal taste and distinction, and that what one mother refers to as frumpy, another sees as classic, and what one mothers deems outlandish another views as respectably vintage ... but what is clear here is that mothers on screen are rarely seen as figures to relate to, personalities to emulate or characters to copy, be it in terms of mothering techniques, disciplinary practices or fashion models. And yet, perhaps surprisingly, mothers are keen to commit to the cooking, home wares and craft techniques seen on screen in line with recent trends in the hobbyist tradition.

\section{Conclusion}

In this chapter I have outlined the ways in which mothers in the audience responded to a question concerning maternal identification, before paying attention to the ways in which they have or have refused to copy particular behavioural techniques or sartorial etiquette from specific performers in a range of television texts. The women who responded to my questionnaire formed a frustrated and disappointed consensus as they referred to a lack of realistic, believable or authentic maternal figures. This was not to suggest that these women did not find escapist pleasures, cultural education or creative inspiration from the women on screen, but it does suggest that mothers in the audience are struggling to see their lived experiences played 
out in the mainstream media, which continues to be a cause for concern, and a missed opportunity for public service and commercial channels alike. At different times in the questionnaire, maternal audiences spoke of watching their favourite television mothers, and they routinely related these preferred figures back to their own lived experiences, with a sense of commonality often located between the audience experience off screen and their chosen on-screen performance. Recognition played a key role in finding a favourite maternal character, cast member or performer, but these self-same women later went on to foreground what they deemed to be the dearth of relatable or recognisable mothers on screen. Rather than speak of confused, contradictory or discordant viewing positions and challenge the maternal responses generously written, it is important to note that viewing pleasures are not and should not be rational, logical or consistent. There is much scope for inconsistencies, changeability and ostensible contradictions both here and in the broader viewing experience, and with this in mind it remains important to note both that television as a medium inspires, entertains and offers escapist fantasy, and that mothers in the audience are keen to balance such pleasures with maternal verisimilitude in the contemporary schedules. 



\section{Bad mothers and poor role models: Maternal inadequacy and the problem of perfection}

Women in the audience find themselves drawn to a number of comedic and dramatic representations of motherhood that span different channels and schedules, and although such depictions offer a range of escapist fantasies, potential role models and the opportunity for emulation, there are a number of maternal depictions that create a sense of pity, disgust and mistrust. It is important to think about the ways in which certain depictions of motherhood are reviled while others revered, and the ways in which these distinctions can be seen to pick up on broader debates concerning the socially acceptable 'good' mother or the culturally inappropriate 'bad' mother as they are evident in the broader social and entertainment landscape (Feasey 20I2b).

I asked the question 'Are there mothers on television that you feel negatively towards, what is it about these mothers that encourages ridicule or disapproval?' With the additional help text asking 'Do you feel negatively towards their appearance, family, maternal behaviour, friendships, relationships, domestic space or working efforts?' It is interesting to note the diversity of responses here in terms of the details provided. I do not mean simply in terms of the length of the responses proposed, but rather, in terms of minutia of information given. While some participants provided generalised comments about those maternal representations that irked or irritated, others spoke about specific genres, texts, characters and narratives. That said, less than I per cent of responses left this question blank, and as such, it is clear that there are a myriad of maternal depictions that create negative reactions from the television audience, and enough of a reaction for participants to provide comment on. And although this may not surprise readers, given some of the representations that are evident on 
the small screen, the genres most frequently cited may surprise theorists from within the fields of television and media studies, because much of what is suggested by audiences negotiates extant literature from those aforementioned areas of research.

Very few women chose to overlook this question, indicating an interest in or desire to communicate what they view as negative or problematic depictions of mothers on screen. And yet, before we look at the ways in which women in the audience judge, rank and qualify mothering practices and performances, it is worth noting that a small number of respondents refused to judge televisual mothers, even fictional creations, however strained their parental performances, due to the emotional, physical and psychological difficulties associated with motherhood and motherwork. We are told that:

... being a mother is tough, we shouldn't criticise.

I try to be non-judgemental, and have an open mind because being a mother is not easy and we all make mistakes.

Offhand I would say no. I sometimes think families are made to look silly for entertainment purposes. I suspect many differ from how depicted.

No, everyone has their own methods and I try not to judge too much on media representation, especially where the children are happy.

And these self-same women went on to challenge those mothers on television who themselves are seen to be judgemental towards other maternal figures. These women are aware that their own maternal thoughts and practices are imperfect, and although parents have different ideas about what is appropriate or acceptable parenting, there is the shared sense that even with the best of intentions we are prone to make mistakes, and that the best we can do is learn from them. They acknowledge that mothers are human and flawed, and are learning on the job' (Speier 2004) and that because 'mothering is a trial and error experience, we need to respect that at best it will be "imperfect"' (ibid.). Imperfect indeed, and for a small number of women in the audience, judgement is not only reserved but rescinded. 
While a small number of mothers commented without judgement, the majority of respondents seemed to speak in agreement against the swathe of negative, problematic and strained maternal figures that they deemed to be saturating the small screen. Indeed, many of these women made the point that 'bad' mothers were so ubiquitous that they found it difficult to think beyond these negative representations. One woman assumed that she was simply unable to recall a positive, favourite or 'good' maternal figure because of her limited viewing practices, telling us that 'I am not sure I watch enough television to be able to answer your questions very well as I have struggled to think of good mums I have seen and I am sure there must be some!'. Others made it clear that irrespective of time spent in front of such texts, there were few positive images to be found:

Mothers on TV never seem far from judgement.

I don't really think there are any fictional mothers on television who I look up to.

Most mothers ... are either too mumsy or trying too hard to look like teenagers.

American sitcom mothers are harassed, frazzled and normally play minor roles.

I find most representations of mothers on television to be reductive or unrealistic.

I couldn't possibly list all the problematic ways mothers are portrayed on television.

Women ... lose their own sense of identity when they become a mother ... disappointing.

Mothers in $T V$ show are either portrayed as negligent or perfect... both are problematic.

I generally feel like mothers on television either are stuck in a relationship, undermined, or left to clean up the messes.

When shows undermine women and make it funny, it pisses me off. It reinforces negative stereotypes and agendas.

Negative images of motherhood are everywhere on television, it somehow seems normal to watch women who are terrible caregivers. 
Most mothers on television are portrayed negatively, they are not showing the reality of what it is to have to care for young children, if at all.

... serves to fuel maternal guilt with the stereotype that women will always choose a family over her career ... as you can't have both.

I have never thought about this before, but now that I do, I realise that most of the programmes that I watch tend to focus on women who are terrible mothers.

Women are usually portrayed as home makers or domineering characters even if they also have a job. Either that or they are tough, unkind, business women.

... patronising and make inappropriate assumptions about how our roles are split and how we relate to our husbands. Many are also ridiculous with their attention to stereotypical concerns.

They are often unrealistically glamourised (e.g.played by actresses not actually old enough to be the mother of their character's children) and restricted to stereotyped clichés of 'the working mother' or the 'stay at home mom'. If they get any storyline at all it's generally restricted to the old standard of the affair or almost affair.

While a small number of women refused to offer negative evaluations of mothers on television, most made the point that the medium of television was judgemental towards mothers in a way not seen with their paternal counterparts. More than one mother' 'objected to the ways that mothers are judged for being mothers, in a way that seldom applies to being a father'. The wider entertainment marketplace applauds men for their fathering efforts, even when they are ineffectual, as the parenting bar seems to be set so incredibly low, any failed attempt at emotional connection or misguided effort at communication is rewarded rather than rebuked (Feasey 2008a). Women, however, have the bar raised just a little higher, so much so in fact that we are reminded that they, and they alone 'remain the best primary caretakers of children, and that to be a remotely decent mother, a woman has to devote her entire physical, psychological, emotional, and intellectual being, 24/7, to her children' (Douglas and Michaels 2005).

Others made the point that they were unable to provide commentary because they refused to watch those programmes that contained what they assumed to be negative or problematic depictions of motherhood. 
I was informed that some mothers in the audience 'try to avoid negative programmes' while others tell me that 'bonestly, if I don't like them, I don't watch the show enough to describe them', and these comments are interesting because there is the suggestion in such responses that the reputation of a genre precedes the viewing experience. Moreover, several women made the point that they avoid a programme or character, but were intimately knowledgeable of the biography and narrative history of those maternal representations, and although I am in no way questioning their responses here, such comments are interesting in terms of what they tell us about the role of women's talk and extra textual media materials.

There is a general point of interest here about the role that news, reviews and other ancillary texts including community gossip play in our understanding of specific programmes. For those women who have chosen to avoid a specific representation of motherhood, they have either once watched and never returned to a programme, or rather, listened to other discussions about a text which then informs their decision to overlook specific titles. Indeed, many theorists have looked to explore the role and nature of promotion, publicity, reviews, interviews and other paratexts on our understanding of a media product (Austin 2002; Barker 2004; Gray 20Io), and it is clearly possible to make decisions about specific programmes based on never actually watching a particular title.

Furthermore, one might consider the gendered nature of these ancillary materials and the ways in which they inform female communication practices. After all, extant research on scandal and women's talk tells us that women bond through gendered discourses such as soap opera, women's magazines and the celebrity gossip sector (Bird 1992; Hermes I995; Johansson 2006). My point here is that women who are actively trying to avoid specific representations might not watch a programme that they themselves find problematic, but that does not mean that they are able to avoid finding out about storylines, narrative arcs or character developments through shared physical and online dialogue with other women, and mothers. While Mary Ellen Brown (1994) reminds us that genres such as soap opera offer a sense of female community beyond the television screen, even a cursory glance at maternal forums such as Mumsnet remind us of the role of television in the lives of these women, with dedicated 'Fun and 
Games' sections for 'telly addicts' and the offer of watching a specific programme as part of the Mumsnet community to inform conversation with other maternal audiences (Mumsnet 2013b).

\section{Avoiding bad mothers ... and the soap opera genre}

Although some of these women do not elaborate on those characters, programmes or genres that they seek to avoid, others are very clear about what they choose to overlook in the schedules, and it is surprising given existing literature on the genre in question. Several women talk about soap opera generally and EastEnders (1985-) in particular as the text or set of texts that they refuse to watch based on its negative presentation of motherhood and motherwork. And this is more than a little surprising given the genre's status as women's programming. Theorists have long been discussing the ways in which the genres narrative forms and structures appeal to the woman in the audience, foregrounding the role of the matriarch and strong women, focusing on the personal, domestic space and role of women in the community, and highlighting the importance of women's voices within the genre and beyond (Brown 1994; Brunsdon 1997; Geraghty 1999; Brunsdon 2000). Soap opera emerged on American commercial radio in the 1930 s and flourished when it transferred to the small screen in the 1950 s, and since the outset, the genre has been and continues to be understood as a woman's genre, with women remaining the largest audience share for British prime-time programmes such as EastEnders, Coronation Street (1960-) and Emmerdale (1972-). Moreover, the ancillary market of official magazines such as Inside Soap and the broader news, reviews and interviews with the actors associated with the genre appear in a rage of media texts deliberately aimed at the female reader. In short, it is surprising to find such hostility directed towards a genre that has its roots in women's discourse. 
Although the soap opera tends to stress that having a baby is 'the single most important thing in a woman's life', the course of the soap opera pregnancy, like that of friendship, marriage and indeed motherhood does not always run smoothly (Rogers 1992). Indeed, one of the general principles of the genre is its commitment to families who are less than perfect, who are strained or struggling in some way (Modleski 2007). The point here is that soap opera refuses to show a contented, happy or harmonious unit for too long; firstly, because domestic trials and private tribulations make up the dramatic action of the genre, and secondly, because creators of these shows assume that the presentation of a jovial, trouble-free family would irk the audience who themselves might be struggling with at least occasional familial disharmony.

While one respondent noted that 'mothers are just in the background holding everything together, worthless and nagging' the majority of women commented that women had a larger, albeit still problematic role to play in the genre. After all, in order to maintain a sense of character development and dramatic interest, maternal figures must be seen to traverse familial trials and tribulations in order to maintain narrative interest and the required cliffhangers from week to week and year to year. However, while many women pointed to the lack of maternal reality here, the truth is that although the difficulties of morning school runs, packing lunch-bags and remembering swimming kits is of some interest to the audiences of suburban sitcoms, it offers little in the way of drama, suspense or character development as necessitated by the contemporary soap opera. The genre is said to act as a 'social barometer' for the wider romantic, sexual, familial and domestic concerns of society (Salmon, cited in Hobson 2003) while reflecting the changes that 'have occurred in family life throughout the periods of their existence' (Hobson 2003). And yet, a short look at the profile of one long-standing character points to the relentless drama afforded a popular figure and the subsequent difficulty of maintaining a respectable, responsible or 'realistic' maternal role:

EastEnders: Carol Branning

Carol Branning was born in the East End of London to Jim and Reenie Branning on ${ }_{3}$ October 1962. When Carol was thirteen she fell in love with David Wicks and slept 
with him. Carol fell pregnant and her family tried to force her to have an abortion but she refused to have the abortion and disagreed. However, Carol's brother Derek Branning hated David and after learning about Carol's pregnancy, Derek beat David up severely and terrorised his family. This resulted in David and his family leaving Walford for Romford in 1976.

Carol is a feisty, loud and strong character, who is fiercely protective of her children. She arrived in 1993, as a worker in the launderette. She soon moves to Albert Square with her partner Alan, and her four children: Bianca, Robbie, Sonia and Billie. When it looks like Bianca is about to start a relationship with David, Carol has to reveal to David that Bianca is actually his daughter, who David thought Carol had aborted.

Carol and Alan get married after Carol's sister April is jilted at the altar. This is despite Carol's father Jim and brother Derek disapproving of the marriage, because Alan is black. However, Alan soon becomes jealous of Carol's friendship with David, and starts an affair, which provokes Carol into having an affair with David. These affairs are short lived, and Carol and Alan soon reunite.

After Billie witnesses an armed robbery, the Jackson family (without Bianca) are moved away from Walford on the Witness Protection Programme. During this time Carol separates from Alan, and starts a relationship with Dan Sullivan. When the Jacksons return to Walford, Bianca realises that she had a relationship with Dan when she was fifteen. She keeps this from Carol, but they soon begin an affair. When Carol finds out about the affair, she kicks Dan out, tells Ricky Butcher (Bianca's husband), and disowns Bianca. She then moves to Balham with Billie.

Carol comes uninvited to Ricky and Bianca's second wedding, to try and stop her son Billie from attending. Despite initially feuding, Carol and Bianca make up, and Carol moves to Walford. Billie and Carol fight regularly over Carol's controlling parenting, and Billie's gang connections. When Jack Branning gets accidently shot by one of Billie's gang members, who wanted to shoot Billie, Billie blames himself, and joins the army.

Billie is allowed to come home on his birthday, and Carol organises a party for him and his friends. During the party, Billie drinks to much alcohol, and the next day he is found dead on the sofa. Carol is distraught, and blames her family, until her brother Max tells her Billie only joined the army to get away from her. She bans her family from attending Billie's funeral, so only her, Alan, and Alan's mother Blossom attend. In her grief, Carol tries to kiss Alan, but he rejects her as he has married again, and has a son. Carol plans to commit suicide by overdose, but is interrupted 
by one of Billie's ex gang members, Connor Stanley. Connor and Carol comfort each other, and end up having sex. Carol however, disapproves of Connor's criminal background, and they break up and get back together many times. During one of the breaks, Connor starts dating Carol's step granddaughter, Whitney Dean. Connor sleeps with Whitney and Carol at the same time, until Bianca finds out and hits him with a metal pole, causing her to go to prison.

In 20II, Carol started a relationship with Eddie Moon, until she finds out he is seeing Vanessa Gold. In 20I2, when David returns to Walford to visit his dying mother Pat, old feelings start to resurface. Carol's brother Derek however hates David because of an old rivalry, and him getting an underage Carol pregnant, so he forbids the reunion. During an argument with Carol, Derek slaps her, which frightens her. The feud between David and Derek eventually escalates to violence. David persuades Carol to leave Walford with him, but after seeing how much she is needed by her grandchildren, he decides to leave without her.

When Bianca is sent back to prison in Suffolk for theft and assault, Carol, along with her grandchildren move away from Walford in order to be closer to her. Carol and her family return to Walford a few months later. On Christmas Day 20I2, Derek dies of a heart attack, which upsets and relieves the Branning family. On the day of Derek's funeral, Carol clashes with Max's secret wife Kirsty, telling her that Max doesn't want her in his life.

In late 2013, Carol begins a relationship with Masood Ahmed, but when they arrange a quiet night in at Carol's house, David returns with a whole lot of trouble. He has been having an affair with his boss's wife Naomi, and he has money which his boss, Don, wants. Don orders his henchmen to beat David up, which is severe. The next few weeks, Carol is torn between David and Masood, and doesn't know who she loves. She eventually opts for David, and leaves Masood to go on a meltdown.

In January 20I4, Carol finds a lump on her breast and fears she may have breast cancer. She has the lump checked out and a few weeks later, Carol is diagnosed with an aggressive form of breast cancer. This devastates Carol, and only tells David, Bianca and Sonia. (Wikia 2014)

The genre has historically gone out of its way to present strained and struggling families in order to appeal to the woman in the audience, but there is the suggestion here that many mothers are turning away from such texts precisely because of these careworn and besieged family depictions: 
The characterisation of mothers in soaps is often too extreme, they show little concern over their children's welfare.

Soap opera mothers in general because they are always making stupid decisions about how to behave without thinking about their children.

Ifeel there are few positive reflections and this saddens me. Mothers in soaps for example, are often shown as flawed or people with real problems.

The portrayal of women in soaps is appalling ... they seem to put themselves first with little thought to their young or grown up children.

I try to avoid negative programmes like EastEnders ... it paints mothers in a poor light because they are not always available for their children when they are needed.

Many of the mothers in soaps encourage disapproval, mainly because their parenting skills leave a lot to be desired... I can't think of any who have stood the test of time.

On soap operas ... pregnancies are rarely shown as complication free and once the babies arrive you rarely see them or there is no discussion over who is looking after them, childcare arrangements etc.

It is sometimes difficult to watch Carol and Bianca in EastEnders, they obviously try their best to love their children and grandchildren but are hampered by the complexity of their relationships and trials of everyday life.

I find maternal characters on soap operas too unbelievable. They are pitched at the extremes. I would rather see reality television when it comes to mothers, you get to see more of the things that have to be dealt with day-to-day.

I do like to watch fictional maternal characters on television and think that they can be very positive images of motherhood but I do get frustrated as I think soaps ... can still portray quite a limited view of motherhood, or being a woman generally, taking on a very domestic role.

People in soap operas who have children at the drop of a hat, change relationships all of the time, and have lives that revolve around themselves without any acknowledgement of the requirements of being a parent. It presents a fake and worrying impression of what responsibility means. 
I have argued elsewhere that soap opera is not simply a woman's genre, but should be understood as a maternal genre due to the commitment not only to women, but mothers, within the long running narratives (Feasey 20 I2a). Peter Buckman tells us that 'the problems of motherhood' (Buckman 1984) are crucial to soap opera, Christine Geraghty argues that the mother figure is the undisputed 'heroine' of the domestic text (Geraghty 1999) and Dorothy Hobson notes that 'child-rearing' is one of the genre's principal storylines (Hobson 2003). Soap opera does not merely represent motherhood, but rather, it represents the 'power of motherhood' (Hobson 2003) within the family unit and such maternal power is most evident in the ways in which the genre foregrounds 'the needs of children for their mothers' in the weekly narratives (ibid.). Tania Modleski's seminal work on the soap opera suggests that two of the most fundamental and oft-repeated narrative devices revolve around unwed mothers and the difficulties of balancing a career and motherhood (Modleski 2007). In short, maternal concerns about pregnancy, labour, caring for young children, guiding older children, providing for families, juggling work and domestic responsibilities and balancing social, sexual and motherwork routines are the mainstay of the genre, and yet the genre that received the most criticism for its maternal depictions was the soap opera, to the extent that several respondents commented that they were not interested in, and made a deliberate effort to avoid watching the fictional domestic drama.

I have previously suggested that soap operas present 'good enough' mothers rather than a more romanticised ideal of maternal care, because in many cases these women are seen to look after their children, but not at the expense of their social, sexual or financial desires (Feasey 2013). My point was that these mothers tend to the physical and emotional needs of their children, often under trying financial and familial circumstances, but they do not do so to the detriment of their independence or individual identity. Based on recent debates in feminist mothering, selfless mothering is understood to be problematic for mother and child in the long run, and a woman's desire to maintain a social and sexual life outside of their mothering role is said to be healthy even if it runs against contemporary notions of acceptable mothering in line with the ideology of the intensive role. Such maternal practices might be seen to be in keeping with feminist parenting 
manuals as they 'challenge the excessive child-centeredness of contemporary parenting practices' (O’Reilly 2008) and encourage women 'to grow as individuals', not just as mothers (Tiemann 2006). However, although feminist mothering manuals encourage women to sustain a selfhood beyond motherhood, several respondents echo Liebes and Livingstone's work when they tell us that maternal characters in the soap opera are often 'fallible, unsympathetic, or too preoccupied with problems in their own lives to support' their children (Liebes and Livingstone 1992). There seems to be the suggestion that the mothers presented in the genre are not simply trying to negotiate their maternal role and other domestic duties, but that they are not taking sufficient responsibility or providing appropriate role models for their children.

The commentary here tells us that the genre has perhaps gone too far in its desire to debunk the 'good' mother myth, with mothers being read as inappropriate and unacceptable rather than what I previously framed as 'good enough'. Based on a wide range of responses, it is clear that the women of soap opera are read as poor mothers because they are too selfish rather than selfless, too quick to look to their own pleasures rather than making decisions based around their children's wants and needs. In short, the participants appear to be judging these maternal figures for challenging the ideology of intensive mothering and for negotiating a more romanticised ideal. For these women, parental responsibility demands maternal sacrifice for the good of the children, irrespective of social, sexual or financial choices. The difficulty of maintaining this delicate balance of mature identity and maternal responsibility can be summed up by the following viewers:

I don't like mothers who are portrayed as only housewives that are waiting on their husbands hand and foot. I don't like mothers who put their children last and only care about themselves, their boyfriends or their appearance.

I do not like to see a matriarch, a bossy women who thinks they know what is best for everyone, keep tabs on cash and read all letters, neither do I like to see women as the underdog, trodden on and abused. I find this too painful to watch. 
I don't enjoy watching self-sacrificing mothers who do everything for the family but then I am uncomfortable watching mothers who put their needs before their children, young or old. Mothers should take on the burden of childcare but not become victims.

I have not amended the comments, nor ordered or re-ordered the wording in any way. What we see here then is the opposing notions of the 'good' mother as martyr and the more selfish woman who maintains her individual identity even after starting a family, and the desire for our screen mothers to propose a satisfying middle ground that mothers in society seem themselves to be struggling to find and maintain.

Moreover, in terms of the notion that few maternal figures have, to quote from one respondent 'stood the test of time', one has to wonder if part of the problem here is the format of the genre itself. For programmes that span several decades and generations, there will be times when the story might need to look to characters who have left the regular cast list, with storylines having to work around the availability of current and available actors, so that an uncaring or inconsiderate mother might be less about the role or responsibilities of a given character, but more about the availability of a performer over a given period. That said, if these comments about unavailable mothers is less about work schedules and more about the representation of those women seen on screen then there is the suggestion that the genre has moved too far from its roots as a domestic drama. Perhaps this is unsurprising given soap opera's recent attempts to move away from traditional feminine narratives and matriarchal characterisations in order to appeal to a broader demographic (Buckingham 1987; Hobson 2003; Feasey 2008a). After all, in order to attract a wider audience, much feminine discourse has been replaced with relational aggression, so that women are seen to cheat, bully, lie and deceive those around them, in line with their male counterparts. And although this behaviour is not directed at children per se, there is the sense that such performances, although common on screen, are not palatable for many mothers in the audience as it points to a level of selfishness and individualism not in keeping with what are seen as more responsible, and thus more appropriate models of parenting. Although some respondents 'can't stand EastEnders because the families are always screaming and shouting at each other', such negative 
representations are not confined to the soap opera genre. While many mothers suggested that television is littered with negative representations of motherhood, the majority of these women went on to talk about the reality television genre and a diverse range of programmes that feature ordinary people as the basis of their negative feelings and frustrations. We find that reality television, the docu-soap, the talk show and celebrity documentaries are dominated by examples of poor motherhood beyond a single character or programme. As with soap opera before it, there are assumptions made about reality television by those mothers who attest to never watch the genre, and several comments were made along the lines of 'I'm sure I would see lots of negative images if I watched reality television'. If indeed, many women clearly watch and enjoy such problem-parenting inspired texts from the reality genre, albeit a pleasure tinged with discomfort. Genres such as soap opera were accused of using pregnancy, babies and children as key narrative tropes that can be called upon or overlooked depending on the storyline and narrative arc, and as such, one of the pleasures of watching reality parenting television is quite simply the fact that the mother and children are together, attempting to interact and communicate, without convenient respite from that relationship.

\section{Reality and recognition: From Supernanny to celebrity}

Extant literature on the original, popular and long-running Supernanny (2004-12) and later Jo Frost: Extreme Parental Guidance (2010-) make it clear that the programme can be understood both as a supportive text for struggling parents and a site for maternal humiliation. And yet, although mothers in the audience are capable of diverse responses to programmes such as Supernanny, the overwhelming majority of those women who mentioned this programme or a more recent imitator made it clear that they derided the genre and dismissed those struggling mothers who played a part in such texts. 
While most women in the audience spoke of feeling uncomfortable with a programme that offers parenting advice, a lone voice applauded those strained mothers who are shown on screen for their decision to provide a more appropriate and harmonious family:

One of the things I am really impressed with is when mothers (parents) are open to helpladvice on programmes like Supernanny. They are obviously struggling and their parenting skills could do with some support, but it is really hard to open yourself up to the criticism, however constructive, on something as important and emotive as mothering. I don't watch it regularly but when I do see it I am impressed by these mother's good intentions, openness and ability to put their children first at this point in their life.

In the main, the parental reality genre in general and Supernanny in particular were seen to be committed to negative images of women as mothers. And although one mother made the point that 'I particularly dislike $T V$ shows portraying "naughty step" type discipline for children. I believe that children respond best to loving kindness from their parents', the majority of respondents spoke negatively about the mothers, not because of their desire to learn disciplinary techniques, but because they were seen trying to parent without such techniques, which they saw as a sign of maternal inadequacy. A number of mothers spoke of their sadness at witnessing what they deemed to be regretful maternal performances:

Reality programmes like Supernanny, I can't believe that some mothers don't seem to take an interest in their children, they show no guidance. The children then don't know what is right and wrong, and then it becomes a vicious cycle.

I think it is really sad to see the ways that children treat their parents on Supernanny, and how the lack of maternal discipline makes these children think that hitting, hurting and name calling is acceptable in the home.

Supernanny tries to help parents who are struggling to raise their children, she (and we) watch them make parenting mistake after parenting mistake, sometimes it is really sad to see how they have slipped into such bad habits, usually with the best of intentions, and then fall back into these routines without much needed support structures.

The mums on Supernanny are unbelievable, they don't seem to realise what they are doing wrong even when it is really obvious to everyone else. It is upsetting to see the impact that 
their poor parenting is having on the children. They talk about the children being naughty but these poor children are just reacting to the erratic decisions made by the mother.

\section{Others, however, relished the opportunity to judge and rank what they referred to as 'shameful' parenting efforts:}

... reassures me that my way is best!

... I like to criticise poor parenting skills.

I sometimes watch 'nanny' programmes, where some guru drops in to sort out a families problems. I do make ... judgements about these mums (families).

Some of the mums on programmes like Supernanny, mums who do not take pride in themselves, who shout at their children all the time and refuse to keep a tidy house.

I don't like reality television as it tends to take the 'extremes' in society, which I can't relate to, however, the people they select tend to make me feel better about myself!

I used to occasionally watch Supernanny and feel lucky that my child didn't behave like theirs. Which I suppose gave me the feeling that I was more successful as a mother.

Unorganised parents, the ones who are constantly late or have children that begrudgingly go to school are often ridiculed and portrayed negatively as a lesser being in programmes like Supernanny.

... nice to see your kids aren't THAT bad after all. I often feel insecure and/or annoyed about others ... preaching to me about how I should be bringing up my children, or presenting their way as an idealised way.

I like to watch programmes like Supernanny and Extreme Parental Guidance, less with an eye on wanting to borrow particular domestic or maternal techniques, more so with the hope that I am maintaining an acceptable domestic space and maternal routine for my family. It sounds terrible to admit but watching the extreme behaviours of the mothers and children in these programmes makes me feel more secure about my motherhood decisions.

I sometimes wonder how the mothers on something like Strictly Come Dancing are coping with looking after the children and the training sessions: I do not think that they are being a 'good' mum as they are not there for their kids, hence it makes me feel that 
I am the 'better' mum. I think that is why I find things like Wife Swap and Supernanny interesting to see if I am doing a better/worse job ... I am interested in the 'real' mothers for comparison purposes if I am being honest.

Supernanny is the parental makeover show, with Jo Frost as the childcare expert offering practical advice and emotional support to parents and children alike. With decades of experience in the field of childcare, Frost seeks to help strained and struggling carers to improve both parental and child behaviours in the home through the use of routines, respect and discipline in a safe and nurturing environment. And although Frost is not a mother herself, there is a sense that her professional childcare role rather than a more emotionally attached maternal status helps those households that she spends time with, allowing her to see where the problems arise and how best, without a sense of maternal guilt or conscience, to propose assistance. Although not all cultural commentators, parental advisers or maternal figures agree with Frost's disciplinary techniques, it is worth noting that most 'of her recommendations are based on recognized authoritative positive parenting behaviours, that is, providing consistency, praise, routine and boundaries' (Ganeshasundaram and Henley 2009).

And although the Montessori movement has recently published a parenting handbook that advocates a far more liberal approach to childcare, encouraging children to take decisions for themselves, without punishment for misbehaving, both the strict regime of Jo Frost and the more liberal approach augmented by the Italian doctor who founded the Montessori movement in the early 1900s are popular with pre-schools within and beyond the UK. Many Ofstead Outstanding pre-schools follow Frost's routines and practices, while a growing number of successful early years providers who feel that such regimes interfere with a child's own natural 'desire to learn and socialise' commit to a more liberal approach (Henry 2012; Hughes 2012).

Although one may talk about parental styles and popular opinions in terms of advocating one of these childcare approaches both at home and in the choice of pre-school, what seems to be overlooked here is the notion of taste and cultural distinction as it is informed by class differences. If one looks at Frost's television career and her broader publication and 
web-based franchise there is a sense that it is aimed at a working and lower middle class household, with Supernanny and Extreme Parental Guidance following the parental tribulations of mainly working-class families, while the Montessori movement and other recent attachment manuals are clearly aimed at and supported by more privileged upper middle class maternal figures. Attachment parenting requires the economic means to live on one income and time to commit fully to motherwork, and although this may not talk of middle class bias in itself, Bill Sears, the founding father of the contemporary attachment movement seems to point to this partiality when he states that mothers should not work outside of the home, and if financial constraints leave them questioning the importance of attachment parenting then they should borrow money from their parents to enable the wife to stay in the domestic arena (Lipkin 20I2), an option not viable for most families outside of the privileged classes.

And although one might argue that co-sleeping is free, that slings costs less than prams and push-chairs and that extended breast-feeding past the recommended six months is actually saving money on early weaning and the cost of formula, economics reporter Helaine Olen looks at the incompatibilities of toddler breastfeeding with the demands of a career, noting that 'whatever one thinks of the pros and cons of attachment parenting ... it doesn't come cheap, especially since there aren't many (if any) employers out there waiting for an employee who turns up with multiple children in slings and otherwise clinging to her body' (Olen, cited in Lipkin 2012). Likewise, Orit Avishai informs us that 'although some mothers may have the financial means to quit their jobs and dedicate themselves to full-time parenting. For most women, this is not a viable choice, since the more time they spend away from work, the larger the negative impact on their potential lifetime earnings' (ibid.). In this same way, the American Sociological Association makes the point that 'breastfeeding for six months or longer is only free if a mother's time is worth absolutely nothing' (Lipkin 2012). To return to the Montessori movement in the early years sector, the notion that pupils engage in individual and small group work of their choice, with children receiving individual instruction for $3-4$ hours a day speaks of a teacher to child ratio not common in either the early years or later school environment. To note that 'classes that spend over an hour a day in whole 
group instruction are departing from the Montessori model' leaves little doubt as to the financial and physical implications of a teaching method beyond most educational establishments (Chattin-McNicholas 1992).

Criticisms of Supernanny range from domestic disorder, mothers taking little interest in their children, showing them no guidance, demanding little respect and tolerating abuse with erratic and futile attempts to discipline such behaviour. None of the respondents talk about badly behaved children per se, rather, there is a clear consensus that it is the parental behaviours or maternal practices in particular that are at fault, with a lack of discipline or insufficient time spent with children being held up as the problem here. And although several commentators talked about what they deemed to be sad or tragic parenting oversights, there was little sense that the mothers were struggling to maintain what are considered to be appropriate childcare practices due to other work, caring or domestic commitments, even though this is something that the fragile and failing mothers in the programme routinely pass comment on in order to justify what are highlighted as their poor maternal choices. Most women who appear in Supernanny are not aware of what Frost and the audience see as poor parenting practices, and indeed, much of their decision making comes from a place of devotion rather than deviancy. It is not uncommon for women to tell us that they are scared to commit to formal, organised, coherent and constant discipline out of fear that such discipline will mean that their children will no longer love them (Supernanny: $\mathrm{S}_{2}: \mathrm{EI}_{\mathrm{I}}$ ). Frost briefly acknowledges the fear being voiced here before making it clear that the opposite is true, because rather than show respect or appreciation for their mothers loving efforts, these children have little opinion of the maternal position in the family home.

A small number of respondents made reference to the agenda setting function of these programmes and the ways in which they are being deployed as part of a broader maternal backlash:

I suppose it's the ones I'm being set up to disapprove of, e.g. who don't provide much in the way of a disciplinary framework or who yell/swear at their kids, feed them junk etc. 
I am shocked at how many shows are around that feature inept mothers - trying to change their behaviour. I'm not against it if it helps, but I wonder if mass culture is undermining women's instincts about their own competence (although I know this is nothing new).

With this in mind, one might question why it is that mothers watch and continue to watch in growing numbers programmes such as Supernanny, and according to those women who completed my questionnaire the answer is three-fold. For pregnant women yet to experience motherhood first hand, Frost offers a visual parenting manual, acting either as a point of practical information or as a way of starting domestic discussions before the arrival of a baby; for mothers who are themselves struggling with childcare practices, Frost acts as a firm but fair tutor, with a proven track record in helping families with their maternal routines and child-centred disciplines; and lastly, for those parents who have less first-hand insights into toddler tantrums and routine behavioural anxieties, the show offers reassurance concerning their day-to-day appropriate maternal techniques. The fact that social and economic commentators are discussing the recent rise in extended family, or multi-generational living for the sandwich generation (a generation of middle aged parents who have caring responsibilities for both young children and elderly parents), demonstrates how living apart from extended families has become the norm (Davidson 2013). At a time when the majority of mothers are living away from their wider family network, there is a sense that they have not been 'taught' by example how to raise and care for their children, in a way that had existed for previous generations, and some respondents saw this as regretful:

I have in the past felt sad about mothers who did not know how to cook appropriate meals for their children or to demonstrate responsibility and respect for the family, as portrayed in a variety of documentaries. I usually felt sorry for them rather than angry as it was more a question that they hadn't been taught rather than deliberately poor decisions.

No wonder these women are struggling, they don't seem to have ever been shown or guided as parents, I know we all have to make it up as we go along to some extent, but having supporting parents available makes the job a lot easier, not just because there is extra childcare help, but because of the practical advice from experienced mothers. 
Another way to think about the Frost franchise is to acknowledge that it is not uncommon to find pleasure, escapism or entertainment in those texts that we deem to be problematic. Existing work on soap opera (Brown 1994), the gendered magazine sector (Feasey 2008b), romance literature (Radway 1984/199I) and the romantic comedy (Brunsdon 1997) have all garnered hypocritical responses by readers who deem a specific genre text retro-sexist or pre-feminist, irrespective of their continued enjoyment of the text in question, with many fully aware of the seeming contradiction or hypocrisy at stake in their responses. Indeed, this is a position often experienced by the film, television and media academic whose theoretical and layman positions are at odds, particularly in the realm of feminist media studies. For example, gender theorists may teach students about the influence of psychoanalytic film theory and the need to renounce Hollywood film in a session on visual pleasure, outline the importance of post-feminism and the liberation of the sexual subject in a debate over contemporary raunch culture (Levy 2006; Attwood 2014) or present debates relating to the social construction of childhood gender roles, even when such formal theories are at odds with their own lived experiences. Indeed, much of the pleasure of watching something deemed unacceptable is based precisely on, rather than in spite of, this sense of disapproval. Watching television that we ourselves see as problematic merely speaks of a televisual version of smoking, eating fast food, drinking more than government initiatives tell us is good for us and forgoing trips to the dentist. We are not unaware of the health implications of these actions, but it still does not always warrant that we abide by socially approved behaviours.

The working class interest and escapist pleasures of Supernanny appear almost subtle in comparison to a range of more recent parental-themed programmes, with shows such as My Big Fat Gypsy Weddings/Holiday/ Christening/Valentine (2010- ), Here Comes Honey Boo Boo (2012-14) and Mom (2013-) being said to have jumped on the current 'white-trash' televisual bandwagon:

I like to get perspective and sometimes a brief stint of reality TV reminds me how lucky I am to have a normal life. 
I sometimes watch Here Comes Honey Boo Boo - simply because I can't quite believe the parenting and am morbidly fascinated!!

You couldn't make up the families in My Big Fat Gypsy Wedding. I don't know whether to laugh or cry at what these young girls are doing with their lives.

I find the clothes and bling lifestyle comic but the behaviour ... deeply troubling. I am repulsed yet drawn to watch these wedding stories unfold.

Why would any mother who herself has experienced life as a gypsy wife and mother wish this for their daughters. Unless there is something that the programme doesn't show or that the women are not telling, it seems at best unhealthy and at worse cruel to encourage a I6 year old child to quash any professional ambitions to lead this life of domestic drudgery.

Glamping for a week is mildly entertaining, but committing your life to a small trailer with all of the social stigma that comes with that domestic environment is rather sad, especially given the financial resources that these families seem to have at their disposal. Tens of thousands on a wedding to then live in a trailer is genuinely confusing to someone outside of the romany lifestyle.

\section{Audience responses picked up on the sometimes 'shocking' stories of young girls wearing sexualised attire, a lack of education or personal ambition and their status as property in the institution of marriage. A recent story on such nuptials informs us that:}

Britain’s youngest Gypsy bride has wed in a lavish ceremony costing £50,000. Danielle Maughan, who has appeared in the hit television show My Big Fat Gypsy Wedding, was one day past her 16 th birthday when she married 2I-year-old Brendan Joyce this weekend ... If [audiences] were expecting a traditional Big Fat Gypsy wedding, they were not left disappointed. The bride wore a six foot wide white dress, with dozens of layers of netting underneath the skirt ... Her heavily embellished corset was studded with crystals and glittery butterflies, and on her head, she wore an elaborate tiara. Her hair was vigorously tonged into brunette ringlets, and her skin was tanned to a deep brown. As befits tradition, there were multiple bridesmaids, who were dressed in voluminous purple creations reminiscent of a Disney princess. After the ceremony, the bridal party moved on to the nearby Open Hearth pub for a reception described as 'raucous'. For the party, the bride swapped her wedding dress for a bottom-skimming lace tutu and a crystal-studded, bow-trimmed corset that revealed her tanned midriff. (Arthurs 20I2) 
However, although Danielle reported that she was 'excited and very, very happy' to be marrying Brendan, she goes on to add that 'when you get married, you think you are going to get away and be your own boss, but it is nothing like that ... You're leaving your mother who owns you and she gives you to another person that owns you - your husband' (ibid.):

As a married woman she now has a life of hard work ahead of her. As teenagers, Gypsy girls are often kept away from school and instead put to work at home, performing chores and housework. Married life is no different, and Danielle will be expected to look after every aspect of the home for herself and her new husband. (ibid.)

And yet the programme has long proved popular with audiences, so much so that hundreds of fans lined the streets surrounding Our Lady Of Walsingham Catholic church in Corby in the hope of catching a glimpse of the limousine, bride, bridesmaids and the extravagant attire, and to a lesser extent, the groom. And although many of these fans may be keen to see a young woman who they admire, or want their own daughters to aspire to, there may of course also be an element of what has come to be understood as 'car-crash', or in this sense, 'white trash' (Hayes 2013) viewing pleasure.

Several commentators made the point that they did not and could not understand the lifestyle on display in the Gypsy stories, so too, it was suggested that mothers who responded to my questionnaire were unable to make sense of the maternal thoughts and practices that were evident in the Toddlers \& Tiaras (2009-) genre of programming, in terms of the pageants themselves, the mothers who strongly encourage their young daughters to take part, the professional instructors or the children themselves. 


\section{Tots, Tiaras and Blinging Up Baby}

\section{Toddlers \& Tiaras offers a behind the scenes look at the often controversial world of children's beauty pageants, with the drama of the show relying on a range of tantrums from stage mothers, daughters and professional parties interested in the victory of young girls in these events:}

Here Comes Honey Boo Boo - find some of the parenting skills shocking.

Any women who is competitive about her children ... gets her priorities wrong.

... those who project their own self worth through assessments of child's own looks. Toddlers \& Tiaras!

I do not like the false show-off mothers in reality television who do not give a true picture of motherhood.

I find it difficult to watch those pushy pageant mothers who put themselves before their children.

I think mums on shows like Blinging up Baby (which I haven't really watched) would drive me mad. Forcing your children to live out your dreams or treating them like a toy pet seems wrong.

I get upset with all those overbearing stage mothers on television who are selfish and only thinking of themselves, not their child's interest and needs. I can find that incredibly frustrating.

It is bad enough to see these young girls presented in this way, but when a little girl does not win a trophy and her mother berates rather than comforts her, you know that the maternal role is falling short.

It is upsetting to see the lengths that these mothers go to to 'belp' their daughters win what they see as important pageant titles, if only they put this much effort in to their education. It worries me what messages these girls are taking away from the experience with so much attention being paid to appearance, and what it will mean for them when they are older. 
Toddlers \& Tiaras is so sad, no amount offake gloss can make this acceptable, it is one thing for grown women to make the decision to enter these contests, quite another for mothers to make that decision for young children. They are meant to be the responsible and respectable ones making decisions for the good of these girls, they must realise that the physical fakery and emotional turmoil is damaging for anyone, especially vulnerable and impressionable young girls.

Although most audiences, even those who have never made a point of watching such reality fare are accustomed to images of very young girls with fake hair, nails, teeth and tans, moving in the style of go-go dancers, it remains shocking for maternal audiences to see these girls dancing in cages, mirroring the sexualised performances more routinely associated with adult performers at specialised night-clubs, and dressed in the popular attire of working girls as popularised in the film Pretty Woman (1990). Indeed,

... with mothers dressing their daughters like surgically-enhanced country singers, fake breasts and all, or hookers with hearts of gold, how could viewers be anything $b u t$ horrified? In all honesty, some of these little girls - the ones who don't aspire to be tax lawyers, at least - look like complete prosti-tots. (Zaretsky 20I2, italics in original)

It is clear that mothers, the driving force behind young girls entering such pageants, take on a role in the makeovers and costumes demanded for each performance. The show itself, and viewer responses make it clear that these women are not acting selflessly at the behest of their children, but that in many cases, it is the mother who seeks the media attention and reaps the financial rewards from their daughter's role in these pageants. In short, these women are living vicariously through their daughter's successes, and are subsequently frustrated and disappointed by what they see as their failings. A recent political remix video makes the point here when it tells us that:

It's difficult being a pageant queen but being a mother of these up and coming contest winners can be even harder. Moms \& Tiaras provides a different insight behind these prepubescent beauty queens: the mothers from the TLC show Toddlers \& Tiaras. (Candler 2013)

The video goes on to edit together maternal commentary, and it very easily gives the impression that these mothers are the ones committed to and 
invested in the pageants, and that the role models that these women provide for their young daughters is based on winning at any cost:

It is my life and if you don't like it, stay away from me ... We do pageants because they are fun and addictive ... It's the winning part that's so addictive ... We would travel up to 24 hours one way for a pageant ... It just becomes almost consuming ... You do drugs because you want to get high, you do pageants because you want to win ... Do I think that what I do is wrong, no ... Beauty is the most important category ... You can make the face beautiful, you use more make up ... I would rather take no crown home than a princess crown. (ibid.)

One might look to the pageant experience and hope that it provides a safe and nurturing space for young girls to build their confidence, make and maintain early friendships and to teach meaningful life lessons such as consideration, respect and the importance of taking part over winning before the onset of adolescence which is when, research shows us, girls start to lose confidence and question their appearance (AAUW 1994). However, this is clearly not how many of these pageant parents are performing here. Indeed, some respondents pointed out that such a focus on appearance for these young girls does not encourage a healthy attitude to surface beauty and body image, with the suggestion that this attention to the assumed physical ideal at such a young age might lead to anxieties over appearance when these girls reach their tween and teenage years.

There is little respect shown between pageant mothers or between mothers and daughters. Dance tutors and other pageant influences invest in the hierarchy of titles and make it clear who will succeed and who is set to fail. In short, little compassion is shown towards these girls and perhaps with this in mind, it is not surprising that these children are then shown physically and verbally abusing one another, with little or no parental interference or apology for such actions. After all, such actions merely echo those that are being displayed by the parents and guardians of the piece. For mothers in the television audience, the programme seems at best inappropriate and at worst a problematic presentation of maternal care. 


\section{Teen motherhood, privacy and wannabe culture}

This notion of maternal self-interest continues in comments made about the broader parenting reality genre, in relation to programmes such as $I 6 \&$ Pregnant (2009-) and Teen Mom (2009-). I6 \& Pregnant is the documentary series that focuses on the controversial subject of teenage pregnancy in America, with each episode following a five-to-seven month period in the life of a teenager as she navigates the mental, physical and financial road to new motherhood, paying particular attention to themes such as marriage, adoption, religion, community and peer gossip, graduating high school and the world of work. Teen Mom is the follow-up documentary series that follows several of the 'stars' of $I 6$ \& Pregnant as they face the challenges of new motherhood as a teenager. While the mothers on Toddlers \& Tiaras were spoken about in overwhelmingly negative and hostile terms, those mothers presented on Teen Mom prompted more mixed reviews, ranging from compassion and empathy to pity, judgement and ridicule. In terms of the compassionate readings:

The saddest thing on Teen Mom is seeing the cycle of poverty played out, teen mothers having daughters who then themselves become teen mothers ... without a formal education to fall back on. These young girls will struggle to better themselves and the cycle continues.

Sometimes I find it difficult to watch young mums on documentaries who are not giving their children the best that they can, they can seem selfish and uncaring. Then I have to remind myself that these mothers are really still children and that they need help to become better parents.

Unwanted teen pregnancy is a real problem in this country and America, the more we can get young girls to face the reality of having children when they themselves are mere children has to be a good thing, and for this, I think programmes like Teen Mom are actually contributing to society. I am not saying I like them, but they serve a useful purpose.

16 \& Pregnant and Teen Mom really do show the painful reality of teenage pregnancy played out in full, you get to see the reality of living in poverty, boyfriends and fathers leave, these young girls leave schooling, grandmothers sacrificing their lives in order to step in ... and the cycle of poverty, struggle, abuse, depression and misery. You watch 
hoping that they get the support that they need to help them break out of their sad situation for the sake of them and their children.

Others offered a more critical reception of the young women on screen:

Teen Mom ... some people shouldn't be allowed to have children!

It makes being a teenage mum look like a career option, and the more family drama the better for popularity and ratings.

It's the children I feel sorry for ... most of these young mothers show more interest in the cameras than they do in their children.

It is one thing to be a terrible parent, another to be seen on television, but quite another again to play up to this failing image for the cameras. I sometimes wonder how much of these shows are exaggerated for exhibitionist effect.

I wonder why these girls agree to go on the programme, is it because they feel that they are receiving much needed attention for their maternal group, because the payments through the show and wider channels will help them to support their children or simply because they want to be one of the new breed of celebrities by any means, I cannot understand why they would want to be presented in this way, or why their parents would encourage it. Don't they realise that their children will be able to watch all this one-day.

Much of what we see on these programmes could be read as problematic parenting whereby these adolescents struggle to realise and perform in line with the responsibilities of motherhood. As such, it is understandable that some audiences question the appropriateness of these girls as parents, and their desire to be filmed for the series. In some cases the teen mothers put their own social and sexual needs before their children's, stay within unsafe and abusive relationships, create friction between generations, demand long-term and routine family assistance and live in inappropriate conditions for a young family. The mothers in question speak of mental illness, violence, suicide attempts, felony charges, drug addiction, overdoses and rehab (TeenMomNews 2014a, 2014b). Some of which is understandable, given, in many respects the lack of clear and constant maternal, educational, career and wider social and domestic guidance offered to these young women. The fact that many of these girls are the most recent in a long line 
of generational teen mothers, living near the poverty line, points to the difficulties of breaking the cycle of disadvantage. Many of these teen mothers are without financial, educational and/or social support, they are young women who have mostly had an unplanned pregnancy who were naïve to the reality of childbirth and parenting, leaving their previous school routine and friendship circles, now struggling in their newfound maternal role.

No wonder then that many respondents felt sadness or sympathy when watching the trials and tribulations of the teen mothers played out in minute detail on the small screen, watching these young girls navigate their way through new motherhood with the added pressures of school, social stigma, peer disapproval and errant partners makes it difficult not to feel compassion for these mothers. The responsibility of new, particularly first time motherhood can be overwhelming for women (Oakley 1979/198I), and that sense of parental responsibility might be compounded when the mother in question is still, herself, a child and often mothering without the father in routine residence. There is a sense that however much audiences feel sadness for the maternal figure, what many are expressing of course is a sense of injustice on behalf of the children of the piece. These newborns, toddlers and infants are seen to be the innocent parties here and audiences watching direct their thoughts, concerns, hopes and anxieties at this new generation growing up in the limelight.

For some, Teen Mom offers an authentic insight into a generation of mothers that are glamorised elsewhere in the media marketplace. The American soap opera routinely glamorises single and teen motherhood and gives the young female audience a misleading picture of this maternal position that takes little account of the reality of teen pregnancy or adolescent motherhood in the contemporary period in terms of poverty, crime, lifelong learning disabilities and behavioural problems. Mary Strom Larson's research, based on questionnaire responses from junior and senior high students, tells us that those who watch daytime soap operas are ill-informed about the reality of teen and single parenthood, basing their opinions about this parenting status on what are overwhelmingly positive experiences for this family unit in the domestic drama (Larson 1996). Indeed, it was suggested in her textual coding that the soap opera went some way towards idealising teen and single motherhood as these fictional female characters 
were routinely seen in professional careers, wearing designer clothing, maintaining enviable social and sexual lives without any obvious restrictions or limitations on their personal, professional or financial freedoms. And this depiction of a serene, spontaneous and successful teen mother was seen to influence young women's perceptions of the reality of this role.

Much of the commentary on Teen Mom however points to the role of deprivation, a general lack of privilege and poverty as the root cause of what is deemed 'failingfamily behaviour' as it is seen on the programme, and some maternal audiences refer to representations of such harsh realities as a useful lesson for young girls in the contemporary environment. Indeed, it is difficult to judge these teenagers against the ideology of intensive mothering or the 'good' mother myth when many of their stories of hardship and hope are so far removed from that, itself romanticised, ideal. That said, although extant research and the commentators here speak of the financial difficulties associated with teen pregnancy and young motherhood, it is worth mentioning that the 'stars' of these television productions are paid for inviting us in to share their turbulent domestic routines.

The eponymous teenage mothers are paid between $\$ 60,000$ to $\$ 65,000$ per season, therefore the problem here is not necessarily a problem of poverty per se, but more a concern about financial management. Those who commented on the show within and outside of my questionnaire point to the ways in which the adolescents are spending vast sums on ephemeral, trivial and inconsequential items, and questioning provision for the children seen the show:

These girls have sacrificed their children's privacy for financial gain, I only hope that they make sure that they are rewarded when the time comes, and that it hasn't all been spent on fake nails, hair and tans.

You can see that some of these girls are going to spend every penny rather than save for their children's future... what a shame that no one really seems to be advising them. This might be their best and only chance at financial security, but they are not treating it as such.

For young mothers who talk of giving their children a better start in life than they had, some of the girls on the programme seem to spend an awful lot of money on themselves. 
I know that you can't see savings as such, but you really have to wonder if they have left anything to help their children when they grow up.

\begin{abstract}
A percentage of the monies from both the parents and grandparents, should be put into a trust fund for the child. This trust fund to be used for advanced education, medical, dental and other NECESSARY items. I feel that the young people should be given financial counseling BEFORE they are given their monies. If a reality star is on substance abuse or shopping abuse etc. then [...] MTV, should pay for counciling because MTV make more money from someone who has an 'illness' [...] Amber ... using her money to buy false nails, false eyelashes, makeup, drugs etc. was such a waste. MTV have a responsibility to these young people because most of these young people come from families that are incapable of giving their children the financial advise that they need [...] MTV has made a mint from these kids, so therefore MTV should be including as part of extra payments, professional financial guidance counseling BEFORE these kids receive their monies. (Aguirre 2010)
\end{abstract}

There are a number of points introduced here, including a debate over a child's right to privacy. While many respondents pointed to notions of child deprivation and insecurity for many of the newborns introduced on the programme, a smaller number of them wrote about their concern for the privacy of the children seen in Teen Mom and the wider reality genre. The young mothers on the show are able to give consent to their appearances on screen and are then able to, within the conditions of their contract, enter, leave and re-enter the show as discussed and agreed in advance with a production team. The children, however, are in no position to consent. Indeed, the United Nations Report by the UK's Children's Commissioners has recommended that the government regulate the appearance of children in reality and the wider television sphere in order to ensure that their right to privacy is not violated (Beckford 2008). Research goes on to tell us that as the reality genre continues to increase from year to year, so too does the number of children that we see on screen, and that using children as cast members leads to a clear and permanent loss of dignity and privacy for those involved. What is more, we discover that, particularly in America, 'the current legal regime is inadequate to protect these children, whose parents have betrayed their best interests for fame and fortune' (Royal 2010; Nobile 2013). 
What is of concern for some audiences here is not simply the loss of privacy for the child whose early years are played out in front of the camera, but the fact that there is then no financial recompense for their loss of privacy. The California Child Actor's Bill (also known as the Coogan Act or Coogan Bill) protects child actors by limiting the amount of hours children can work, requiring teachers be present on 'set', and demanding that employers set aside is per cent of a child's pay and place it in a blocked trust account, however this law does not cover those children who are seen within the reality television genre. In short, the parents have sole access to their Teen Mom salary, and unless they chose to do so, the children being seen from week to week will not be financially rewarded for their time on camera (Gornstein 2010). With this in mind we discover that:

These kids are not classified as performers, denying them the protection of Coogan laws. In fact, the children are not even classified as workers, also denying them the protection of child labor laws. Kid reality stars fall through the cracks of the protections crafted by early 20 th-century reformers, who likely never imagined that someone would consent to potty-training their children on camera. (Levey 2010)

In order to protect privacy and secure financial futures we are told that 'legislators and lawyers need to step in to ... protect the best interests of children' within and beyond the reality television genre (ibid.). Indeed, American states are all encouraged to pass Coogan laws for child performers, broadening the definition so as to include children on shows such as Supernanny, Toddlers \& Tiaras, My Big Fat Gypsy Wedding and Teen Mom, to name just some examples mentioned by maternal audiences. Early reality television was focused on adults, and it is only more recently that we have seen children firstly on the margins and then more recently again, at the centre of such programming, and there is a clear sense that in legal, cultural and creative circles, existing laws are not doing enough to protect either the dignity, privacy or financial integrity of the children in these shows. Bearing in mind that the actions of these children are not only being seen on television, but will be available through internet channels for decades to come, when these children are well into their adult years, means that this must be taken seriously by policy makers and producers alike. 
Some respondents made the point that the young mothers in these programmes are seeking fame, renown and notoriety, with the suggestion that they are using their status within the Teen Mom series to elevate their public position, placing them within the sphere of celebrity culture for an interested and invested female audience. And there does seem to be some evidence to support this suggestion; after all, many of these teen mothers go on to have entertainment careers outside of the show that made them famous, maintaining a celebrity lifestyle in the manner of what Chris Rojek refers to as an 'attributed' celebrity. An 'attributed' performer is, we are told, someone whose fame rests heavily on their ability to capture and maintain media interest, with a public profile committed to sharing each and every moment of their personal and private life with the tabloid and celebrity gossip sector (Rojek 200I; Turner 2006). From sex-tapes and nude photos to confessional biographies and beauty blogs, many of the 'stars' of the series find a way to maintain a level of public attention beyond their time on the programme in question. Irrespective of whether these young mothers sought fame and therefore approached the producers or whether their time on the programme opened up a desire for celebrity, these young women epitomise the contemporary culture of wannabe celebrity. WAGs, socialites, kiss and tell escorts, glamour girls and reality television performers have created a new breed of approachable, available and accessible personality.

The tabloid and celebrity gossip sector tend to focus on the changeability of celebrity and the narrative of female transformation. Regardless of whether the sector is applauding an actress for her weight gain, condemning a presenter for her weight loss, mocking a socialite for a new hairstyle, praising an Olympic medallist for her sartorial makeover or commenting on a new romance, pregnancy or plastic surgery procedure of a reality television contestant, what each of these stories has in common is change, changeability and the modification of a female figure. Claudia Croft talks about 'the celebrity trajectory theory', which refers to the notion that 'a life in motion is ... more interesting than one that appears stagnant. It doesn't ... matter whether their trajectory is upwards to career success ... or downwards to addiction and tragedy. As long as they keep their lives moving, we keep watching.... and the more it looks like a trashy soap opera, the better' (Croft 2006). Croft makes it clear that Madonna set the pace for celebrity 
changeability and transformation in the late 1980 s with her regular hair, clothing and image makeovers. However, we are told that changing a wig every few months is no longer dramatic enough to garner audience interest, and that the public now demand that a young 'star' change her outfit several times a day and her sexual partners with similar frequency (ibid.).

Croft suggests that the most popular and successful 'stars' of the modern day are in flux, in short, offering up a point of discussion and instigating women's talk for the celebrity gossip reader (ibid.). Indeed, the ways in which the changing celebrity can be seen to act as 'gossip-fodder' is crucial here. After all, extant literature on the celebrity gossip reader makes it clear that the latest entertainment news is understood as, and deliberately coveted because, it stimulates informal talk between women and creates a sense of group cohesion. It is as if an understanding of celebrity 'trivia' serves as a connection between females, with readers being united by an appreciation of, or at least through a discourse surrounding a particular gendered text (Hermes i995; Feasey 2008b).

Even a cursory glance at Teen Mom and the surrounding media discourses relating to the 'stars' of the show demonstrate that changeability is key to coverage in the media; after all, within one brief news update on the teen mothers we find talk of arrests, sex tapes, diet successes and slimmer figures, plastic surgery, maternal feuds, drug, addiction and rehab confessionals (TeenMomNews 2014a, 2014b). Although I do not want to appear flippant about such issues, it is clear that, irrespective of whether that change is serious or superficial, positive or destructive, to be condemned or applauded, change is key to media interest within and beyond the maternal teen text. The fact that these young women can change their hair colour, relationships, body weight and sartorial style on a monthly, weekly or even daily basis is the key point here. It is not seen to be interesting to report on a reality star who is consistently too thin, too well groomed or in a stable relationship, but rather, the growing tabloid sector is keen to foreground those dramatic and somewhat less significant changes. If we consider that divorce rates, unemployment and the cost of living are rising, then it might come as little surprise to find readers interested in the downward spiral of once commercially successful figures. Indeed, reporting on the failed relationships, career decline, financial losses and questionable maternal 
techniques and practices of recognisable young women might be seen as one more way in which the young tabloid reader identifies with the female celebrity. Alternatively, the depiction of recent romances or the triumph over medical or financial adversity might offer hope to those women who look to these figures to make sense of their own lived reality (Johansson 2006). Either way, it appears to be the changeability of female celebrity rather than the stagnant life of the famous figure that appeals.

\section{Named and shamed: Price, Katona and Hopkins}

While some respondents were highlighting their distaste and mistrust of the teen mothers for their interest in the celebrity lifestyle, many others were foregrounding two mothers well known for their popular and longrunning reality television commitments. Kerry Katona and Katie (also known previously as Jordan) Price were spoken about in the majority of negative comments directed at mothers on the small screen, and commentated on, at length, in many cases. For some respondents these two figures were interchangeable in terms of their maternal credentials and what they considered to be their inappropriate mothering roles.

While Katona found fame as a member of an all girls group Atomic Kitten, Katie Price came to notoriety as a glamour model for The Sun. Both women have had multiple marriages and very public divorces, numerous children from different partners and a life played out in a series of very intimate reality television shows. These women have each forged a career in the entertainment sphere, through a steady stream of reality shows, celebrity columns and confessional biographies. Like a number of other 'attributed' celebrities their careers are 'an ongoing process of managing, repudiating, and creating the scandals that afford [them] media attention' (Bell 2008). Indeed, one cannot overestimate the importance of these reality television performances on their subsequent star images and celebrity status, with the charges of crudeness, exhibitionism, and humiliation being thrown at 
both the shows and the stars in question (Feasey 2012a). Although Price is an incredibly successful media personality, with an estimated net worth of $£ 4 \circ$ million due to a range of equestrian ranges, fashion, beauty and clothing lines, book deals and television contracts; Katona has faced multiple drug, alcohol and smoking scandals, been declared bankrupt at the High Court, lost her endorsement deals, magazine columns and television shows before facing a recent repossession order.

However, irrespective of financial success or official endorsement and sponsorship deals, both women have played a large part in the British tabloid sector for over a decade, with their personal lives being exposed and interrogated in intimate detail by a willing public. These women are both skilled celebrities in that they understand their role as 'attributed' performers and play their transformative roles perfectly, with romantic, sartorial and physical changeability being their modus operandi. And although the column inches and viewing schedules dedicated to the physical, emotional, medical, mental and sartorial trials and tribulations of these recognisable women make it clear that audiences are interested in their life and love stories, there is clear judgement in relation to their maternal roles:

I am interested in celebrity but I don't like intrusive videos of the children - I think it is wrong.

Kerry Katona, what is worse, that she doesn't spend enough time with her children, or that she does.

Kerry Katona, she should not have custody of those four children. Drugs, drama, bankruptcy, you shouldn't let your children watch all of this play out in public.

Kerry Katona, she stands for everything that is wrong about celebrity, no talent, no skill ... using those poor children as media money makers when all her other options are running out.

Kerry Katona, I feel sorry for her children, I bet they have never had such a thing as a play date, how could they, between feuding with partners, financial disasters and forced house moves, alcohol and drug addictions, time in rehab... I often hope that they have doting stafflooking after them because there is little mother love here. 
Kerry Katona and Katie Price... so many children from so many fathers, it's difficult to keep up. I hope that these women adore bigfamilies, but I can't help wonder if it is all just part of a media interest story when their popularity starts to fade.

Katie Price, Kerry Katona and other celebrity car crashes are not setting good examples for other people's children so how can they for their own? They may be very good to their children but the images that they project are damaging to women in general by saying it's ok to behave like that.

Ifeel slightly guilty saying this but I do judge many of the reality television mothers who include their children in the filming of these shows. Kerry Katona and Katie Price for example. Not only do I question their parenting techniques but the very fact that they are exposing their children at such a young age to the full gaze of the television cameras and crew seems at best intrusive and at worst problematic in terms of the children's understandings of home, family, privacy and safety. It might be stretching the point but it looks exploitative.

Katie Price, jumping from one man to another and fighting in front of her kids, shameful.

Katie Price, because of the different, broken relationships that she is putting her children through.

Katie Price, I'm sure she is a good mother when she's at home and with the help of her eight nannies. But I hate her crudeness and aggression. And that she's only in the paper/ magazines when she's berating her exes. Is that all she does??? I just don't get it?? And doesn't she realise her children will read everything nasty she says one day.

Katona and Price are both seen through their long and varied reality television formats spending time with and time away from their families, with the children being a key part of these productions. Although these programmes are filmed for our entertainment and highly edited, there is a sense that these women are showing us and sharing, quite literally, their maternal thoughts and practices, for good or ill.

I have previously argued that media celebrities such as Price, Katona and Alicia Douvall are appealing maternal figures for the woman in the audience precisely because they present a more selfish, sexual and social image of motherhood that debunks both the ideology of intensive mothering and the romanticised 'good' mother myth that is said to dominate the wider media agenda. I suggested that it is precisely the inappropriate 
and unacceptable depiction of these women as mothers, but also as lovers, friends, business women and daughters that made them palatable, and indeed, pleasurable to a viewing public, because they presented a version of mothering without martyrdom. Both Price and Katona have been awarded mother of the year honours, are applauded amongst the general populace for their patronage of children's charities, proved popular with the voting audience on the reality show I'm A Celebrity, Get Me Out of Here (2002-) and continue to be popular with magazine editors as demonstrated by their continued and repeated inclusion in the gossip and women's sector. However, as noted by Croft, changeability and transformation is key, irrespective of the direction of travel, and for every maternal commendation and media contract, there is an assault charge or accusation of neglect, an appearance on the worst mother list or a question about maternal custody (Feasey 20I2a). One might suggest that the media and monetary fortunes of both women can be tracked through their maternal status, and with both women being new mothers at the time of writing, they are in a position to reclaim the affections of those mothers interested in the celebrity and gossip sector.

However, even though one can give examples of the ways in which these women might prove popular with television viewers, maternal audiences made very few positive comments about these women or their mothering capabilities. It is difficult to view Katona as 'mother of the year' due to her drug-addicted and self-confessed maternal neglect; however, it is hard not to empathise with a young woman who has spent years watching her own mother's fight against drug addiction and mental health problems. Katona is open about her childhood spent between foster homes, her addictions and bi-polar struggles, and she is adamant that she will try to 'break the fucking cycle here of my upbringing' (TNC $\left.\mathrm{S}_{2}: \mathrm{E}_{3}\right)$. Katona did not have an 'appropriate' maternal role model, but she is trying to become one for her own children. And although one might challenge the appropriateness of a bipolar mother presenting her own life and the life of her growing children on national television, the use of her children in demanding celebrity photo shoots, the crudeness of language expressed and the open hostility between herself and the fathers of her children, there is an uncomfortable honesty being expressed here which is not viewed elsewhere in mainstream 
programming or the wider media agenda. And although Price has not suffered such financial hardships either in her formative years or as a celebrity figure, she has talked openly about her parents' divorce, child abuse, rape, miscarriage, fertility concerns and the struggles she faces as a mother of a blind son diagnosed with sepo-optic dysplasia, Prader-Willi syndrome, ADHD, oppositional defiance disorder, and autism.

Many mothers face difficulty, hardship and feel themselves and their children removed from the privileged life of the comfortable classes; and others across all class, taste and financial classifications face injustice, disability and non-traditional family units, and yet maternal audiences made it clear that they judged these women for what they deem to be their selfish practices and resultant maternal failings. The intimacy of address and the brutal honesty on offer clearly appeals to a viewing audience, but an audience who judge and ridicule rather than one who feels empathy for the women in question.

Both women are judged, like the eponymous teen mothers before them for not merely allowing their children on screen, but for actually encouraging their engagement with the public sphere in terms of contracts and endorsements. As an extension of their status as 'attributed' celebrities within and beyond the realm of reality television, these children were said to be missing out on what were seen to be more traditional and expected activities befitting their age group, activities unlikely in a household filled with camera crews and the wider paparazzi collective. The fact that these women do work and spend time away from home and from families in order to fulfil their media contracts makes it clear that they are not practicing intensive mothering, but it is the changing relationships and feuding between partners that many respondents found to be most troubling here. These women were seen to enter relationships, engagements and marriage contracts on a whim, with divorces being unsurprising and expected. The concern is less for the mental or emotional wellbeing of the women involved in these changing relationships, but for the children who find themselves introduced to, invested in and then removed from friendships with a number of boyfriends, fiancés and husbands, with the brash and aggressive feuding that often ensues. With mothers away from the family home, a number of men involved and then absent from the domestic scene, 
this is what is of concern to the women in the audience. What is interesting here is that while several women felt empathy and sadness for the struggling teen mothers in the aforementioned show, these self-same women spoke of their hostility towards Price and Katona. One might question if it is the age of the mothers on screen, the longevity of their celebrity profiles or their distance from British audiences that led to such diverse comments for what are, in many respects, similar maternal figures.

The teen mothers, although struggling and occasionally selfish and in need of emotional and practical support are available to their children, whereas Price and Katona speak of their maternal devotion while often working away from the family home, and maybe this is one of the key differences here. The teen mothers are doing their best under challenging circumstances and can still navigate their way towards appropriate parenting, whereas Price and Katona are experienced mothers who continue to position themselves against traditional maternal roles and responsibilities. Moreover, the young women on Teen Mom can appear interchangeable, and new faces are introduced from season to season, whereas Price and Katona are individual personalities, intimately known to and by the British public. When respondents talk about the teen mothers they tend to speak about these women as a group rather than individuals - their frustrations and failures were seldom aimed at a specific maternal figure, whereas Katona and Price have made a career out of being recognisable individual personalities.

One does have to question whether there is a class dimension to the commentaries here, not in terms of the respondents, but rather in terms of those maternal figures that they find themselves judging negatively. After all, the world of film stardom and celebrity culture is peppered with women who have many children by different fathers, repeatedly married and divorced with little outrage or comment from either the tabloids, broadsheets or wider maternal blogs. Kate Winslet, Christine Brinkley, Erykah Badu each have three children by three different fathers; the difference here perhaps is that these are professional women with less stake in the celebrity gossip sector who are not flaunting their maternal status or revealing the day-to-day minutia of their relationships with the female audience for profit. Moreover, the notion of child privacy and media contracts for children seems to draw selective criticism, after all, Victoria Beckham has allowed 
her children to, at different times, take part in her reality television shows, and take on their own endorsement deals, while Jada Pinkett Smith and Angelina Jolie both encourage their children to play a part in the entertainment industry with little in the way of public hostility or outrage. With this in mind, I would suggest that it is not the privacy debate, the number of fathers, or the negotiation of intensive mothering practices at issue per $s e$, but the combination of such factors that position Price and Katona as such problematic figures in the contemporary celebrity landscape.

In relation to my question about mothers on television who audiences might feel negatively towards, many focused on the figures of Price and Katona, with some mention of 'Octomum ... that frightfully selfish creature who gave birth to 8 children even though she was already a mother to 6', otherwise known as Nadya Suleman and the panellists on the lunchtime talk show, Loose Women (1999- ) such as Coleen Nolan, Kaye Adams and Jane Moore who 'all seem to have loads of plastic surgery although they present themselves as very down to earth'. However, only one other name appeared with any frequency, and this woman is another uniquely British phenomenon. Katie Hopkins. Hopkins is a mother of three who first came to the attention of the television watching audience as a contestant on the reality show, The Apprentice (2005-). Although Hopkins was in the final of the third series of the show, she withdrew from her place, stating that she would not be able to accept the job for fear of uprooting her daughters from their home to a new London base. And although this is surprising in itself after II weeks of competing for the prize on offer, a job with Sir Alan Sugar and $£ £ 100,000$ starting salary, it was not her departure that created media interest in this figure. Since leaving the show Hopkins has become like the teen mothers, Katona and Price before her, an 'attributed' celebrity, with time spent in the I'm a Celebrity... Get Me Out of Here jungle, on the This Morning (1988-) sofa, not to mention the broader newspaper and magazine columns. Hopkins presents herself as a businesswoman and a journalist, known for her quick wit and acerbic commentary. She delivers strong opinions on women, work and family life and her notoriety stems from her outspoken, often controversial public statements concerning the royal family, other celebrities, maternity leave, women in business, obesity and motherhood. 
Hopkins suggests that it is possible to make class and taste judgements based on the Christian names of a child, and rather than apologise for this elitist outburst, she goes on to tell us that it is not only acceptable, but sensible to do so in order to alleviate unwanted playdates. Her thoughts on children's names on This Morning went viral, attracting to million hits globally in just four days:

Chantelle, Charmaine, Chardonnay and Tyler ... there's a whole set of things that go with children like that, who are quite a disruptive influence in school and that's why I don't like those kind of children ... I tend to think that children who have intelligent names tend to have fairly intelligent parents and they make much better playdates for my children ... We are really time short in this world and we need shortcuts to make decisions. It's very effective. (Hopkins, cited in Cable and Kirkova 2013)

Based on the media furore following this announcement, Hopkins went on to publish The Class Book of Baby Names (2013), in part, as a response to requests for her to \# ratemyname, and in part, to maintain her celebrity trajectory:

Chardonnay: Non-uniform day. Tyler, Chardonnay, Princess and Angel can't see what's so different from a normal day.

CHARMAINE: Any school lost property box. Always filled with uniforms labeled for Charmaine and Chardonnay. But misspelled.

RILEY: I can hear the collective sigh as another baby is born with only the state to call 'daddy'. Many of us choose to add the pre-fix 'Blimey Old' to the news of this joyous birth.

ROBYN: Teacher: 'Robyn, where have you been?' Answer is in the question miss'

TIFFANY: The conversation with a Tiffany and her mum goes something like this: 'Mum, the form says I need another next of kin'. 'Oh for Christ sakes Tiffany, just put I dunno'.

TANYA: Teacher: 'Tanya, have your got your voluntary contribution for the school trip?' 'No, mum said Sky Sports Subs were due'. 
TYRONNE: Not too many steps to tyranny is it? One small step for man. One giant leap for thug kind.

TYLER: IOam Tyler eating his breakfast Mars Bar. Opens day 4 on his mums giro advent calendar. Only io to go. I had a dream in the night that Tyler got his GCSE results. The piece of paper was really really small.

WAYNE: Meet Wayne. He is on Free School Meals. He also has an iPhone, iPad and latest Wii. A wonder of modern parenting.

STANLEY: Stanley? No, sorry. I can't help but think knife crime. (Hopkins 2013)

\section{Her barbed commentary shifted focus from children to mothers when she informed the interested (and otherwise) public that:}

The difference between most mothers and me is that I didn't sit around drinking coffee at baby group for 12 months after the birth of my baby. No, in three weeks I was back in my suit, back at my desk earning profit for my business and I don't see why other women shouldn't do the same ... To be honest it's beyond me why any working woman would want to take more than a couple of weeks off. Perish the thought of becoming a bloated, brainless version of your former self whose only topic of conversation is which organic vegetable combo you've pureed that week in your sad Tupperware tub. (Hopkins, cited in Duff 20II)

\section{And a recent scathing attack on what she refers to as her most despised maternal stereotypes lead to further outrage for the social commentator:}

The 'Parent Teachers Association' mum: avoid the Parent Teachers Association mum at all costs. Having given up a job she loved for her kids, PTA mum has found her calling as head of the Parent Teachers Association ... Smug doesn't even come close.

The 'home-school' mum: she has chosen to remove her precious kids from all human contact and spend her every waking moment in their company ... Home school kids tend to end up terrified and wide eyed; beaten up for calling 'Miss' - 'Mummy' and hiding in the toilets from Brandon trying to cut off their absurdly long hair.

The 'dad' mum: imagining sex with dad-mum makes you gag in your mouth. Someone needs to tell him to grow a pair and man the hell up. 
The 'eco' mum: eco-mum cycles to school with unwashed children clinging to the framework of her bike, helmet stuck to her egg white washed hair. Feel pity for the kids.

The 'fat' mum: fat mum does drop off and pick up without ever actually leaving the car and belches out her fat kids in a cloud of cigarette smoke and crisp packets. Stare opened mouthed at her sheer size wearing only lycra and a sneer. (Hopkins, cited in Anais Rach 2014)

A small number of respondents stated that they did not judge mothers on television, but a larger number said that they tried not to make judgements about other mothers in their day-to-day lives, with one notable exception, that being the outspoken Hopkins. Many mothers pointed to this woman as an example of rudeness, negativity, classism and 'desperate celebrity', and in some sense these responses were more damning than those aimed at their reality television counterparts, due in part to her impeccable education, privileged financial position and multiple career options. Whereas the teen mothers, Price and Katona demand media attention for income, Hopkins was said to be thriving in the world of business and commerce before the transition to celebrity. Comments on the televisual performer told us that:

Katie Hopkins portrays us as judgemental woman.

The only one that really springs to mind is Katie Hopkins.

I don't feel any negativity towards any of the mothers on television, apart from Katie Hopkins.

Katie Hopkins for sure - I feel for her kids as they'll be ridiculed themselves when they're older.

Women like Katie Hopkins who are very opinionated and use their children as weapons with no thought to how their children feel.

Katie Hopkins is a disgrace. She should not be allowed airtime. I feel so sorry for her children as she is everything a mother shouldn't be.

Katie Hopkins is a terrible example of mothers on television. Mothers are role models and everything that they do should be setting an example to their children. 
Katie Hopkins, I really can't tell if she believes what she is saying about mothers, children and social mobility or if she is playing the pantomime villain for celebrity status... and I don't know which is more troubling.

Katie because her beliefs on parenting; motherhood and life in general are so polar opposite to mine. I feel negatively about her life in general, she spews a lot of hate. Especially towards mothers and she judges children on names!

Katie Hopkins, she seems to despise everyone and everything, Ifor one wish that she would keep her hate-filled and hurtful comments to herself, it's one thing to think them and discuss them with friends and family but quite another to announce them to a mass public.

Katie Hopkins (the one that is always giving her opinion of children such as their names, social status or on attachment parenting etc.) Her kids look miserable and she is a judgemental, ill-informed person that obviously enjoys being hated by the nation for her ridiculous opinions (one way to stay famous I guess).

Ifeel negativity towards Katie Hopkins who sometimes appears as a social commentator representing 'mothers' on various TV programmes. She is extremely outspoken, likes the sound of her own voice and does not appear to take on board the other side of the argument. She is frequently rude to others who are debating a certain issue and I believe is not a fair representation of mothers.

The argument between Katie Hopkins and Holly Willoughby on This Morning was eye opening; I can't believe that a supposedly smart and educated woman would find it appropriate to make such scathing and snobbish comments in front of the cameras. She (and others) may find what she says acceptable, but she must understand the impact that her words are going to have on ordinary people... and maybe that is the point!

Katie Hopkins is a forthright and opinionated mother of three who appears unapologetic about her own mothering practices or her outspoken views concerning mothers, their working lives, maternity choices and childcare activities. And although some look to her media performances as those of a pantomime villain exaggerating their cruelty for entertainment purposes, there are others who appear genuinely insulted by the comments made. Indeed, one angry and frustrated mother went to the effort of writing 'an open letter to Katie Hopkins' in order to confess all of the ways in which she would disappoint the television personality, before making it clear 


\title{
that she and other women should not apologise for their maternal efforts, however removed they are from what Hopkins sees as the ideal:
}

\author{
Dear Katie,
}

May I call you Katie? Maybe I should stick to Ms. Hopkins, because you've made it clear - you don't like me. In fact, apparently, you hate me. A lot. I don't really get why you would feel such hate towards me, it's such a strong, negative word and I wonder why you feel the need to use that word against someone you don't know ... maybe you have issues. Anyway, I digress. This isn't about you, it's about me. Or, more particularly, what you don't like about me. And I almost feel I should apologise, because it seems, in that department, I'm very, very talented. I said almost. For I not only chair the PTA of a school, but I also home school. Isn't that clever? I manage to run around school berating parents to do such exhausting tasks like saving used stamps and collecting vouchers from their supermarket, and just being extremely SMUG ... all the while ensuring my other child has minimal contact with the outside world ... I KNOW!!!! How immense is that???? I am so hardcore. It's possible that you never thought that one person could embody so many things you dislike all at one time but I am sure, if I put my mind to it, there are plenty of other things you don't like about me too. Let's have a little think? My ${ }_{4} \mathrm{YO}$ has an IPAD. My 5 YO has two. And yet neither of them is mute. It's actually quite amazing. You are wondering how I do it, aren't you? Because, according to you, I'm supposed to fit into one of your tiny little boxes, aren't I? Well, I don't. I'm almost sorry about that. I said almost. Because I'm not sorry.

I am overjoyed with my two very different, very individual children ... And I am overjoyed to parent them both in the way they need, however different they are. I could say that you are very lucky to have had 3 children who are all utterly identical, but it's far more likely that they aren't all that similar, they are simply terrified of stepping outside of the tiny box you've defined as perfect. But they will, Katie ... You just wait, oh ... they will. I know what you are thinking now. You've got to me, and that was your aim wasn't it? But you are wrong. This isn't about you. This is to every single mum and dad who got up this morning determined to do the best for their child. Even when breakfast was supposed to be banana muesli but ended up being chocolate pancake. Even when the school run degenerated into a series of rants about lost ties and shoes and unbrushed teeth. Even when homeschool started with a game of minecraft. Because life isn't about living in a box ... regarding the whole dad-mum thing ... It's actually quite wrong, when you are dropping your child to school, to be thinking about sex with the dads of fellow pupils... Just saying...

Karen. (Bower 2014) 
Katie Hopkins has found media attention and continues to maintain a celebrity profile due to her views on family and class in Britain, and although she has been petitioned to leave certain high-profile entertainment positions, she continues to maintain a media presence through avenues such as Yahoo Lifestyle! with blog titles including: 'There's nothing strong about wimping out of childbirth' and 'full-time mum is NOT a job title - it's a biological status' (Hopkins 20I4a, 2014b). Hopkins has made a career on the back of her 'mother wars' rhetoric, whereby she incites hostility between what she sees as the respectable middle class professional full-time working mother and the stay at home contingent, and it is this level of maternal hierarchy, mother ranking and domestic judgement that is deemed distasteful and disrespectful to the woman in the audience.

Although audiences judged Katie Price and Kerry Katona on their celebrity efforts and maternal practices, these same audiences saved their real anger and irritation for Hopkins, and such commentary seems to echo in the wider media agenda. After all, while the exploits of Price and Katona are documented, mocked and ridiculed by a myriad of media texts, it is Hopkins who is referred to as the 'national public hate figure' (Ellen 2007; Aitkenhead 2014) of the three, and I believe that this is due in part to her inability to play to acceptable or traditional maternal roles. Although these women are all 'attributed' celebrities with media contracts, non-traditional work patterns, children from different fathers and multiple marriages who incite celebrity feuds, the difference between them is that the former 'stars' speak of motherhood as their priority, while the latter makes no such claims. Indeed, those respondents who criticise Price and Katona for their perceived domestic failings make the point that they feel a higher level of hostility towards Hopkins because 'as a mothers who works 24/7 and never see her children ... what's the point in having them?', a question not asked of any other mother on the small screen. Moreover, when we see more general comments telling us that mothers in the audience respond negatively to those women in the media spotlight who give what they see as scant attention to their children, one might assume that they are again talking about figures such as Hopkins, as the personality speaks candidly about her professional priorities over and above her motherwork commitments: 
I feel negative towards mothers who don't pay enough attention to their children.

... the ones that work full time, look super glamorous and you don't really see their children.

Isometimes wonder whether television personalities who work long hours at the expense of family time have their priorities right.

Although it would be difficult to suggest that Price or Katona are 'good' mothers in terms of their commitment to the ideology of appropriate intensive parenting, when these women speak on their reality shows and the wider media sphere, they talk at length about their children, and the important place that they have in their lives. Moreover, the narrator commentary on these programmes remind us, routinely, to the point of extreme repetition, that these women are mothers first and foremost, that their most memorable days are those with the children and how they like nothing more than spending time with them. Irrespective of the images seen or promotions available, these women speak about their desire for motherhood and their passion for that role, and in the case of Katona, make repeated public apologies concerning her maternal failings. In this way, these celebrity mothers manage to maintain their public profiles while simultaneously foregrounding their maternal responsibilities.

Hopkins, however, makes no such claims. She is very clear that seeing a mother work is as important, if not more important, than spending time with her children. Hopkins recently suggested that a child's birthday does not have to be a special day and that it was being overdramatic to suggest that a child's birthday was important to mothers as it reminded them of the day that they gave birth. She states that she holds one combined party every other year for her three children because it is more efficient than the alternatives, and informs us that if she is away on business, her children can choose to open their presents in the week or wait until she gets home at the weekend to open them with her. In short, she is reminding audiences that she often works on her children's birthdays and that when any celebrations do happen, they happen at a time that is convenient for her. When asked 'aren't you being emotionally defunct?' Hopkins replies that 'hard-working mums recognise birthdays have to wait' (Hooper 2013). The archetypal 'good' mother would put her children's birthday before 
any other commitments, the 'good enough' mother might have to miss spending time with their children on their birthday through work, sickness or other caring commitments, but would make it clear that they would prefer to be with their children, going to the effort of reminding the children and themselves of the importance of this event, Hopkins however makes no such concession. And I believe it is her lack of maternal guilt, remorse or repentance that audiences find difficult to watch or accept. She is a strong woman who provides for her children, there are no questions about alcoholism, addiction, rehab or financial failings and she does not parade her children in the entertainment arena for media contracts, and yet she is judged more harshly than any other mother mentioned in the responses. Not only has Hopkins 'debunked' the 'good' mother myth, but she is that rare women who makes it clear that she is not trying to live up to that romanticised ideal, and it is her maternal non-conformity that promotes fear, frustration, irritation and anger from women in the audience. It has been suggested that the ideology of natural-intensive mothering ... has become the official and only meaning of motherhood, marginalizing and rendering illegitimate alternative practices of mothering. In so doing, this normative discourse of mothering polices all women's mothering and results in the pathologizing of those women who do not or can not practice intensive mothering' (O’Reilly 2004 , italics in original), with Hopkins as a case in point.

One might suggest that Hopkins has encouraged audiences to discuss the role and responsibility of motherhood and prompted a debate concerning the unrealisable ideal of the serene and selfless mother, and as such we might suggest that, even if we dislike her views or despair at her class commentary, her outbursts are meaningful, if not necessarily well meaning. The fact that she provokes maternal debate could be useful in a bid to quash the 'good' mother myth that appears to dominate the wider media agenda. As a full-time working mother with children from two fathers, she is unapologetic about how removed her domestic life is from the ideology of intensive mothering and the traditional nuclear unit, and her stance, although not well-liked, may at least present an alternative way of mothering. 
Due to the timing of the participant commentaries, one might have expected Nigella Lawson to figure in a discussion about imperfect or problematic motherhood due to the very public fall from grace for the 'domestic goddess' (Goldman 2014). And yet although Katie Hopkins and others in the news and blogosphere commented on the unmasking of the perfect domestic figure on the back of the recent and very public fraud trial, these revelations were not mentioned by a single participant. Rather, for those who spoke about the journalist/broadcaster/television personality/gourmet and food writer, they continued to berate her, not for her domestic turbulence but for her continued 'goddess' presentation. Katie Hopkins refers to Lawson as a 'self-confessed drug-taker, spendthrift, and a self-obsessed flirt determined to show other women they were imperfect' (Flint 2013). And it is this final part, the image of the impossibly serene and utterly capable domestic figure that women in the audience found problematic:

Nigella Lawson has always made me feel a bit cross ... the image that she portrayed for herfamily life as a 'domestic goddess' was, I feel, pernicious, actively promoting an ideal most women would struggle mightily to even approach. Contemporary women are working earlier and longer hours than previous generations. They want to be good mothers and achieve in their work and be happy and fulfilled as individuals. This is a struggle for every woman. Any representation that does not represent the complexity of motherhood, the joys and this struggle with concepts of self as worker/woman makes me very cross.

\section{Non-fiction and maternal perfection}

These feelings of frustrated inferiority were not limited to the figure of Nigella; rather, Nigella stands as just one example of a maternal, televisual perfection that mothers in the audience feel incapable of emulating. Therefore, while Hopkins received overwhelming hostility for her nontraditional maternal role, other women were berated for presenting a romanticised maternal image, an image that makes mothers feel inadequate by comparison. 
Negatively towards ... stereotyped mothers with a too perfect life.

Those that act like everything is perfect - I think I blame them for the false expectations of parenthood!!

I get particularly sick of the super-organised working mom because it only makes the rest of us feel inferior.

I don't like 'perfect' mother portraits - I like motherhood shown to be messy and full of mistakes but with a sense of humour.

I get annoyed at those mums who are portrayed as being 'perfect' ... because that is a mum that doesn't exist, and we shouldn't be made to feel exists.

I often feel insecure and/or annoyed about others ... preaching to me about how I should be bringing up my children, or presenting their way as an idealised way.

Subconsciously I probably glance at 'celeb' mothers in magazines or on TV - to see how glam, thin, well slept they are - despite having babies ... then wish I hadn't!

I feel that in celebrity and other non-fictional programmes mothers (such as Kirstie Allsopp) are presenting a fantasy lifestyle that makes 'veryday' mothers feel guilty.

No, I don't like to judge other women - except the ones who use the experience of motherhood to make other women feel inadequate. Those women I feel negatively towards.

Intensive uber-mum bit actually annoys me, those perfect women who make everything look effortless, these women can only make it look easy because they have help that the rest of us don't have.

Those perfect Cath Kidston-esque mums who manage to work and perform all of the necessary domestic and childcare duties with ease, no fuss, no compromise, not real. That is not the reality of motherhood, well certainly not in my house.

I can't think of any specific examples but I feel negatively towards people who appear to be able to look pristine, have pristine homes and a career and children as I feel that their children must be suffering in some way as a result (although this is irrational!).

Those perfect mothers irritate me, the ones that look amazing, have well behaved children, bold down meaningful work and still manage to make it to the bake sale on a Friday 
afternoon ... farcical. Even when they are meant to be endearing or funny, they irritate ... there is nothing funny about comparing yourself to these women.

Celebrity mothers who talk about how they have wonderful bodies and great relationships with their kids when I think that we all would say that with the money for a personal trainer and several nannies... I don't find that it upsets me in how I run my life but I hate that it puts pressure on all women to think that this is how you need to be.

Any celebrity that has their figure back straight away! I am always suspicious of them, as Ifeel it is unrealistic for the majority of the female population who have babies to try to emulate them. They are often held up as an example of what we strive for and actually concentrating on getting yourself back to yourself after a baby is the most important thing.

Generally so called 'celebrity mums' as they pretend that they have done it all and have the perfect life. Lost all their baby weight in a week etc. when you know they probably have a lot of help with childcare and domestic help etc. unfortunately this then becomes the norm and mums who don't have the luxury of all the help and make up artists etc. feel under pressure to be that perfect celebrity mum.

Mothers who work in TV e.g.presenters, who return to work quickly after having a baby and then appear very glamorous. i.e. well turned out, slim, etc. I realise this is unfair of me, but I find it hard not to be judgemental about this. Returning to work early is the bigger concern but I don't think it is helpful for the average mum and especially those who are struggling or have postnatal depression to see other women apparently managing it all and also looking radiant.

I always find the representation of the white middle class mother at the school gates a comic, almost negative, stereotype as they are almost always with a southern accent i.e. Londoner who has a child called Poppy or Daisy, dressed in Joules clothing and almost always immaculately presented as are the children, in clean ironed uniform. The mothers themselves are always part of the PTA and organise bake sales and fundraisers. In my experience most parents are only too pleased if they have managed to make the school gates before the start of registration or that they have a child who isn't kicking and screaming that they have to go to school in the first place.

These women are not explicitly referencing the ideology of intensive motherhood or idealised maternal practices, but nonetheless it is clear that they are in tune with extant literature from the field of media motherhood studies as they talk about perfect, unattainable images of femininity, physicality and domesticity that they fail to live up to, and which in turn, leaves 
them feeling inadequate. The feelings that these women express have been considered in recent years and the image of maternal perfection that they speak of has at different points, in different volumes been referred to as the 'good' mother (Feasey 2012a), the 'mask of motherhood' (Maushart 1999) and the 'mommy myth' (Douglas and Michaels 2005), all of which are said to be performing in line with the ideology of intensive mothering. We are told that the serene and selfless mother acts as 'the "legitimate" standard to which mothers are compared ... she becomes an ideal to believe in, and one that people both expect and internalize' (Green 2004). Shari Thurer echoes this point when she states that 'media images of happy, fulfilled mothers, and the onslaught of advice from experts, have only added to mothers' feelings of inadequacy, guilt, and anxiety. Mothers today cling to an ideal that can never be reached but somehow cannot be discarded' (Thurer 2007). The theorist continues by commenting that even though the current standards for good mothering are formidable, self-denying and elusive, they continue to influence our domestic arrangements and what we think of as appropriate motherwork practices (ibid.). The women who responded to my questionnaire noted that they found what on the surface might appear to be motivational role models to be anything but. Those women on television who manage to successfully balance careers and domestic practicalities with ease, maintaining an attractive and serene manner to the audience are seen as, variously, smug, inauthentic and unconvincing.

What is interesting here is that the perfect mother is, in all but two cases, never named, a programme never pointed to nor a genre highlighted. Rather, the perfect mother seems to speak for a myriad of different women across a multitude of platforms, channels, genres, texts and characterisations. The perfect mother can be understood as a blanket term for those women who make pregnancy and motherhood look effortless and satisfying against a backdrop of maternal reality that is struggling in the contemporary climate. Susan Maushart makes this point when she tells us that the 'gap between image and reality, between what we show and what we feel, has resulted in a peculiar cultural schizophrenia about motherhood' (Maushart 1999, 2007). The comments make it clear that these perfect maternal figures are not only irritating in and of themselves, but that they are in some sense damaging our maternal self-esteem. The point here is that although 
we know we are not perfect mothers and shouldn't compare ourselves to those composed creatures, we cannot help but do so, with feelings of guilt and shame to follow. Judith Warner echoes this point when she informs us that 'the ideal of motherhood we carry in our heads is so compelling that even though we can't fulfil it and know that we probably shouldn't even try, we berate ourselves for falling short of succeeding' (Warner 2007).

In much the same way as women are said to struggle to live up to the unrealistic 'beauty myth' (Wolf I991; Redmond 2003) that saturates the contemporary media environment and men are seen striving for a version of hegemonic masculinity that is always out of reach (Connell 1995), the mask of perfect motherhood offers a flawless yet unrealisable ideal for contemporary mothers. Indeed, even those women in a position of family or financial privilege struggle to maintain this romanticised image, with the rest of us falling far shorter of this impossible ideal.

The fact that those women who responded to my questionnaire made it clear that they are unable to emulate this maternal ideal does not seem to lessen the power of this model; rather, it means that many expecting, new and existing mothers continue to watch this romanticised image while finding their own practices wanting. In the same way that the fashion industry continues to create incomparably slender models and the beauty industry continues to airbrush women to the point of physical perfection; the entertainment area continues to present us with perfect maternal role models. All three are enjoyed by ordinary women, and rallied against by this self-same group. This is not about pointing out contradictions or hypocrisy but rather, to point to the complex and sometimes frustrating relationships that we have with the fashion, beauty and entertainment arena.

Moreover, it is clear to see that in each instance where a commentator has noted what they find to be an unattainable image of maternal perfection, they go on to point out its disconnect from their own, or what they see as a more 'ordinary' and 'everyday' maternal thought, experience or practice. Many women here position themselves in opposition to and as different from, the perfect maternal role; that said, it is not uncommon to find pleasure in a more perfect or alternative figure. Harlequin readers seek pleasure in romance narratives removed from their own domestic situation (Radway 1984/1991), Hollywood audiences find escapism in 
the shopping film that charts a make-over unlike any they will experience (Brunsdon 1997), and that same audience 'worship' glamorous female film stars who are unlike them in every conceivable way (Stacey 1994). Pleasure can be found in gendered experiences that offer audiences entertainment and escapism. We can find ourselves watching at a distance or being drawn in to identify on some level with these idealised mothers, so that, for the time that we spend in their company we can enjoy pointing out our differences with cynical amusement or find pleasure in being transported into a more serene maternal world for the short duration of the show or scene in question. The problem for some mothers then of course is when we turn off and close the book, the perfect image remains and we cannot help but judge ourselves by their standards, which then further perpetuates the 'good' mother myth.

\section{Conclusion}

In this chapter I have looked at the ways in which women in the audience and the wider social networking sphere have spoken negatively about soap opera, reality television and the impossibly perfect maternal image. Respondents made the point that they judged and derided those maternal figures who put their social and sexual desires before their children's emotional needs within scripted and reality programming, even as they acknowledged and in many cases felt compassion, for the struggles that some of these mothers face in order to bring up their children. And yet while many women found these strained mothers problematic maternal characters, so too, many women found the romanticised ideal mother a fascinating yet frustrating figure to watch. After all, while viewing poor mothers in extremely turbulent domestic situations gives us a sense of comfort because 'the behaviors of the children are so exaggerated that most viewers have the ability to distance themselves somewhat from the show, as they watch in fascination and horror as the family implodes in front of 
their very eyes' (Tally 2008), watching ideal figures can also encourage us to question our own maternal practices.

It is worth noting of course that the limited maternal depictions highlighted here are not restricted to representations of motherhood on small screen programming. A recent study by advertising agency Saatchi $\&$ Saatchi noted that women in the audience are angered and frustrated by what they deem to be unrealistic, patronising and negative depictions of motherhood in contemporary advertising. In line with my own findings, the research noted that the 'perfect' mother and the 'stressed out mum who cannot cope' were the most problematic stereotypes in these short media texts. The study 'found major faults by advertisers including the fact that women who have children do not want to be categorised simply as mothers as if nothing else mattered' perhaps explaining why only 19 per cent of women believed that there were examples of mums in advertising that they could relate to (Chahal 2014). Indeed, Marketing Week editor Ruth Mortimer went as far as to suggest that advertisers should ban the word 'mum' from all advertising because 'there is no identikit person' (Mortimer 2014). Perhaps rather than ban the word mum, we should embrace the word mothers, plural, in order to depict the wide and varied range of maternal images, thoughts and practices that exist today. And if advertising agencies are uninterested in creating figures of maternal diversity as part of a social action agenda, then perhaps the fact that the estimated spending power of mothers is said to be worth $£$ I.9 billion might go some way towards encouraging them to look beyond what are termed 'grating' and tired stereotypes (Mortimer 2014). 


\section{Conclusion: A call for maternal diversity}

The women who responded to my questionnaire have been open, honest and indeed candid about the pleasures, frustrations and criticisms as they see them in relation to representations of motherhood on television and their views have offered the first real insight into this topic within the fields of television, media and gender studies. However, their voices have not only added significant original thought to the academic community, but must be seen to open up a dialogue with the wider entertainment arena. Although many women spoke of favourite maternal characters, preferred presenters and mothers on the small screen that they were invested in, there was a general consensus that they did not feel fairly or appropriately depicted on television. Women felt that there were very few mother figures that they could relate to and that those women who were regularly and routinely seen on screen were often rigid stereotypes and stock characters with only a narrow version of motherhood being presented.

With this in mind, my final question asked women to think about the depiction of motherhood in terms of the scope and breadth of maternal types represented, to which the overwhelming majority of respondents made the point that television did not provide a sufficiently broad range of maternal images. Participants routinely commented that minority groupings were dramatically under-represented on screen, be it in terms of fostering and adoption roles, lesbian mothers, disabled mothers or mothers with disabled children, non-white mothers, grandparents and mothers with older children, stay at home mothers and what was routinely termed 'normal' or 'ordinary' mothers. And it is with these comments that I wish to conclude the book and open up future discussion with academics, educators, public service providers and a wider range of commercial broadcasters. 


\section{Overlooked and unrepresented: Foster mums and adoptive parents}

One commentator suggested that 'it is good that we are seeing more programmes about adoption on television' and many would agree that we are indeed seeing increased instances of fostering and adoption on mainstream programming, and yet, 'more' in this regard was still said to be very little, so much so that many mothers felt the need to comment on the underrepresentation of these maternal figures. Moreover, it was suggested that the limited depictions of foster and adoption are only seen when the subject is 'topical' within the broader social and political environment or a deliberate 'plot device' and thus not a subject that is seen across a range of programme titles or genres or with any regularity or consistency:

I've never seen a foster mum on television.

I don't believe adoptivelfostering are covered well.

Adoptive and foster parents are under-represented.

You seldom see adoptive or foster parents on television.

There is very little on television about fostering/adoption.

There is hardly any fostered or adopted children on soaps.

I don't think there is enough representation of adoptive and fostering roles.

I've been very interested in programmes about adoption - not that well represented.

Very few adoptive parents on $T V$. Those who are, their portrayal is far removed from the reality.

Fostering and adoption is only really represented in drama when it will lead to some disaster as part of the plot. 
I can't think of any mothers on television with adoptive or fostering roles, which would be nice to see a lot more of.

There is not much around fostering and adoption, which is a shame as it might make more people come forward.

You really don't see much with regards to foster care or adoptive families, and what is portrayed is often negative and stereotypical in the sense that the child is always rebelling against them or harbours resentment.

Adoption and fostering are seldom seen on television and the suggestion here is that when these families are seen they tend to be presented as troubled or problematic. I am not suggesting that all foster parents or adoptive mothers are without family turmoil or tribulations, but if this is the ways in which mothers in the audience read these limited depictions then these depictions must be addressed. One mother makes the point that a lack of foster and adoptive parents on screen, and the focus on problematic representations within that limited number might actually have a real and worrying impact on people coming forward to care for children.

The NSPCC informs us that 'following a significant fall in the number of children in care over the past 30 years, numbers rose in the UK between 2008 and 2013 from 81,315 to 91,667' (Simkiss 2012). The number of children seeking foster homes and adoption families is increasing and the number of people coming forward is failing to keep up with demand. Recent research tells us that 'at least 9,000 new foster families will be needed in the UK ... to cope with the growing numbers of children in care' (Burns 2013). There is a record number of children in foster care and the Fostering Network tells us that it is struggling to recruit sufficient numbers of foster carers to replace the 13 per cent who leave the system each year, and this is before we consider that they need a diverse pool of carers 'to help fostering services find the right foster home for every child, first time' (ibid.). A Department for Education spokesman said 'foster carers are the unsung heroes of the care system. They make an invaluable difference to vulnerable children - offering them routine, stability and loving homes' and yet they are rarely if ever seen on our television screens, and even then, the family dynamics tends to be portrayed in a negative light. If one considers that it is important to 
bust myths about who can apply to foster' (ibid.), to highlight 'the skills that foster carers need, and to be clear about where there are current gaps' (ibid.) then one might assume that public service programming would have a role to play in this regard.

\section{Overlooked and unrepresented: Disability and impairment}

The fostering network makes the point that 'across the UK there is currently a particular need to find people who can care for ... disabled children' (Burns 2013) and while fostering and adoption are rarely seen on television, so too, disabled mothers or mothers with disabled children were said to be rarely depicted. Mothers in the television audience commented that disability was 'bidden' from television viewers and that notions of disability in the family home were rarely, if ever documented in factual programming or created in fictional titles. Maternal audiences were sympathetic to the representations of disabled children presented on hospital programming or community drive programmes, and spoke of the 'inspirational parents of children with terminal or life limiting conditions' that they encountered during these shows, and yet, the overwhelming majority of respondents highlighted the paucity of physical disability or mental impairment on the small screen:

You don't see many disabled mothers on TV.

It's very rare to see a mum with disabilities on television.

Some mothers are under-represented - especially disabled.

Intelligent strong positive portrayals of ... the disabled ... missing from everywhere.

I think that ... disabled mothers and adoptive and fostering mothers are under-represented. I want to know their stories. 
Probably not equally represented when it comes to disability, sexual preference or adoptive and fostering roles.

Depressed mothers seem to be under-represented ... they are not discussed or acknowledged in a positive way.

Disability is rarely shown on $T V$, neither is mental health unless there is a murder or other awful consequence for that character.

Parents of children with special needs aren't on TV much ... especially in incidental roles rather than documentaries that set out to dramatise their situation in some way.

I suffered from terrible postnatal anxiety and depression following many years of health problems and fears prior to conceiving. Therefore, if I am going to watch anyone, I would rather watch someone who has been through similar experiences ... but they are rarely if ever shown.

There isn't an even distribution. I would be interested in more of the cultural differences in how people deal with motherhood, I would be keen to know and understand more about adoptive/fostering situations too and mothers that have children with disabilities. I think these are more enlightening programmes that we can learn so much more from, about people and about ourselves.

Disabled Mums are ... really under-represented, and are probably the most underpresented group of all. I think the general public's view (as well as many establishments who help/deal with parents) seem to think that disabled people cannot cope and/or should not be allowed to parent just because they are disabled, (have read cases of this type in various newspapers and TV programmes), but this is not always the case. More representation of this group, and in particular, fair unbiased and positive representation is needed/would help in this area to help dispel this view.

According to the Department for Work and Pensions and the Office for Disability Issues 'there are over I m million people with a limiting long term illness, impairment or disability' in the UK (GovUK 2014). In terms of mental health alone, postnatal depression affects one in ten women after having a baby while clinical depression affects one in ten of us at some point in our lives, irrespective of gender (NHS 2014e, 20I4f). Mental health charities, government ministers and the ongoing national 'Time to Change' anti-stigma advertising campaign tell us that one in four people in 
the UK will suffer a mental health problem at some point in their lives and yet there continues to be a stigma surrounding physical and even more so, mental disability. The fact that ' $82 \%$ of children with learning disabilities are bullied and $79 \%$ are scared to go out because they are frightened they might be bullied' (Lipsett 2007) means that more education is needed, and perhaps popular television alongside public health campaigns can play a role in depicting disability as a common and accepted experience amongst family units. And yet, representations of physical and mental disability on television are said to be conspicuous in their absence.

Disabilities might affect a minority of the television-watching audience, but these minority groups deserve recognition and respect in order to further challenge long-standing negative associations. Disabled children and parents alike are currently overlooked on television outside of those texts whereby the disability is crucial to the character or story development; what is needed of course is a variety of leading roles, secondary characters and peripheral figures who happen to be disabled rather than disability being the cornerstone of a particular dramatic arc. One mother, speaking about a DIY SOS (1999- ) renovation project to help the family of a physically and mentally disabled young girl commented that 'I often can't watch as I find it so upsetting to think of children in these positions and the impact on the family' but maybe what is missing here is the regular and routine depiction of disability as a part of family life rather than an experience to be singled out, problematised, pitied or 'solved'.

While disability was seldom seen as part of the family story, so too, infertility was said to be excluded from popular programming, and, much like representations of disability and fostering before it, the suggestion was that greater visibility could lead to greater societal understanding and in turn, greater social acceptance. After all 'one in seven couples may have difficulty conceiving' which equates to approximately 3.5 million people in the UK alone (NHS 2014a):

ICSI conceptions and high-risk pregnancies not represented.

I look up to mothers who have experienced similar difficulties to me physically and emotionally... I wish we could see these stories. 
As someone who tried for eight years to get pregnant, I find it very annoying when women my age are introduced to soaps the children they are shown to have are too old for them to have had them. Most women are portrayed as getting pregnant easily.

Infertility is a common experience among women within and beyond the UK, and yet this experience 'is not usually discussed publicly' (Striff 2005). Indeed, a woman's infertility story is generally only witnessed by the medical profession, and as such, infertility continues to be shrouded in secrecy and shame for the woman in question (Feasey 20r4a). The inclusion of infertility storylines in fictional programming and an acknowledgement of this disease (of the reproductive system) in more factual texts might go some way to exposing the commonality of this experience and the emotional, medical and financial support networks available (Sterling 2013).

\section{Overlooked and unrepresented: Lesbian and other mothers}

Lesbian mothers, be it by adoption, heterosexual sex or insemination are growing in number (Fisher 2010), yet they are rarely seen on television and when they are viewed, they are often challenged as 'inappropriate' for family audiences (Kuruvilla 20I4). Mothers in the audience made it clear that not only were lesbian mothers ignored and overlooked on the small screen, but that this lack of visibility was disappointing for the wider society. They made the point that depictions of lesbian families would go some way towards educating adults and children alike about non-traditional domestic units, which in turn would be beneficial to those children who fail to see their domestic environment presented on screen or, for many, in the school environment. One lesbian parent mentions that 'at the age of I4, my daughter had to decide when and to whom she would "come out" as the child of a gay parent. Sometimes she did not want to bring friends home in case they noticed. And she had to hear "that's so gay" being used in place of "that's so stupid" hundreds of times a week' (Carille 2014). The 
lack of lesbian mothers was mentioned by many women in the audience, with some suggesting that they had never seen such a figure on popular mainstream programming:

You don't see many gay mothers for example.

I have not seen many same sex parents ... on $T V$.

... I can't think of a gay or lesbian couple with children on television.

Very few same-sex couples or parents with disabilities are portrayed.

I think there should be more gay, minority, disabled etc. And I'm white middle class and married!

... my feeling is that the only way that under-represented groups, such as gay, lesbian etc. mothers, are played is either as deviant or funny.

I think there is representation for family mums, single mums, but less so on gay couples pro adoptive or fostering roles. I actually think these would be more inspiring cases.

Under-represented - lesbian mums, disabled mums, adoptive/fostering mums, mum's who choose to rear their children themselves but are not 'bippyish' or home educators, or on benefits.

I think the marital status of being in a heterosexual, married relationship is over-represented and given a disproportionately positive status on TV, especially to other maternal groups - in particular to being in a gay/lesbian relationship.

I do not think every potential 'type' of mother is represented on TV at all. I think more same sex parents, adoptive and foster parents would be beneficial for the general public to appreciate family life without the typical norm of mum and dad/single parent family.

Although 'Stonewall has been working to support schools and families to work constructively together and other activists and organisations have been creating a step-change in the visibility of families with LGBT parents' (Carille 2014) there is the suggestion by mothers in the audience that television could play a far greater role in bringing lesbian families in to the 
mainstream in order to assist inclusivity and to address homophobic bullying within the education system.

\title{
Overlooked and unrepresented: Bumbling triers
}

\begin{abstract}
Although they are not considered alternative or minority in the traditional sense of the word, many women felt that what they varyingly termed 'normal', 'ordinary', 'good enough', 'realistic' and 'real-ish' mothers were rarely seen on screen:
\end{abstract}

Realistic mother figures are under-represented in comedy and drama.

The ordinary caring do the best you can while juggling life is under-represented.

I think mothers who try and get on with it are overlooked on television, but I think that is partly the point.

It sometimes seems like normal mums are under-represented - you have to be different to get noticed.

... normal women for whom dieting and saying that everything is back to how it was before birth is not their main topic of conversation.

I think that the kind of mother that is good-enough, that doesn't always get it right, but tries, the 'real-ish' mother is lacking. Mothers on television are often either good (unrealistically patient and caring, hyper organised and efficient) or bad (unable/unwilling to care for the child, either physically or emotionally). It would be nice to see more of us bumbling triers.

Mothers as mothers are under-represented ... motherhood is something that is central to one's life, that takes up all one's time. TV mothers have children that go to bed, so they can sit up and have a glass of wine like an adult. TV mothers have children that go into another room to play so they can have a conversation or get something done. The centrality of child-rearing to the life of a mother is invisible. 
Furthermore, stay at home mothers were said to be under-represented on screen:

There are not enough housewives.

Stay at home mothers aren't on much either.

Stay at home motherhood seems under-represented or explored.

I'm a stay at home mother and you don't see many of those on $T V$.

Most are television presenters who then do the 'working mum' thing ... I am a stay at home mum.

Stay at home mums. If we are on television, we're either lazy benefit claiming ones or the wealthy mummy who lunches. The normal everyday stay at home mum is a minority... it seems and something to be ridiculed.

Stay at home mums seem to be represented less than women who work outside of the home - I feel that this puts pressure on women to feel they should be trying to do everything, when in fact being a mother is ultimately the hardest thing most women will ever do.

Not that many stay at home mums (I do work very part-time and am self employed so can choose my hours and only work when my husband is around to look after the children). Typically I think that mothers on TV are either working (to make ends meet or because they want a career) or they are single, on benefits and living a less than ideal lifestyle - often depicted in soap operas.

Recent research tells us that 2.04 million women are looking after family or home, a fall of almost I million since records began 20 years ago' (Peacock 2013). These figures are said to 'echo a long-term trend in which more mothers are returning to work after childcare' with 'one in three' working mothers now in the position of primary breadwinner for the family (ibid.). That said, the ideal of the traditional nuclear unit prevails as three out of four new mothers in a recent report have stated that they would 'stay at home to bring up their child if they could afford to ... six out of ten mothers who return to work after having a baby do so only to pay off debt or ease financial pressures. Just one in seven said they wanted to develop their 
career' (Doughty 2012). Although politicians, civil servants and academics have all provided evidence to demonstrate benefits associated with working motherhood, prioritising subsidised childcare over and above child benefits for stay at home caregivers we are told that a traditional family - with a breadwinning father and a full-time mother - remains the ideal for the vast majority of women' (ibid.).

Both stay at home mothers who currently fail to see their lives reflected on screen and alternative family units who find pleasure, comfort or entertainment in the depiction of the traditional family unit point to the lack of the full-time mother on television, which is perhaps surprising given the history of the feminised domestic medium and the presumed televisual popularity of this domestic role. One mother applauded the character of Debra Barone/Patricia Heaton in Everybody Loves Raymond because 'she is the most "real" and funny mother character I've seen but mostly because it's more about her role and the dynamic in the whole family as a stay at home mother, rather than how she particularly relates to her children'. Her position as a stay at home mother is crucial to her reception here but other mothers made it clear that she was a lone figure in the television landscape.

In terms of other notable mentions, representations of attachment parenting, breastfeeding mothers, funny mothers, non-white mothers, grandmothers, mothers with older children, older mothers and career women who have given up their professional role for full-time motherhood were said to be absent from our screens.

\section{Too much attention and over-representation: Working class motherhood}

There seems a commonality of viewing experience in terms of those mothers who were seen to be over-represented on the small screen, namely 'poor' struggling working class mothers and the ostensibly 'good' middle class 'yummy mummy'. 
Those mothers that are marginalised and deemed unacceptable are said to dominate popular programming, with an emphasis on single, teen and working class maternal figures positioned in opposition to their more 'appropriate' middle class counterparts. While the struggling figures are routinely seen in the reality television genre, middle class mothers tend to be in fictional programming, the former encourages voyeurism and participant humiliation and the latter is said to be positioned as the more appropriate figure. Many mothers make it clear that television relies heavily on two particular maternal stereotypes, and that these figures stand in binary opposition in terms of acceptable and unacceptable motherwork thoughts and practices. However, what they have in common is that both groups are dominated by white, heterosexual, biological mothers. In terms of those struggling figures:

I think working class mothers in the UK are portrayed badly.

There has been a lot of poor underage and teen mothers lately.

Class variation is non-existent outside of reality television ... but I think that reality television ... is geared towards laughing at poor people.

Young mums, particularly young single mums (as well as single mums of all ages) are often portrayed extremely negatively which I think is most likely disproportionately unfair and helps to increase the unfair negative views of the public against these groups.

The few programmes that have been on the working class/poor, like the current TV reality show Benefits Street, show the family and the mums in a very negative light, which I think is very disproportionate to reality, helping to build up unrealistic negative views by and in the general public and totally not in comparison to the representations of the middle class currently on $T V$ or from the recent past, the majority of whom are overly proportionately seen in a good light.

There seems to be much attention paid to teen/single/struggling pregnant women and young mothers in a range of long-running shows, one-off documentaries and special television schedule line-ups. I can understand the drama that stems from these representations, but there does seem to be a sense of over-representation here at the expense of less 'xtreme' versions of mothering. The voyeurism that starts with Supernanny is 
heightened in these shows, perhaps for a middle class audience who can feel removed and at a safe distance from these figures.

For every audience member who commented on the negative over-exposure of the working classes, there was another mother in the audience who spoke about the more favourable over-exposure of the more comfortable middle-class:

Generally the white, middle classes.

Middle class mothers are portrayed as 'yummy mummies'.

It's usually the typical white British 2.4 children school run mum.

These mothers speak of the over-representation of the 'yummy' middle class mother and make little mention of the fact that these women may or may not work outside of the home. Only two mothers included the notion of professional commitments in relation to this particular figure, foregrounding the potential narrative interest created around competing private and public worlds:

White middle class... perhaps with the drama of a stressful job she has to arrange around the household chores. That is the only norm on the TV really, well the only one I seem to see.

Professional working mothers seems increasingly well represented, perhaps because of the obvious dramatic potential - in factual as well as drama programmes.

Another mother spoke with frustration at the ways in which mumsnet representatives are positioned in the media as if to speak for mothers within and outside of the parental website, the suggestion being that the mothers who established mumsnet and many of the women who read and contribute to the site are from the privileged middle classes, and therefore should not be presented as the maternal voice.

Mothers in the audience were quick to point out that they themselves were not stereotypes, did not fit into narrow or neat maternal categories and could not be easily classified in relation to working, domestic or familial practices. From this perspective, many of these women felt disappointment 


\section{and frustration at the limited stereotypes that they encountered on screen. Speaking of a desire for a more diverse presentation of the maternal role we were told that:}

There is still a long way to go.

I want strong female characters, some of whom will be terrible mothers.

I do think it's important to see mothers - in all their variety - in different roles on television and to have their views represented.

There are way too many extremes either domestic goddesses that are perfect or complete louts on reality $T V$. Mothers are generally not well represented.

I think there is too much lazy stereotyping on television and not enough breadth and variety, also not enough acknowledgement of the grind of motherhood along with the joy.

Mothers who are portrayed for being a person whilst being a mum are under-represented ... most mothers are there for being a mother as a primary reason, not a secondary reason.

Programmes are rarely produced to go beyond stereotypes... many Channel 4 programmes try to make too much of class and parenting and don't show the complexities offamily life.

I mostly get annoyed by the stereotypes, the patronising tones, the fact that mums are either rich with nannies/cleaners/PAs etc., or poor and on benefits, and there is rarely the middle ground.

I love diversity and find many types of characters interesting, however many mothers are portrayed as either stay at home mothers or 'out of control' career women. I wish there was a lot more diversity on $T V$ !

Need ... a broader spectrum of diversity - ones who do more than drink coffee and get their nails done in their downtime. For me - I run half marathons, I belong to a drumming group, I write, knit and read ... My friends run businesses, walk, climb mountains, do amazing art, are herbalists, run groups. We are part of a woodland owning co-operative.

I definitely think that the range of options for motherhood shown on television is limited. Most mothers are either celebrities, like pop stars and television presenters who's lives don't represent reality for most, or those on reality television or in the soaps who are 
either at the top end of the wealth spectrum or considered 'working class' and portrayed probably unfavourably.

Minorities are under-represented across all roles but for me what is missing is non stereotypical roles. I'd like to see a Latina mother who doesn't talk loudly or an Asian mother who accepts the child as is, or the stay at home mom who doesn't watch soap operas and craft. I work in education and meet mothers who break all roles on a regular basis. What makes them good mothers is their care and love for their children. What makes them interesting people is their care and love for their own beings. I wish there were more non-gimmicky roles.

Many of those mothers who spoke of their enjoyment at watching factual and fictional maternal roles being played out on the small screen were the self-same mothers who spoke of frustrations at the lack of realistic representations and their desire for more diversity in relation to the maternal social types, stereotypes and archetypes that are currently viewed on popular programming. This is not a case of confusion, but rather, speaks of the complexity of entertainment, escapism and pleasure for those women in the audience. These women spoke of their disapproval of specific programmes, characters, personalities and very occasionally of their dislike or distrust of particular genres, formats or channels. What was clear, however, was that these women were casting blame at the programmes rather than the creative, management or marketing personnel behind the production. No one spoke with frustration against a particular writer, director, producer or editor, in part because the questions were worded so as to focus responses onto maternal figures rather than behind the scenes operatives, which leaves scope for future research concerning the creative and commercial decisions made concerning those maternal representations that we currently see on the small screen.

It is not my place here to tell audiences where specific instances of disability in the family may be seen or to point out that lesbian mothers are visible on mainstream programming, although both can be seen and extant research exists to account for such representations (Thomas 2007; Esterberg 2008). Rather, what I want to do here is, as I hope to have done throughout the volume, to give voice to the mother in the audience. If one of these women suggests that they rarely see representations of stay at 
home motherhood or another suggests that too much attention is given to single teen mothers then this is valued and valuable findings. The fact that many of these women form a consensus in terms of those maternal figures that they see both under and over-represented on screen must then be taken more seriously as they speak to wider concerns in the television marketplace within and beyond public service broadcasting.

\section{And finally: A few notable exceptions}

Although women commented on the continued, predictable maternal stereotypes that they saw on television, with many suggesting that they would relish the opportunity to watch a more diverse, complex and characterdriven range of mothers on screen, there were a small number of programmes that were said to be set apart from these rather narrow depictions. The factual documentary programme that follows the lives of 25 children born at the turn of the millennium, Child of Our Time (2000-) and the more recent reality pregnancy and childbirth production, One Born Every Minute (2010-) were commended for taking a more 'realistic' look at motherhood and parent-child relations removed from the more sensationalistic or salacious content of much televisual fare. So too, the scripted drama, In the Club (2014) was applauded for breaking away from sugar-coated and romanticised notions of pregnancy and new motherhood in favour of acknowledging a set of wider social and sexual concerns that impact on maternal efforts such as redundancy, family stability and continuing education. Irrespective of history or genre, these texts were all singled out for what was deemed their commitment to maternal diversity, little seen elsewhere in the schedules.

At the outset of the research I sought to gain socio-economic, ethnic and marital details from participants, assuming that such data would help me to order and interrogate maternal responses, but there was little obvious classification that could be drawn from these categories. It was not the case 
that lesbian or single mothers were only asking to see their own lifestyle more frequently or positively depicted, or that stay at home or working mothers were interested solely in maternal depictions that resembled their lived experiences; rather, the ways in which women in the audience read and responded to depictions, or lack thereof, of motherhood on television could not be readily or easily accounted for due to either their domestic commitments, working practices or other social or cultural markers. These women were on occasion seen to form a consensus, but these were across classifications rather than restricted to them. My point here then is simply that in relation to maternal responses to popular contemporary television programming, motherhood could be read as both a unifying category and one that spans a multitude of maternal thoughts, beliefs and practices.

At the time of writing, several hundred mothers have looked at my questionnaire, and with this in mind, my hope is that these findings will encourage further academic and social research concerning both the representation of motherhood in the media and the reception of those images by women in the audience. I would encourage future research to consider the circuit of maternal image production, examining the relationship between representation, audiences, television producers and media owners in relation to the wider social, sexual, political and economic arena. And beyond that, I can but hope that independent creatives, prosumers and more mainstream entertainment providers respond to the call for greater maternal diversity on and beyond the small screen. My concern, however, is that representations of motherhood are on the decline rather than assent, as recent literature speaks of a new trope ... the absent mother, missing, presumed dead in popular media culture (Karlyn 20II; Aström 2015; Feasey 2015). 



\section{Bibliography}

${ }_{4} \mathrm{OD}$ (2013a) 'Kirstie Allsopp's Home Style - Episode 4: Parties', 4 OD, Available at: $<$ http://www.channel 4.com/programmes/kirstie-allsopps-home-style/ondemand/55324-004> (accessed 25/ri/2014).

${ }_{4} \mathrm{ODD}(2 \mathrm{OI} 3 \mathrm{~b})$ 'Kirstie's Handmade Treasures - Episode 22: Damson Jam', 4 OD, Available at: <http://www.channel4.com/programmes/kirsties-handmade-treasures/ episode-guide $>$ (accessed 25/II/2014).

${ }_{4} \mathrm{OD}$ (2OI2) 'Kirstie's Vintage Home - Episode $5:$ Iman and Heather', $4 \mathrm{OD}$, Available at: <http://www.channel 4.com/programmes/kirsties-vintage-home/ondemand/54293-005> (accessed 25/II/2014).

AAUW (1994) 'Shortchanging Girls, Shortchanging America: Executive Summary', $A A U W$, Available at: <http://www.aauw.org/resource/shortchanging-girlsshortchanging-america-executive-summary/ $>$ (accessed 04/07/2014).

abc (2014) 'Modern Family: Claire Dunphy Played by Julie Bowen', abc, Available at: $<$ http://abc.go.com/shows/modern-family/cast/character-claire> (accessed 20/10/2014).

Addison, Heather (2009) 'Modernizing Mother: The Maternal Figure in Early Hollywood', in Motherhood Misconceived: Representing the Maternal in U.S. Films, eds Heather Addison, Mary Kate Goodwin-Kelly and Elaine Roth, Albany: State University of New York Press, 63-80.

Aguirre, Susan (2010) 'Do the Teen Moms (or Their Kids) Get Paid?: Comment', E!, Available at: <http://uk.eonline.com/news/213901/do-the-teen-moms-ortheir-kids-get-paid $>$ (accessed 07/07/2014).

Aitkenhead, Decca (2014) 'Katie Hopkins Interview: Can You Imagine the Pentup Rage?' Guardian, Available at: <http://www.theguardian.com/tv-and$\mathrm{radio} / 2014 / \mathrm{feb} / \mathrm{r} 4 /$ katie-hopkins-interview $>$ (accessed 09/07/2014).

Allsopp, Kirstie (2015) Kirstie's Homemade Home, London: Hodder \& Stoughton.

Anais Rach, Jessica (2014) 'Katie Hopkins' Rant: I Hate Fat Mums, Home Schooling Mums, Eco Mums and Stay-at-Home Mums and Dads', Closer, Available at: <http://www.closeronline.co.uk/20I4/or/katie-hopkins-i-hate-fat-mums-homeschooling-mums-eco-mums-and-stay-at-home-mum-and-dads $\#$. $\mathrm{U}_{70}{ }_{3} \mathrm{~V}_{5} \mathrm{~N}_{3} \mathrm{wI}>$ (accessed 09/07/2014).

Ang, Ien (1985/1996) Watching Dallas: Soap Opera and the Melodramatic Imagination - Translated by Della Couling, London: Routledge. 
Ang, Ien (1982) Het Geval Dallas, Netherlands: SUA.

Arthurs, Deborah (2012) 'Britain's Youngest Gypsy Bride Gets Married Aged 16 Years and One Day in $£ 50,000$ Ceremony in $6 \mathrm{ft}$ Wide Dress', Mail Online, Available at: <http://www.dailymail.co.uk/femail/article-2I47488/My-Big-Fat-GypsyWedding-Britains-youngest-gypsy-bride-gets-married-50-0oo-celebration.html> (accessed OI/12/2014).

Asher, Rebecca (2012) Shattered: Modern Motherhood and the Illusion of Equality, London: Vintage.

Aström, Berit (2015) 'The Symbolic Annihilation of Mothers in Popular Culture: Single Father and the Death of the Mother', Feminist Media Studies, 5:4, 593-607.

Attwood, Feona (2014) 'Onscenity: Sex, Commerce, Media and Technology in Contemporary Society', Arts \& Humanities Research Council, Available at: <http:// www.onscenity.org> (accessed 07/07/2014).

Austin, Thomas (2002) Hollywood, Hype and Audiences: Selling and Watching Popular Film in the Iggos, Manchester: Manchester University Press.

Babycentre November 2009 Birth Club (2012) 'BBC Parenting - They're Kidding, Right?' babycentre, Available at: <http://community.babycentre.co.uk/post/ a17265565/bbc_parenting_-_their_kidding_right $>$ (accessed 19/11/2014).

Baker-Whitelaw, Gavia (2014) 'Guess How Many Female Writers are Joining Dr Who This Season', The Daily Dot, Available at: <http://www.dailydot.com/geek/ doctor-who-season-8-male-writers/> (accessed I9/II/2014).

Bale, Karen (2011) 'Holly Willoughby: Mothers Can't Win - We're Damned if we Work and Damned if We Don't', Daily Record, Available at: <http://www. dailyrecord.co.uk/entertainment/celebrity/holly-willoughby-mothers-cantwin-1086842> (accessed I4/IO/2014).

Barker, Martin (2004) 'News, Reviews, Clues, Interviews and Other Ancillary Materials - a Critique and Research Proposal', Scope: An Online Journal of Film Studies, Available at: <http://www.nottingham.ac.uk/scope/documents/2004/february2004/barker.pdf $>$ (accessed oI/12/2010).

Barker, Martin et al. (2014) 'Participations: Journal of Audience and Reception Studies: Statement of Aims', Participations, Available at: <http://www.participations.org/ statement_of_aims.htm> (accessed 06/10/2014).

Bartlett, Helen (2014) 'Helen Bartlett Photography: An Effortless and Enjoyable Experience', Helen Bartlett Photography, Available at: <http://www.helenbartlett. co.uk/portraits/how-it-works.php> (accessed I9/II/2014).

Bates, Laura (2014) 'The EveryDay Sexism Project', EveryDay Sexism, Available at: <http://everydaysexism.com> (accessed I4/Io/20I4). 
BBC (2014) 'Public Purposes: Reflecting UK Audiences', BBC, Available at: <http:// www.bbc.co.uk/aboutthebbc/insidethebbc/whoweare/publicpurposes/com munities.html> (accessed 19/II/2014).

BBC (20Ir) 'Cherry's Parenting Dilemmas', $B B C$ three, Available at: <http://www. bbc.co.uk/programmes/bor39kbs> (accessed 20/10/2014).

BBC (2orlb) 'Cherry's Parenting Dilemmas: Where I Went for Advice', $B B C$ three Blog, Available at: <http://www.bbc.co.uk/blogs/legacy/bbcthree/2011/o8/ cherryparenting.shtml $>$ (accessed 20/10/2014).

BBC (2002) 'Modern Mums Suffer Sleep Deprivation', BBC News, Available at: <http://news.bbc.co.uk/I/hi/health/1906858.stm> (accessed 19/1I/2014).

Beckford, Martin (2008) 'United Nations Orders Labour to Stop Reality TV Shows Exploiting Children: A Highly Critical United Nations Report has Ordered the Government to Stop Reality TV Shows Exploiting Children', The Telegraph, Available at: <http://www.telegraph.co.uk/news/politics/labour/3129928/ United-Nations-orders-Labour-to-stop-reality-TV-shows-exploiting-children. html> (accessed 07/07/2014).

Bell, Emma (2008) 'From Bad Girl to Mad Girl: British Female Celebrity, Reality Products and the Pathologization of Pop-Feminism', Genders, 48, Available at: <http://www.genders.org/g48/g48_bell.html> (accessed Io/08/2010).

Bennett, James (2010) Television Personalities: Stardom and the Small Screen, London: Routledge.

Bennett, James (2008) 'The Television Personality System: Televisual Stardom Revisited after Film Theory', Screen, 49:1, 32-50.

Berger, Arthur (2013) Media and Communication Research Methods: An Introduction to Qualitative and Quantitative Approaches, London: Sage.

Bird, Elizabeth (1992) For Enquiring Minds: A Cultural Study of Supermarket Tabloids, Knoxville: The University of Tennessee Press.

Bonifazi, Wendy (2003) 'Midlife Motherhood: Late Expectations?' Nurseweek, Available at: $<$ http://www2nursingspectrum.com/articles/print/html?AID = $10670>$ (accessed Io/o8/201I).

Borisoff, Deborah (2005) 'Transforming Motherhood: "We've Come a Long Way", Maybe', Review of Communication, 5:I, I-II.

Bower, Karen (2014) 'An Open Letter to Katie Hopkins', Railman Blog, Available at: $<$ http://railman.blog.co.uk> (accessed 09/07/2014).

Bradford, Kelly Rose (2012) 'Mum of Two Holly Willoughby Admits she Couldn't do Anything without Her Hired Help!' Parentdish, Available at: <http:// www.parentdish.co.uk/20I2/II/26/mum-of-two-holly-willoughby-admits-shecouldnt-do-anything-without-nanny/> (accessed I4/10/2014). 
Brennen, Bonnie (2012) Qualitative Research Methods for Media Studies, London: Routledge.

Brown, Mary Ellen (1994) Soap Opera and Women's Talk: The Pleasure of Resistance, London: Sage.

Brown, Tamara Mose, and de Casanova, Erynn Masi (2009) 'Mothers in the Field: How Motherhood Shapes Fieldwork and Researcher-Subject Relations', Women's Studies Quarterly, 37:3/4, 42-57.

Brunsdon, Charlotte (2003) 'Lifestyling Britain: The 8-9 Slot on British Television', International Journal of Cultural Studies, 6:1, 5-23.

Brunsdon, Charlotte (2000) The Feminist, the Housewife, and the Soap Opera, Oxford: Clarendon Press.

Brunsdon, Charlotte (1997) Screen Tastes: Soap Opera to Satellite Dishes, London: Routledge.

Brunsdon, Charlotte, and Spigel, Lynn (eds) (2007) Feminist Television Criticism Second Edition, Maidenhead: Open University Press.

Buckingham, David (1987) Public Secrets: EastEnders and its Audience, London: BFI. Buckman, Peter (1984) All For Love: A Study in Soap Opera, London: Secker \& Warburg.

Burns, Judith (2013) 'Foster Care Myths Threaten Crisis, Claims Charity', BBC News, Available at: <http://www.bbc.co.uk/news/education-23987900> (accessed $30 / 01 / 2015)$.

BustedKate (2013) 'Celebrities Who Have Talked About Their Miscarriages', BabyMed, Available at: <http://www.babymed.com/blogs/bustedkate/celebrities-whohave-talked-about-their-miscarriages $>$ (accessed 24/03/2014).

Cable, Simon, and Kirkova, Deni (2013) 'Holly Willoughby and Katie Hopkins Baby Names Bust-up is an Internet Sensation', Mail Online, Available at: <http://www. dailymail.co.uk/femail/article-2356736/This-Morning-row-Holly-WilloughbyKatie-Hopkins-baby-bust-gets-million-YouTube-hits-days.html> (accessed O2/12/2014).

Candler, Angelisa (2013) 'Moms and Tiaras', Angelisa Candler's Videos, Available at: <http://vimeo.com/66605823> (accessed OI/12/2014).

Carille, Anna (2014) 'Wow, You Really do Have Two Mums!: What it's Like When the Children of Lesbian Mothers go to School', The Independent, Available at: <http://www.independent.co.uk/voices/comment/wow-you-really-dohave-two-mums-what-its-like-when-the-children-of-lesbian-mothers-go-toschool-9144432.html> (accessed 02/12/2014).

Carmon, Irin (20II) 'Why So Few Women are Writing for Television', Jezebel, Available at: <http://jezebel.com/5838810/tv-writers-talk-about-whythere-are-so-few-women-among-them?utm_source=feedburner\&utm 
medium=feed\&utm_campaign $=$ Feed\% ${ }_{3} \mathrm{~A}+$ jezebel\%2Ffull+\%28Jezebel\%29> (accessed $\left.19 / \mathrm{II} / 20 \mathrm{I}_{4}\right)$.

Chahal, Mindi (2014) 'The Five Myths of Marketing to Mums', Marketing Week, Available at: <http://www.marketingweek.com/2014/04/ro/the-five-mythsof-marketing-to-mums/> (accessed 26/07/2015).

Chattin-McNicholas, John (1992) 'Montessori Programs in Public Schools: ERIC Digest', ericdigests.org, Available at: <http://www.ericdigests.org/1992-2/mon tessori.htm $>$ (accessed 03/07/2014).

Christensen, Dorthe (2010) 'Sharing Death: Online Performances of Grief', paper presented at the Social Aspects of Death, Dying and Bereavement Symposium, British Sociological Association, Available at: <http://www.britsoc.co.uk/media/25956/ Media_and_DDB_programme_2010_final.pdf $>$ (accessed 04/02/2015).

Connell, R.W. (1995) Masculinities, Berkeley: University of California Press.

Couldry, Nick, Livingstone, Sonia, and Markham, Tim (2009) Media Consumption and Public Engagement: Beyond the Presumption of Attention, Basingstoke: Palgrave Macmillan.

Cowan, Katherine, and Valentine, Gill (2006) 'Tuned Out: The BBC's Portrayal of Gay and Lesbian People', Stonewall, Available at: <http://www.stonewall.org. uk/documents/tuned_out_pdf_I.pdf $>$ (accessed 19/II/2014).

Cox, Lauren (2014) 'Hayden Panettiere Flaunts Huge Bare Bikini Baby Bump, 8 Months Pregnant', Hollywood Life, Available at: <http://hollywoodlife. $\mathrm{com} / 2014 /$ II/19/hayden-panettiere-bikini-baby-bump-pregnant-pics/> (accessed 28/01/2015).

Croft, Claudia (2006) 'The Celebrity Trajectory Theory: They Can Go Up or Down. Just as Long as They're Going Somewhere', The Sunday Times, Available at: <http://www.thesundaytimes.co.uk/sto/style/articleI74254.ece> (accessed $07 / 07 / 2014)$.

Daly, Tess (2013) 'Tess Daly: Back To School, Back To Strictly', Yahoo Lifestyle, Available at: <https://uk.lifestyle.yahoo.com/tess-daly--back-to-school--back-tostrictly---131608495.html $>$ (accessed 10/07/2014).

Daly, Tess (2010) The Baby Diaries: Memories, Milestones and Misadventures, London: Vermilion.

Davidson, $\operatorname{Max}(2013)$ 'Generation Game: the Return of the Extended Family Home', The Telegraph, Available at: <http://www.telegraph.co.uk/property/buying sellingandmoving/10046242/Generation-game-the-return-of-the-extendedfamily-home.html> (accessed 10/07/2014).

Deacon, David, Pickering, Michael, Golding, Peter, and Murdock, Graham (1999) Researching Communications: A Practical Guide to Methods in Media and Cultural Analysis, London: Arnold. 
Deacon, Michael (2010) 'Andy Hamilton on the Secret to Outnumbered's Success', The Daily Telegraph, Available at: <http://www.telegraph.co.uk/culture/tvan dradio/bbc/754543I/Andy-Hamilton-on-the-secret-to-Outnumbereds-success. html? mobile $=$ basic $>($ accessed 20/10/2014).

Della-Ragione, Joaana (2013) 'Tess Daly: Strictly has Given me so Many Magical Moments', Express, Available at: <http://www.express.co.uk/news/showbiz/ 446298/Tess-Daly-Strictly-has-given-me-so-many-magical-moments> (accessed I4/10/2014).

Deller, Ruth (20II) 'Twittering on: Audience Research and Participation Using Twitter', Participations: Journal of Audience \& Reception Studies, 8:1, 216-245.

Dent, Tamsyn (2013) 'Motherhood is the Antithesis of Creativity: Conflicting Public Policies and the Clash Between Ideal Creative Workers and Ideal Parents', paper presented at the Media Futures Research Seminar Series, Bath Spa University, Available at: $<$ http://tamsyndent.wordpress.com/2013/10/ro/event-alert-bathspa-university-media-future-research-centre/ $>$ (accessed 07/10/2014).

Desser, David, and Joweth, Garth (eds) (2000) Hollywood Goes Shopping, London: University of Minnesota Press.

Diamond, Anne (2010a) 'The UGLY Truth about Pregnant Women on TV: Pregnancy Phobia hasn't Changed Since I appeared on Screen with my Bump', MailOnline, Available at: <http://www.dailymail.co.uk/femail/article-I252094/The-UGLYtruth-pregnant-woman-TV-Pregnancy-phobia-changed-I-appeared-screenbump-says-ANNE-DIAMOND.html $>$ (accessed 20/10/2014).

Diamond, Anne (2010b) 'Anne Diamond', Peoplematter.tv, Available at: <http://www. peoplematter.tv/artistmanagement/Anne\%2oDiamond/annediamondhome. htm> (accessed 18/06/2010).

Doughty, Steve (2012) ' $75 \%$ of New Mothers Would Stay at Home to Bring up Their Child if They Could Afford to',MailOnline, Available at: <http://www.dailymail. co.uk/news/article-2199539/75-new-mothers-stay-home-bring-child-afford-to. html> (accessed 02/12/2014).

Douglas, Susan, and Michaels, Meredith (2005) The Mommy Myth: The Idealization of Motherhood and How it Has Undermined All Women, London: Free Press.

Dow, Bonnie (1996) Prime-Time Feminism: Television, Media Culture, and the Women's Movement Since 1970, Philadelphia: University of Pennsylvania Press.

Dowell, Ben (2013) 'Janet Ellis - I Still Haven't Received my Gold Blue Peter Badge', Radio Times, Available at: <http://www.radiotimes.com/news/2013-06-17/janetellis---i-still-havent-received-my-gold-blue-peter-badge $>$ (accessed 20/10/2014).

Duff, Charlie (20II) 'Katie Hopkins: Only Three Weeks Maternity Leave is Necessary', Business Zone, Available at: <http://www.businesszone.co.uk/topic/staff/ 
katie-hopkins-only-three-weeks-maternity-leave-necessary/34971> (accessed 09/07/2014).

Dunne, Gillian (2000) 'Opting Into Motherhood: Lesbians Blurring the Boundaries and Transforming the Meaning of Parenthood and Kinship', Gender \& Society, I 4:I, II-35.

Dworkin, Shari and Wachs, Faye Linda (2004) 'Getting Your Body Back: Postindustrial Fit Motherhood in Shape Fit Pregnancy Magazine', Gender \& Society, I8:5, 610-624.

Ellen, Barbara (2007) 'What Katie Did - and Who She Did Along the Way', The Observer, Available at: <http://www.theguardian.com/theobserver/2007/ dec/16/features.review67> (accessed 09/07/2014).

ENEI (2014) 'Environment Agency', ENEI, Available at: <http://www.enei.org.uk/ pages/environment-agency.html (accessed 23/06/2014).

Esterberg, Kristin (2008) 'Planned Parenthood: The Construction of Motherhood in Lesbian Mother Advice Books', in Feminist Mothering, ed. Andrea O'Reilly, New York: State University of New York Press, 75-88.

Everingham, Christine (1994) Motherhood and Modernity: An Investigation into the Rational Dimension of Mothering, Buckingham: Open University Press.

Feasey, Rebecca (2015) 'Television and the Absent Mother: Why Girls and Young Women Struggle to find the Maternal Role,' paper presented at the 'Missing, Presumed Dead: Absent Mothers in the Cultural Imagination' Conference, Umea University, II-I2 June 20I5.

Feasey, Rebecca (2014a) 'From Heartache to Happiness: the Codes, Conventions and Clichés of the 40-something Celebrity Infertility Story', MaMSIE: Studies in the Maternal, Available at: <http://mamsie.org/mamsieblog/?s=feasey> (accessed 02/12/2014).

Feasey, Rebecca (2014b) 'Motherhood and the Media', Mothers on Mothers: Maternal Readings of Popular Television, Available at: $<$ https://motherhoodandtelevision. wordpress.com/motherhood-and-the-media/> (05/02/2015)

Feasey, Rebecca (2014c) 'Mothers Watching Mothers on Television: Questionnaire', Bath Mums, Available at: <https://bathmums.co.uk/chat/view/285657> (accessed 23/06/2014).

Feasey, Rebecca (2014d) 'Mothers Watching Mothers on Television: Questionnaire', Net Mums, Available at: <http://www.netmums.com/coffeehouse/netmumsmums-panel-25I/media-requests-7/1048911-mothers-watching-mothers-televi sion-questionnaire-all.html> (accessed 23/06/2014).

Feasey, Rebecca (2014e) 'Mothers Watching Mothers on Television: Questionnaire', Mumsnet, Available at: <http://www.mumsnet.com/Talk/ 
media_nonmember_requests/ar965810-Mothers-Watching-Mothers-on-Tele vision-Questionnaire?msgid $=44308784 \# 44308784>($ accessed 23/06/2014 $)$.

Feasey, Rebecca (2013) 'From Soap Opera to Reality Programming: Examining Motherhood, Motherwork and the Maternal Role on Popular Television', Imaginations: Journal of Cross-Cultural Image Studies/Revue d'Études Interculturelles de l'Image, 4:2. Available at: <http://www3.csj.ualberta.ca/imaginations/?p=48II > (accessed or/07/2014).

Feasey, Rebecca (2012a) From Happy Homemaker to Desperate Housewives: Motherhood and Popular Television, London: Anthem Press.

Feasey, Rebecca (2012b) 'Absent, Ineffectual and Intoxicated Mothers: Representing the Maternal in Teen Television', Feminist Media Studies, I:12, I55-159.

Feasey, Rebecca (201I) 'Mothers on the Naughty Step: Supernanny and Reality Parenting Television', FlowTV, is, Available at: <http://flowtv.org/2011/II/motherson-the-naughty-step/> (accessed o1/07/2014).

Feasey, Rebecca (2008a) Masculinity and Popular Television, Edinburgh: Edinburgh University Press.

Feasey, Rebecca (2008b) 'Reading heat: the Meanings and Pleasures of Star Fashions and Celebrity Gossip', Continuum: Journal of Media and Cultural Studies, 22:5, 683-695.

Feasey, Rebecca (2006a) 'Watching Charmed: Why Teen Television Appeals to Women', Journal of Popular Film and Television, 34:1, 2-9.

Feasey, Rebecca (2006b) 'Fame Body: Star Styles and Celebrity Gossip in heat Magazine' in Framing Celebrity, eds Su Holmes and Sean Redmond, London and New York: Routledge, 177-194.

Fisher, Sarah (2010) 'NCT: Service Development and Policy - Meeting the Needs of Lesbian Mothers', NCT, Available at: <http://www.nct.org.uk/sites/default/ files/related_documents/Fisher\%2oMeeting\%2othe\%2oneeds\%20of\%20 lesbian\%2omothers_o.pdf> (accessed 02/12/2014).

Flint, Hannah (2013) 'Katie Hopkins Defends Charles Saatchi as she Launches Scathing attack on "Not so Perfect" Nigella Lawson', MailOnline, Available at: <http://www.dailymail.co.uk/tvshowbiz/article-2519396/Katie-Hopkinsdefends-Charles-Saatchi-attacks-Nigella-Lawson.html> (accessed Io/07/2014).

Ford, Gina (2014) 'The Secret to Calm and Confident Parenting', An Official Gina Ford Website, Available at: <http://contentedbaby.com> (accessed 06/10/2014).

Ford, Gina (2013) Good Mother Bad Mother. London: Vermillion.

Ford, Gina (2012) The Contented Mother's Guide: Essential Advice to Help you be a Happy, Calm and Confident Mother, London: Vermillion.

Ford, Gina (2010) From Crying Baby to Contented Baby, London: Vermillion.

Ford, Gina (2007) The Contented Baby's First Year, London: Vermillion. 
Ford, Gina (2006) The Complete Sleep Guide for Contented Babies and Toddlers, London: Vermillion.

Ford, Gina (2006) The Contented Little Baby Book of Weaning, London: Vermillion. Foster, Alistair (20I4) 'Holly Willoughby: You Can Combine TV Job and Motherhood, London Evening Standard, Available at: <http://www.standard.co.uk/ showbiz/holly-willoughby-you-can-combine-tv-job-and-motherhood-9093017. html> (accessed I4/10/2014).

Foster, Jill (20II) 'All Rise for Mary Queen of Cakes! Great British Bake Off Judge Shares a Few Slices of her Wisdom', MailOnline, Available at: <http://www. dailymail.co.uk/femail/article-2046689/Great-British-Bake-Off-judge-MaryBerry-shares-wisdom.html> (accessed I4/10/2014).

Fox, Patty (1995) Hollywood Legends as Fashion Icons, New York: Angel City Press.

Freeman, Hadley (2014) 'Forget Kirstie Allsopp's Advice - Listen to Me, the Nigel Farage of Fertility', The Guardian, Available at: <http://www.theguardian. $\mathrm{com} /$ lifeandstyle/2014/jun/03/kirsty-allsopp-advice-nigel-farage-woman-lifechoices $>$ (accessed $14 / 10 / 2014)$.

Frost, Vicky (2009) 'Does Sky1's Modern Family Remind you of Anything?' Guardian, Available at: http://www.theguardian.com/tv-and-radio/tvandradioblog/2009/ oct/15/outnumbered-modern-family-sitcom (accessed 20/10/2014).

Gailey, Elizabeth Atwood (2007) 'Self-Made Women: Cosmetic Surgery Shows and the Construction of Female Psychopathology', in Makeover Television: Realities Remodelled, ed. Dana Heller, London: I.B. Tauris, I07-II8.

Ganeshasundaram, Raguragavan, and Henley, Nadine (2009) 'Reality Television (Supernanny): A Social Marketing "Place" Strategy',Journal of Consumer Marketing, 26:5, 311-319.

Geraghty, Christine (2000) 'Re-Examining Stardom: Questions of Texts, Bodies and Performance', in Re-Inventing Film Studies, ed. Christine Gledhill and Linda Williams, Oxford: Oxford University Press, 183-202.

Geraghty, Christine (1999) Women and Soap Opera: A Study of Prime Time Soaps, Cambridge: Polity Press.

Gerstmann, Peter (2014) 'Standardized Survey Classifications - Individuals', PGA Group, Available at <http://www.pgagroup.com/standardized-survey-classifi cations.html> (accessed: 23/06/2014).

Giedroyc, Mel (2005) From Here to Maternity: One Mother of a Journey, London: Ebury Press.

Gillies, Val (2006) Marginalised Mothers: Exploring Working-Class Experiences of Parenting, London and New York: Routledge.

Glennie, Alasdair (2013) 'Why Feminism is a Dirty Word: Bake Off Star Says she Does Not Want Women's Rights', MailOnline, Available at: <http://www.dailymail. 
co.uk/news/article-2269289/Why-feminism-dirty-word-Mary-Berry-Bake-Offstar-says-does-want-womens-rights.html> (accessed $\mathrm{I} 4 / \mathrm{IO} / 20 \mathrm{I} 4)$.

Glennie, Alasdair (2012) ‘Enjoy Cooking, You'll be Doing it All your Lives': The Great British Bake Off's Mary Berry Encourages Young Wives to Start on their Culinary Skills, MailOnline, Available at: <http://www.dailymail.co.uk/tvshowbiz/ article-2191768/The-Great-British-Bake-Offs-Mary-Berry-encourages-youngwives-start-culinary-skills.html> (accessed 28/or/2015).

Glymore, Madelyn (2013) 'Gender Disparity in American and British Television Writing Staffs', Stop It, Show! Available at: <http://stopitshow.blogspot. co.uk/2013/08/gender-disparity-in-american-and.html > (accessed I4/10/20I4).

Goldman, Kevin (2014) 'Recipe for Scandal', Vanity Fair, Available at: <http:// www.vanityfair.com/society/2014/o2/nigella-lawson-charles-saatchi-scandal > (accessed or/07/2014).

Gordon, Bryrony (2014) 'Kirstie Allsopp: 'I Don't want the Next Generation of Women to Suffer the Same Heartache', The Telegraph, Available at: <http:// www.telegraph.co.uk/finance/personalfinance/money-saving-tips/ro868367/ Kirstie-Allsopp-I-dont-want-the-next-generation-of-women-to-suffer-the-sameheartache.html> (accessed I4/10/2014).

Gorenstein, Sarah Preston (2014) 'Celebrities Really Are Just Like Us', Parenting, Available at: $<$ http://www.parenting.com/blogs/trying-conceive/sarah-prestongorenstein/celebrities-really-are-just-us> (accessed 24/03/2014).

Gornstein, Leslie (2010) 'Do the Teen Moms (or Their Kids) Get Paid?' E!, Available at: <http://uk.eonline.com/news/213901/do-the-teen-moms-or-their-kids-getpaid $>$ (accessed 07/07/2014).

GovUK (2014) 'Statistics: Disability Facts and Figures', Gov.UK, Available at: $<$ https:// www.gov.uk/government/publications/disability-facts-and-figures/disabilityfacts-and-figures $>$ (accessed 02/12/2014).

Graham, Emily (2008) 'Jane Kaczmarek on Being a Real-Life Mom', School Family, Available at: <http://www.schoolfamily.com/school-family-articles/article/759jane-kaczmarek-real-life-mom> (accessed 20/10/2014).

Gray, Jonathan (2010) Show Sold Separately: Promos, Spoilers, and Other Media Paratexts, New York: New York University Press.

Green, Fiona (2004) 'Feminist Mothers: Successfully Negotiating the Tensions Between Motherhood as Institution and Experience', in Mother Outlaws: Theories and Practices of Empowered Mothering, ed. Andrea O'Reilly, Toronto: Women's Press, $31-42$.

Gyngell, Kathy (20I4) 'Kirstie Allsopp is off Location with her Whacky Advice to Young Women', The Conservative Woman, Available at: <http://conservativewoman. 
co.uk/kathy-gyngell-kirstie-allsopp-qualifications-before-parenthood-youngwomen/> (accessed 02/12/2014).

Hall, Melanie (2013) "Ill Informed" Mary Berry Criticised for Condemning Maternity Leave, The Telegraph, Available at: <http://www.telegraph.co.uk/ women/9829933/Ill-informed-Mary-Berry-criticised-for-condemning-maternityleave.html> (accessed I4/10/2014).

Hamamoto, Darrell (1991) Nervous Laughter: Television Situation Comedy and Liberal Democratic Ideology, New York: Praeger.

Hansen, Anders, Cottle, Simon, Negrine, Ralph and Newbold, Chris (1998) Mass Communication Research Methods, London: Palgrave Macmillan.

Haralovich, Mary Beth (ed.) (1999) Television History and American Culture: Feminist Critical Essays, London: Duke University Press.

Haskell, Molly (1974) From Reverence to Rape: The Treatment of Women in the Movies, New York: Holt.

Hayes, Charlotte (2013) When Did White Trash Become the New Normal, Regnery Publishing.

Hays, Sharon (1998) The Cultural Contradictions of Motherhood, New Haven and London: Yale University Press.

Held, Virginia (1983) 'The Obligations of Mothers and Fathers', in Mothering: Essays in Feminist Theory, ed. Joyce Trebilcot, New Jersey: Rowman \& Allanheld, 7-2O.

Henry, Julie (2012) 'Ditch the "Naughty Step", Says New Parenting Guide', The Telegraph, Available at: <http://www.telegraph.co.uk/education/education news/9150574/Ditch-the-naughty-step-says-new-parenting-guide.html> (accessed 03/07/2014).

Hermes, Joke (1995) Reading Women's Magazines: An Analysis of Everyday Media Use, Cambridge: Polity Press.

Hobson, Dorothy (2003) Soap Opera, Cambridge: Polity Press.

Holland, Patricia (1998) 'The Politics of the Smile: Soft News and the Sexualisation of the Popular Press', in News, Gender and Power, eds Cynthia Carter, Gill Branston and Stuart Allen, London: Routledge, 17-32.

Holland, Patricia (1987) 'When a Woman Reads the News', in Boxed In: Women and Television, eds Helen Baehr and Gillian Dyer, London: Pandora, 133-150.

Hooper, Abi (2013) 'Katie Hopkins' This Morning Return: Work Comes Before my Children's Birthdays', Closer, Available at: <http://www.closeronline. co.uk/2013/09/katie-hopkins-this-morning-return-work-comes-before-mychildren-s-birthdays\#.U70Yfis $\mathrm{N}_{3} \mathrm{wI}>$ (accessed 09/07/2014).

Hopkins, Katie (2014a) 'There's Nothing Strong About Wimping Out Of Childbirth', Yahoo Lifestyle, Available at: <https://uk.lifestyle.yahoo.com/blogs/ 
katie-hopkins/katie-hopkins-nothing-strong-about-wimping-out-of-child birth-100245060.html> (accessed 09/07/2014).

Hopkins, Katie (20I4b) 'Full-time Mum is NOT a Job Title - it's a Biological Status', Yahoo Lifestyle, Available at: <https://uk.lifestyle.yahoo.com/katie-hopkins-fulltime-mum-not-job-title-biological-status-exclusive-191521285.html> (accessed $09 / 07 / 2014)$.

Hopkins, Katie (2013) The Class Book of Baby Names - Kindle Edition, London: Thistle Publishing.

Hornig Priest, Susanna (2010) Doing Media Research - 2nd Edition, London: Sage. Horten, Lisa (2014) 'Lessons For Your Own Modern Family From Julie Bowen', Popsugar, Available at: <http://www.popsugar.com/moms/Julie-Bowen-TalksAbout-Modern-Family-3390774I > (accessed 28/or/2015).

Hughes, Kathi (2012) Learning Together: What Montessori Can Offer Your Family, The Montessori St Nicholas Charity: Ist Edition.

Ibrahim, Yasmin (2010) 'Martyrdom in the Blogosphere: Conjoining Offline Rituals with Virtual Commemorations' paper presented at the Social Aspects of Death, Dying and Bereavement Study Group Symposium, The British Sociological Association, Available at: <http://www.britsoc.co.uk/media/25956/Media_and_ DDB_programme_2010_final.pdf $>$ (accessed 07/02/2015).

Ison, Rianne (2013) 'Strictly Come Dancing's Tess Daly Wants Some Mummy Mates', Best, Available at: <http://www.bestdaily.co.uk/showbiz/news/as15240/ strictly-come-dancings-tess-daly-wants-some-mummy-mates.html> (accessed I4/IO/2014).

Jackson, Peter; Stevenson, Nick and Brooks, Kate (200I) Making Sense of Men's Magazines, Cambridge: Polity.

Jarvis, Alice-Azania (2010) 'The Timeline: Maternity Leave', The Independent, Available at: <http://www.independent.co.uk/life-style/health-and-families/features/ the-timeline-maternity-leave-2113236.html $>$ (accessed I4/10/2014).

Jenkins, Henry (2009) 'The Message of Twitter: Here it is and Here I am', Confessions of an Aca-Fan, Available at: <http://henryjenkins.org/2009/08/the_mes sage_of_twitter.html> (accessed 09/10/2014).

Johansson, Sofia (2006) 'Sometimes You Wanna Hate Celebrities: Tabloid Readers and Celebrity Coverage', in Framing Celebrity: New Directions in Celebrity Culture, eds Su Holmes and Sean Redmond, London: Routledge, 342-358.

Joseph, Georgina (2013) 'Maternity Leave Discrimination: A Working Mother's Story of Losing her Job - and How She Got Over it', The Telegraph, Available at: <http://www.telegraph.co.uk/women/mother-tongue/10270357/Maternityleave-discrimination-A-working-mothers-story-of-losing-her-job-and-how-shegot-over-it.html $>$ (accessed I4/10/2014). 
Kamberelis, George and Dimitriadis, Greg (2013) Focus Groups: From Structured Interviews to Collective Conversations, London: Routledge.

Karlyn, Kathleen (2011) Unruly Girls, Unrepentant Mothers: Redefining Feminism on Screen, Texas: Texas University Press.

Kendrick, Keith (2012) 'Holly Willoughby Reveals how she Juggles being a Mum with Presenting Two Flagship TV Shows', Parentdish, Available at: <http://www. parentdish.co.uk/2012/03/28/holly-willoughby-reveals-how-she-juggles-beinga-mum-with-presenting-two-tv-shows/> (accessed I4/ro/20I4).

Kennedy, Lauren Paige (20II) 'Julie Bowen: Modern Mother, Modern Family', WebMD, Available at: <http://www.webmd.com/a-to-z-guides/features/juliebowen-modern-mother-modern-family $>$ (accessed 20/10/2014).

Klass, Mylene (2009) My Bump and Me, London: Virgin Books.

Kuruvilla, Carol (2014) 'Conservatives Angry after Disney Channel Debuts Lesbian Couple on Good Luck Charlie', Daily News, Available at:<http://www.nydai lynews.com/entertainment/tv-movies/disney-channel-debuts-lesbian-couplegood-luck-charlie-article-1.1603673> (accessed 02/12/2014).

Lampert, Nicole (201I) 'I've Lost it all Twice, Not Again: TV Star Myleene Klass on why she Returned to Work Weeks after the Birth of the Daughter she Thought she'd Never Have', MailOnline, Available at: <http://www.dailymail.co.uk/ femail/article-I393432/Myleene-Klass-returned-work-weeks-birth-daughterAva.html> (accessed I4/10/2014).

Langer, John (198I) 'Television's Personality System', Media, Culture \& Society, 3:4, $351-365$.

Larson, Mary Strom (1996) 'Sex Roles and Soap Operas: What Adolescents Learn About Single Motherhood', Sex Roles, 35:1/2, 97-IIO.

Lauzen, Martha (2014) 'Boxed In: Employment of Behind-the-Scenes and On-Screen Women in 2013-14 Prime-time Television', Center for the Study of Women in Television and Film, Available at <http://womenintvfilm.sdsu.edu/files/2013I4_Boxed_In_Report.pdf $>$ (accessed I9/II/20I4).

Leon, Anya (20II) 'Julie Bowen: I Wanted One Baby - Not Two!' People: Momse' Babies, Available at: <http://celebritybabies.people.com/2011/o8/29/julie-bowen-iwanted-one-baby-not-two/> (accessed 20/10/2014).

Levey, Hilary (2010) 'Reality TV Kids Need the Law on Their Side', USA Today, Available at: <http://usatoday3o.usatoday.com/news/opinion/forum/201006-26-levey25_ST_N.htm > (accessed 07/07/2014).

Levy, Arial (2006) Female Chauvinist Pigs: Women and the Rise of Raunch Culture, New York: Pocket Books.

Liebes, Tamar, and Livingstone, Sonia (1992) 'Mothers and Lovers: Managing Women's Role Conflicts in American and British Soap Operas', in Comparatively 
Speaking: Communication and Culture Across Space and Time, eds Jay Blumer et al. London: Sage, 94-I20.

Lipkin, Elline (2012) 'Momtroversy: How Feminist Is Attachment Parenting?' Ms.Blog, Available at: <http://msmagazine.com/blog/2012/06/13/momtroversy-howfeminist-is-attachment-parenting/ $>$ (accessed 03/07/2014).

Lipsett, Andrea (2007) 'Eight of out Io Disabled Children Bullied, Report Finds', Guardian, Available at: <http://www.theguardian.com/education/2007/jun/18/ schools.children $>$ (accessed 02/12/2014).

Lotz, Amanda (2014) Cable Guys: Television and Masculinities in the 2Ist Century, New York: New York University Press.

McAleenan, Patrick (2014) 'Why Aren't More Gay Men Becoming Parents?' The Telegraph, Available at: <http://www.telegraph.co.uk/men/relationships/father hood/10877807/Why-arent-more-gay-men-becoming-parents.html $>$ (accessed 24/II/2014).

Macaulay, Sean (2010), 'Jo Frost Interview', The Telegraph, Available at: <http:// www.telegraph.co.uk/family/7051886/Jo-Frost-interview.html> (accessed Io/08/20II).

MacDonald, Marianne (2008) 'Strictly Tess Daly on Marriage, Motherhood and Being Bossy', MailOnline, Available at: <http://www.dailymail.co.uk/home/you/ article-541237/Strictly-Tess-Daly-marriage-motherhood-bossy.html $>$ (accessed I4/10/2014).

MacIntyre, April (20II) 'Julie Bowen Spills 'Modern Family' Drinking Game Secrets', $M \& C$, Available at: <http://www.monstersandcritics.com/smallscreen/news/ article_1663838.php/Julie-Bowen-spills-Modern-Family-drinking-game-secrets $>$ (accessed I4/IO/2014).

McVeigh, Tracy (2013) 'One in Seven Women are Made Redundant After Maternity Leave', Guardian, Available at: <http://www.theguardian.com/law/2013/ $\mathrm{mar} / \mathrm{og} /$ women-on-maternity-leave-illegal-discrimation $>($ accessed $\mathrm{I} 4 / \mathrm{ro} / 20 \mathrm{I} 4)$.

McVeigh, Tracy (2012) 'Forty Years of Feminism - But Women Still do Most of the Housework', Guardian, Available at: <http://www.theguardian.com/soci ety $/ 20 \mathrm{I} 2 / \mathrm{mar} / \mathrm{IO} /$ housework-gender-equality-women $>($ accessed I4/10/2014).

McVeigh, Tracy and Helm, Toby (2012) 'Recession Hits Middle-Aged Women Worst, New Research Finds', Guardian, <http://www.theguardian.com/society/20I2/ $\mathrm{jul} / 08 /$ recession-hits-middle-aged-women-hardest $>$ (accessed 02/I2/2014).

Malnick, Edward (2013) 'Sharp Rise in Number of Cohabiting Gay Couples', The Telegraph, Available at: <http://www.telegraph.co.uk/news/politics/10417785/ Sharp-rise-in-number-of-cohabiting-gay-couples.html> (accessed 24/II/20I4).

Maushart, Susan (2007) 'Faking Motherhood: The Mask Revealed', in Maternal Theory: Essential Readings, ed. Andrea O’Reilly, Toronto: Demeter Press, 460-48I. 
Maushart, Susan (1999) The Mask of Motherhood: How Becoming a Mother Changes Everything and Why We Pretend it Doesn't, London: Pandora.

Maxted, Anna (2013) 'My Child is Crying Because ..., Guardian, Available at: <http:// www.theguardian.com/lifeandstyle/2013/oct/25/my-child-is-crying-greg-pem broke > (accessed 19/II/20I4).

Media Parents (2014a) 'Home' Media Parents, Available at: <http://www.mediapar ents.co.uk> (accessed 07/10/2014).

Media Parents (2014b) 'Testimonials', Media Parents, Available at: <http://www. mediaparents.co.uk/about/testimonials.html $>$ (accessed 07/10/20I4).

Media Parents (2014c) 'Five Minutes with ... Rebecca Feasey', Media Parents, Unpublished.

Miller, Tina (2005) Making Sense of Motherhood: A Narrative Approach, Cambridge: Cambridge University Press.

Modleski, Tania (2007) 'The Search for Tomorrow in Today's Soap Opera: Notes on a Feminine Narrative Form', in Feminist Television Criticism - Second Edition, eds Charlotte Brunsdon and Lynne Spiegel, Maidenhead: Open University Press, 29-40.

Mortimer, Ruth (2014) 'Ban the Word Mum from Segmentation: There is no Identikit Person', Marketing Week, Available at: <http://www.marketingweek. $\mathrm{com} / 2014 / 04 /$ ro/ban-the-word-mum-from-segmentation-there-is-no-identikitperson/> (accessed 26/07/2015).

Moseley, Rachel (2003) Growing Up with Audrey Hepburn: Text, Audience, Resonance, Manchester: Manchester University Press.

Mumazine (2013) 'Strictly's Tess Daly on Motherhood', Mumazine, Available at: $<$ http://www.mumazine.com/article/2013/10/19/strictlys-tess-daly-mother hood $>$ (accessed I4/IO/2014).

Mulvey, Laura (1975) 'Visual Pleasure and Narrative Cinema', Screen, 16:3, 6-18.

Mulvey, Laura (1989) Visual and Other Pleasures, Bloomington: Indiana University Press.

Mumsnet (2014a) 'About Us', Mumsnet, Available at: <http://www.mumsnet.com/ info/aboutus > (accessed 07/10/2014).

Mumsnet (2014b) 'Acronyms', Mumsnet, Available at: <http://www.mumsnet.com/ info/acronyms $>$ (accessed 07/10/2014).

Mumsnet (20I4c) 'Kirsty Allsop', Mumsnet, Available at: http://www.mumsnet.com/ Talk/womens_rights/a2097147-Kirsty-Allsop> (accessed 02/12/2014).

Mumsnet (2013a) 'Who are Your Favourite TV Mums?' Mumsnet, Available at: <http://www.mumsnet.com/Talk/telly_addicts/ar931348-Who-are-yourfavourite-TV-mums $>$ (accessed 20/10/2014). 
Mumsnet (2013b) 'Mumsnet Talk: Watch Orange is the New Black with Mumsnet', Mumsnet, Available at: <http://www.mumsnet.com/Talk/watch_with_mum snet/ar93822I-Watch-Orange-is-the-New-Black-with-Mumsnet-and-win-aniPad-mini (25/II/20I4).

Nathan, Sara, and McConnell, Donna (2010) 'I Feel Let Down and Disappointed,' says Denise Van Outen After Being Axed from BBC Talent Show Due to Pregnancy', MailOnline, Available at: <http://www.dailymail.co.uk/tvshowbiz/ article-1251832/I-feel-let-disappointed-says-Denise-Van-Outen-axed-BBC-talentpregnancy.html> (accessed 28/or/Is).

NCT (2014a) 'What we Do for Parents', NCT, Available at: <http://www.nct.org. uk/about-nct/what-we-do-parents> (accessed 07/10/2014).

NCT (2014b) 'Bromsgrove NCT Facebook Community', NCT, Available at: <https:// www.facebook.com/Bromsgrove.NCT> (accessed 07/10/2014).

NCT (2014c) 'Achievements', NCT, Available at: <http://www.nct.org.uk/aboutnct/achievements $>$ (accessed 07/10/2014).

Neithercott, Tracey (2014) 'Julie Bowen's Role as a Modern Woman', Capitol File, Available at: <http://capitolfile-magazine.com/personalities/articles/juliebowen-modern-family $>$ (accessed 20/10/2014).

NHS (2014a) 'Infertility', NHS Choices, Available at: <http://www.nhs.uk/condi tions/infertility/Pages/Introduction.aspx $>$ (accessed 24/03/2014).

NHS (20I4b) 'IVF', NHS Choices, Available at: <http://www.nhs.uk/Conditions/ IVF/Pages/Introduction.aspx > (accessed 24/03/2014).

NHS (2014c) 'How to Get to Sleep', NHS Choices, Available at: <http://www.nhs. uk/Livewell/insomnia/Pages/bedtimeritual.aspx $>$ (accessed 24/II/20I4).

NHS (2014d) 'Gay Health: Having Children', NHS Choices, Available at: <http:// www.nhs.uk/Livewell/LGBhealth/Pages/Havingchildren.aspx $>$ (accessed $24 / \mathrm{II} / 2014)$.

NHS (2014e) 'Post Natal Depression: Introduction', NHS Choices, Available at: <http://www.nhs.uk/conditions/postnataldepression/Pages/Introduction. aspx $>$ (accessed 24/II/2014).

NHS (20I4f) 'Clinical Depression: Introduction', NHS Choices, Available at: <http:// www.nhs.uk/Conditions/Depression/Pages/Introduction.aspx $>$ (accessed 24/II/2OI4).

Nobile, Liana (2013) 'The Kids are Not Alright: An Open Call for Reforming the Protections Afforded to Reality Television's Child Participants', UC Davis Journal of Juvenile Law \& Policy, Available at: < http://jjlp.law.ucdavis.edu/archives/ vol-17-no-2/08-nobile-macro-17-2.pdf > (accessed 07/07/2014). 
Not on the High Street (2014) 'Why Shop With Us', Not on the High Street.com, Available at: <http://www.notonthehighstreet.com/about/why_shop_with_us > (accessed 25/II/20I4).

Oakley, Ann (2013) 'Ann Oakley on Women's Experience of Childbirth', Social Science Bites, Available at: $<$ http://www.socialsciencespace.com/2013/04/podcast-annoakley-on-womens-experience-of-childbirth/> (accessed I8/06/20I4).

Oakley, Ann (1979/198I) Becoming a Mother (Reprinted as From Here to Maternity. Harmondsworth: Penguin), Oxford: Martin Robertson.

Oakley, Ann (1974/1985) The Sociology of Housework, London: Martin Robertson.

O’Brien, Anne (2014) 'Men Own Television?: Why Women Leave Media Work', Media Culture \& Society, 36:8, I207-I218.

Office for National Statistics (2014a) 'SOC2010 Volume I Structure and Descriptions of Unit Groups', ONS, Available at: <http://www.ons.gov.uk/ons/guide$\mathrm{method/classifications/current-standard-classifications/soc2oro/soc2oro-}$ volume-I-structure-and-descriptions-of-unit-groups/index.html> (accessed 26/06/2014).

Office for National Statistics (20I4b) 'Ethnic Group', ONS, Available at: <http:// www.ons.gov.uk/ons/guide-method/measuring-equality/equality/ethnic-natidentity-religion/ethnic-group/index.html> (accessed 26/06/2014).

Office for National Statistics (2013a) 'Internet Access: Households and Individuals', ONS, Available at: <http://www.ons.gov.uk/ons/rel/rdit2/internet-access--households-and-individuals/2013/stb-ia-2013.html> (accessed 26/06/2014).

Office for National Statistics (2013b) 'Live Births in England and Wales by Characteristics of Mother: Statistical Bulletin', ONS, Available at: <http://www.ons. gov.uk/ons/dcpi71778_296157.pdf> (accessed 24/03/2014).

Office for National Statistics (20I2) 'Families and Households, 20I2', ONS, Available at: <http://www.ons.gov.uk/ons/dcpi71778_284823.pdf> (accessed 24/11/2014).

Oliver, Jools (2006) Minus Nine to One: The Diary of an Honest Mum, London: Penguin.

Onderko, Patty (2014) 'The Terrible Twos: A Myth?' Parenting, Available at: <http:// www.parenting.com/article/terrible-twos-myth $>$ (accessed I9/II/20I4).

O'Reilly, Andrea (2008) 'Introduction', in Feminist Mothering, ed. Andrea O'Reilly, New York: State University of New York Press, I-24.

O'Reilly, Andrea (2004) 'Introduction', in From Motherhood to Mothering: The Legacy of Adrienne Rich's OfWoman Born, ed. Andrea O’Reilly, New York: State University of New York Press, I-23.

Paskin, Willa (2012) 'Is Modern Family Really that Good?' Salon, Available at: <http:// www.salon.com/2012/10/03/is_modern_family_really_that_good/ $>$ (accessed 31/07/2014). 
Peacock, Louisa (2013)' Number of Stay-at-Home Mothers Falls to New Record Low', The Telegraph, Available at: <http://www.telegraph.co.uk/women/mothertongue/10241815/Number-of-stay-at-home-mothers-falls-to-new-record-low. html> (accessed O2/12/2014).

Plunkett, John (2010) 'We Didn't Drop Denise Van Outen Because of Pregnancy, Says BBC', Guardian, Available at: <http://www.theguardian.com/media/2010/ $\mathrm{feb} / \mathrm{r} 8 /$ denise-van-outen-bbc-pregnancy $>$ (accessed 20/10/2014).

Press, Andrea (1991) Women Watching Television: Gender, Class and Generation in the American Television Experience, Philadelphia: University of Pennsylvania Press. Prynne, Miranda (2014) 'Sex Comes into Every Evaluation of a Woman, says Jon Snow', The Telegraph, Available at: <http://www.telegraph.co.uk/culture/tvan dradio/ro601057/Sex-comes-into-every-evaluation-of-a-woman-says-Jon-Snow. html> (accessed I4/10/2014).

Radway, Janice (1984/199I) Reading the Romance: Women, Patriarchy and Popular Literature, London: The University of North Carolina Press.

Redmond, Sean (2003) 'Thin White Women in Advertising: Deathly Corporeality', Journal of Consumer Culture, 3:2, 170-190.

Rock, Lucy (20II) 'Antenatal Care Goes Two-Tier as NCT Classes Boom and NHS Classes are Cut Back. But Who's Suffering Most?' The Observer, Available at: $<$ http://www.theguardian.com/commentisfree/20II/aug/28/child-birth-classesmotherhood $>$ (accessed 07/10/2014).

Rogers, Deborah (1992) 'Rockabye Lady: Pregnancy as Punishment in Popular Culture', Journal of American Studies, 26:1, 8I-83.

Rojek, Chris (200I) Celebrity. London: Reaktion Books.

Rowley, Emma (2013) 'Sheryl Sandberg: Future Moms Are Wrecking Their Own Careers', The Daily Telegraph, Available at: <http://www.businessinsider.com/ sheryl-sandberg-future-moms-are-wrecking-their-own-careers-before-they-evenbegin-20I3-2> (accessed I4/IO/2OI4).

Royal, Dayna (2010), 'Jon \& Kate Plus the State: Why Congress Should Protect Children in Reality Programming', Akro Law Review, 43:435, Available at: <http:// papers.ssrn.com/sol3/papers.cfm?abstract_id $=$ I452986> (accessed 23/oI/20I2).

Ryan, Maureen (201I) 'Why Is Television Losing Women Writers? Veteran Producers Weigh In', AolTV, Available at: <http://www.aoltv.com/2011/09/o8/womentelevision-producers-decline/> (accessed I9/II/20I4).

Sandler, Kevin (2003) 'Synergy Nirvana: Brand Equity, Television Animation, and Cartoon Network', in Prime Time Animation: Television Animation and American Culture, ed. Carol Stabile and Mark Harrison, London: Routledge, 89-109.

Sawyer, Jolie (2014) 'Love Claire Dunphy', Pinterest, Available at: <https://www. pinterest.com/jlssaw/love-claire-dunphy/> (accessed 20/10/2014). 
Shewfelt, Raechal Leone (2013) 'Julie Bowen's "Modern" Approach to Motherhood', Yahoo Celebrity, Available at: <https://celebrity.yahoo.com/blogs/goddess/juliebowen-modern-approach-motherhood-192345771.html > (accessed 20/10/2014). Shulman, Alezandra (2009) 'Year-long Maternity Leave, Flexi Hours, Four Day Weeks ... Why Would ANY Boss Hire a Woman?' MailOnline, Available at: <http:// www.dailymail.co.uk/debate/article-I226157/Vogue-editor-Alexandra-Shulmanasks-boss-hire-woman.html> (accessed I4/IO/2OI4).

Simkiss, Doug (2012) 'Chapter II: Looked After Children and Young People: Annual Report of the Chief Medical Officer 2012, Our Children Deserve Better: Prevention Pays,',Gov.UK, Available at: <https://www.gov.uk/government/uploads/ system/uploads/attachment_data/file/252661/33571_2901304_CMO_Chap ter_II.pdf> (accessed O2/12/2014).

Skeggs, Beverley, Wood, Helen, and Thumin, Nancy (2008) 'Oh Goodness, I am Watching "Reality" Television: How Methods Make Class in Audience Research', European Journal of Cultural Studies, II:I, 5-24.

Smith, Simon (2015) 'BBC Academy: Mums in TV', $B B C$, Available at: <http:// www.bbc.co.uk/academy/production/article/art20130702112135761> (accessed 27/07/2015).

Sof, Franz (2014) 'The Rise of Gay \& Lesbian Parenting in The UK', CoParents. co.uk, Available at: <http://www.coparents.co.uk/blog/the-rise-of-gay-lesbianparenting-in-the-uk-infographic $>$ (accessed 30/oI/2015).

Speier, Diane (2004) 'Becoming a Mother' in Mother Matters: Motherhood as Discourse and Practice: Essays From the Journal of The Association for Research on Mothering, ed. Andrea O'Reilly, Toronto: Association for Research on Mothering, I4I-I53.

Stacey, Jackie (1994) Star Gazing: Hollywood Cinema and Female Spectatorship, London: Routledge.

Stansfield, Liz (2014) 'Celebrity Mums and their Micro Maternity Leaves', Parentdish, Available at: <http://www.parentdish.co.uk/celebrity/celebrity-mums-micromaternity-leave/\#!slide=aol_1007199 $>($ accessed I4/IO/2014).

Sterling, Evelina (2013) 'From No Hope to Fertile Dreams: Procreative Technologies, Popular Media, and the Culture of Infertility', Georgina State University, Available at: $<$ http://scholarworks.gsu.edu/cgi/viewcontent.cgi?article $=1069 \&$ con text $=$ sociology_diss $>($ accessed 24/03/2014).

Stock, Jon, and Smith, Rebecca (2014) 'Outnumbered v Modern Family: Which is the Best Family Sitcom?' The Telegraph, Available at: <http://www.telegraph.co.uk/ culture/tvandradio/bbc/10604205/Outnumbered-v-Modern-Family-Which-isthe-best-family-sitcom.html> (accessed 20/10/2014).

Stone, Pamela (2008) Opting Out: Why Women Really Quit Careers and Head Home, California: University of California Press. 
Stonewall (2014) 'Families and Parenting', Stonewall, Available at: <http://www. stonewall.org.uk/what_we_do/research_and_policy/4171.asp > (accessed 24/II/20I4).

Striff, Erin (2005) 'Infertile Me: The Public Performance of Fertility Treatments in Internet Weblogs', Women \& Performance: a Journal of Feminist Theory, is:2, I89-206.

Striking Women (20I4) 'Maternity> (and Paternity) Leave and Pay', Striking Women, Available at: <http://www.striking-women.org/module/workplace-issues-pastand-present/maternity-and-paternity-leave-and-pay $>$ (accessed I4/IO/20I4).

Styles, Ruth (2013) 'Mary Berry is my Idol: Celebrity Mother Holly Willoughby Talks Juggling Children with a Busy Career', MailOnline, Available at: <http:// www.dailymail.co.uk/femail/article-2297574/Holly-Willoughby-talks-jugglingchildren-work-busy-celebrity-mother.html> (accessed I4/10/2014).

Sullivan, Dana (2014) 'Your 20-Month-Old's Social and Emotional Development: Terrible Twos Preview', babycenter, Available at: <http://www.babycenter.com/o_ your-20-month-olds-social-and-emotional-development-terrible_127332r.bc $>$ (accessed I9/II/20I4).

Tally, Margaret (2008) 'Reality Television and Contemporary Family Life: Make Over Television and the Question of Parenting', paper presented at the Annual Meeting of the American Sociological Association, Available at: $<$ http://www. allacademic.com//meta/p_mla_apa_research_citation/2/3/9/2/7/pages239270/ p239270-I.php> (accessed Io/08/20II).

TeenMomNews (2014a) 'The Latest Updates On Your Favorite Teen Mom Stars', Teen Mom News, Available at: <http://www.teenmomnews.com/\#> (accessed $\mathrm{OI} / \mathrm{I} 2 / 2014)$.

TeenMomNews (20r4b) 'Amber Portwood Planning Powerful Tell-All Book', Teen Mom News, Available at: <http://www.teenmomnews.com/2014/o7/amberportwood-planning-powerful-tell-all-book/> (accessed: 07/07/2014).

Thomas, Carol (2007) 'The Baby and the Bath Water: Disabled Women and Motherhood in Social Context', in Maternal Theory: Essential Readings, ed. Andrea O'Reilly, Toronto: Demeter Press, 500-519.

Thomas, Chloe (2012) 'Mary's Guilt Over her Working Motherhood: Bake Off Star Now Says She Regrets Juggling Career and Family Life', MailOnline, Available at: <http://www.dailymail.co.uk/femail/article-2249643/Mary-Berry-Bake-starsays-regrets-juggling-career-family-life.html $>$ (accessed I4/10/20I4).

Thurer, Shari (2007) 'The Myths of Motherhood', in Maternal Theory: Essential Readings, ed. Andrea O'Reilly, Toronto: Demeter Press, 331-344.

Tiemann, Amy (2006) Mojo Mom: Nurturing Your Self While Raising a Family, New York: Spark Press. 
Turner, Graeme (2006) 'Celebrity, The Tabloid and the Democratic Public Sphere', in The Celebrity Culture Reader, ed. David Marshall, London: Routledge, 487-509. TV.com (2008) 'Malcolm in the Middle Forums', TV.Com, Available at: <http://www. tv.com/shows/malcolm-in-the-middle/forums/which-family-do-you-think-isbetter-the-simpsons-or-the-wilkersons-353-1106444/ (20/10/2014).

Van Outen, Denise (2011) Bumpalicious: How to Relax and Enjoy Your Pregnancy, London: Headline.

Wall, Cara (2005) The Dark Secrets of Stars Hollow', Salon, Available at: <http:// www.salon.com/2005/09/27/gilmore_porn/> (accessed 19/1I/2014).

Warner, Judith (2007) 'The Motherhood Religion', in Maternal Theory: Essential Readings, ed. Andrea O'Reilly, Toronto: Demeter Press, 705-725.

Wells, Paul (1998) 'Where Everybody Knows Your Name: Open Convictions in Closed Contexts in the American Situation Comedy', in Because I Tell a Joke or Two: Comedy, Politics and Social Difference, ed. Stephen Wagg, New York: Routledge, $180-201$.

Wertman, Tonya (2013) 'Infertility and the Media', SheKnowsParenting, Available at: $<$ http://www.sheknows.com/parenting/articles/991979/infertility-celebritiesand-the-media $>$ (accessed 24/03/2014).

White, Anna (2013) 'Mary Berry's Poisonous Recipe for New Mothers Leaves a Sour Taste', The Telegraph, Available at: <http://www.telegraph.co.uk/women/ mother-tongue/9831316/Mary-Berrys-poisonous-recipe-for-new-mothers-leavesa-sour-taste.html> (accessed I4/IO/20I4).

Wikia (2014) 'Welcome to EastEnders Wikia: Carol Jackson', Wikia, Available at: $<$ http://eastenders.wikia.com/wiki/Carol_Jackson> (accessed oI/o2/2014).

Wolf, Naomi (2002) Misconceptions: Truth, Lies and the Unexpected on the Journey to Motherhood, London: Vintage.

Wolf, Naomi (199I) The Beauty Myth: How Images of Beauty are Used Against Women, London: Vintage.

Wolff, Janet (1993) 'Review - Women Watching Television: Gender, Class, and Generation in the American Television Experience by Andrea L. Press; Enduring Values: Women in Popular Culture by June Sochen', Gender and Society, 7:4, 619-621.

Woollett, Anne (1994) 'The Mandate for Motherhood: Having Children - Accounts of Childless Women and Women with Reproductive Problems', in Motherhood: Meanings, Practices and Ideologies, ed. Ann Phoenix, Anne Woollett and Eva Lloyd, London: Sage, 47-65.

Yee, Danny (2013) 'The National Childbirth Trust and the Class System', Oxford Blog, Available at: $<$ http://wanderingdanny.com/oxford/2013/06/the-nationalchildbirth-trust-and-the-class-system/> (accessed 07/10/2014). 
Yuppy Mom (2010) 'Celebrities \& Infertility’, Yuppy Mom, Available at: <http:// thepregnantyuppy.blogspot.co.uk/2010/or/celebrities-infertility.html $>$ (accessed 24/03/2014).

Zaretsky, Staci (2012) 'Mother of Tots \& Tiaras Star Sues for Millions after Daughter is Sexualised on the Web', Above the Law, Available at: <http://abovethelaw.

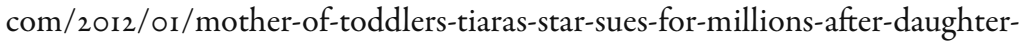
is-sexualized-on-the-web/> (accessed 04/07/2014). 


\section{Index}

I6 \& Pregnant 187

abuse 87, 172, 179, I91, I99

Addison, Heather 156

adoption 137, 187, 217-20, 223

Aguirre, Susan I9I

Aitkenhead, Decca 207

Allsopp, Kirstie 74-6, 78-9, 82, 86, I32,

$$
\text { I45-9, I5O, } 2 \text { II }
$$

Ang, Ien 12

Antiques Roadshow 79

The Apprentice $20 \mathrm{I}$

Asher, Rebecca 28

Aström, Berit 233

Attwood, Feona I8I

audience(s) I-I9, 3I-2, 36-9, 42-8, 53,

$55,57-8,60-70,74-5,79-82,85$,

$88-105$, I07-8, II2, II 4-23, I26-9,

I3I-8, I40-55 passim, I58-9,

I6I-2, I65-9, I73-5, I79-233

passim

maternal I, 3-4, 38, 42, 45, 47, 60, 6I,

$74,90,93,159,166,185,190,192$, 198-9, 220

television $3,32,55,64,68,97-8$, I19, I4I, I6I, I86

Austin, Thomas 165

Avishai, Orit 178

babies I5, 28-9, 4I, 44, 46, 56-60, 65-7I,

$73,76,82-4,92,99, \mathrm{IIO}, \mathrm{II} 4-15, \mathrm{I2} 3$,

I25, I28-9, I32, I47, I67, I70, I74,

I8O, I84, 202-3, 2II-I2, 22I, 226

antenatal I9-20, 28, 49 babycentre 123, 125

Badu, Erykah 200

Bakewell, Joan 8I

Baker-Whitelaw, Gavia I2I

Baldwin, Dan 6I

Bale, Karen 62

Barker, Martin I9, I65

Bates, Laura 73

Bath 44-5

BBC 8I-2, 84-5, 95, II6-I7, I2I, I23-5,

$$
\text { I29, } 148
$$

beauty $63,67,112,150,153,184-6,193$, 196, 214

Beckford, Martin I9I

Beckham, Victoria 66, 69, 200

Beeny, Sarah 82, I45

behaviour I4-15, 21, 33, 37, 39, 79, 94, 104, II7, I22-7, I32, I43, I45, I58, I6I, $173,176-7,179-82,189-90$

Bell, Emma 195

Bennett, James 53-4

Berger, Arthur 7

Berry, Mary 55, 67-74, 78-9, 86, I45

Bird, Elizabeth 165

bisexual(s) 137

Blue Peter 8I

Bonifazi, Wendy 78

The Book Show 80

Borgen 102

Brigitte Nyborg $102-3$

Borisoff, Deborah I

Bower, Karen 206

Bradbury, Julia 79

Bradford, Kelly Rose $63-4$ 
Brady, Karren 65, I3I

Bragg, Rosalind 72-3

Breaking Bad I02, I19, 132

Skyler White 102, 132

Brennen, Bonnie 34, 36

Brinkley, Christine 200

Britain I6, 49, 69, 79, 8I, I20-I, I38, I46, I 49, I 82,207

broadcasters $116,210,217$

Broadchurch $102-3$

Ellie Miller $\mathrm{IO}_{2}-3$

Brooks, Kate II-I2, 17, 38

Brothers and Sisters 133

Brown, Mary Ellen I64-5, I8I

Brown, Tamara Mose 30-I

Bruce, Fiona $79-80$

Brunsdon, Charlotte 8, I48-9, I66, I8I, 2 I5

Buckingham, David 173

Buckman, Peter $17 \mathrm{I}$

Bundchen, Gisele 66

Bunton, Emma 63

Burns, Judith 219-20

Cable, Simon 202

The California's Child Actor's Bill 192

Candler, Angelisa I85

care-givers I, 93, 98, III, I6I, I63, 227

Carille, Anna 223-4

Carmon, Irin 120

Casanova, Erynn Masi de 30-I

celebrity/ies 2, 3, 7, 36-7, 47, 53-I05, IIO, II2, I50-7, 165, 174, I88, 193-208, 21I-I2, 230

Chahal, Mindi 216

Changing Rooms 54

characters (TV) 3-4, 13-14, 37, 39, 42, 53, 80, 86-105, 107-43 passim, I53, I55, I58-9, I6I, I64-74 passim, I89, 213, 215, 217, 22I-2, 230-2

Chattin-McNicholas, John 179
Cherry's Parenting Dilemmas $84-5$

child, childhood I, I4, I6, I9-30, 40, $44,49-50,55-99,102-4, \mathrm{III}-17$, I22-48, I54-7, I62-232

childbirth 19-20, 23-4, 48-9, 58, 66, 69, $83,85,148,156,189,207,232$

childcare $15,22,28-9,38,48-9,56-7,60$, $64-5,67,73,75,99, \mathrm{II}-13, \mathrm{I23}$, I3I, I38, I40, I45, I57, I70, I73, I77, I79-80, 205, 2II-I2, 226-7

Child of Our Time 232

Christensen, Dorthe 36

cinema 16

comedy $47,53,86-7,93,95,97,104,118$, I43, I8I, 225

Connell, R.W. 214

content analysis 7, II, I5, 22, II7

Coronation Street 166

Couldry, Nick 37

Countryfile 80

Cowan, Katherine 117

Cox, Lauren 82

Crawford, Joan 16

Crime Watch 80

Croft, Claudia 193-4, 198

culture $5, \mathrm{IO}, \mathrm{I3}, \mathrm{I} 6,37,43,46,54,80$, IOI, I39, I5O, I80-I, I87, I93

Dallas $\mathrm{I} 2-\mathrm{I} 3$

Daly, Tess 55-62, 67, 74, 79-80, I52

Dancing on Ice 6I

daughters 51, 57, 59, 66, 70, 78, 84-5, $96, \mathrm{II} 8, \mathrm{I25}, \mathrm{I} 33-5, \mathrm{I} 40, \mathrm{I} 49, \mathrm{I} 56$, I68-9, I 82-7, 198, 20I, 223

Davidson, Max 180

Deacon, Michael 36, 93

Della-Ragione, Joaana 60

Deller, Ruth 37

demographic 2, I2, I7-I8, 33, 38, 40, 50, 67, I05, II 8, I2I, I35, 173

Dent, Tamsyn 45, 67 
depression 58, I87, 212, 221

designer (clothes) I5, 62, 79, I50, 190

Desperate Housewives I26-8, I3I

Desser, David I5O

development, of children I, 98,

$$
\text { I22-4, } 127
$$

Diamond, Anne 8I-3

Dimitriadis, Greg 35

disability I5, I89, 199, 220-2, 224, 23I

Donnelly, Dec 55

Doughty, Steve 227

Douglas, Susan I, 2, 58, I64, 213

Douvall, Alicia 197

Dowell, Ben 8I

Downton Abbey 133

drama I2, 46, 47, 53, 82, IO2, II4-I6, II8-I9, I33, I6I, I67, I7 I, I73, I84, I88-9, 196, 225, 228-9, 232

Duff, Charlie 203

Dworkin, Shari 157

EastEnders 166-7, 170, 173

Carol Branning 167-9

economy, economic 5, $12,25,26,38,40$, $49,79,91,117-18,120,151,178,180$ education $23,49,76-8,87, \mathrm{I} 30, \mathrm{I} 42, \mathrm{I} 48$, I5 8, I82, I84, I87, I91, 204, 219, 222, 225, 23I-2

Ellen, Barbara 207

Ellis, Janet 8I

Emmerdale 166

emotion(s) I, I4, 20, 25-6, 34, 44, $58-60,83,87,91,98-9,116,122$, I30, I42, I62, I64, I7I, I77, I85, 196, 199-200, 208, 215, 222-3, 225

entertainment I, 3-4, 8, 37-8, 54, 63-7, $74,80,83,104,118,136,141-2$, I48-50, I6I-2, I64, I8I, I93-5, 197, 201, 205, 207, 209, 214-I5, $217,227,231,233$

Esterberg, Kristin 23I ethnicity, ethnic 40-I, 50, 86, II7,

I54, 232

Everingham, Christine 2I-4, 29, 50

Everybody Loves Raymond I30, I43, 227

Debra Barone 130, I43, 227

family $9, \mathrm{I} 2-15,2 \mathrm{I}-2,25-8,4 \mathrm{I}-50,53$, $56-8,6 \mathrm{I}-\mathrm{I} 49$ passim, $\mathrm{I} 6 \mathrm{I}-232$ passim

Farmiga, Vera 65

fashion 53, 7I-2, I45, I47-8, I50-I, I53-6, I58, 196, 214

father, fatherhood I5, 21, 26, 28, 47, 70, $79,93,95,119,164,168,178,187$, I89, I97-8, 200-I, 207, 209, 227

Faulkner, Lisa 132

Feasey, Rebecca 2, 8, 43-4, 48, 77, 87, 90, I36, I 42, I50-I, I56, I6I, I64, I7I, 173, I8I, 194, 196, 198, 213, 223,233

female(s) 3, 7, 9-II, I4-I6, 30, 47, 59, 63, $72,78,80-2,114,119-21,136,148$, I50, I56, 165-6, I89, 193-5, 200, $212,215,230$

feminist $3-4,8-10,13,16,19,21,28-31$, $68-70,76, \mathrm{I} 2 \mathrm{I}, \mathrm{I} 7 \mathrm{I}-2, \mathrm{I} 8 \mathrm{I}$

fiction $9,12,53,210$

film 2, 3, 7, 16, 18, 31, 54, 66, 68, II5, I26, I 48, I50-I, I8I, I85, I97, 200, 215

Fisher, Sarah 223

Flint, Hannah 2 Io

focus group (s) 7, 9, II-I2, I7-I9, 3I-5, 38,117

Ford, Gina $28-9$

Foster, Alistair $63-4$

Foster, Jill 69-70

foster/ing 40, 137, 213-24

Fox, Patty I5I

Freeman, Hadley 78

friend/ship I2, I5, 21, 29, 42, 44, 47-8, 6I, 76, 79, 89, 92, I07, II2, I6I, 
I67-8, I23, I28, I33-6, I43-4, I68, 186, 189, 198-9, 205, 223, 230

Frost, Jo I42, I 45, I74, I77, I79-8 I

Frost, Vicky 96

Frostrup, Mariella 79

Gailey, Elizabeth Atwood I56

Ganeshasundaram, Raguragavan 177

Garraway, Kate 82

gay (parents) II7, I37-8, I4I, 223-4

gender 4, 7-19, 28, 30, 36, 43, 47, 69, 87, I20, $138,165,181,194,215,217,221$

generation(s) I, 3, I3, I7, 7I-2, 77-8, 82, 96, I04, I18, I36, I40-I, I56, I73, I80, I88-9, 210

Geraghty, Christine 154, I66, I7I

Gerstmann, Peter 4I

Giedroye, Mel 59

Gilmore Girls 133-6

Lorelai Gilmore $133-6$

Glennie, Alasdair 69-70

Goldman, Kevin 210

Good Morning Britain 8I

The Good Wife $\mathrm{IO}_{2}-3, \mathrm{I} 32$

Alicia Florrick $102-3,132$

Gordon, Bryony 76-7

Gornstein, Leslie 192

gossip 47, 53, 55, 77-8, 165, 187, 193-4, I98, 200

magazines 3, 7, 47

government 29, 44, 47, 48, 7I, I37, I8I, I91, 22I

Graham, Emily 90

Gray, Jonathan 165

The Great British Bake Off 67-70, 145-6

Green, Fiona I, 213

group discussion II, I7-I9, 3I-35, 38

Gyngell, Kathy 78

Hall, Melanie 7I-3

Halpin, Trish 63
Hamamoto, Darrell 9I

Hamilton, Andy 93

Haralovich, Mary Beth 8

Haskell, Molly I6

Hayes, Charlotte 183

Healey, Cherry 83-6

Healey, Una 66

Held, Virginia I, 99

Hello! (magazine) 70

Helm, Toby 149

Henley, Nadine 177

Henry, July 177

Here Comes Honey Boo Boo I8I-2, 184

Hermes, Joke IO-II, I65, 194

Hindmarch, Anya 7I-2

Hobson, Dorothy II 8, I67, I7I, 173

Holden, Amanda 65

Holland, Patricia 8I

home I, I3, I5, 2I-2, 26-7, 45-6, 53, 6I-3, $68-79,87,89,93-102$ passim, III-I7, I24, I28-32, I40, I45-50, I56, I58, I64, I68, I75, I77-9, I83, I86, 197-203, 206-8, 21I, 217, 219-20, 223-4, 226-32

Hopkins, Katie 195, 20I-IO

Hooper, Abi 208

House Iо I

Dr Lisa Cuddy IоI-2

housewife/ves I0, 86, 98, I26-8, I30-I,

$$
\text { 172, } 226
$$

housework 19, I13, I39, I83

How I Met Your Mother II5, I27-8

Hughes, Kathi 177

Hunniford, Gloria 82

husband(s) 6I, 67, 69-70, 88, 90-3, 97-8, IO2, II2-I3, II5, I17, I28, I34, I35, I45, I64, I68, I72, I83, 199, 226

Ibrahim, Yasmin 36 


\section{I'm a Celebrity ... Get Me Out of \\ Here 198, 201 \\ In the Club 232 \\ infant $21,83,96,114,189$ \\ infertility $36,77-8,222-3$ \\ Inside Soap 166}

interview/er 2, 7, 9-14, 17-28, 3I-5, 38, 4I, 49-50, 57-8, 6I, 70, 74, 76,

Ison, Rianne 58 $82,100,165-6$

ITV I2I

Jackson, Peter II-I2, I7, 38, I68

Jarvis, Alice-Azania 69

Jenkins, Henry 37

Johansson, Sofia 165, 195

Joseph, Georgina 73

Joweth, Garth 150

Kamberelis, George 35

Karlyn, Kathleen 233

Katona, Kerry 195-8, 200-I, 204, 207-8

Kelly, Lorraine 82

Kendrick, Keith 63-4, 66

Kennedy, Lauren Page 97, 99-100, I30

Kerr, Deborah 16

Kirkova, Deni 202

Klass, Myleene 59, 65-66, 70

Kuruvilla, Carol 223

Lampert, Nicole 66

Larson, Mary Strom I4-15, 32, I89

Lauzen, Martha II9

lesbian (parents) I37-8, 217, 223-4, 231, 233

Levey, Hilary 192

Levy, Arial I8I

Liebes, Tamar 172

lifestyle 3, II-I2, 44, 53-4, 58, 60, 75, 83, II2, II5, II7-I8, I45, I48, I5O, I57, I82-3, I93, I95, 207, 21I, 226, 233
Lipkin, Elline 178

Livingstone, Sonia 37,172

Location Location Location 74, 146

London II, 75, 93, 167, 201, 212

Loose Women 55, 201

Lotz, Amanda 8, II8-I9

McAleenan, Patrick 137

Macaulay, Sean I45

McConnell, Donna 63

MacIntyre, April 100

McPartlin, Ant 55

McVeigh, Tracy 69, 83, I49

magazines (for women/mothers) 2-3, 7 , IO-I2, 45, 47, 54-5, 64, 70, 74, $84, \mathrm{II} 2, \mathrm{I32}, \mathrm{I} 43$, I50-I, I54, I57-8, I65-6, I8I, I97-8, 20I, 2II

Maggneson, Sally $8 \mathrm{I}$

Malcom in the Middle 86, 90-1, 93, 96, 143

Lois Wilkerson 86-7, 90-2, 104, 143 male(s) 9, I5, I6, 47, 80, II8-I9, I2I, I73 men II-I2, I5, 28, 46, 63, 69, 72, 76, II9-2I, I37-8, I64, I99, 214

marginalisation 2, 25, 27, 40

Marie Claire (magazine) 63

Markham, Tim 37

masculinity II, 47, II 8, II 9, 2 I 4

maternity $19,28,49,57,59,65-74,78,83$, I52, 20I, 205

Maushart, Susan I, 213

media I-5, 7-5I, 55, 57-8, 6I, 67, 76, 83, $87,102,142,148,157,159,162$, 165-6, I8I, I85, I89, 193-209 passim, 212-14, 216-17, 229, 233

marketplace 37, 55, 57, 61, 157, I89

popular 2, 7, 27, 43, 233

Michaels, Meredith I, 2, 58, I64, 213 middle-class $13-14,17-18,22-3,25-6$, $48-50,76,86,93-4,96,98,148$, I54, $178,207,212,224,227-9$ 
Miller, Tina 24-5, 29

Modern Family 86, 96-98, 100

Claire Dunphy 86, 96-9

Modleski, Tania 167, I7I

Moffat, Steven I2I

Dr Who I2I

Mom I8I

Montessori movement $177-9$

morality 2I, 4I, 89, 94

Mortimer, Ruth 216

Moseley, Rachel I7, I5I

mothers (mums/moms) I-233 passim

archetype 3, 53, 23I

'bad' mothers 4, 29, I6I-2I5

celebrity 58-60, 64, I5I, I56-8, 208, 212

criticism 3-4, 65, 82, I71, 175, I79, 200, 217

escapist/ism 2-3, I2, 16, 60, 80, 104, II5, II9, I33, I36, I4I-2, I58-9, I6I, I8I, 2I4-I5 see also mothers, pleasures

frustrations $2,4, \mathrm{II}, 32,38,40,42,88$, $92-3,98,115-16,122-3,134,14 I$, I74, 200, 209, 217, 229, 230-I

'good' mothers I, 2, 4, 8, 20, 23, 25, 48, $64-5,85,93,98$, 100, I30, I50, I6I, $172-3,190,197,208-9,213,215$

guilt, feelings of 20,25, 70, 103, III, II5, I30-I, I77, 209, 2II, 2I3-I4 maternal images 8, 100, 104, 116,136 , I5 4, 210, 215-17, 233

maternal identification $3,13,16,32$, 104, 107-59

nurturing I, 22, 28, 74, 88, 98, 130 , 177, 186

pleasures $2-4,9, \mathrm{II} 2-13,18,32,38$, 40, $108,119,126,133,136,141-2$, I5I, I58-9, I72, I74, I8I, I83, 2I4I5, 217, 227, 23I see also mothers, escapism single $2,14-15,26,40,84,86,134$, 136, 189, 206, 224, 226, 228, 232-3 sleep deprivation 58-9, I2I, I27-32 stereotypes 4, 9, I6, 89, I02, I08, IIO-I3, II6, II 8, I54, I63-4, 203, $211-I 2,216-17,219,228-32$

teen 40, 136, I87-95, 199-201, 204, 228,232

television mothers 86, $108, \mathrm{II}_{3}, \mathrm{I3} 4$, I55, I59, I62, I97, 204

tropes 3, 27, 53, 233

working 22, 55-65, 70, 74, IOI, II3, II5, I29, I30-2, I57, I64, 207, 209, 226-7, 229, 233

and the workplace 22, 27-9, 47, $68-72,83,130$

motherhood I-233 passim depictions of $\mathrm{I}-2,4,38,55,104,116$, I4I, I6I-2, I64, 216

representations of $\mathrm{I}-5,7-8,3 \mathrm{I}-2$, 86, IIO-II, II7, II9, I6I, I63, I74, $216-17,233$

mothering $\mathrm{I}-233$ passim alternative practices of 2, 4I, I4O, I4I, 209

ideology of intensive mothering $\mathrm{I}-2$, $8,22-3,26,48,57,64,93,98-9$, I72, 190, 197, 199, 201, 209, 213 poor $16 I-215,227-8$ motherwork I-3, 5, 8, 19-20, 24, 26, 29, 3I, $47,58,60,64,70,83,86,87$, IOI-2, IO4, IO 8, II6-I8, I2I, I32, I36, I4I-2, I62, I66, I7I, I78, 207, 213,228

MTV I9I

Mumsnet 44-5, 48-9, 51, 78, 86, I23, $165-6,229$

Murray, Jenny 8I My Big Fat Gypsy Wedding 18I-2, 192

Nathan, Sara 83 
Neithercott, Tracey 99-I00

Netmums 44

netnographies 7,36

networks(s) I2, 30, 32, 36-7, 44-8, 50, 55,

$74,76,78,119-20,136,180,215$,

219-20, 223

news (in the media) 2, 19, 37, 54, 63, 77, 79, 80-I, IOI, I04, I47, I52, I65-6, I88, I94, 20I-2, 210, 22I

Newsnight 80

NHS 49, 77, 129, 137, 221-2

Nobile, Liana I9I

Oakley, Ann 17, 19-21, 24, 30, 32, 34,189

O'Brien, Anne 45

Olen, Helaine 178

Oliver, Jamie 55

Oliver, Jools 59

Onderko, Patty 122

One Born Every Minute 232

oral histories 7,34

O'Reilly, Andrea I, 2, I72, 209

Outnumbered 86, 93-6, 99, I26, I43

Sue Brockman 86, 94

parent/hood, parenting 2, 4, I4, I5,

$17,20-2,25-30,44-9,58-9$,

$65,69-70,77-8,83-5,87,90$,

92-IOO, IO8, IIO, II2, II 4, II 8 ,

I22-45 passim, I5O, I54, I62,

164, I68, 170-92, 197, 199-200,

202-3, 205-6, 208, 2II-I2,

$217-24,227,229-30,232$

Paskin, Willa 97

patriarchy/al 9, I6, II 9

Peacock, Louisa 226

Peppa Pig II3-I4

performer(s) 3, 47, 54-5, 61, 64, 66, 74, 79, 80-I, I05, I49, I58, I73, I85, $192-3,196,204$ play, playground $21,37,49-50,56,58,70$, $79,85, \mathrm{II} 2, \mathrm{I} 23-6, \mathrm{I} 35,225$ playgroup $2 \mathrm{I}-2,50$

Plunkett, John 83

The Politician's Husband 102

Freya Hoynes 102

poverty, poor $14,73,91,187,189-90,215$, $227-8,230$

pregnancy/t I5, 19-20, 23-4, 28, 3I, 46, 48, 55, 58-61, 63, 67, 69, 71, 74, $8 \mathrm{I}-3$, I2I, I32, I42, I5I-7, I67-7I, 174, I80, 187, 189-90, 193, 213, $222-3,228,232$

presenter(s) (tv) 3-4, 53-7, 63, 66-7, $74-6,79-83,104,112,131-2,152$, 193, 212, 217, 226

Pretty Woman 185

Price, Katie 195-201, 204, 207-8

Priest, Susanna Hornig 7, 34, 42

Prynne, Miranda 63

qualitative technique $7,3 \mathrm{I}-3$

quantitative technique 7

questionnaire $2-4,7,9,15-16,19,24$, $31-3,39-44,48-50,53,55,74,76$, 78, 86, I04, I07-8, I17, II9, I23, I25, I30, I44, I49, I58-9, I80, I83, I89-90, 213-I4, 217, 233

Rach, Anais 204

Radway, Janice 9-I2, I6, 32, I8I, 214

Raver, Kim 65

Reaid, Susanna 8I

reader response 9-II, 5I

realism I2-I4, 96, I3I, I36

reception studies 9, I2, 19

Redmond, Sean 214

relationship(s) I3, 26, 28, 37, 92, 93, 102, I07, I10, I29, 133-4, I63, I68-70, I74, I88, I94, I97, I99, 212, 224

religion, religious $23,44,87,187$ 
respondent(s) 4, I2-I3, I6-17, 33, 39-40, $42-4,48,50,53,55,57,65,74,76$, $78-80,85$, I08, I1 4, I16, I1 8, I36, I62-3, I67, I7I-5, I79-80, I86, 189, 191, 193, 195, 199-200, 204, 207, 215, 217, 220

responses (by women to motherhood on TV) $2-3,7,25,32,38,40-53$ passim, 104, I07, 127, 132, 156, I59, I61, I65, I72, I74, I82, 209, 23I-3

Revolution 102 Rachel Matheson $\mathrm{IO}_{2}$

Rippon, Angela 8I

Rock, Lucy 49

Rogers, Ginger 16

Rogers, Deborah 167

Rojek, Chris 193

romance(s) 3, 7, 9, II-I2, I8I, I93, I95, 214

Rosenberg, Debra Gilbert І00, 130

Rowley, Emma 73

Royal, Dayna i91

Ryan, Maureen II9-2I

Ryan, Shawn I2I

same-sex couples 137,224 ,

sartorial 3, 6I, I07, I5I-2, I55, I58,

$$
\text { 193-4, } 196
$$

Sears, Bill $\quad$ i78

self-help I, 30, I29, I42

Sex and the City II5, I27-8

sex, sexual $2,8,28,37,39,44,86-7,96$, $98-9,103,129-30,135,137-8,140$, I54, I56, I67, I69, I7 I-2, I8I, I82, 185, I88, 190, 193-4, 197, 203, 206, $215,221,223-4,232-3$

sexism II, 63, 73, 87, I20

Shewfelt, Raechal Leone 99

Shulman, Alexandra 7i-3

Simkiss, Doug 219

The Simpsons 86-90, 93, 98
Marge Simpson 86-90, 98, 104 sitcoms 53-105, IIO, II3-I4, I63, I67

Skeggs, Beverley 17-I8, 38

Smith, Rebecca 94

Smith, Simon 120

Snow, Jon 63,67

snowball technique I2, 44

soap opera 3, 7, I2-I5, 53, I18, I29, I43, I65-7, 170-4, I8I, I89, I93, 215, 218, 223, 226, 230-I

social sciences I4, I7, 19-2I, 29-3I

society $7,15,22-3,28,31,41,78,130,156$, $167,173,176,187,222-3$

sociology $9,21,178$

$\operatorname{son}(s) \quad 46,51,65,68,75,78,83,92,96-7$, IOI, II2, I24, I27, I44, 168, 199

spectators $8,15-16,19$

Speier, Diane 162

Spencer, Phil 74

Spigel, Lynn 8

Stacey, Jackie I5-16, 32, I5 I, 215

Stansfield, Liz 66

Star Trek: The Next Generation I03

Dr Beverley Crusher I03

stars, stardom 3, 7, I6, 47, 53-105, II3, I50-2, I68, I87, 190-7, 200, 207, 215,230

Sterling, Evelina 223

Stevenson, Nick II-I2, I7, 38

Stone, Pamela 26-8

Stonewall II7, I37, 224

Strictly Come Dancing 57, 60, 61, 176

Striff, Erin 36, 77, 223

Styles, Ruth 63, 69

Sullivan, Dana 122

Supernanny 17, 89, 92, I42-5, 174-8I, I92, 228

survey $9,32-4,38,4 \mathrm{I}, 78$

Tally, Margaret I42, 216 
teen/agers $15,40,44,47,53,67,84,90$, $96,98,109, \mathrm{II} 2-13, \mathrm{I} 33, \mathrm{I} 35-6, \mathrm{I} 63$, I $83,186-201,204,204,228,232$ see also mother, teen

Teen Mom 187-8, 189-94, 200 television, TV 2-4, 7-9, I2-I4, 3I-2, $37-8,43,45-50,54-7,6 \mathrm{I}-70$, $75,79-83,86,92-3,97-8$, IOI-2, I04-5, I07-23, I28, I3O, I32, I34, I36, I40-65, I75, I77, I8I-233 passim

American 12-13, 15, 90, 96, 110, II9-2I, I33, I36, I44, I63, I89

British 54, 83, I21, I47, 166 chat shows 53-4, 152 personality $53,57,68,70,79,8 \mathrm{I}, \mathrm{IO} 4$, IO 8, 205, 208, 210 reality show $17, \mathrm{I} 26, \mathrm{I95}, \mathrm{I9} 8,20 \mathrm{I}$, 208,228

reality television $17-18,53,60,68,126$, 170, 174, 176, I84, 192-3, 195, I97, 199, 201, 204, 215, 228, 230

This Morning 6I-3, 66, I55, 20I-2, 205-6

Thomas, Carol 23I

Thomas, Chloe 70

Thumin, Janet $17-18,38$

Thurer, Shari 213

Tiemann, Amy 172

toddlers $28-9, \mathrm{II} 4, \mathrm{I} 2 \mathrm{I}-9, \mathrm{I} 32-3, \mathrm{I} 42-5$, I78, I80, I83-5, I89, I92

Toddlers \& Tiaras 183-5, I87, 192

Turner, Graeme 193

Valentine, Gill II7
Van Outen, Denise 59, 65, 82-3

Vogue (magazine) $7 \mathrm{I}$

Wachs, Faye Linda 157

The Walking Dead 102

Lori Grimes ${ }_{102}$

Wall, Cara 134-5

Wark, Kirsty 79-80

Warner, Judith I, 2 I 4

Watchdog 80

West Wing I Abbey Bartlett IOI-2

Willoughby, Holly 55-6, 6I-7, 69-70, $74,79-80,104,152,205$

Winslet, Kate 200

Wolf, Naomi 23-5, 28-9, 2I4

Wolff, Janet 9

women I-233 passim domestic role I, 28, 88, I04, I28, I70, 227

magazines 2, I0, 165

working women 22, 30, 69, 71, 87, II 7,203

Wood, Helen $17-18,38$

Woollett, Anne 78

working class I4, 17-18, 25-6, 48, 86, $90-3,154,178,181,227-9,23 \mathrm{I}$

The Xtra Factor 65

Yee, Danny 49

You Me Baby (magazine) 84

Young, Kirsty 79

Zaretsky, Staci I85 
